\author{
SANDIA REPORT \\ SAND2007-3293 \\ Unlimited Release \\ Printed June 2007
}

\title{
Heliostat Cost Reduction Study
}

Gregory J. Kolb, Scott A. Jones, Matthew W. Donnelly, David Gorman, Robert Thomas, Roger Davenport, and Ron Lumia

Prepared by

Sandia National Laboratories

Albuquerque, New Mexico 87185 and Livermore, California 94550

Sandia is a multiprogram laboratory operated by Sandia Corporation,

a Lockheed Martin Company, for the United States Department of Energy's

National Nuclear Security Administration under Contract DE-AC04-94AL85000.

Approved for public release; further dissemination unlimited.

Sandia National Laboratories 
Issued by Sandia National Laboratories, operated for the United States Department of Energy by Sandia Corporation.

NOTICE: This report was prepared as an account of work sponsored by an agency of the United States Government. Neither the United States Government, nor any agency thereof, nor any of their employees, nor any of their contractors, subcontractors, or their employees, make any warranty, express or implied, or assume any legal liability or responsibility for the accuracy, completeness, or usefulness of any information, apparatus, product, or process disclosed, or represent that its use would not infringe privately owned rights. Reference herein to any specific commercial product, process, or service by trade name, trademark, manufacturer, or otherwise, does not necessarily constitute or imply its endorsement, recommendation, or favoring by the United States Government, any agency thereof, or any of their contractors or subcontractors. The views and opinions expressed herein do not necessarily state or reflect those of the United States Government, any agency thereof, or any of their contractors.

Printed in the United States of America. This report has been reproduced directly from the best available copy.

Available to DOE and DOE contractors from

U.S. Department of Energy

Office of Scientific and Technical Information

P.O. Box 62

Oak Ridge, TN 37831

Telephone: $\quad$ (865) 576-8401

Facsimile: $\quad$ (865) 576-5728

E-Mail: $\quad$ reports@adonis.osti.gov

Online ordering: http://www.osti.gov/bridge

Available to the public from

U.S. Department of Commerce

National Technical Information Service

5285 Port Royal Rd.

Springfield, VA 22161

Telephone: $\quad$ (800) 553-6847

Facsimile: (703) 605-6900

E-Mail: $\quad$ orders@ntis.fedworld.gov

Online order: $\quad$ http://www.ntis.gov/help/ordermethods.asp?loc=7-4-0\#online

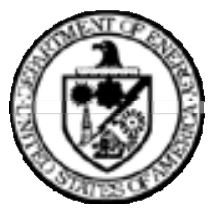


SAND2007-3293

Unlimited Release

Printed June 2007

\title{
Heliostat Cost Reduction Study
}

\author{
Gregory J. Kolb \\ Solar Systems Department \\ Scott A. Jones \\ USNDS Systems Engineering Department \\ Matthew W. Donnelly \\ Manufacturing Processing Department \\ Sandia National Laboratories \\ P.O. Box 5800 \\ Albuquerque, New Mexico 87185-1127 \\ David Gorman \\ Advanced Thermal Systems \\ 5031 W. Red Rock Drive \\ Larkspur, CO 80118 \\ Robert Thomas \\ Advanced Thermal Systems \\ 6201 S. Clarkson St. \\ Centennial, CO 80121 \\ Roger Davenport \\ Science Applications International Corporation \\ 9455 Towne Centre Drive \\ Mail Stop W-2 \\ San Diego, CA 92121 \\ Ron Lumia \\ University of New Mexico \\ MSC 01-1150 \\ Albuquerque, NM 87131
}

\begin{abstract}
Power towers are capable of producing solar-generated electricity and hydrogen on a large scale. Heliostats are the most important cost element of a solar power tower plant. Since they constitute $\sim 50 \%$ of the capital cost of the plant it is important to reduce heliostat cost as much as possible to improve the economic performance of power towers. In this study we evaluate current heliostat technology and estimate a price of $\$ 126 / \mathrm{m}^{2}$ given year-2006 materials and labor costs for a deployment of $\sim 600 \mathrm{MW}$ of power towers per year. This 2006 price yields electricity at $\$ 0.067 / \mathrm{kWh}$ and hydrogen at $\$ 3.20 / \mathrm{kg}$. We propose research and development that should ultimately lead to a price as low as $\$ 90 / \mathrm{m}^{2}$, which equates to $\$ 0.056 / \mathrm{kWh}$ and $\$ 2.75 / \mathrm{kg} \mathrm{H}_{2}$. Approximately 30 heliostat and manufacturing experts from the United States, Europe, and Australia contributed to the content of this report during two separate workshops conducted at the National Solar Thermal Test Facility.
\end{abstract}

Further dissemination only as authorized to U.S. Government agencies and their contractors; other requests shall be approved by the originating facility or higher DOE programmatic authority. 


\section{ACKNOWLEDGMENTS}

Funding for this research project was provided by the U.S. Department of Energy under contract DE-AC04-94AL85000 and was conducted as part of the Solar Hydrogen Generation Research Project managed by University of Nevada Las Vegas. 


\section{TABLE OF CONTENTS}

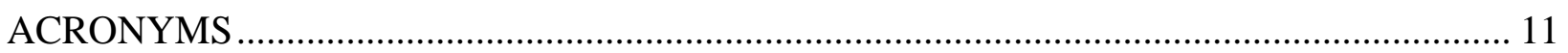

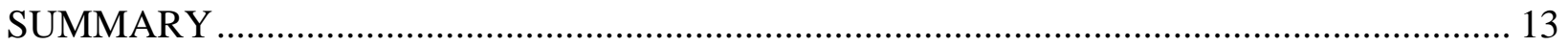

Heliostat Development History ......................................................................................... 14

Estimation of Heliostat Prices in 2006........................................................................... 17

Evaluation of Technology Improvement Opportunities ................................................... 18

R\&D Project Selection Given Uncertainty and a Constrained R\&D Budget.......................... 21

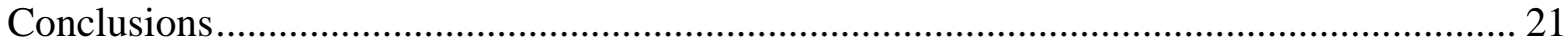

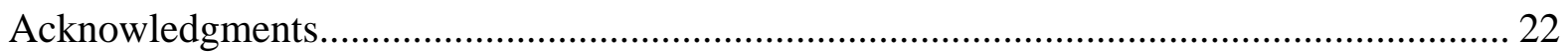

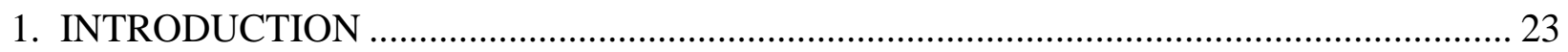

2. OVERVIEW OF HELIOSTAT TECHNOLOGY DEVELOPMENT HISTORY ................... 27

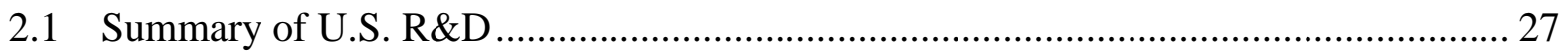

2.2 Summary of European R\&D.................................................................................. 32

3. ESTIMATION OF CURRENT HELIOSTAT PRICES ....................................................... 37

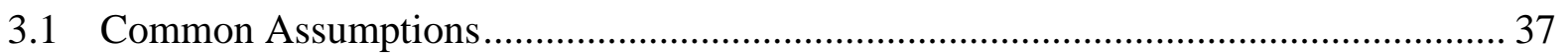

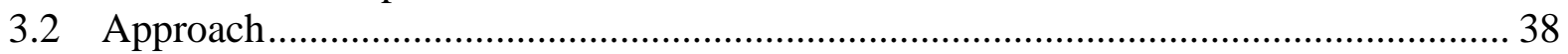

3.3 Price Re-Baseline Summary ………………................................................................ 38

3.4 History of Glass/Metal Heliostat Development .............................................................. 39

3.5 Year 2006 Price Estimate for ATS Glass/Metal Heliostat................................................. 43

3.6 History of SM Heliostat Development .................................................................... 52

3.7 Year 2006 Price Estimate for Pedestal-Mounted SM Heliostat....................................... 55

3.8 Evaluation of Heliostat Price Estimates.......................................................................... 62

3.8.1 Comparison of Estimated Glass/Metal Heliostat Prices to Prior

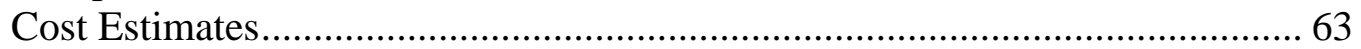

3.8.2 Price Sensitivity of the Glass/Metal Heliostat ..................................................... 64

3.8.3 Comparison of SM Heliostat Price Estimates...................................................... 64

3.8.4 General Comments Regarding Supplier Estimates.............................................. 66

4. ECONOMIC VALUE OF HELIOSTAT OPTICAL VARIABLES .......................................... 67

5. A MANUFACTURING PERSPECTIVE OF THE BASELINE ATS HELIOSTAT............... 71

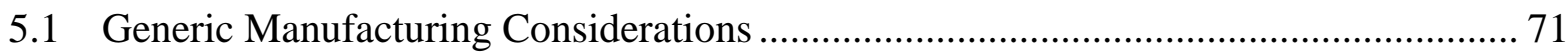

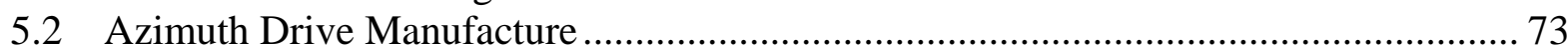

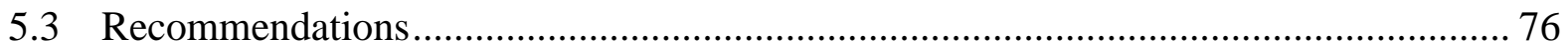

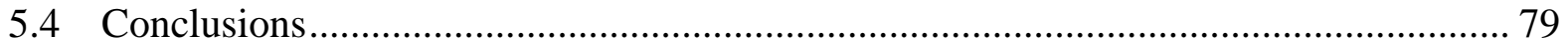

6. EVALUATION OF TECHNOLOGY IMPROVEMENT OPPORTUNITIES ........................... 81

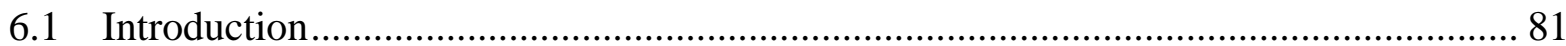

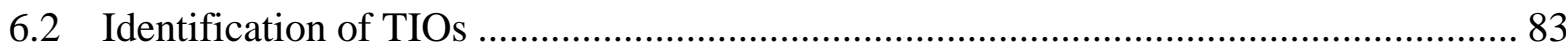

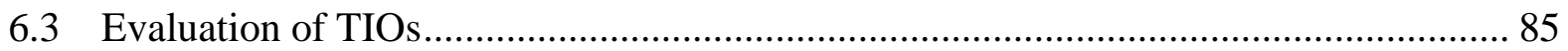

6.4 Project Selection Given Uncertainty and a Constrained R\&D Budget........................... 91

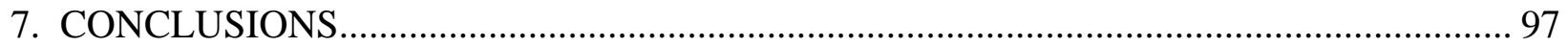

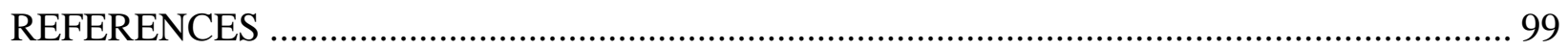


APPENDIX A. Heliostat Cost as a Function of Size For Molten-Salt Power Towers.............. 101

APPENDIX B. DLR Germany Project to Develop a Low-Cost Heliostat Drive ...................... 145

APPENDIX C. Small Heliostat R\&D in Europe and Australia............................................... 147

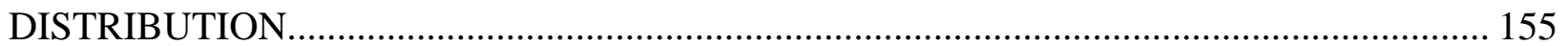




\section{LIST OF FIGURES}

Figure S-1. Power tower concepts of current interest to the USDOE solar energy program. .....13

Figure S-2. Heliostat concepts developed in the United States between 1975 and $1982 . . . . . . . . . .15$

Figure S-3. Mid-1980s path to low-cost heliostats................................................................16

Figure S-4. The ASM 150-m² SM heliostat built by SBP/Steinmüller. ....................................17

Figure S-5. In the mega-ganged heliostat proposed by DLR (left), up to $\sim 500 \mathrm{~m}^{2}$ of multiple facets are coupled via a common drive. ................................................19

Figure 1-1. Power tower concepts of current interest to the USDOE solar energy program. .....23

Figure 1-2. Heliostats dominate the capital cost of power towers........................................24

Figure 2-1. Heliostat concepts developed in the United States between 1975 and 1981...........27

Figure 2-2. From 1982 to 1988, Solar One (near Barstow, California) used 1,818 pedestalmounted heliostats built by Martin Marietta......................................................28

Figure 2-3. Highly automated central manufacturing plant proposed by General Motors.........29

Figure 2-4. Mid-1980s path to low-cost heliostats. Cost based on 50,000 units/yr. .................30

Figure 2-5. Advanced Thermal Systems (ATS) built a 148-m² glass/metal heliostat.................31

Figure 2-6. The 145-m² multi-faceted SM heliostats built by SAIC ........................................32

Figure 2-7. In 2006, PS-10 (near Seville, Spain) uses 624 pedestal-mounted heliostats built

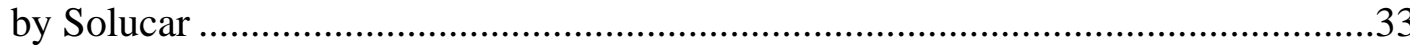

Figure 2-8. Solucar heliostats. A 69-m ${ }^{2}$ model is shown at top. ..........................................33

Figure 2-9. Partial-carousel heliostat studied by Solucar....................................................34

Figure 2-10. The ASM-150 heliostat built by SBP/Steinmüller. .............................................35

Figure 2-11. In the ganged concept, multiple facets are coupled via a single common elevation drive and single common azimuth drive. Sizes as large as $488 \mathrm{~m}^{2}$ are

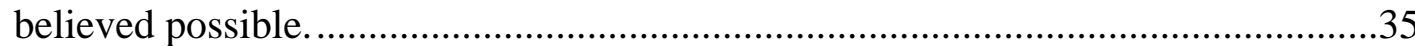

Figure 3-1. ATS fourth-generation prototype $148-\mathrm{m}^{2}$ heliostat. ...........................................42

Figure 3-2. Pilkington glass estimated mirror cost/volume curve from SolMaT project...........47

Figure 3-3. First SM heliostat prototype at SERI............................................................53

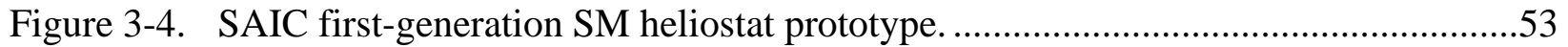

Figure 3-5. Second-generation SM heliostat prototype.......................................................54

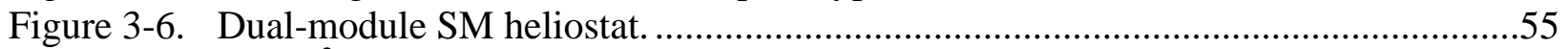

Figure 3-7. 145- $\mathrm{m}^{2}$ SAIC SolMaT heliostat design with 3-m-diameter SM mirror modules. ....56

Figure 4-1. The base-case 100-MWe molten salt power tower consists of a 700-MWt receiver with a surface area of $1380 \mathrm{~m}^{2}$, a 240-m-tall-tower, and 9500 ATS-type heliostats $\left(147 \mathrm{~m}^{2}\right.$ each, 2 mrad slope error [11]) that surround the tower...............67

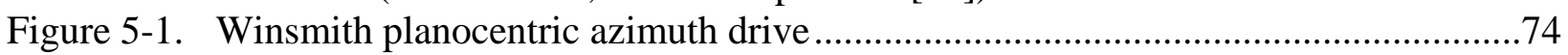

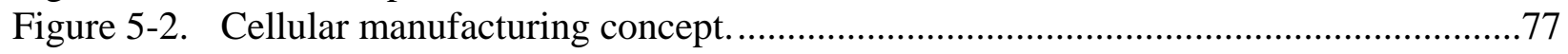

Figure 6-1. Given 50,000 heliostats/yr, S\&L estimated a 92\% progress ratio. Heliostat

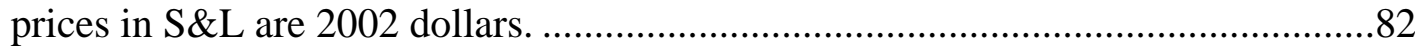

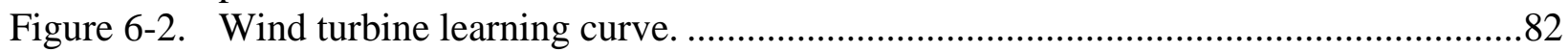

Figure 6-3. The "pipe-in-pipe” azimuth drives at White Cliffs required little maintenance during the 17-year operating history of the plant..................................................88

Figure 6-4. The 320-m² PV trackers at APS use hydraulic drives. .........................................89

Figure 6-5. NM Tech water-ballasted heliostats...............................................................90 
Figure 6-6. A A signal mirror combined with an optical camera (instead of man) could be used to accurately reflect the suns rays from a heliostat to the receiver target (instead

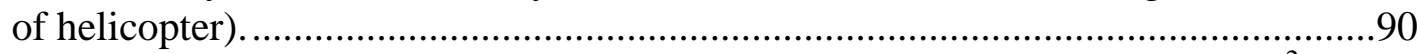

Figure 6-7. The pipe-in-pipe azimuth drive is expected to reduce heliostat price by $\$ 8 / \mathrm{m}^{2}$.......91

Figure 6-8. Bernoulli or Yes/No Distribution..................................................................92

Figure 6-9. Crystal Ball results for expected heliostat price reduction achieved with a \$5 M

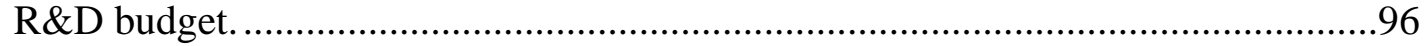




\section{LIST OF TABLES}

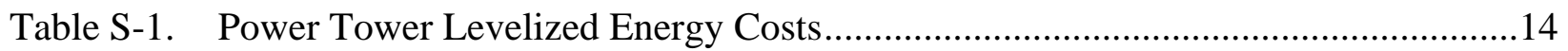

Table S-2. Heliostat Prices Given 50,000 Units/Yr..................................................................18

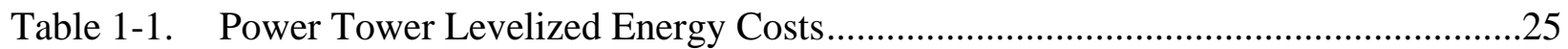

Table 3-1. Summary of Heliostat Price Estimates $\left(2006 \$\right.$ per $\left.\mathrm{m}^{2}\right)$...............................................38

Table 3-2. Requirements of the Second-Generation Heliostats .....................................................41

Table 3-3. Historical Heliostat Prices [11] (1981\$ per $\mathrm{m}^{2}$ ) ....................................................43

Table 3-4. ATS Heliostat Weight ............................................................................................44

Table 3-5. Price Indices Used for Extrapolation of Glass/Metal Heliostat Costs from 1986

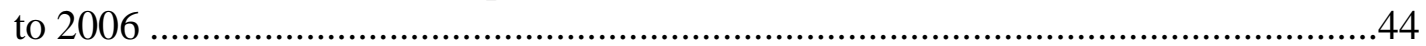

Table 3-6. Extrapolation of Glass/Metal Heliostat Costs to 2006\$...........................................45

Table 3-7. Major Suppliers of Heliostat Components.....................................................................45

Table 3-8. Estimate of Pedestal Cost Using Steel and Processing Costs .....................................48

Table 3-9. S Summary of Structural Steel Price Estimates and Quotes ..........................................48

Table 3-10. Summary of Basis for Bottom-Up Pricing of Glass/Metal Heliostats at 50,000 Heliostats Per Year Production Rate....................................................................49

Table 3-11. Mirror Module Costs for Glass/Metal Heliostats at 50,000 Heliostats Per Year......50

Table 3-12. Structure Component Costs for Glass/Metal Heliostats at 50,000/yr ........................50

Table 3-13. Motion Control Costs for Glass/Metal Heliostats at 50,000 Heliostats Per Year.....51

Table 3-14. Total Cost of Glass/Metal Heliostats at 50,000 Heliostats Per Year .........................51

Table 3-15. Cost Breakdown for Glass/Metal Heliostats at 5,000 Heliostats Per Year................52

Table 3-16. Comparison of $150 \mathrm{~m}^{2} \mathrm{SM}$ and Glass/Metal Heliostat Costs (1986\$) ........................57

Table 3-17. SAIC Second-Generation Heliostat Mirror Module Production Cost Estimate, With Mavis Results for Comparison......................................................................57

Table 3-18. Weight Estimate for 150- $\mathrm{m}^{2}$ Second-Generation SM Heliostat Mirror Module and Support Structure with Thin Glass Mirrors..........................................................58

Table 3-19. Indices Used for Projection of Prior Cost Estimates for SM Heliostats ....................59

Table 3-20. Extrapolated SM Heliostat Price............................................................................59

Table 3-21. Bottom-Up Cost Components from Vendors ........................................................60

Table 3-22. Bottom-Up Price Estimate for SM Heliostat at 50,000 Per Year, Compared to Extrapolation and Glass/Metal Heliostat Estimate $\left(2006 \$ / \mathrm{m}^{2}\right)$

Table 3-23. Bottom-Up Price Estimate for SM Heliostats at a Production Rate of 5,000 Per

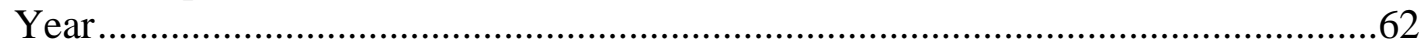

Table 3-24. Summary of Heliostat Price Estimates ......................................................................62

Table 3-25. Comparison of Bottom-Up Price Estimate and Extrapolated Mavis Price for Glass/Metal Heliostats $\left(2006 \$ / \mathrm{m}^{2}\right)$

Table 3-26. Sensitivity Results for Glass/Metal Heliostat Cost Components...............................64

Table 3-27. Summary of SM Heliostat Price Estimates, and Comparison to Glass/Metal Heliostat Estimate ..............................................................................................65

Table 4-1. Economic Value of Heliostat Optical Variables......................................................68

Table 6-1. Effect of Heliostat Cost on Power Tower Economics. .............................................81

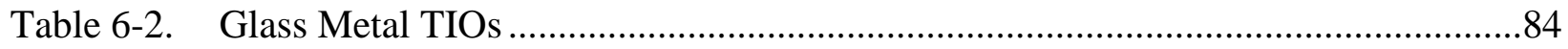

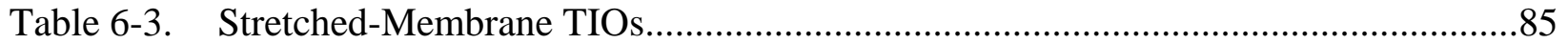

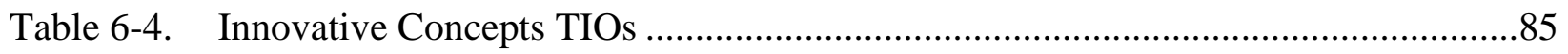

Table 6-5. Possible R\&D Projects Suggested by Brainstorming ..............................................86 
Table 6-6. Price Reduction Potential Resulting from Proposed Heliostat R\&D Projects..........87

Table 6-7. $\quad$ R\&D Prototype Success Probability .................................................................92

Table 6-8. Expected Return of R\&D Based on Point Estimates .............................................93

Table 6-9. Cost of Proposed R\&D Projects ........................................................................93

Table 6-10. Budget-Constrained Funding Priorities ............................................................95 


\section{ACRONYMS}

\begin{tabular}{|c|c|}
\hline APS & Arizona Public Service \\
\hline ATS & Advanced Thermal Systems \\
\hline BOM & Bill of Materials \\
\hline CPI & Consumer Price Index \\
\hline $\mathrm{CT}$ & Cycle Time \\
\hline DFM & design for manufacturing \\
\hline DOE & Department of Energy \\
\hline EPA & Environmental Protection Agency \\
\hline LEC & levelized energy cost \\
\hline NSTTF & National Solar Thermal Test Facility \\
\hline O\&M & operation and maintenance \\
\hline $\begin{array}{l}\text { PPI } \\
\text { PV }\end{array}$ & $\begin{array}{l}\text { Producer Price Index } \\
\text { photovoltaic }\end{array}$ \\
\hline $\mathrm{R} \& \mathrm{D}$ & research and development \\
\hline RFP & request for proposal \\
\hline SAIC & Science Applications International Corporation \\
\hline SERI & Solar Energy Research Institute \\
\hline SKI & Solar Kinetics, Incorporated \\
\hline SM & stretched membrane \\
\hline SolMaT & Solar Manufacturing Technology \\
\hline TIO & technology improvement opportunity \\
\hline UV & ultraviolet \\
\hline WIP & work in progress \\
\hline
\end{tabular}




\section{SUMMARY}

Power towers are often predicted to be the least expensive method of producing solar-generated electricity and hydrogen on a large scale. Plants capable of producing $100 \mathrm{MW}$ of electricity or $100,000 \mathrm{~kg} /$ day of hydrogen appear feasible. Twenty-four-hour operation is achieved through integration of a large (13-hour) thermal energy storage system, as depicted in Figure S-1.

\section{Solar electric power plant}

- $100 \mathrm{MW}_{\mathrm{e}}$ Rankine-cycle electric plant

- $700 \mathrm{MW}_{\mathrm{t}}, 565^{\circ} \mathrm{C}$ molten salt receiver

- $13 \mathrm{hr}$ molten salt storage

- Same as Sargent \& Lundy 100 MWe plant

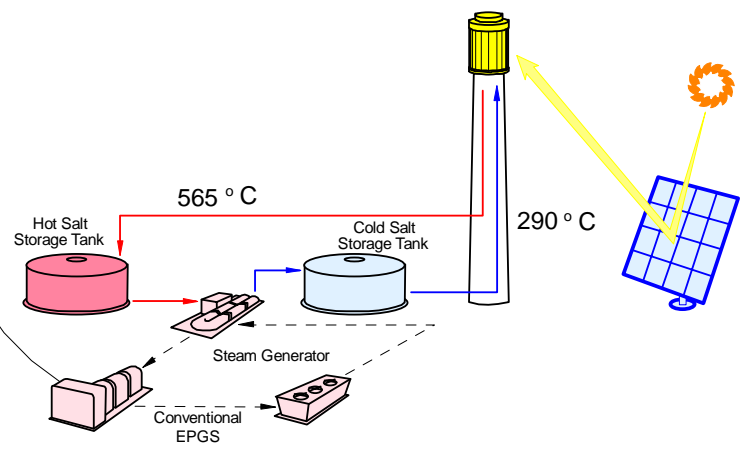

\section{Solar hydrogen plant}

- $255 \mathrm{MW}_{\mathrm{t}} / 60 \mathrm{MW}_{\mathrm{e}}$ hybrid-sulfur $\mathrm{H}_{2}$ plant

- $700 \mathrm{MW}_{\mathrm{t}}, 950{ }^{\circ} \mathrm{C}$ solid particle receiver

- $13 \mathrm{hr}$ solid particle storage

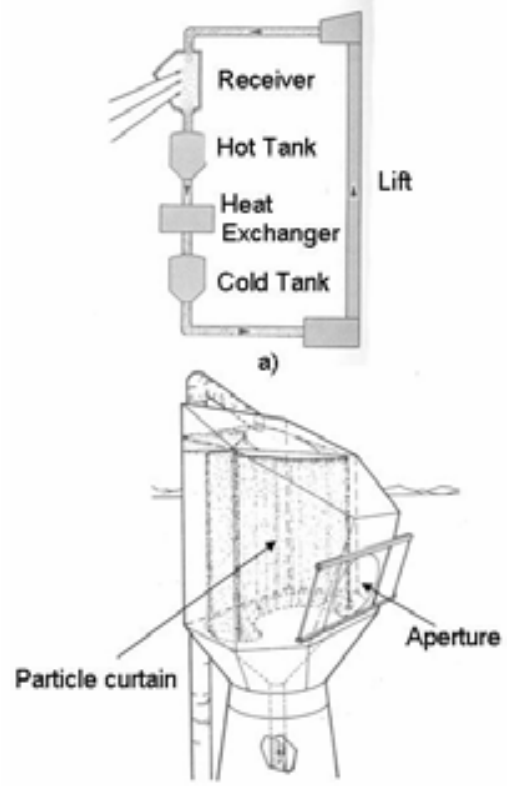

b)

Figure S-1. Power tower concepts of current interest to the USDOE solar energy program.

Heliostats are the most important cost element of a power tower plant because they typically contribute $\sim 50 \%$ to the total cost of the plant. Consequently, it is important to reduce the cost of heliostats to as low as possible to improve the economic viability of solar power towers.

Given different prices for heliostats, we used standard Department of Energy (DOE) methods to calculate the levelized energy cost (LEC) for the plants shown in Table S-1. Power tower LECs are attractive given a heliostat price of $\$ 100 / \mathrm{m}^{2}$ and may be low enough to be competitive on the open market, especially if carbon-offset trading becomes the norm. A price $\sim \$ 100 / \mathrm{m}^{2}$ thus appears to be a reasonable goal for heliostats. 
Table S-1. Power Tower Levelized Energy Costs

\begin{tabular}{|c|c|c|}
\hline $\begin{array}{c}\text { Heliostat } \\
\text { Price }\end{array}$ & $\begin{array}{c}\text { Molten Salt } \\
\text { Power Tower } \\
\text { (S\&L economics) }\end{array}$ & $\begin{array}{c}\text { Hybrid Sulfur } \\
\text { Hydrogen Plant } \\
\text { (H2A economics) }\end{array}$ \\
\hline \hline$\$ 80 / \mathrm{m}^{2}$ & 5.4 cents $/ \mathrm{kWh}$ & $\$ 2.6 / \mathrm{kg}$ \\
\hline$\$ 100 / \mathrm{m}^{2}$ & 5.9 cents $/ \mathrm{kWh}$ & $\$ 2.9 / \mathrm{kg}$ \\
\hline$\$ 150 / \mathrm{m}^{2}$ & 7.3 cents $/ \mathrm{kWh}$ & $\$ 3.5 / \mathrm{kg}$ \\
\hline$\$ 200 / \mathrm{m}^{2}$ & 8.7 cents $/ \mathrm{kWh}$ & $\$ 4.1 / \mathrm{kg}$ \\
\hline
\end{tabular}

The objectives of this study were the following:

- Review the history of heliostat development that has led to the current state of the art.

- For state-of-the-art heliostats in the United States, develop price estimates in current 2006 dollars.

- Identify technology improvement opportunities (TIOs) that lead to a significant price reduction.

- Estimate the price-reduction potential of the TIOs and estimate the research and development $(R \& D)$ cost necessary to achieve this potential.

- Determine whether it is feasible to achieve the preliminary goal of $\$ 100 / \mathrm{m}^{2}$.

This study was performed during calendar year 2006. During the first half of 2006 Sandia National Laboratories established subcontracts with heliostat manufacturers and manufacturing experts to form a core team of six individuals. In July, a two-day workshop was held at the National Solar Thermal Test Facility (NSTTF) in Albuquerque, New Mexico, to discuss heliostat technology and to identify TIOs. Approximately 30 heliostat and manufacturing experts from the United States, Europe, and Australia participated in this workshop. After the workshop the core team developed price estimates for current heliostats and evaluated the price-reduction potential of the TIOs. The core team also proposed R\&D projects that address the majority of the TIOs. Nearly the full team of experts reassembled in November to obtain critical review of the analysis conducted by the core team.

\section{Heliostat Development History}

The heliostat development effort in the USA was initiated in 1975 when four industry teams were funded to complete design studies for first-generation heliostats. These studies included cost estimates and each contractor built four to six heliostats. To significantly reduce the cost, second-generation designs were developed in late 1977 and additional prototypes were built and tested through 1981. Heliostats developed during the first- and second-generation period were built by the industry teams depicted in Figure S-2. The Jones heliostat was investigated separately in 1982. There are five different concepts shown in the figure: (1) pedestal mounted (left); (2) bubble-enclosed membrane (top); (3) ganged (right); (4) carousel (center); and (5) rotating field (bottom). After extensive evaluation, the pedestal-mounted heliostat was shown to have a cost advantage over the other approaches, and it was selected for application at the Solar One Pilot Plant in 1982. 

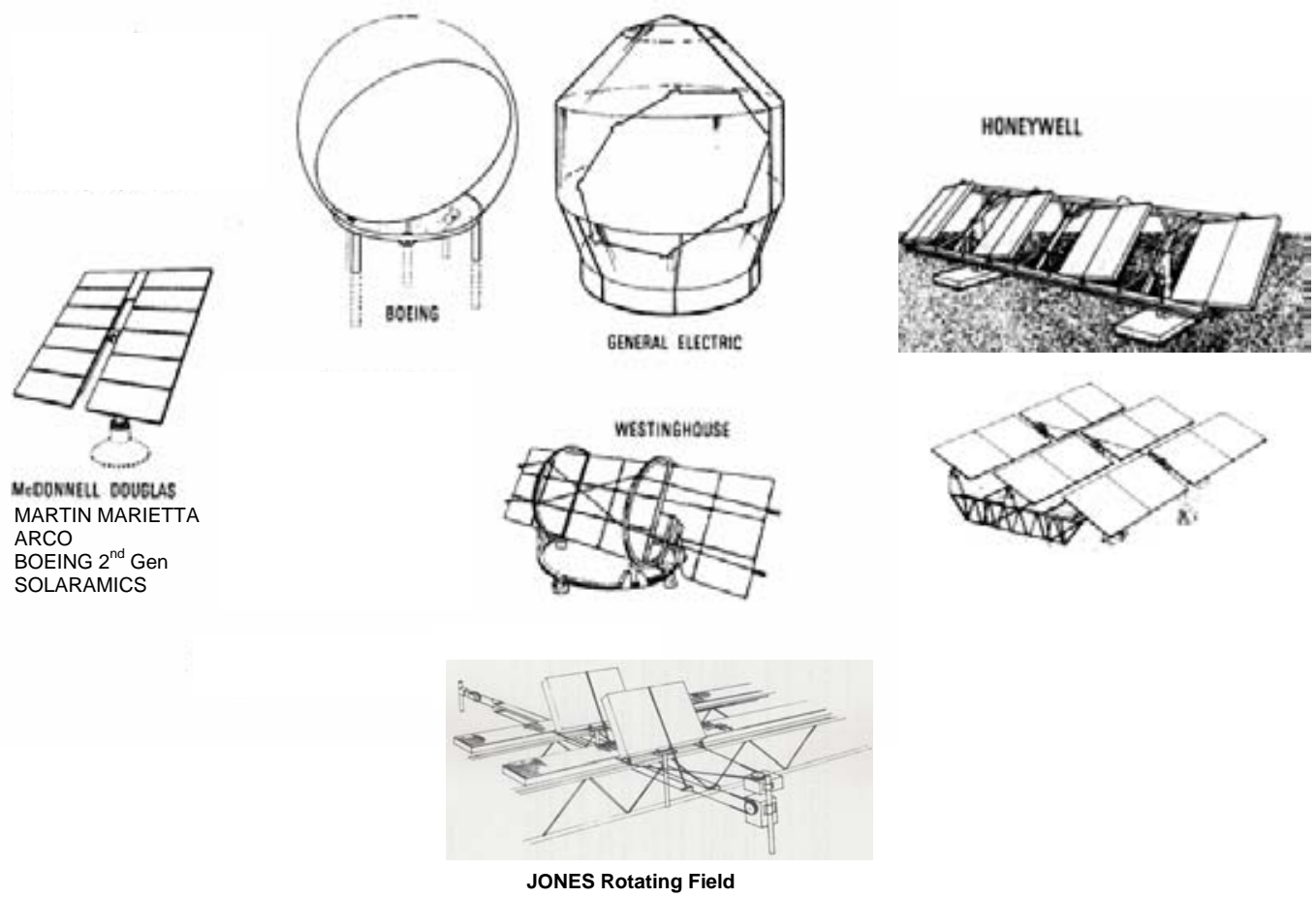

Figure S-2. Heliostat concepts developed in the United States between 1975 and 1982.

The heyday of heliostat development in the United States occurred during the second-generation period ending in 1981. The DOE budget for heliostat development was \$7.3 M, equivalent to \$19 M in today's dollars. This budget level allowed for extensive optimization and cost studies, and more than 100 technical references can be found in Mavis. An example is the detailed massmanufacturing analysis performed by General Motors, in which assembly lines were proposed capable of producing 50,000 McDonnell Douglas heliostats/yr. The second-generation studies predicted the heliostat price to be $\$ 100$ to $\$ 150 / \mathrm{m}^{2}$ (\$1980) for a $\sim 60-\mathrm{m}^{2}$ size.

Shortly after the second-generation period, McDonnell Douglas continued to optimize their heliostat. They examined many design variables and decided the best way to reduce cost was to increase heliostat size to at least $100 \mathrm{~m}^{2}$. Their analysis showed a 20\% cost reduction. To further reduce cost, Sandia proposed even larger $150 \mathrm{~m}^{2}$ heliostats and also began to investigate a large, circular stretched-membrane (SM) concept. Bigger was predicted to be better due to the improved economies of scale for the heliostat components. In addition, fixed costs per heliostat (controls, installation, and operation and maintenance (O\&M)) could be spread over more area to reduce the $\$ / \mathrm{m}^{2}$ contribution from these elements. The SM concept was proposed because it was lighter and simpler (i.e., fewer parts) than the glass/metal heliostat. The mid-1980s path to lowcost heliostats is summarized in Figure S-3. This led to the construction of full-scale $\left(148-\mathrm{m}^{2}\right)$ glass/metal and a sub-scale $\left(50-\mathrm{m}^{2}\right) \mathrm{SM}$ prototypes in the late $1980 \mathrm{~s}$. 

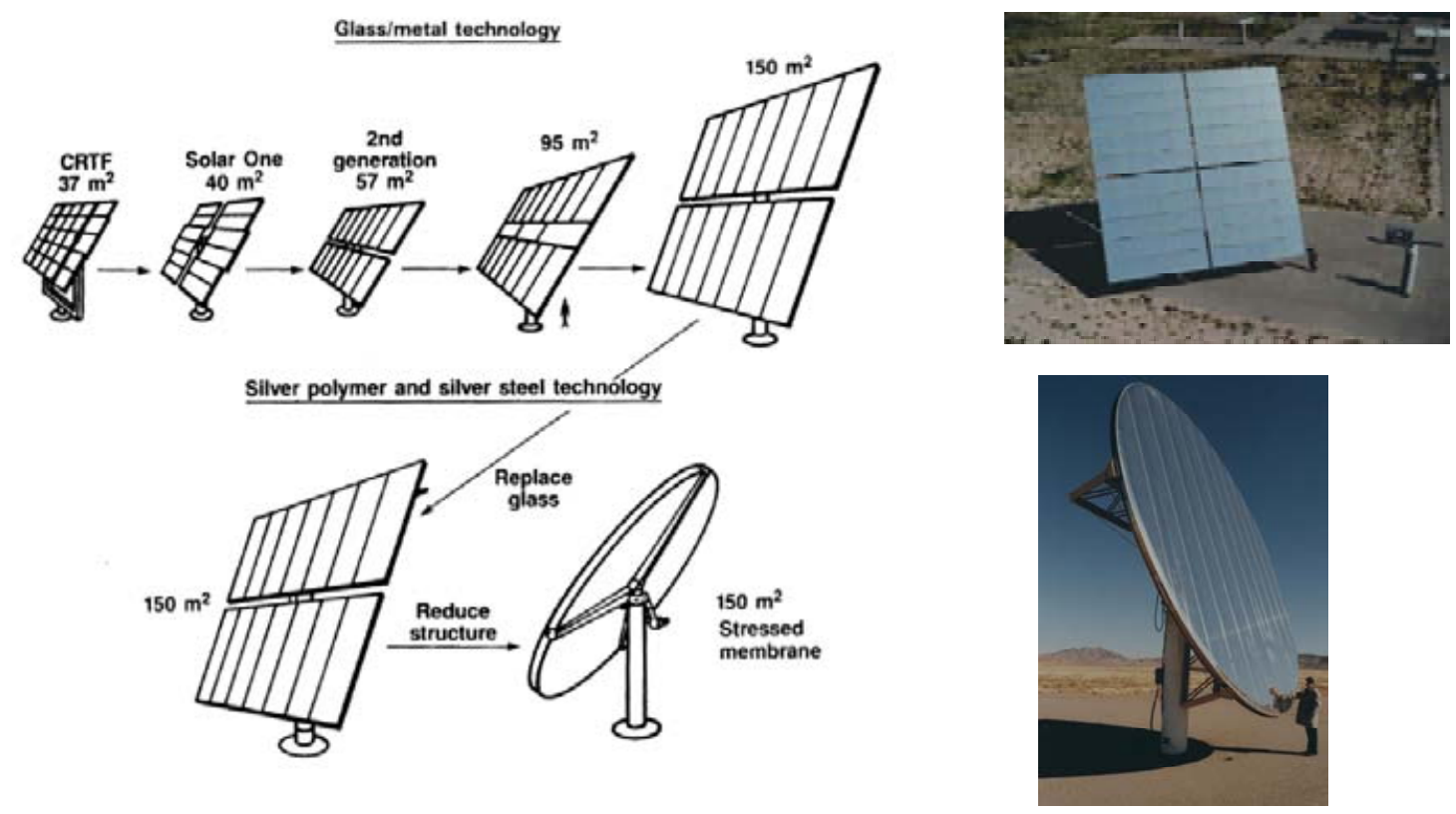

Figure S-3. Mid-1980s path to low-cost heliostats. Also shown are the 148- $\mathrm{m}^{2}$ glass/metal (top) and 50- $\mathrm{m}^{2} \mathrm{SM}$ prototypes.

The 1980s vision of building larger heliostats to achieve a lower $\$ / \mathrm{m}^{2}$ cost was reaffirmed by a recent detailed analysis performed by Sandia. A few research organizations have predicted that very small (10 to $20 \mathrm{~m}^{2}$ ) heliostats could be cheaper. However, these organizations are generally using heliostats within an ultra-high concentration power tower system. Such systems require small beam sizes, which can be more easily achieved with small heliostats. For the lowerconcentration power towers depicted in Figure S-1, the analysis predicts that low-cost heliostats are most likely to be $\geq 150 \mathrm{~m}^{2}$.

The 148- $\mathrm{m}^{2}$ Advanced Thermal Systems (ATS) heliostat has successfully operated for the last 20 years at the NSTTF in Albuquerque. It has survived multiple high-wind events, some in excess of $90 \mathrm{mph}$, and the quality of the beam has not degraded significantly.

The SM heliostats proved to be mechanically sound. However, the polymer mirror glued to the metal membrane quickly degraded due to ultraviolet (UV) damage and the face-up stow position led to hail-induced membrane denting. The mirror surfaces were not replaced and the heliostats were mothballed after a few years. Because of this experience, Sandia recommended the use of thin glass rather than a polymer film. SM heliostats employing glass were built and tested at Solar Two and in Spain (Figure S-4) in the mid 1990s.

Most recently, in 2006 and 2007 more than 200,000 $\mathrm{m}^{2}$ of heliostats were installed at the PS-10 and PS-20 projects in Spain. A large-area $\left(121-\mathrm{m}^{2}\right)$ pedestal-mounted heliostat similar to the ATS was selected after an evaluation of alternate concepts indicated it was the low-cost option. 


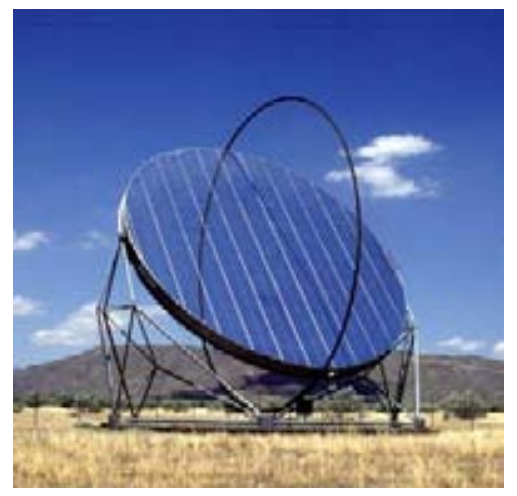

Figure S-4. The ASM 150- $m^{2}$ SM heliostat built by SBP/Steinmüller.

\section{Estimation of Heliostat Prices in 2006}

A detailed analysis of heliostat price has not been conducted by Sandia for more than 10 years. The price of steel and other elements of the heliostat have undergone recent significant changes, so it is necessary to bring price estimates up to date.

We first analyzed the weight of the $148-\mathrm{m}^{2}$ ATS heliostat to obtain a lower-bound cost estimate. The heliostat has a total weight of $6385 \mathrm{~kg}$. When broken down by material type, $87 \%$ of the heliostat is found to be constructed of simple steel (4006 kg) components and mirrors (1518 kg). In 2006, carbon steel at the mill costs about \$0.65 per kilogram and steel products that are relatively simple to fabricate cost about $\$ 2.17$ per kilogram (Schuff Steel, USA). The price of high-reflectance flat mirrors is \$1.10 per kilogram (Gardner Glass, USA). Using the \$2.17/kg price for the simple steel components of the heliostat and adding the mirrors gives a total of about $\$ 70 / \mathrm{m}^{2}$ as the minimum possible cost of the ATS. The price will be greater due to the inclusion of overhead and profit as well as the fact that the remaining $13 \%$ of the weight (primarily the azimuth drive) consists of non-simple steel components that require significant machining.

We next estimated the installed price of the ATS, as well as $150-\mathrm{m}^{2} \mathrm{SM}$ heliostats that are pedestal-mounted. We performed a sanity check on our "bottom-up" cost analysis by extrapolating historical studies using the appropriate produce-price and consumer price indexes. Heliostat prices were estimated given production rates of 5000/yr and 50,000/yr. This corresponds to 60 MWe and 600 MWe of power plants and bounds the deployment scenarios presented in the Sargent \& Lundy study.

The 2006 installed price of the ATS was estimated to be $\$ 164 / \mathrm{m}^{2}$ given $5000 / \mathrm{yr}$ and $\$ 126 / \mathrm{m}^{2}$ given 50,000 yr. The lower price at the higher production rate is primarily due to a lower-cost azimuth drive; at the higher rate more automation would be incorporated into the factory that produces the drive. The installed price of the SM at the same production levels was $\$ 180$ and $\$ 143 / \mathrm{m}^{2}$, respectively. The price breakdown given $50,000 / \mathrm{yr}$ is presented in Table S-2. 
Table S-2. Heliostat Prices Given 50,000 Units/Yr

\begin{tabular}{|l|lc|lc|}
\hline & $\begin{array}{c}\mathbf{1 5 0} \mathbf{~ m}^{\mathbf{2}} \text { Stretched } \\
\text { Membrane } \\
\text { Heliostat Price }\end{array}$ & $\begin{array}{c}\text { 148 } \mathbf{~ m}^{\mathbf{2}} \text { ATS Glass/Metal } \\
\text { Heliostat Price }\end{array}$ \\
\hline Mirror Module & $\$$ & 42.99 & $\$$ & 23.06 \\
\hline Support Structure & $\$$ & 19.08 & $\$$ & 21.21 \\
\hline Drive & $\$$ & 26.67 & $\$$ & 27.11 \\
\hline Drive electrical & $\$$ & 1.76 & $\$$ & 1.78 \\
\hline Controls & $\$$ & 1.87 & $\$$ & 1.94 \\
\hline Pedestal & $\$$ & 16.73 & $\$$ & 16.96 \\
\hline \multicolumn{1}{|c|}{ Total Direct Cost: } & $\$$ & 109.11 & $\$$ & 92.06 \\
\hline Overhead/Profit (20\%) & $\$$ & 21.82 & $\$$ & 18.41 \\
\hline \multicolumn{1}{|c|}{ Total Fabricated Price: } & $\$$ & 130.93 & $\$$ & 110.47 \\
\hline Field wiring & $\$$ & 7.30 & $\$$ & 7.40 \\
\hline Foundation & $\$$ & 2.30 & $\$$ & 2.28 \\
\hline Field alignment/checkout & $\$$ & 2.41 & $\$$ & 6.34 \\
\hline \multicolumn{1}{|c|}{ Total Installed Price: } & $\$$ & 142.90 & $\$$ & 126.50 \\
\hline
\end{tabular}

Despite the fact that the SM heliostat weighs $\sim 830 \mathrm{~kg}$ less than the ATS and is easier to align in the field, it still costs more due to the use of costly stainless steel in the membrane and supporting ring. Also, the fabrication of a single large membrane from available one-meter widths is cumbersome and adds to the price. However, several features of an SM heliostat relative to a glass/metal heliostat are estimated to be worth about $\$ 10 / \mathrm{m}^{2}$ on a system basis. The circular shape of the heliostat allows tighter packing of heliostats in the field and requires fewer overall heliostats for the same power output. Also, each membrane reflector can be focused at the exact slant range to the receiver, which is not practical with fixed-focus glass/metal heliostats, and this leads to a smaller and less expensive receiver. Thus, considering the optical improvement estimated by DELSOL analysis, the effective price of the SM heliostat is \$170 and $\$ 133 / \mathrm{m}^{2}$, respectively.

\section{Evaluation of Technology Improvement Opportunities}

The $\$ 126 / \mathrm{m}^{2}$ price is higher than the $\$ 100 / \mathrm{m}^{2}$ goal. However, this price does not include the effect of learning that naturally occurs over a several-year period of deployment. Sargent \& Lundy estimated a 92\% progress ratio ${ }^{1}$ during the initial 9-GW deployment of solar power towers over 16 -year period. Given $9 \mathrm{GW}$ of heliostat deployments, there are four doublings of production. Thus, a heliostat that costs $\$ 126 / \mathrm{m}^{2}$ during the initial deployment will cost $0.92^{4} * 126=\$ 91 / \mathrm{m}^{2}$ after $9 \mathrm{GW}$. The source of this cost reduction is twofold: technology improvements and manufacturing/installation productivity advancements. In this section we

1 Historical deployments of wind turbines over a similar time period suggest this progress ratio is reasonable. For example, the Danish deployed $10 \mathrm{GW}$ of wind turbines with a progress ratio of 92. To a first order, wind turbines and heliostats can be viewed as similar; both are large steel outdoor structures with gear drives. 
focus on possible TIOs. We will show that the TIOs identified during this study could yield $\sim 50 \%$ (or $\sim \$ 17 / \mathrm{m}^{2}$ ) of the expected cost reduction from $\$ 126$ to $\$ 91 / \mathrm{m}^{2}$ during the $9-\mathrm{GW}$ deployment scenario. The remaining $50 \%$, due to productivity advancements, is expected but not analyzed here.

TIOs were identified within brainstorming sessions involving 30 international participants attending a two-day workshop. The group proposed many incremental improvements to existing glass/metal and SM heliostat designs as well as totally new types of heliostats. Some of the new types of heliostats are depicted in Figure S-5. The participants voted on 29 TIOs and the votes were tallied to obtain a numeric score for each TIO.
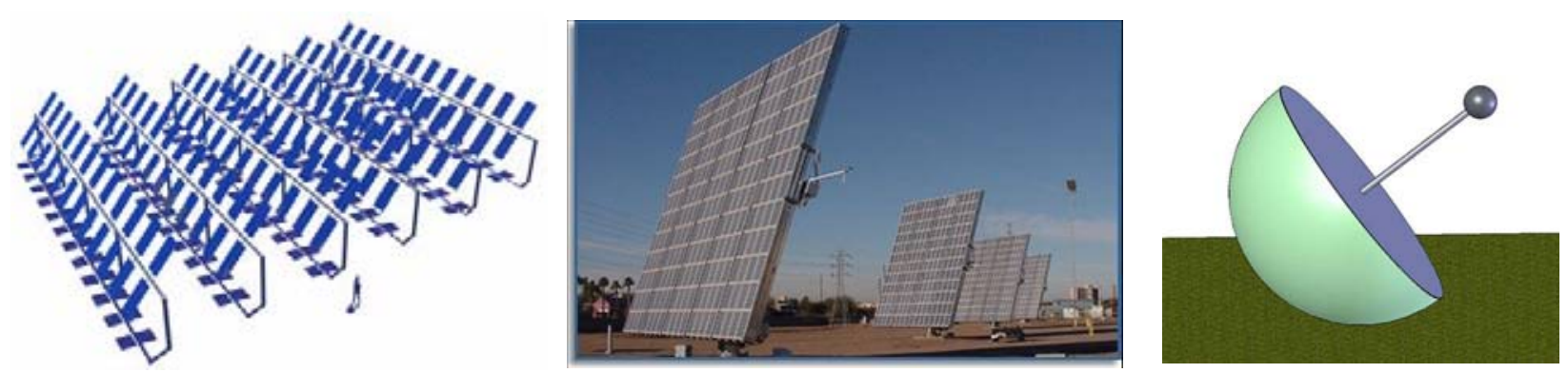

Figure S-5. In the mega-ganged heliostat proposed by DLR (left), up to $\sim 500 \mathrm{~m}^{2}$ of multiple facets are coupled via a common drive. In the mega-helio proposed by Arizona Public Service (center), an existing 320- $\mathrm{m}^{2}$ PV tracker would be converted to a heliostat. The water-ballasted heliostat proposed by New Mexico Tech (right) is moved by pumping water between internal chambers. The ball at the end the post is a counterweight.

In the months following the initial workshop, the core heliostat team evaluated the TIOs. The goals of this evaluation were to:

1. Propose future R\&D projects that address the lion's share of the TIOs.

2. Estimate expected reduction in heliostat price resulting from each R\&D project.

3. Estimate the cost of performing the R\&D for each project.

4. Rank the proposed R\&D projects given different possible DOE funding scenarios to identify the projects that give the "most bang for the buck."

The core team identified seven possible projects that addressed $76 \%$ of the total votes cast by the 30 international experts. The projects are briefly described below

Project 1 - Large SM facet. In this project, a large $\left(150-\mathrm{m}^{2}\right)$ stretched-membrane facet is developed that can be integrated into a pedestal-type heliostat. In the United States, only 50- $\mathrm{m}^{2}$ facets have been built. Scale-up to $150 \mathrm{~m}^{2}$ was proposed to reduce cost on a $\$ / \mathrm{m}^{2}$ basis. However, analysis presented in the previous section indicates that this type of SM heliostat actually results in a higher cost. This project was therefore eliminated from further consideration. 
Project 2 - Less conservative azimuth drive. The azimuth drive is the most significant heliostat cost contributor. It appears the design of the azimuth drive may be too conservative and lowercost drive could be developed given a better understanding of the wind loads and torques on the heliostat drive. Significant cost reduction can also be achieved through highly automated production-line manufacturing techniques. A production line does not currently exist. A 33\% price reduction $\left(\sim \$ 8 / \mathrm{m}^{2}\right)$ is targeted.

Project 3 - Pipe-in-pipe azimuth drive. The brainstorming group explored different approaches to the conventional gear-type drive historically built by Winsmith and Flender. At the White Cliffs plant in Australia, a pipe-in-pipe approach was successfully used to position relatively small $\left(\sim 7 \mathrm{~m}^{2}\right)$ solar dishes. In this concept, azimuth motion is achieved by rotating a pipe within the fixed pedestal. The driving motor is located at the bottom of the pedestal and the wind loads on the drive are distributed along the length of the pipes, as opposed to a single point within the conventional drive. Cost reductions relative to a gear-type drive appear feasible because manufacturing of the pipe-in-pipe could be simpler. A 33\% price reduction relative to the current conventional azimuth drive $\left(\sim 8 / \mathrm{m}^{2}\right)$ is targeted.

Project 4-Large carousel-type SM heliostat. A large heliostat like this has been operating in Spain (see Figure S-4). Analysis conducted in the 1990s indicate the cost of this heliostat should be significantly lower than a glass/metal heliostat built by a Spanish company. However, a few in the brainstorming group suggested the concrete foundation for the ASM-150 is too complex and costly. The group then explored ideas on how to drastically reduce the cost of the foundation. Precast concrete foundations that "roll off a truck" were thought to be a possible low-cost solution. A $>10 \%$ capital cost reduction relative to the ATS is targeted. This appears feasible because it weighs $\sim 50 \%$ less than the ATS. Combining this with the performance improvement of $\sim \$ 10 / \mathrm{m}^{2}$ described in the previous section should result in an overall cost reduction of $\sim 20 \%$.

Project 5 - Large single-fabric-based SM facet. Today's SM facets are created by welding multiple strips of stainless steel across a ring. The welding process is complex and cumbersome. The brainstorming group thought that significant cost reduction for the facet could be achieved if the stainless steel strips were replaced with a single large piece of fabric. Besides eliminating expensive stainless steel, connection to the outer ring could be greatly simplified by using an "embroidery-hoop" method, i.e., two concentric hoops are press-fit to form the connection between the material and the ring. The fabric must not leak air to maintain the vacuum within the facet plenum. Thus, the fabric would need to be impregnated with a sealer. Rough calculations suggest this facet could lead to an additional cost reduction of $\sim \$ 7 / \mathrm{m}^{2}$ relative to the carousel heliostat described in Project 4.

Project 6 - Mega-heliostat. Arizona Public Service (APS) currently operates several large-area two-axis photovoltaic (PV) concentrators (see Figure S-5). This device could be converted to a heliostat by replacing the Fresnel-PV modules with mirrors. At this size the use of hydraulic type azimuth and elevation drives appears to be justified. The brainstorming group generally concluded that hydraulic drive systems are more complex and require more maintenance than mechanical drive systems. However, they are very strong and could be the preferred low-cost approach for mega-heliostats. Engineering scaling laws indicate the cost of this heliostat could 
be $\$ 21 / \mathrm{m}^{2}$ less than the $148-\mathrm{m}^{2}$ ATS heliostat. However, the optical quality of the megaheliostat will be worse than the ATS because the reflected beam will be larger. DELSOL predicts an optical penalty is $\sim \$ 3 / \mathrm{m}^{2}$. Thus, the net cost reduction is $\sim \$ 18 / \mathrm{m}^{2}$.

Project 7 - Water-ballasted heliostat. Students at New Mexico Tech are exploring innovative "water-ballasted" heliostats (Figure S-5). Heliostat tracking is achieved by pumping water between chambers located on the back of the mirror. This eliminates the use of costly gear drives. NM Tech has their own funding from the Environmental Protection Agency (EPA) to explore these concepts. We will keep abreast of their progress. No DOE funding is requested at this time.

\section{R\&D Project Selection Given Uncertainty and a Constrained R\&D Budget}

The price reductions from the proposed heliostat R\&D projects are highly uncertain. For each project we developed a best estimate, an optimistic bound, and a pessimistic bound, as well as the cost of each R\&D project. Since the purpose of R\&D is to reduce uncertainty, the bounds will shrink as the work progresses. However, given our current state of knowledge, we need to decide which $R \& D$ projects should be given highest priority. If money were no object, all the projects could be pursued. However, we live in a world of limited R\&D budgets and need to identify those that will give the "most bang for the buck." Fortunately, there are tools available to help the decision maker.

Crystal Ball software is being used by USDOE and many other organizations to assess the risk/uncertainty of achieving the goals of proposed $\mathrm{R} \& \mathrm{D}$ projects. Uncertain parameters are propagated via Monte Carlo simulation. Many pre-programmed models exist that can be adapted to solve a particular problem. One such model, "Budget-Constrained Project Selection," was adapted to solve the problem at hand.

Crystal Ball predicts $\sim \$ 8 \mathrm{M}$ in R\&D is needed to achieve a mean price reduction of $\$ 17 / \mathrm{m}^{2}$. However, a $\$ 5 \mathrm{M}$ budget achieves $\$ 16 / \mathrm{m}^{2}$ and gets the "most bang for the buck." For this case, Crystal Ball predicts there is an $80 \%$ chance of achieving at least a $\$ 10 / \mathrm{m}^{2}$ price reduction, a $50 \%$ chance of achieving $\$ 16$, and a $20 \%$ chance of achieving $\$ 24$. Given a $\$ 5 \mathrm{M}$ budget, priority should be given to developing the mega-helio, the carousel heliostat, and the fabricmembrane mirror facet. Given a $\$ 1$ to $\$ 2 \mathrm{M}$ budget, a mean price reduction of $\sim \$ 10 / \mathrm{m}^{2}$ is expected and priority should be given to developing a less-conservative azimuth drive and the mega-helio.

\section{Conclusions}

The main conclusions are summarized below.

Heliostat price is strongly dependent on production rate. Given current technology, the price of heliostats in 2006 is estimated to be $\$ 164 / \mathrm{m}^{2}$ given 5000/yr and $\$ 126 / \mathrm{m}^{2}$ given 50,000/yr. The key to achieving reasonable production rates is for a solar company to obtain multiple powerpurchase agreements from electric-utility companies over a several-year period. For example, a 
solar dish developer (SES, Inc.) has recently signed agreements with 2 utilities to deploy up to $1750 \mathrm{MW}$. With these agreements in hand, SES can now justify a highly automated production facility. Like SES, a power tower developer needs to sign multiple power-purchase agreements. However, if the SES projects proceed as planned, the power tower developer could benefit because the dish azimuth drive is nearly identical to the heliostat azimuth drive.

The ATS heliostat is the current low-cost baseline in the USA. It is cost-efficient from a manufacturing point of view. Except for the azimuth drive, it uses common parts that are already mass-produced. It has successfully operated for 20 years.

Large heliostats are more cost-efficient than small ones. Like most engineered systems, heliostats benefit from "economies of scale." Thus, large heliostats cost less on a $\$ / \mathrm{m}^{2}$ basis than very small ones.

$R \& D$ should be able to reduce the heliostat price by at least $\$ 17 / \mathrm{m}^{2}$. A price reduction from $\$ 126 / \mathrm{m}^{2}$ to $\$ 109 / \mathrm{m}^{2}$ was estimated by evaluating TIOs proposed by 30 heliostat and manufacturing experts. Continued price reduction from $\$ 109 / \mathrm{m}^{2}$ to $\$ 90 / \mathrm{m}^{2}$ is expected through learning during the deployment of the initial $9 \mathrm{GW}$ of power plants over a decade or more.

\section{Acknowledgments}

Funding for this research project was provided by the U.S. Department of Energy under contract DE-AC04-94AL85000 and was conducted as part of the Solar Hydrogen Generation Research Project managed by University of Nevada Las Vegas. 


\section{INTRODUCTION}

Power towers are often predicted to be the least-expensive method of producing solar-generated electricity and hydrogen on a large scale [1, 2]. Plants capable of producing $100 \mathrm{MW}$ of electricity or $100,000 \mathrm{~kg} /$ day of hydrogen appear feasible. Twenty-four-hour operation is achieved through integration of a large (13-hour) thermal energy storage system, as depicted in Figure 1-1.

Solar electric power plant

- $100 \mathrm{MW}_{\mathrm{e}}$ Rankine-cycle electric plant

- $700 \mathrm{MW}_{\mathrm{t}}, 565{ }^{\circ} \mathrm{C}$ molten salt receiver

- $13 \mathrm{hr}$ molten salt storage

- Same as Sargent \& Lundy 100 MWe plant

\section{Solar hydrogen plant}

- $255 \mathrm{MW}_{\mathrm{t}} / 60 \mathrm{MW}_{\mathrm{e}}$ hybrid-sulfur $\mathrm{H}_{2}$ plant

- $700 \mathrm{MW}_{\mathrm{t}}, 950^{\circ} \mathrm{C}$ solid particle receiver

- $13 \mathrm{hr}$ solid particle storage

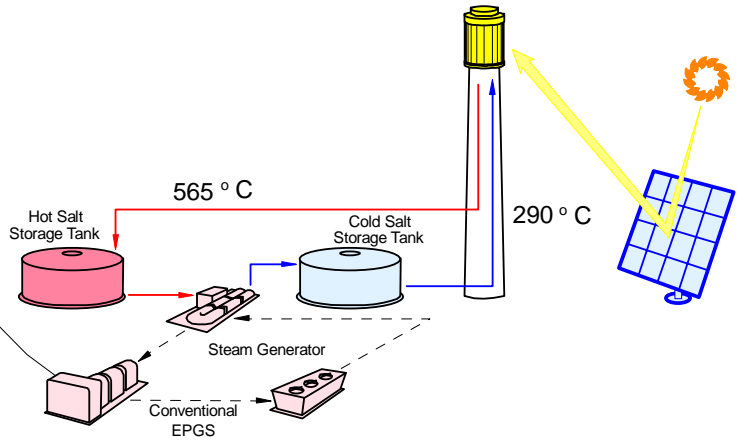

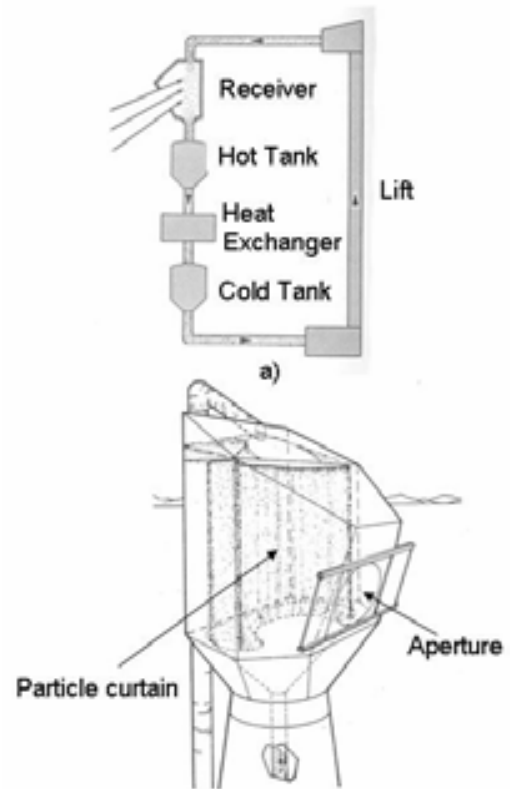

b)

Figure 1-1. Power tower concepts of current interest to the USDOE solar energy program.

Heliostats are the most important cost element of a power tower plant. As indicated in Figure 1-2, they contribute more than $50 \%$ to the total cost of the plant. Consequently, it is important to reduce the cost of heliostats as much as possible to improve the economic viability of solar power towers. 
Electric Power Plant

- $100 \mathrm{MWe}$

- $1.36 \mathrm{E} 6 \mathrm{~m}^{2}$ heliostats

- $13 \mathrm{hr}$ thermal storage

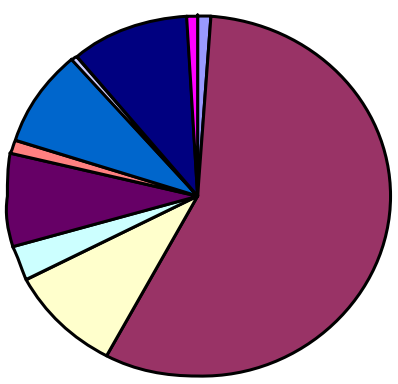

口 Struct/Improve

$\square$ Heliostats

$\square$ Receiver

$\square$ Tower/Piping

口Thermal Storage

$\square$ Steam Generator

$\square$ EPGS

$\square$ Controls

口 BOP

$\square$ Land

Hydrogen Plant

- 100,000 kg/day

- $1.36 \mathrm{E} 6 \mathrm{~m}^{2}$ heliostats

- $13 \mathrm{hr}$ thermal storage

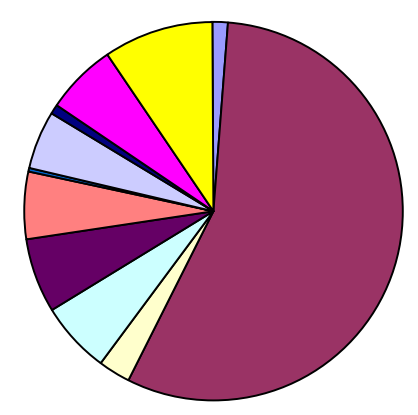

$\square$ Struct/Improve

$\square$ Heliostats

$\square$ Receiver

$\square$ Tower/Piping

$\square$ Thermal Storage

$\square$ Heat Exchanger

$\square$ Controls

$\square$ BOP

- Land

$\square$ Electrolyzer

$\square$ Thermo-Chem Plant

Figure 1-2. Heliostats dominate the capital cost of power towers. In this example, heliostats are assumed to cost $\$ 150 / \mathrm{m}^{2}$. The cost breakdown for the electric plant is taken from Sargent \& Lundy [1].

The Department of Energy's (DOE's) accepted methods for calculating levelized energy cost (LEC) are described in the Sargent \& Lundy study [1] for electric plants and H2A [3] for hydrogen plants. Applying these methods to the plants described above results in the LECs shown in Table 1-1. Power tower LECs are attractive given a heliostat price of $\$ 100 / \mathrm{m}^{2}$ and may be low enough to be competitive on the open market, especially if carbon-offset trading is implemented. In addition, tax incentives that are U.S. law for solar electricity could further lower the hydrogen LECs shown in the table. U.S. law stipulates a $10 \%$ investment tax credit $^{2}$ and five-year accelerated depreciation for solar electric plants. The solar hydrogen LECs are reduced by $25 \%$ if these tax laws and other Sargent \& Lundy financial assumptions are made rather than the base-case economic assumptions in H2A. A price $\sim \$ 100 / \mathrm{m}^{2}$ thus appears to be a reasonable goal for heliostats.

2 In 2006 the investment tax credit was actually 30\%. However, this tax credit has a sunset clause. The permanent tax credit is $10 \%$ and the analysis of electric plants in this report assumes this value. 
Table 1-1. Power Tower Levelized Energy Costs

\begin{tabular}{|c|c|c|}
\hline $\begin{array}{c}\text { Heliostat } \\
\text { Price }\end{array}$ & $\begin{array}{c}\text { Molten Salt } \\
\text { Power Tower } \\
\text { (S\&L economics) }\end{array}$ & $\begin{array}{c}\text { Hybrid Sulfur } \\
\text { Hydrogen Plant } \\
\text { (H2A economics) }\end{array}$ \\
\hline \hline$\$ 80 / \mathrm{m}^{2}$ & 5.4 cents $/ \mathrm{kWh}$ & $\$ 2.6 / \mathrm{kg}$ \\
\hline$\$ 100 / \mathrm{m}^{2}$ & 5.9 cents $/ \mathrm{kWh}$ & $\$ 2.9 / \mathrm{kg}$ \\
\hline$\$ 150 / \mathrm{m}^{2}$ & 7.3 cents $/ \mathrm{kWh}$ & $\$ 3.5 / \mathrm{kg}$ \\
\hline$\$ 200 / \mathrm{m}^{2}$ & 8.7 cents $/ \mathrm{kWh}$ & $\$ 4.1 / \mathrm{kg}$ \\
\hline $300 / \mathrm{m}^{2}$ & 12 cents $/ \mathrm{kWh}$ & $\$ 5.4 / \mathrm{kg}$ \\
\hline
\end{tabular}

The objectives of this study are the following:

- Review the heliostat-development history defining the current state of the art.

- For state-of-the-art heliostats in the United States, develop price estimates in current 2006 dollars.

- Identify technology improvement opportunities (TIOs) that lead to a significant price reduction.

- Estimate the price-reduction potential of the TIOs and estimate the research and development $(R \& D)$ cost necessary to achieve this potential.

- Determine whether it is feasible to achieve a preliminary goal of $\$ 100 / \mathrm{m}^{2}$.

This study was performed during calendar year 2006. During the first half of 2006 Sandia National Laboratories (SNL) established subcontracts with heliostat manufacturers and manufacturing experts to form a core team of six individuals. In July, a two-day workshop was held at the National Solar Thermal Test Facility (NSTTF) in Albuquerque, New Mexico, to discuss the current state of the art of heliostats and to identify TIOs. Approximately 30 heliostat and manufacturing experts from the United States, Europe, and Australia participated in this workshop. After the workshop the core team developed price estimates for current heliostats and evaluated the price-reduction potential of the TIOs. The core team also proposed R\&D projects that address the majority of the TIOs. Nearly the full team of experts reassembled in November to review the analysis conducted by the core team. This report was written after receiving comments from the experts on the material presented in November. 


\section{OVERVIEW OF HELIOSTAT TECHNOLOGY DEVELOPMENT HISTORY}

\subsection{Summary of U.S. R\&D}

A brief overview of the U.S. heliostat development history is presented in this section. More detail can be found in Chapter 3 .

Heliostat development in the United States was initiated in 1975 when four industry teams were funded to complete design studies for first-generation heliostats. These studies included cost estimates and each contractor built four to six heliostats. To significantly reduce the cost, second-generation designs were developed in late 1977 and additional prototypes were built and tested through 1981. Heliostats developed during the first- and second-generation period were built by the industry teams shown in the upper portion of Figure 2-1. The Jones heliostat was investigated separately in 1982 [4]. There are five different concepts shown in the figure:

(1) pedestal-mounted (left); (2) bubble-enclosed membrane (top); (3) ganged (right); (4) carousel (center); and (5) rotating field (bottom). After extensive evaluation [5], the pedestal-mounted heliostat was shown to have a cost advantage over the other approaches, and it was selected for application at the Solar One Pilot Plant in 1982 (Figure 2-2).
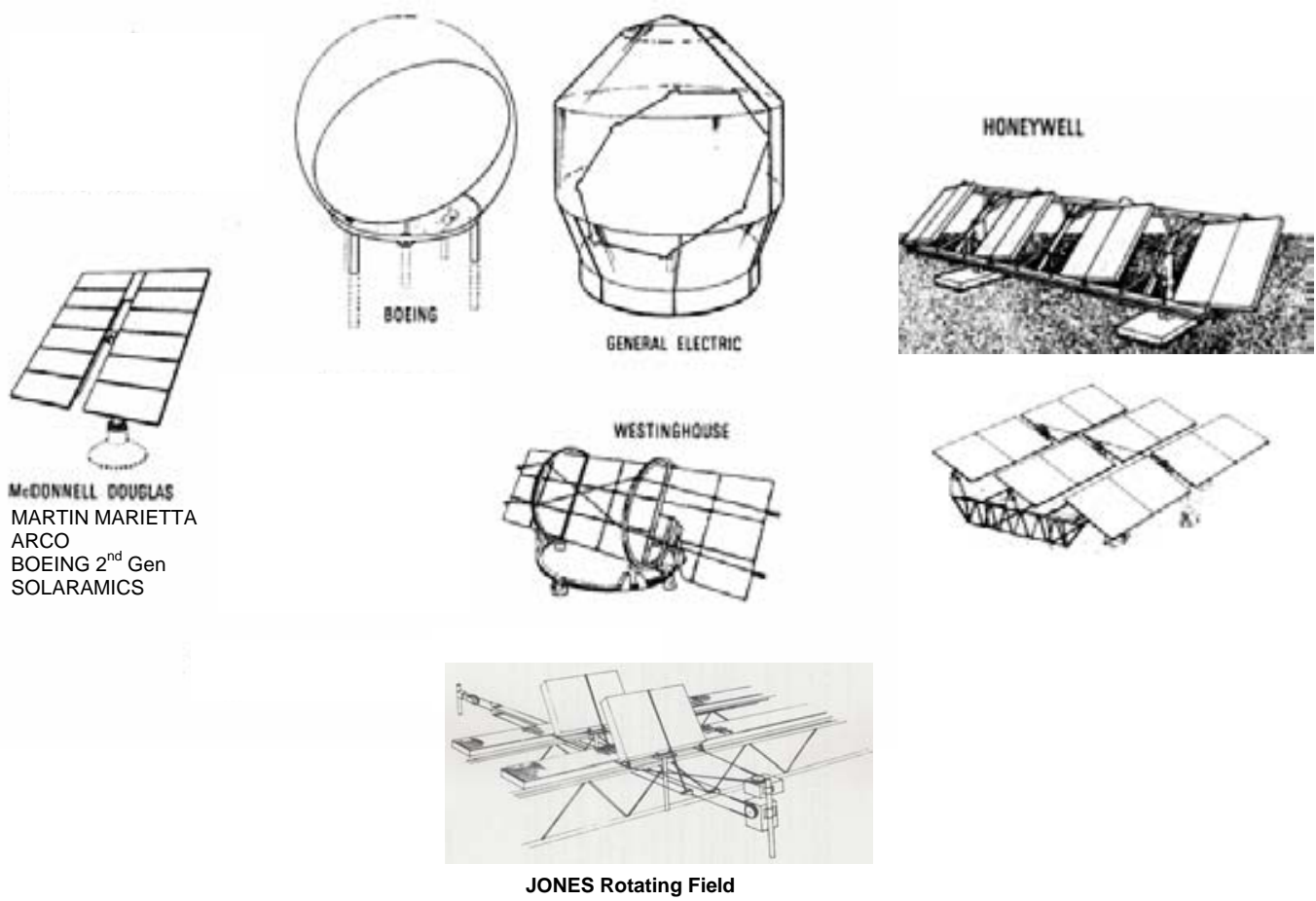

Figure 2-1. Heliostat concepts developed in the United States between 1975 and 1981. 


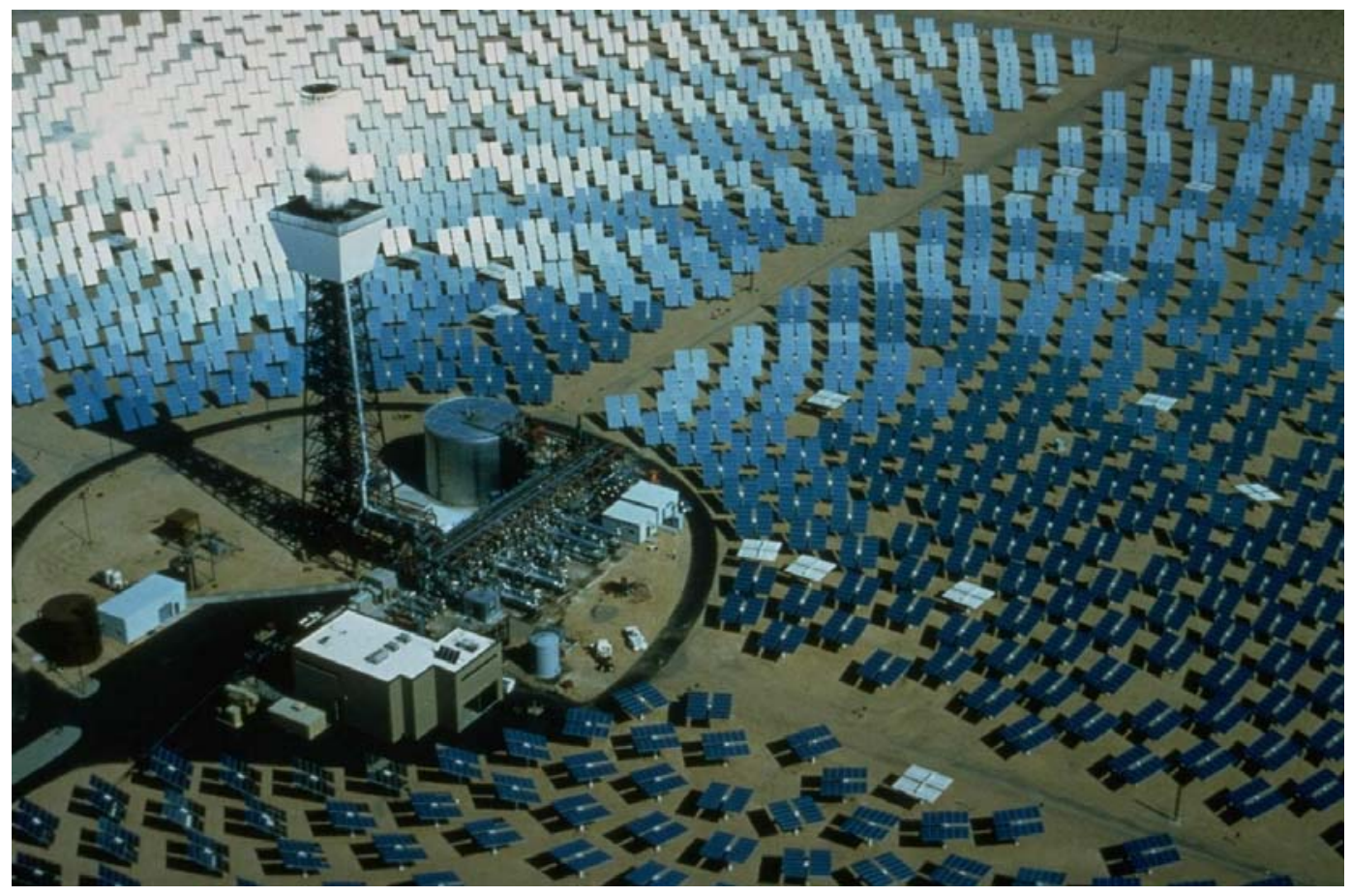

Figure 2-2. From 1982 to 1988, Solar One (near Barstow, California) used 1,818 pedestal-mounted heliostats built by Martin Marietta. Each heliostat was $39.1 \mathrm{~m}^{2}$ for a total area of $71,130 \mathrm{~m}^{2}$. The heliostat field was used again during the Solar Two project from 1996 to 1999.

The heyday of heliostat development in the United States occurred during the second-generation period ending in 1981. The DOE budget for heliostat development was $\$ 7.3 \mathrm{M}$, equivalent to $\$ 19$ M in today's dollars. This budget level allowed for extensive optimization and cost studies, and more than 100 technical references can be found in Mavis [5]. An example is the detailed mass-manufacturing analysis performed by General Motors [6] in which assembly lines were proposed capable of producing 50,000 McDonnell Douglas heliostats per year (Figure 2-3). The second-generation studies predicted the heliostat price to be $\$ 100$ to $\$ 150 / \mathrm{m}^{2}$ (1980\$) for a $\sim 60-\mathrm{m}^{2}$ size.

Shortly after the second-generation period, McDonnell Douglas continued to optimize their heliostat. They examined many design variables and decided the best way to reduce cost was to increase heliostat size to at least $100 \mathrm{~m}^{2}$ [7]. Their analysis showed a 20\% cost reduction. To further reduce cost, Sandia [5] proposed even larger 150- $\mathrm{m}^{2}$ heliostats and also began to investigate a large, circular stretched-membrane (SM) concept. Bigger was predicted to be better due to the improved economies of scale for the heliostat components. In addition, fixed costs per heliostat (controls, installation, and operation and maintenance (O\&M)) could be spread over more area to reduce the $\$ / \mathrm{m}^{2}$ contribution from these elements. The SM concept was proposed because it was lighter and simpler (i.e., fewer parts) than the glass/metal heliostat. The mid1980s path to low-cost heliostats is summarized in Figure 2-4 [5]. This led to the construction of full-scale $\left(148-\mathrm{m}^{2}\right)$ glass/metal and several sub-scale $\left(50-\mathrm{m}^{2}\right)$ SM prototypes in the late $1980 \mathrm{~s}$ (Figure 2-5). 


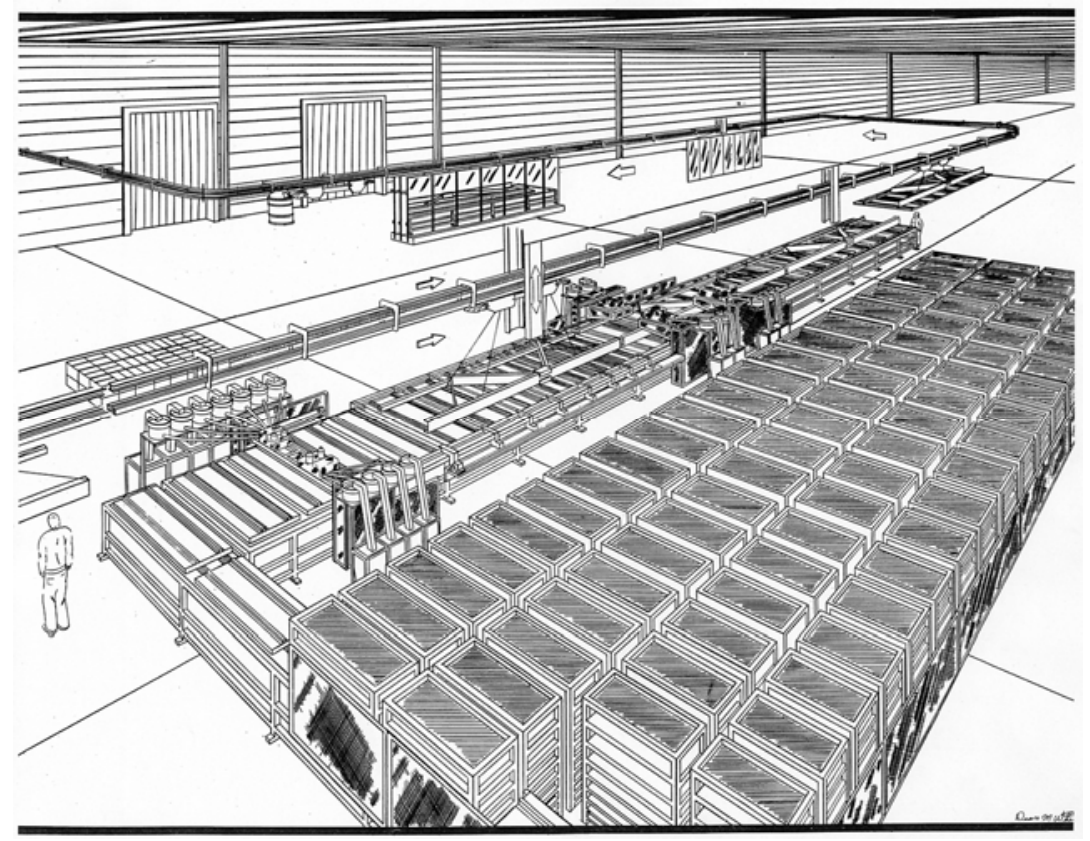

Figure 2-3. Highly automated central manufacturing plant proposed by General Motors.

The 1980s vision of building larger heliostats to achieve a lower $\$ / \mathrm{m}^{2}$ cost was reaffirmed by a detailed Sandia analysis performed in the year 2000 (see Appendix A). At that time a few research organizations (especially the Israelis) were predicting that very small (10 to $20 \mathrm{~m}^{2}$ ) heliostats could be cheaper. However, these organizations were generally using heliostats within an ultra-high concentration power tower system. Such systems require a small beam size, which can be more easily achieved with small heliostats. For the lower-concentration power towers of interest in this report, the analysis predicts that low-cost heliostats are most likely to be $\sim 150 \mathrm{~m}^{2}$. The analysis suggests the optimum might be as low as $50 \mathrm{~m}^{2}$, but the cost data supporting the larger $150-\mathrm{m}^{2}$ size is much more defensible.

The 148-m² ATS heliostat has successfully operated for the last 20 years at the NSTTF in Albuquerque. It has survived multiple high-wind events, some in excess of $90 \mathrm{mph}$, and the quality of the beam has not degraded significantly.

The SM heliostats proved to be mechanically sound. However, the polymer mirror quickly degraded due to ultraviolet (UV) damage and the face-up stow position led to hail-induced membrane denting. The mirror surfaces were not replaced and the heliostats were mothballed after a few years. Because of this experience, Sandia recommended the use of thin glass rather than polymer films. An SM heliostat employing thin glass was built and tested in 1998 (Figure 2-6). Rather than a single large facet, the heliostat was composed of several membrane facets. This design approach was taken because the Stirling-dish program had developed a dish that used the same facets and cost reductions were predicted given mass production to support both commercial dish and power tower projects. The glass-covered facets have proven to be reliable, but the optical quality of the heliostat was not as good as the ATS. In addition, the commercial deployments needed to achieve the cost reductions did not occur. Consequently, the multifaceted SM heliostat was abandoned. 


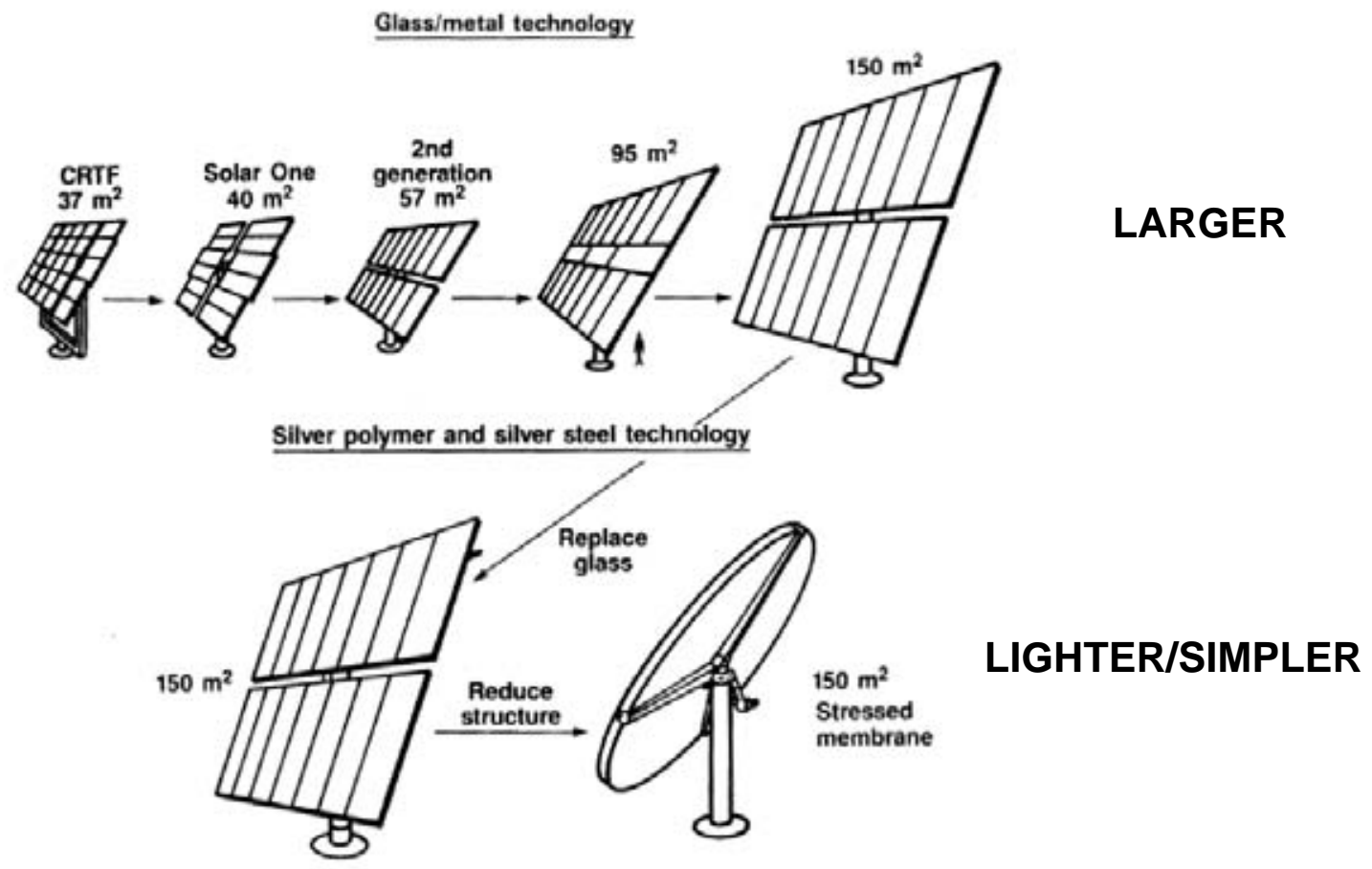

Heliostat Cost Estimate

June 1986 Dollars

$150 \mathrm{~m}^{2}$ Mass Production

Price in $\$ / \mathrm{m}^{2}$

\begin{tabular}{lrrr}
\hline \multicolumn{1}{c}{ Component } & \multicolumn{2}{c}{ Stressed Membrane } & Glass \\
\cline { 2 - 4 } & SKI & SAIC & Metal \\
\hline \hline Reflective Assembly & $\$ 21.00$ & $\$ 30.30$ & $\$ 32.80$ \\
Support Structure & 8.70 & 6.30 & 10.40 \\
Drives & 11.60 & 11.60 & 11.60 \\
Drive Electrical & 0.95 & 0.95 & 0.95 \\
Foundation & 6.70 & 6.70 & 6.70 \\
Pedestal & 1.90 & 1.90 & 1.90 \\
Field Wiring & 4.00 & 4.00 & 4.00 \\
Controls & 1.90 & 1.90 & 1.90 \\
Field Assembly/Checkout & 1.30 & 1.30 & 6.30 \\
Total Price Year 1 & & & \\
$\quad$ Price Year 2 & $\$ 58.05$ & $\$ 64.95$ & $\$ 76.55$ \\
$\quad$ Price Year 4 & $\$ 52.25$ & $\$ 58.45$ & $\$ 68.90$ \\
$\quad$ Price Year 8 & $\$ 47.00$ & $\$ 52.60$ & $\$ 62.00$ \\
SKI - Solar Kinetics, Inc. & $\$ 42.30$ & $\$ 47.35$ & $\$ 55.80$ \\
SAIC - Science Application International Co. & & & \\
\hline
\end{tabular}

Figure 2-4. Mid-1980s path to low-cost heliostats. Cost based on 50,000 units/yr. 

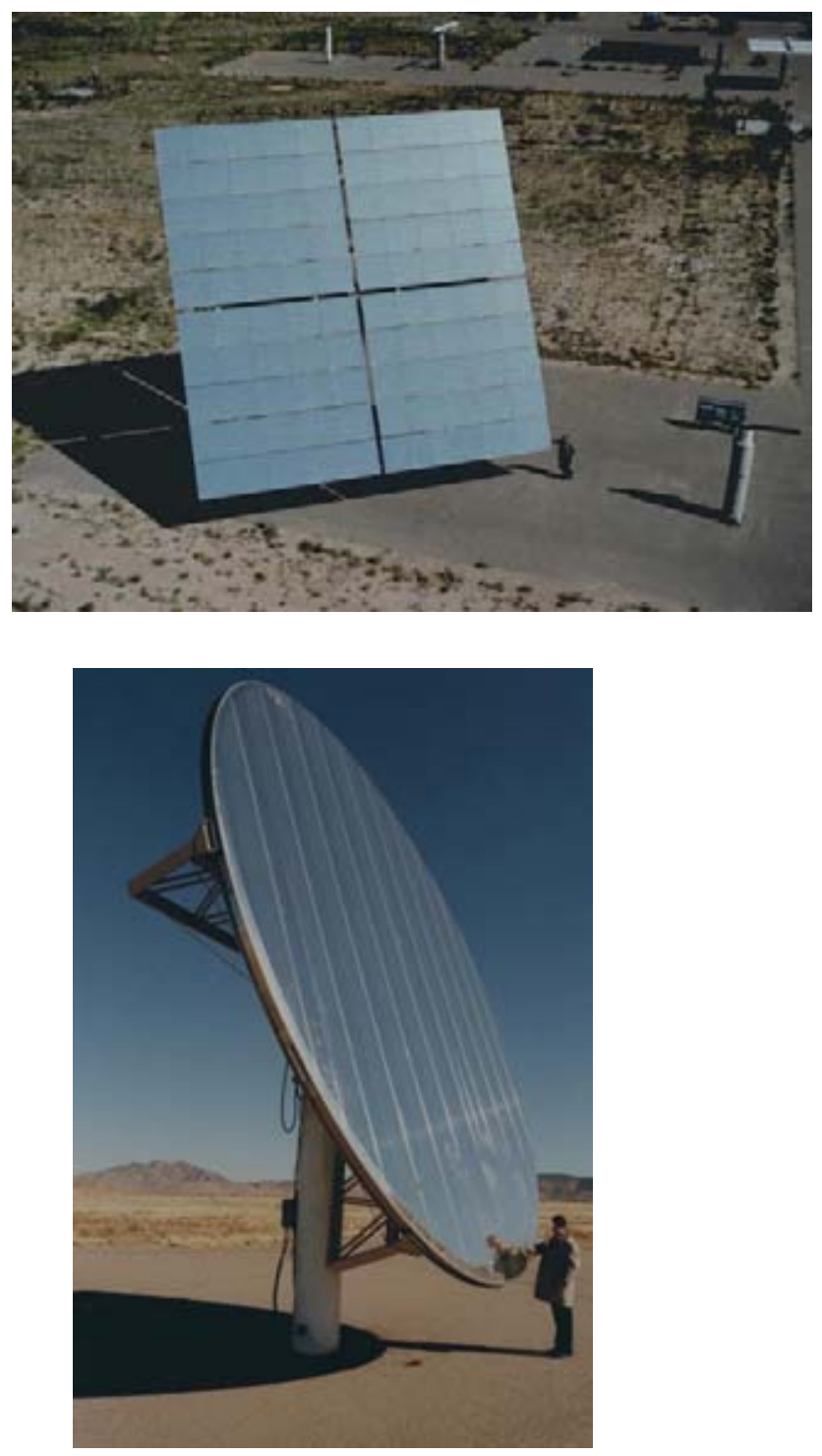

Figure 2-5. Advanced Thermal Systems (ATS) built a 148- $m^{2}$ glass/metal heliostat. Science Applications International Corporation (SAIC) and Solar Kinetics, Incorporated (SKI) built four $50 \mathrm{~m}^{2}$ SM heliostats similar to the one shown.

Because of the excellent experience with the ATS heliostat and its relatively simple design, Sandia considers it to be the current low-cost option in the United States. The most recent assessment of power tower system economics [1] has also adopted it as their baseline.

In 2006 there were no commercial-scale power tower projects proposed for construction in the United States. Consequently, the USDOE is currently not sponsoring heliostat R\&D. 


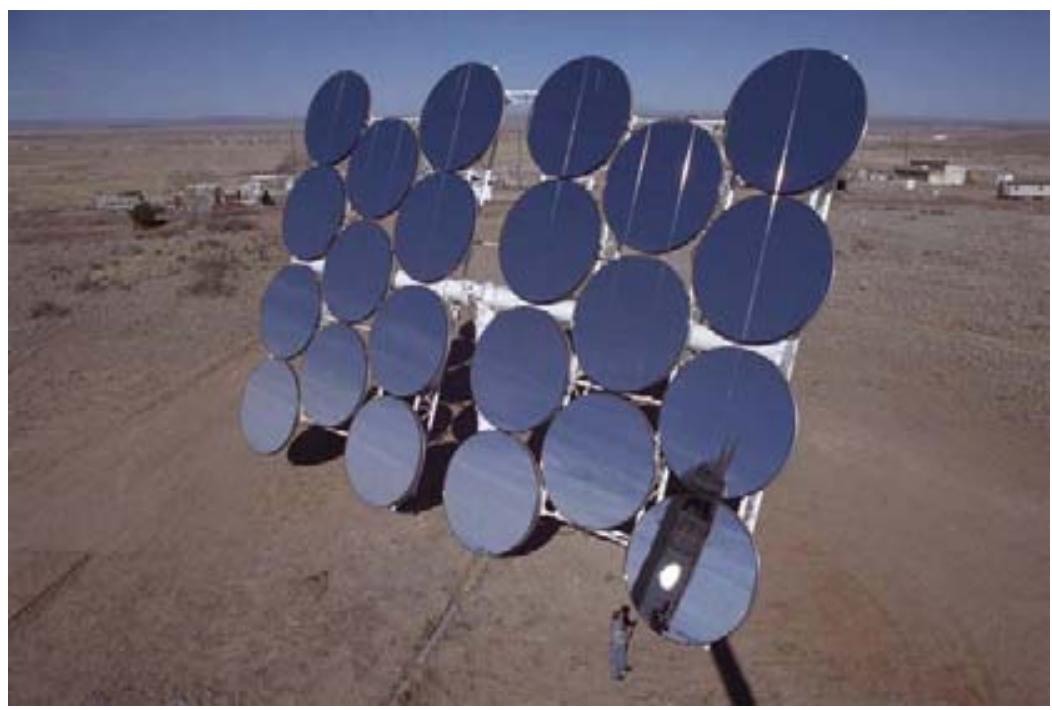

Figure 2-6. The 145- $m^{2}$ multi-faceted SM heliostats built by SAIC.

\subsection{Summary of European R\&D}

In 2006 there are several power tower projects in Europe as well as an active governmentsponsored heliostat R\&D program. The power tower projects in Europe are listed below:

- $\quad$ PS-10, 10 MWe (SOLUCAR):

o grid connection in October 2006

- $\quad$ PS-20, 20 MWe (SOLUCAR):

o erection started in fall 2006

- $\quad$ Solar-Tres, 15 MWe (SENER):

o milestone: receiver test in fall 2006

- Jülich, 1.5 MWe (KAM):

o project decision taken in July 2006

- Adrano, $200 \mathrm{kWe}$ (SHAP):

o erection started in fall 2006

- Themis (CNRS):

o refurbishment of Themis solar plant

The PS-10 project in Spain completed startup in late 2006 (Figure 2-7). Large-area (121- $\mathrm{m}^{2}$ ) pedestal-mounted heliostats were installed after an evaluation of alternate concepts indicated they were the low-cost option. The evaluation was performed by Solucar, the plant developer [8]. Solucar is a Spanish company that has a long history of heliostat development. They installed the original CESA-1 heliostat field at the Plataforma Solar test facility in Almeria in the 1980s. Over the years Solucar has studied pedestal-mounted heliostats with sizes from 30 to $121 \mathrm{~m}^{2}$ (Figure 2-8). They have also investigated the full-carousel type, similar to that depicted in the center of Figure 2-1, as well as the partial-carousel approach shown in Figure 2-9. 


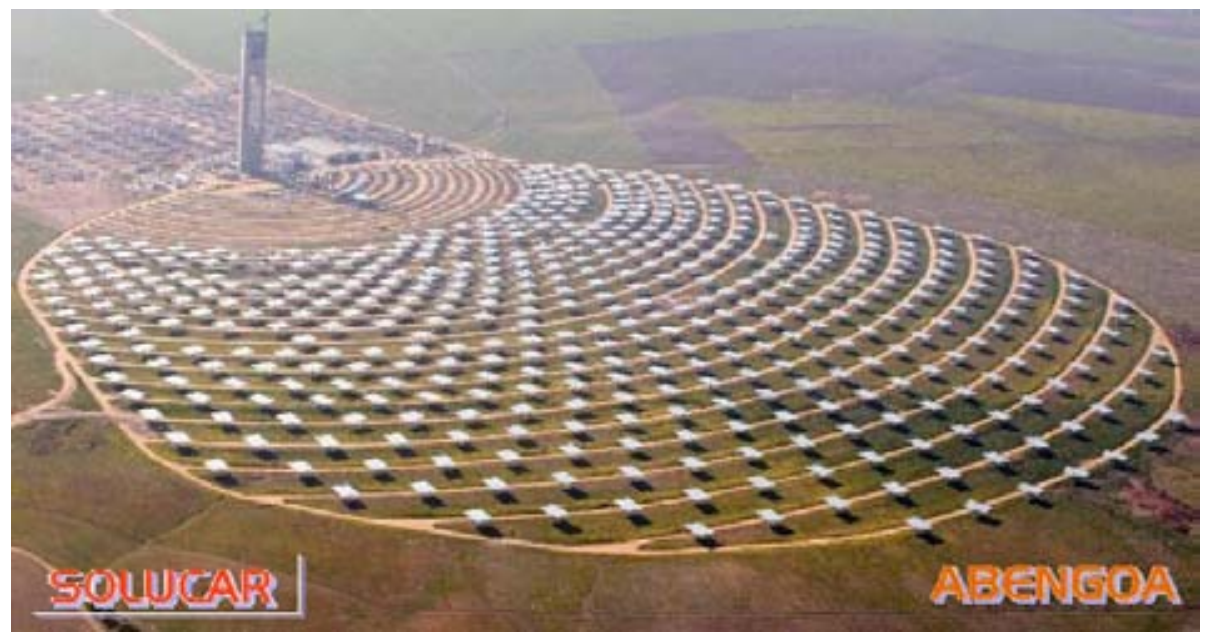

Figure 2-7. In 2006, PS-10 (near Seville, Spain) uses 624 pedestal-mounted heliostats built by Solucar. Each heliostat is $121 \mathrm{~m}^{2}$ for a total area of 75,504 $\mathrm{m}^{2}$.

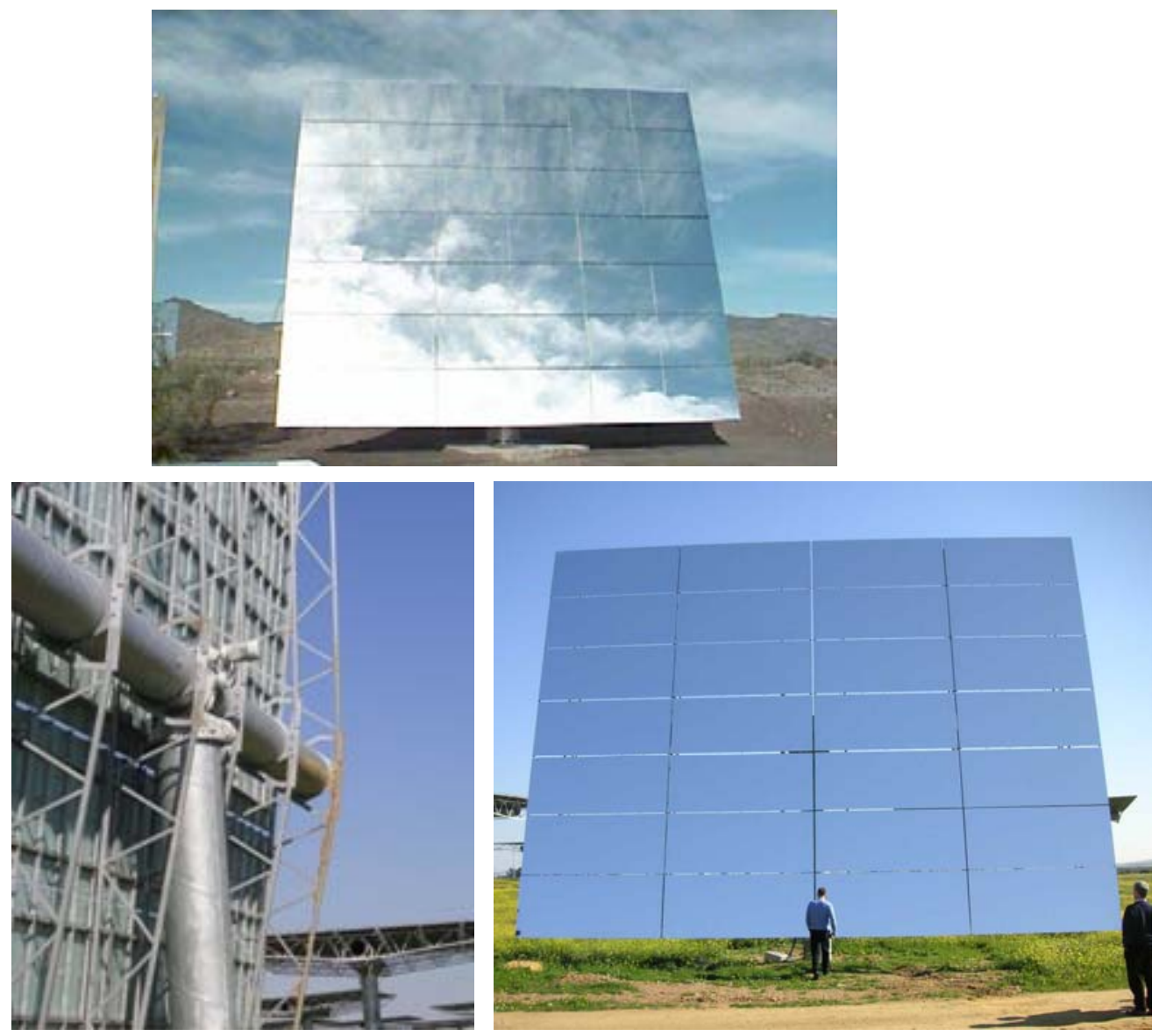

Figure 2-8. Solucar heliostats. A 69- $\mathrm{m}^{2}$ model is shown at top.

The PS-10 heliostat at bottom measures $121 \mathrm{~m}^{2}$. Cost of PS-10 heliostat is $140 \mathrm{Euro} / \mathrm{m}^{2}$. 

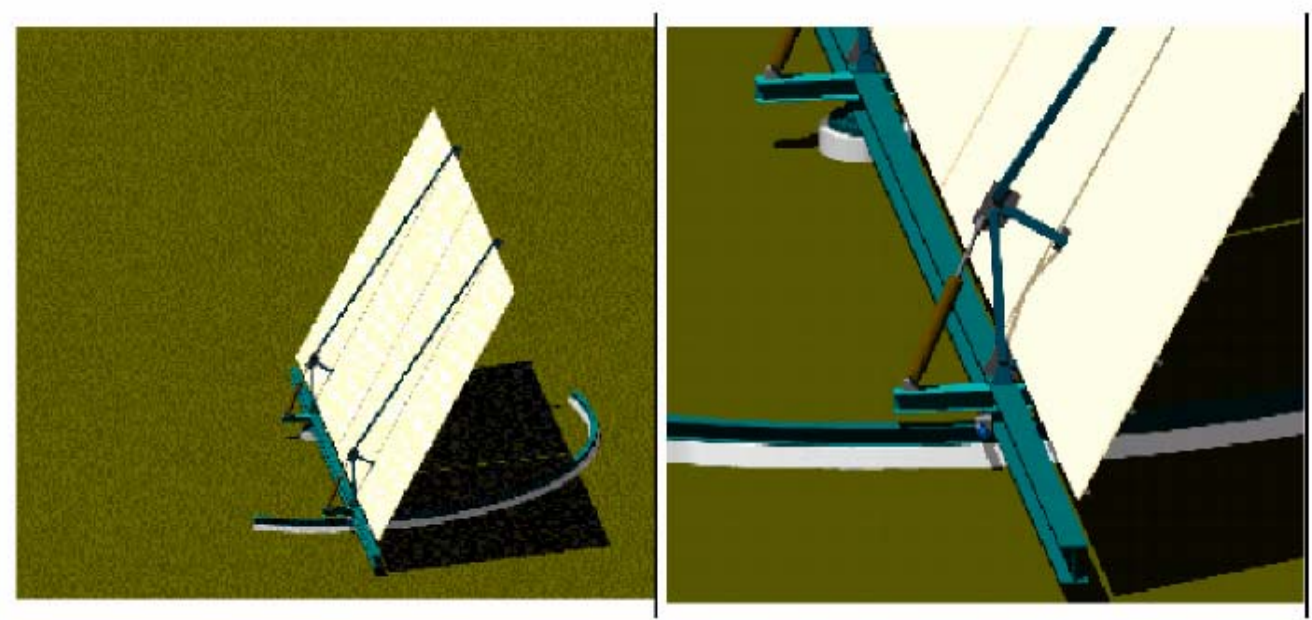

Figure 2-9. Partial-carousel heliostat studied by Solucar.

The German national laboratory DLR is evaluating the loads on the PS-10 and PS-20 heliostats both in the field and during wind tunnel tests. A thorough understanding of these loads is expected to lead to a less conservative and lower-cost heliostat. For example, this information will be used to help develop a lower-cost azimuth drive (see Appendix B). The main results of this R\&D program (called Heliant) will be made available to the United States through our cooperative SolarPACES working agreement.

Unlike Solucar, the German company Steinmüller prefers the full-carousel heliostat (Figure 2-10). They built a 150-m² SM prototype in the mid 1990s. Thin-glass mirrors are glued to the membrane and can be stowed face down. These features have solved the mirror longevity issue that plagued the early SM heliostats in the United States. The optical quality of this heliostat is significantly better than a glass/metal heliostat. In addition, its weight is about half that of the glass/metal heliostat, and analysis conducted in the mid 1990s [9] indicated that it would be significantly lower than Spanish glass/metal heliostats available at that time. It is not clear if this can still be claimed since Solucar has continued to improve their glass/metal heliostat. Steinmüller is not currently producing this heliostat.

Another large-area heliostat of current R\&D interest is being studied by DLR and KAM within the Co-Mint project. They are investigating the ganged heliostat shown in Figure 2-11.

The interim results of the ongoing investigation are listed below:

- considered sizes: $244 / 488 \mathrm{~m}^{2}$

- low specific weight achievable $\left(\sim 15 \mathrm{~kg} / \mathrm{m}^{2}\right)$

- $\quad$ slightly reduced power delivery ( -3\%)

- reduced drive cost

- many moving parts and foundations

- accuracy and lifetime of components difficult to assess

- cost estimate difficult 


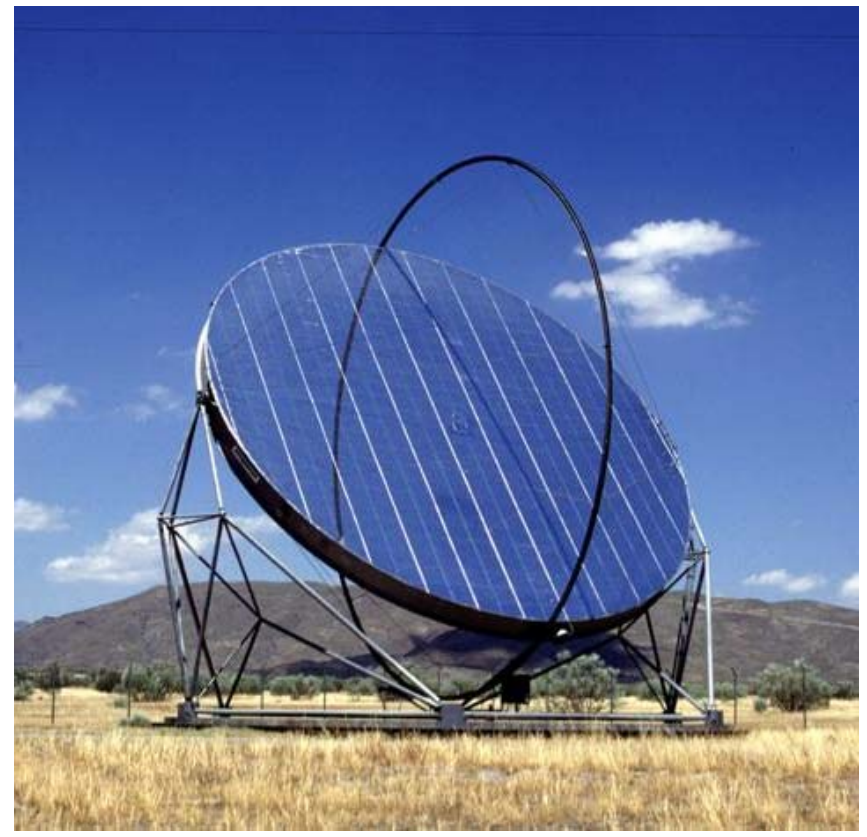

Figure 2-10. The ASM-150 heliostat built by SBP/Steinmüller.

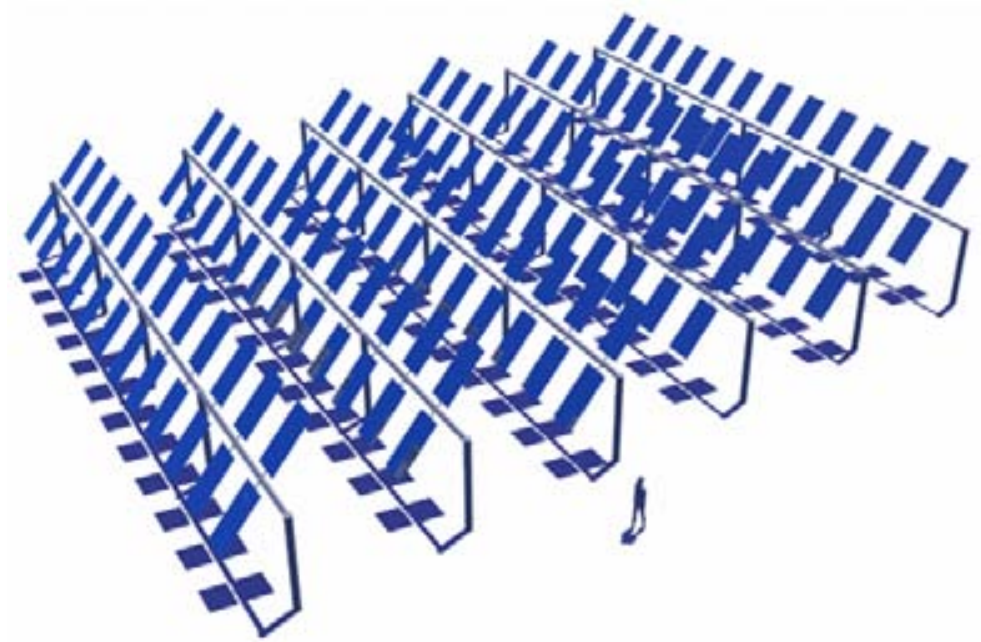

Figure 2-11. In the ganged concept, multiple facets are coupled via a single common elevation drive and single common azimuth drive. Sizes as large as $488 \mathrm{~m}^{2}$ are believed possible.

Thus it is unclear whether the ganged approach will lead to a lower-cost heliostat. When the United States looked at a smaller ganged heliostat in the late 1970s, this approach was abandoned in favor of the conventional pedestal-mounted heliostat (see Figure 2-1).

Besides the large-area heliostats described above, small heliostats are being pursued for use within small ( $\leq 1.5 \mathrm{MW}$ ) European and Australian tower projects. Small heliostats have excellent optical quality but are typically predicted to have a much higher cost per square meter. As described earlier in this chapter, their use is not appropriate for the power tower projects of interest to the United States. Readers who are interested in small heliostat R\&D in Europe and Australia are referred to information presented in Appendix C. 


\section{ESTIMATION OF CURRENT HELIOSTAT PRICES}

In this chapter we evaluate the present-day price of heliostats for solar power towers. Production prices for glass/metal and SM heliostats were updated and evaluated in 2006 dollars.

With the exception of a few small plants built for R\&D purposes, no solar power towers have been built or are planned in the United States (although there are now initial commercial plants being implemented in Spain). Heliostats comprise 50\% of the total system cost for a commercial power tower system (see Chapter 1). Because there is presently no commercial heliostat production market in the United States, and because heliostat development has been minimal over the past decade or more, it is desirable to re-baseline and evaluate the potential price of heliostats so that better estimates can be made of the potential for solar power towers.

As described in Chapter 2, the USDOE historically emphasized development of two types of heliostats: (1) so-called "conventional” or "glass/metal” heliostats composed of large steel structures that support large glass or glass/metal composite mirror panels; and (2) SM heliostats composed of a thin membrane of steel or aluminum stretched over a structural ring to form a thin, flat "drum” structure, with thin glass or polymer film mirrors attached to the membrane. Glass/metal heliostats have been through many cycles of development and improvement, and have been field-tested and proven in several fields of heliostats at the NSTTF at Sandia National Laboratories, at Solar One/Two in Daggett, California, and other places. The Solar One/Two field is the largest heliostat field in the United States Solar One included 1,818 heliostats, each $39 \mathrm{~m}^{2}$, and for Solar Two the heliostat field was increased by an additional 108 heliostats, each $95 \mathrm{~m}^{2}$. SM heliostat modules have been fielded for testing with $50-\mathrm{m}^{2}$ round mirror modules, and commercial designs have been developed for $150-\mathrm{m}^{2}$ mirror modules.

\subsection{Common Assumptions}

In order that this study produce results that could be compared directly, a set of common assumptions was developed for the pricing exercise. Also, a common database of materials and other costs was developed and used for the exercise.

Price vs. Cost. This study concentrated on installed heliostat prices, defined as the amount that a power plant integrator would have to pay a subcontractor for a heliostat that was installed, wired, aligned, and ready to operate. This is in contrast to the bare production cost of the heliostat materials and labor to the heliostat manufacturer. Therefore, the final prices include a $20 \%$ overhead/profit value that represents the profit needed by the heliostat manufacturer/installer to make their business viable.

Common Database of Materials Costs. In the course of this study, suppliers of heliostat materials and required components were contacted and estimated costs were solicited. Where appropriate, these costs were used for both the glass/metal and SM heliostat costing evaluations.

Assumed Production Rates. Another common assumption made in this study was the range of production rates for the cost estimates. This range was derived from the results of the Sargent \& 
Lundy study [1] that looked at the potential implementation of solar towers for power production in the United States. The upper bound considered in that study resulted in the implementation of about $9 \mathrm{GW}_{\mathrm{e}}$ of solar electrical production by 2020, and required a production rate of about 50,000 heliostats per year. The lower bound in the Sargent \& Lundy study was about 5,000 heliostats per year.

\subsection{Approach}

In order to determine expected installed prices for heliostats, Sandia contracted with two former contractors that had been involved in the development and testing of glass/metal and SM heliostats from the beginning. ATS was a spin-off from ARCO Solar and the principal personnel were involved in the development of the earlier ARCO glass/metal heliostats and systems. SAIC was one of the original contractors involved in SM concentrator development for heliostats and dish concentrators. Updated production cost estimates, current installation cost estimates, and other cost factors were supported by ATS and SAIC.

As a baseline, the heliostat costs estimated in the Sandia study by Clay Mavis [5] were used. The values in that report were updated to 2006 dollars using cost-of-living and materials cost adjustment factors. For comparison to these extrapolated figures, bottom-up price estimates of both glass/metal and SM heliostats were constructed using present-day material and component costs.

\subsection{Price Re-Baseline Summary}

The results of the pricing exercise are summarized in Table 3-1. The table presents the heliostat price estimates generated in this study for both the low (5,000 heliostats per year) and high (50,000 heliostats per year) production rates.

Table 3-1. Summary of Heliostat Price Estimates (2006\$ per $\mathrm{m}^{2}$ )

\begin{tabular}{|l|c|c|}
\hline & $\mathbf{5 , 0 0 0}$ per year & $\mathbf{5 0 , 0 0 0}$ per year \\
\hline \hline $\begin{array}{l}\text { Glass/Metal Heliostat: } \\
\text { Mavis Estimate (extrapolated to 2006\$) }\end{array}$ & - & $\mathbf{\$}$ \\
\hline ATS Bottom-Up Estimate & $\$ 164$ & $\$ 126.5$ \\
\hline $\begin{array}{l}\text { SM Heliostat: } \\
\text { Mavis Estimate (extrapolated to 2006\$) }\end{array}$ & - & $\mathbf{\$} 152$ \\
\hline SAIC Bottom-Up Estimate & $\$ 181$ & $\$ 143$ \\
\hline
\end{tabular}


Several conclusions can be drawn from this study:

- The best-estimate price for a glass/metal heliostat at a production volume of 50,000 heliostats per year is presently about $\$ 126 / \mathrm{m}^{2}$.

- The price for an SM heliostat is about $\$ 145 / \mathrm{m}^{2}$. The SM heliostat, although it has potential for significantly lower weight, uses exotic materials whose costs overshadow the weight savings compared to glass/metal heliostats.

- The estimates made by extrapolating earlier cost studies and those from a bottom-up pricing exercise agreed within a few percent for both glass/metal and SM heliostats. This gives confidence that the prices are consistent. General inflation has increased prices by $60 \%$ to $70 \%$ since the late 1980 s.

- Heliostat prices may be expected to drop between $25 \%$ and $30 \%$ if the production volume is increased from 5,000 to 50,000 heliostats per year. Since such significant savings can be achieved by volume of production alone, with all other things being equal a speedier implementation of power tower systems will cost less than a slower implementation in the long run.

- Drive and pedestal account for $30 \%$ of the total materials cost of the SM heliostat. A low-cost, non-pedestal drive like the ASM-150 (see Figure 2-10) might reduce the cost significantly.

- As described in Chapter 4, improved optical quality and other features of SM heliostats should be worth about $\$ 10 / \mathrm{m}^{2}$ compared to glass/metal heliostats. Including this factor, the price of a SM heliostat is nearly the same as a glass/metal heliostat.

- It is difficult to get consistent cost estimates from suppliers for such a study for several reasons:

o Large production quantities are beyond some supplier's current capacities and therefore require large extrapolations of production.

o Nascent market - suppliers are unfamiliar with this market.

o No competitive pressure - with no developed, competitive market for heliostats, suppliers tend to be conservative in their estimates.

The above factors result in a wide range of prices with much uncertainty. A production pricing study that includes representative manufacturing companies could possibly provide a higher degree of certainty. However, the most accurate pricing can only be obtained by issuing competitive Request for Proposals (RFPs) with the promise of a real, expanding, long-term market.

\subsection{History of Glass/Metal Heliostat Development}

Commercial glass/metal heliostat development in the United States started in 1975, after the first Arab oil embargo and when large solar power systems first began to be considered. Many contractors participated in multiple design and testing programs sponsored by the USDOE to the improve performance and reduce the cost of heliostats. 
A first-generation heliostat program was conducted from 1975-1978, with four participants: Boeing, Honeywell, Martin Marietta, and McDonnell Douglas. The results of this program were as follows:

- The Honeywell design (Figure 2-1) was eliminated due to high glass stress and high cost.

- The Boeing design (Figure 2-1), a plastic bubble containing a lightweight SM reflector and tracking system, was considered too costly and suffered from performance penalties due to the losses in light passing through the bubble.

- The McDonnell Douglas design was judged best overall based on cost and performance.

In 1976-1977, a heliostat field was fabricated for the NSTTF at Sandia in Albuquerque. After a competitive bid process, Martin-Marietta heliostats were chosen for the field, and 222 heliostats were fabricated and installed. The heliostats were each $37 \mathrm{~m}^{2}$ in size and used a "shaving mirror" support with a rotating base and two pylons supporting the mirrors.

In 1978-1979, a pilot plant heliostat program was instituted to design and develop heliostats for the proposed 10-MW $\mathrm{MW}_{\mathrm{e}}$ power plant that was to be built (Solar One). McDonnell Douglas and Martin Marietta were selected as participants in the program, and each contractor produced prototype heliostats that were subjected to rigorous testing. The Martin Marietta design was selected as the best to meet the pilot plant requirements.

In 1978-1982, the Solar One power plant was built, near Daggett, California. The purpose of the system was to demonstrate technical and operational feasibility of a solar power tower system. The plant size was chosen as $10 \mathrm{MW}_{\mathrm{e}}$, with a once-through superheated steam generator positioned at the top of a tower within a surround heliostat field. The system had provision for some thermal storage. The heliostat field consisted of 1,818 39- $\mathrm{m}^{2}$ heliostats produced by Martin Marietta. Each heliostat consisted of 12 glass mirror modules mounted to a torquetube/truss structure. The mirror modules themselves consisted of a formed sheet steel pan with glass mirrors bonded over the open side.

In parallel with the fabrication of the Solar One heliostat field, in 1979-1981 a second-generation heliostat development program was initiated to make further improvements and bring down the cost of heliostats. Prototypes were built and tested, and production costs for 50,000 units/year were estimated. The participants in this program included Boeing, McDonnell Douglas [6], Martin Marietta, Westinghouse, and ARCO Power Systems [10]. Design specifications were set by Sandia, including operational, optical, and survival requirements. A summary of some of the requirements is given in Table 3-2. 
Table 3-2. Requirements of the Second-Generation Heliostats

\begin{tabular}{|c|c|c|}
\hline Requirement & Value & Affected Subsystems \\
\hline $\begin{array}{l}\text { Operational Requirements: } \\
\text { Tracking modes }\end{array}$ & Track, standby, wire walk, stow & Software \\
\hline Operational winds & $\begin{array}{l}\text { Track up to } 35 \mathrm{mph} \text {; slew up to } \\
50 \mathrm{mph}\end{array}$ & Drive and Structure \\
\hline Tracking singularity & Resolve in 15 minutes & Drive and Motors \\
\hline Emergency defocus & 3 minutes & Software, Drive, and Motors \\
\hline Electrical Resiliency & $\begin{array}{l}\text { Operate through three-cycle } \\
\text { dropout }\end{array}$ & Electronics \\
\hline $\begin{array}{l}\text { Optical Requirements: } \\
\text { Beam pointing }\end{array}$ & $\begin{array}{l}1.5 \text { mrad RMS max each axis for } \\
\text { reflected beam }\end{array}$ & Controls, Software, Drive \\
\hline Beam quality & $\begin{array}{l}\text { Theoretical shape plus } 1.4 \mathrm{mrad} \\
\text { fringe }\left(32^{\circ} \mathrm{F} \text { to } 122^{\circ} \mathrm{F}\right)\end{array}$ & Mirror Module and Structure \\
\hline Wind deflection & $\begin{array}{l}3.6 \text { mrad RMS max on reflective } \\
\text { surface }\end{array}$ & Structure and Drive \\
\hline Foundation deflection & $\begin{array}{l}0.45 \text { mrad RMS max set after } \\
\text { survival loads; } 1.5 \text { mrad max } \\
\text { twist or tilt in } 27 \mathrm{mph} \text { wind }\end{array}$ & Pedestal and Foundation \\
\hline $\begin{array}{l}\text { Survival Requirements: } \\
\text { Wind survival }\end{array}$ & $\begin{array}{l}50 \mathrm{mph} \text { in any orientation } \\
90 \mathrm{mph} \text { at stow }\end{array}$ & $\begin{array}{l}\text { Structure, Mirror Module, Drive, } \\
\text { and Pedestal }\end{array}$ \\
\hline Temperature & $-20^{\circ} \mathrm{F}$ to $122^{\circ} \mathrm{F}$ & Mirror Module \\
\hline Hail & $\begin{array}{l}\text { 3/4-inch diameter at } 65 \mathrm{ft} / \mathrm{sec} \text { at } \\
\text { any orientation } \\
\text { 1-inch diameter at } 75 \mathrm{ft} / \mathrm{sec} \text { in } \\
\text { stow }\end{array}$ & Mirror Module \\
\hline Cold water shock & & All Mechanical Parts \\
\hline Lifetime & $\begin{array}{l}30 \text { years, minimal repair and } \\
\text { maintenance }\end{array}$ & All Parts \\
\hline
\end{tabular}

The second-generation heliostat design resulting from this effort from ARCO [10] included the following features:

- Reflective surface area of $52.8 \mathrm{~m}^{2}$.

- Steel pipe pedestal, driven into ground by vibratory hammer, with tapered shims for leveling the drive.

- Winsmith two-stage azimuth/elevation gear drive of gray cast iron, with off-the-shelf bearings.

- Open loop tracking with stepper motors.

- Structure consisting of torque tubes with standard roof trusses as vertical elements.

- Mirror modules with second-surface glass mirrors mounted onto a sheet metal box support structure with a three-point mount.

- Total installed cost of $\$ 127 / \mathrm{m}^{2}$ (1982\$) including land, field wiring, and controls. 
Continuing development occurred at ARCO in the period following the second-generation heliostat program. ARCO developed third- and fourth-generation heliostats as part of commercial projects they undertook for solar thermal enhanced oil recovery and tracking photovoltaic (PV) systems. In 1981-1982, ARCO installed 30 modified Northrup secondgeneration heliostats in a 1-MW $\mathrm{MW}_{\text {th }}$ field supplying power to a steam generator near Taft, California. That system operated from 1983 to 1986 in an automated, hands-off manner. In the same time period, ARCO enlarged the second-generation design and installed 108 95- $\mathrm{m}^{2}$ trackers with PV panels for Southern California Edison at their Lugo substation. This system operated from 1983 to 1990, and included improvements such as replacing stepper motors with DC motors and Hall-effect encoders. ARCO also built the Carissa Plains enhanced PV project in 1982-1983. This system had 756 trackers of $95 \mathrm{~m}^{2}$ each, and 41 trackers with $148 \mathrm{~m}^{2}$ of PV panels and flat mirrors to give two suns of illumination. This project resulted in what became the fourth-generation ARCO heliostat design.

Finally, in 1985-1986 the USDOE conducted a large-area heliostat development program. ATS, a spin-off from ARCO Solar, and SPECO participated in the program. ATS used the existing $148-\mathrm{m}^{2}$ ARCO fourth-generation glass/metal heliostat design and SPECO developed a $200-\mathrm{m}^{2}$ heliostat during the program. Prototypes of each heliostat were installed (see Figure 3-1) and tested at SNL.
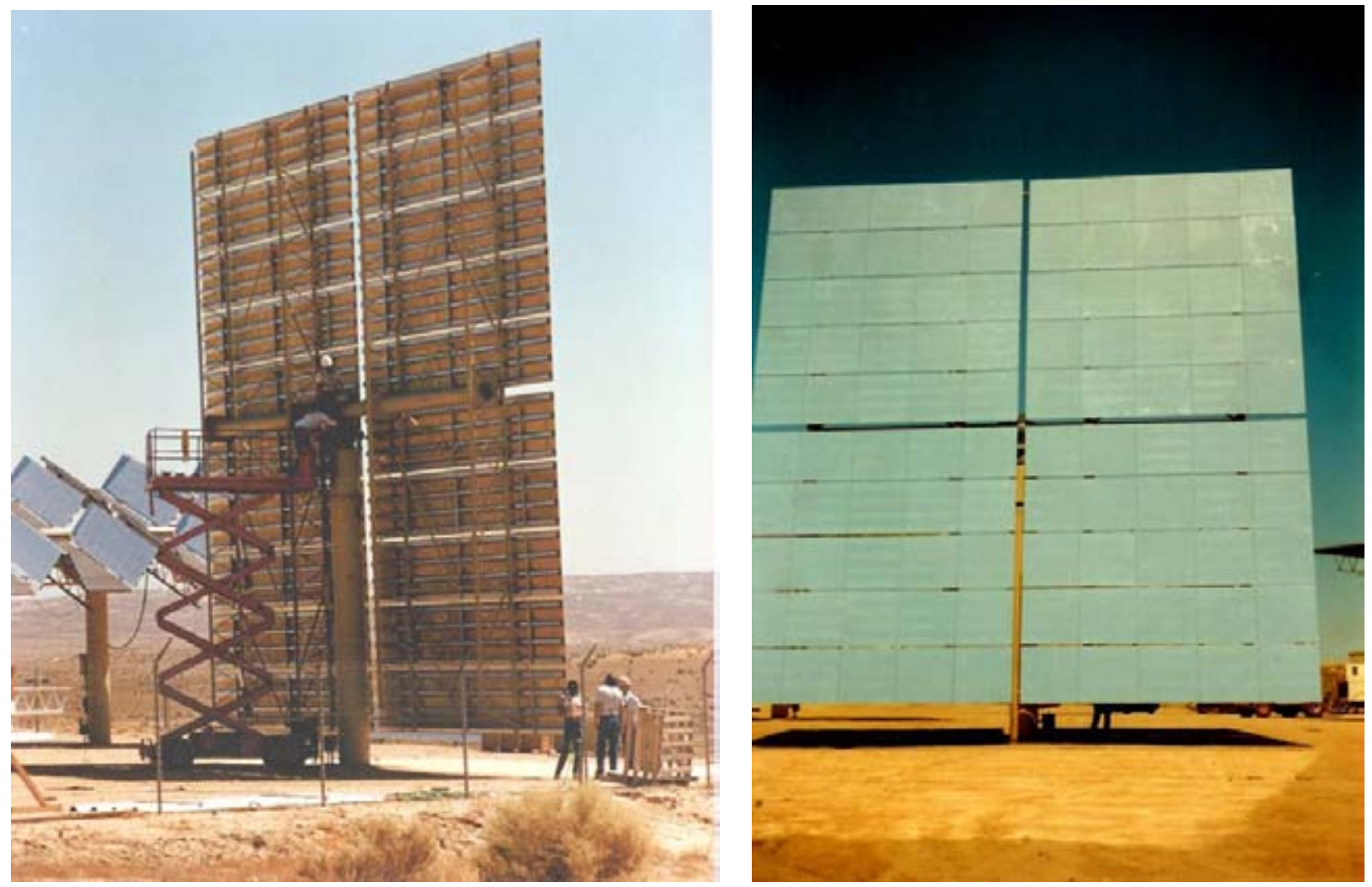

Figure 3-1. ATS fourth-generation prototype $148-m^{2}$ heliostat. 
Unfortunately, the SPECO system was destroyed during a high-wind event shortly after installation. The ATS heliostat survived, was extensively tested, and continues to operate up to the present time. It represents the state of the art in glass/metal heliostats, and was therefore chosen as the baseline system for this study. Some features of the ATS design are:

- Mirror modules constructed by bonding thick glass mirrors directly to roll-formed sheetmetal hat sections.

- Mirror curvature built in by the assembly fixture during fabrication.

- Roof-truss/torque-tube support structure.

- Maximum use of standard parts.

- On-site or near-plant assembly of mirror modules and torque-tube/truss structures.

- Final assembly and canting of heliostat on short assembly fixture before lifting onto pedestal.

Cost estimates have been generated throughout the heliostat development program. Table 3-3 summarizes some of these.

Table 3-3. Historical Heliostat Prices [11] (1981\$ per $\left.\mathrm{m}^{2}\right)$.

\begin{tabular}{|c|c|c|}
\hline Date & Source & Price $\left(1981 \$ / \mathrm{m}^{2}\right)$ \\
\hline 1977 & 222 NSTTF heliostats & $\$ 1,076$ \\
\hline 1980 & 1911 Solar One heliostats & $\$ 756$ \\
\hline 1983 & 756 Carissa Plains heliostats & $\$ 256$ \\
\hline 1980 & Estimate for 50,000 heliostats per year & $\$ 157$ \\
\hline 1988 & Estimate for 2,500 heliostats per year & $\$ 141$ \\
\hline
\end{tabular}

\subsection{Year 2006 Price Estimate for ATS Glass/Metal Heliostat}

An updated price was estimated three different ways: the cost of basic manufactured materials based on weight, extrapolation from historical studies, and a bottom-up approach. Each of these analyses is discussed in this section.

Heliostat Weight Analysis. A weight breakdown of the ATS fourth-generation heliostat is summarized in Table 3-4. The heliostat has a total weight of 13,881 pounds. When broken down by material type, $87 \%$ of the heliostat is found to be constructed of "dumb" steel $(8,709 \mathrm{lb})$ and mirrors (3,300 lb). Using generic prices for these components, a lower-bound cost estimate can be developed. Carbon steel at the mill costs about $\$ 0.30$ per pound, and fabricated steel products are about $\$ 1.00$ per pound. Mirror prices are about $\$ 0.50$ per pound. Using the $\$ 1.00 / \mathrm{lb}$ price for the "dumb" steel components of the heliostat and adding the mirrors gives a total of about $\$ 70 / \mathrm{m}^{2}$ as the minimum possible cost of a heliostat system. 
Table 3-4. ATS Heliostat Weight

\begin{tabular}{|c|c|c|}
\hline & $\begin{array}{l}\text { Component } \\
\text { Weights }\end{array}$ & $\begin{array}{c}\text { Total Weight } \\
\text { (Ib) }\end{array}$ \\
\hline Mirror Module Assemblies & & $5,120 \mathrm{lb}$ \\
\hline Glass & $3,300 \mathrm{lb}$ & \\
\hline Steel & $1,580 \mathrm{lb}$ & \\
\hline Fasteners & $80 \mathrm{lb}$ & \\
\hline Adhesive & $160 \mathrm{lb}$ & \\
\hline Trusses and Attachment Plates & $4 \times 250 \mathrm{lb}$ & $1,000 \mathrm{lb}$ \\
\hline Torque Tube Assemblies & $2 \times 1064 \mathrm{lb}, 24 \mathrm{lb}$ fasteners & $2,152 \mathrm{lb}$ \\
\hline Cross Bracing Structure and Attachments & & $544 \mathrm{lb}$ \\
\hline Gear Drives (azimuth \& elevation + fasteners) & & $1,512 \mathrm{lb}$ \\
\hline Motors \& Controls & & $120 \mathrm{lb}$ \\
\hline \multirow[t]{2}{*}{ Pedestal Assembly } & & $3,433 \mathrm{lb}$ \\
\hline & Total Heliostat Weight: & $13,881 \mathrm{lb}$ \\
\hline \multicolumn{3}{|l|}{ Breakdown by Type of Materials: } \\
\hline Structural Steel & & $8,709 \mathrm{lb}$ \\
\hline Gear Drives (steel and cast iron) & & $1,500 \mathrm{lb}$ \\
\hline Steel Fasteners and Misc. & & $104 \mathrm{lb}$ \\
\hline Motors \& Controls (Steel, Copper, etc.) & & $120 \mathrm{lb}$ \\
\hline Glass Mirrors & & $3,300 \mathrm{lb}$ \\
\hline Adhesives & & $160 \mathrm{lb}$ \\
\hline
\end{tabular}

Heliostat Price Based on Extrapolations of Prior Studies. The results of the 1986 study by Clay Mavis [5] were used as a basis for an extrapolation of the price of glass/metal heliostats. The Mavis results represent the price of heliostats at an assumed production rate of 50,000 heliostats per year and included overhead and profit in each of the price components. To estimate prices in 2006\$, consumer and producer price indices were calculated for the period from 1986 to 2006. The Consumer Price Index (CPI) is a good measure of the inflation of general components such as fasteners and electrical equipment. Producer Price Indices (PPIs) are more specific indices that consider the costs of specific materials. Table 3-5 summarizes the values of the indices used in this analysis.

Table 3-5. Price Indices Used for Extrapolation of Glass/Metal Heliostat Costs from 1986 to 2006

\begin{tabular}{|l|l|}
\hline Consumer Price Index & 1986-2006: $185 \%$ \\
\hline Producer Price Index: Steel & $1986-2006: \quad 163 \%$ \\
\hline Producer Price Index: Concrete & $1986-2006: \quad 185 \%$ \\
\hline
\end{tabular}


Using these price inflators, the components of the heliostat were inflated from the values in the Mavis study. Table 3-6 shows the results of this analysis. In the table, the first column has the 1986 costs from the Mavis study, the next column is the extrapolated cost in 2006 dollars, and the final column describes the way the indices were applied to each component. No increase was assumed for electronic components, as their prices have tended to decrease, rather than increase, since the 1980s.

Table 3-6. Extrapolation of Glass/Metal Heliostat Costs to $2006 \$$

\begin{tabular}{|c|c|c|c|}
\hline \multirow{2}{*}{ Item } & \multicolumn{2}{|c|}{ Price in \$/SQ M } & \multirow{2}{*}{ Index Used } \\
\hline & $1986^{*}$ & 2006 & \\
\hline Mirror Modules & $\$ 32.80$ & $\$ 58.27$ & $\begin{array}{l}2 / 3 \text { glass, } \mathrm{CPI}=1.85 \\
1 / 3 \text { steel, } \mathrm{PPI}=1.63\end{array}$ \\
\hline Support Structure & $\$ 10.40$ & $\$ 16.95$ & PPI steel = 1.63 \\
\hline Drives & $\$ 11.60$ & $\$ 18.91$ & PPI steel $=1.63$ \\
\hline Drive Electrical & $\$ 0.95$ & $\$ 1.78$ & $\mathrm{CPI}=1.85$ \\
\hline Foundation & $\$ 6.70$ & $\$ 11.66$ & $\begin{array}{l}1 / 2 \text { concrete, } \mathrm{PPI}=1.85 \\
1 / 2 \text { steel, } \mathrm{PPI}=1.63\end{array}$ \\
\hline Pedestal & $\$ 1.90$ & $\$ 3.10$ & PPI steel = 1.63 \\
\hline Field Wiring & $\$ 4.00$ & $\$ 7.40$ & $\mathrm{CPI}=1.85$ \\
\hline Controls & $\$ 1.90$ & $\$ 1.90$ & No increase \\
\hline $\begin{array}{l}\text { Field } \\
\text { Assembly/Checkout }\end{array}$ & $\$ 6.30$ & $\$ 11.66$ & $\mathrm{CIP}=1.85$ \\
\hline Total & $\$ 76.55$ & $\$ 131.63$ & Avg. increase $=1.72$ \\
\hline
\end{tabular}

The total heliostat cost inflated from $\$ 76.55 / \mathrm{m}^{2}$ to $\$ 131.63 / \mathrm{m}^{2}$, an increase of $72 \%$ over the 20-year period.

Bottom-Up Production Price Estimate for Glass/Metal Heliostats. To perform a bottom-up production estimate for glass/metal heliostats, ATS updated its existing cost estimate for the fourth-generation heliostat using present-day information from component and material producers. Potential suppliers for major components were contacted and cost estimates were solicited at production levels appropriate for 5,000 per year and 50,000 per year heliostat production rates. Table 3-7 summarizes the major suppliers and components for which detailed data were obtained.

Table 3-7. Major Suppliers of Heliostat Components

\begin{tabular}{|l|l|}
\hline Azimuth Drives & Peerless Winsmith \\
\hline Elevation Drives & Duff Norton \\
\hline Glass Mirrors & Gardner, Pilkington, PPG, Naugatuck Glass, and others \\
\hline Structure & Schuff Steel, Butler Corp., Zimmerman Metals \\
\hline
\end{tabular}


Peerless Winsmith was the participant in a development program for a low-cost azimuth drive for heliostat and dish concentrators sponsored by the USDOE in 1988 [12]. Subsequently, they have continued to be involved in testing and development and have improved their low-cost design, substituting a gear-based drive train for the original chain drive and making other improvements. Based on their latest design, they provided estimates for the price of their drives of $\$ 5,700$ each at 5,000 per year and $\$ 3,000$ each at 50,000 units per year. The large drop in price at the higher production rate resulted from implementation of a dedicated and automated production line at that rate.

Duff Norton has provided elevation ballscrew drives for many solar concentrators over the years. The elevation ballscrew is a commodity item that is not solar-specific. The prices obtained from Duff Norton were $\$ 1,500$ at 5,000 per year and $\$ 1,000$ at 50,000 per year.

Glass mirror prices were difficult to determine with high precision during this effort. The quantities of glass required for the 50,000 heliostat-per-year production rate $\left(7,500,000 \mathrm{~m}^{2}\right.$ per year) is small compared to total glass production capacities. However, this production rate is significant compared to the mirror production capacities of present-day mirror manufacturers. One historical price available to this effort was a quote from Pilkington Glass for the Solar Manufacturing Technology (SolMaT) program in 1995 of $\$ 22.50 / \mathrm{m}^{2}\left(\$ 2.10 / \mathrm{ft}^{2}\right)$ for low-iron mirrors. The PPI for mirrors between 1995 and 2006 showed a 10\% increase, giving a presentday estimated price of $\$ 25 / \mathrm{m}^{2}$. Pilkington also supplied information about the decrease in price with volume, as shown in Figure 3-2. ${ }^{3}$ Finally, they provided a data point comparing thin (1-mm) and thick (4-mm) glass mirrors. The Pilkington data showed the thin glass mirrors to be about $10 \%$ less expensive than the thicker mirrors. The savings in material costs are largely nullified by the extra expense in handling and breakage losses with the thin mirrors. As another data point, the A.D. Little study performed in 2001 [13] arrived at a price of $\$ 13.30 / \mathrm{m}^{2}$ $\left(\$ 1.24 / \mathrm{ft}^{2}\right)$, or about half the Pilkington estimate.

Several present-day glass mirror manufacturers were contacted for price estimates. One manufacturer who preferred to remain anonymous quoted a range of $\$ 37.70 / \mathrm{m}^{2}$ to $\$ 53.80 / \mathrm{m}^{2}$ $\left(\$ 3.50 / \mathrm{ft}^{2}\right.$ to $\left.\$ 5.00 / \mathrm{ft}^{2}\right)$. PPG quoted $\$ 28.50 / \mathrm{m}^{2}\left(\$ 2.65 / \mathrm{ft}^{2}\right)$ for low-iron glass only, and Naugatuck Glass estimated $\$ 27 / \mathrm{m}^{2}\left(\$ 2.50 / \mathrm{ft}^{2}\right)$ for thin $(1-\mathrm{mm})$ low-iron glass mirrors. Finally, Gardner Glass estimated $\$ 10.01 / \mathrm{m}^{2}\left(\$ 0.93 / \mathrm{ft}^{2}\right)$ for their 4 -mm low-iron mirrors (trade name Starphire) at the lower production rate, decreasing $20 \%$ to $\$ 8.00 / \mathrm{m}^{2}\left(\$ 0.74 / \mathrm{ft}^{2}\right)$ at the 50,000 heliostat-per-year production rate. Their estimated cost for silvering glass provided by others was $\$ 2.15 / \mathrm{m}^{2}\left(\$ 0.20 / \mathrm{ft}^{2}\right)$.

Although there was a wide range of prices quoted for glass mirrors, the Gardner Glass estimate was chosen as the best baseline for the bottom-up heliostat price estimate since it was obtained from direct interactions with the company president and the general manager of one of their

3 FLABEG is now manufacturing these mirrors in Germany. A rough price estimate for heliostat mirrors was obtained from Josef Langenkamp (Flagsol) on January 29, 2007. The estimate was $21 \mathrm{Euro} / \mathrm{m}^{2}$ given 750,000 $\mathrm{m}^{2}$ and $18 / \mathrm{m}^{2}$ Euro given $7,500,000 \mathrm{~m}^{2}$. The price includes the protective back-side paint layers. Given an extended production run (several years), Josef suggests the price might be further reduced up to $10 \%$. Given an exchange rate of $1.3 \$$ Euro, the price for $750,000 / \mathrm{yr}$ for several years is thus $1.3^{*} 21^{*} 0.9=\$ 24.6 / \mathrm{m}^{2}$ in 2006 , virtually the same as we obtained by escalating Figure 3-2 by the PPI. 
production plants. Since additional protective paint layers are required on the back side of the mirror for outdoor exposure, the prices were increased by $\$ 0.20 / \mathrm{ft}^{2}$, resulting in estimated costs of $\$ 12.16 / \mathrm{m}^{2}\left(\$ 1.13 / \mathrm{ft}^{2}\right)$ and $\$ 10.22 / \mathrm{m}^{2}\left(\$ 0.94 / \mathrm{ft}^{2}\right)$ for the low and high production rates, respectively. The prices for thin glass mirrors for the SM heliostat were estimated as $10 \%$ less than the thicker mirrors based on the historical Pilkington data, giving values of $\$ 10.95 / \mathrm{m}^{2}$ in low production and $\$ 9.14 / \mathrm{m}^{2}$ in high production.

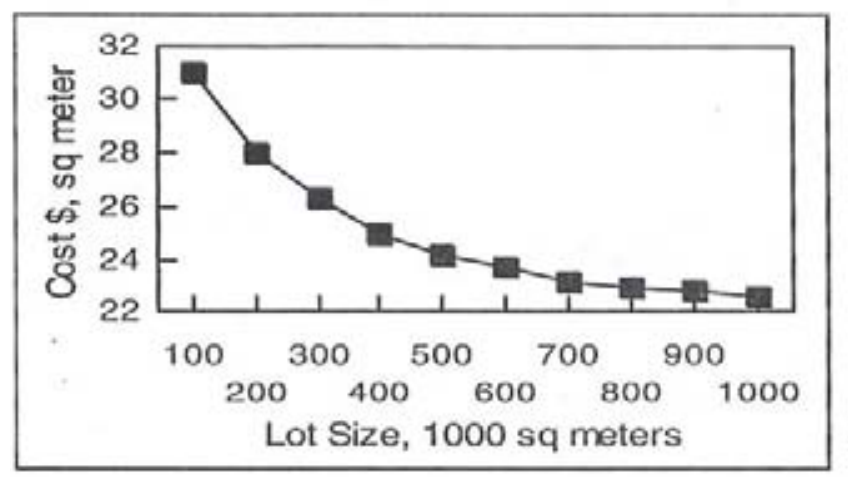

Cost reduces with increasing volume $\$ 29 / \mathrm{m}^{2}$ near term markets incl shipping

Base

$1.2 \mathrm{~mm} \quad \$ 28.50 / \mathrm{sq} \mathrm{m}$

$4 \mathrm{~mm} \quad \$ 31.00 / \mathrm{sq} \mathrm{m}$

Figure 3-2. Pilkington glass estimated mirror cost/volume curve from SolMaT project.

Prices for structural steel components were solicited from several steel fabrication companies. Butler Corporation is a producer of metal buildings and was solicited for steel truss prices. They estimated complete truss prices at $\$ 1.36 / \mathrm{lb}$ at the low production rate and $\$ 1.31 / \mathrm{lb}$ at the high production rate. Similarly, Zimmerman metals provided estimates for the pedestal and torque tubes, which are essentially just large pipes. Their estimates were $\$ 1.16 / \mathrm{lb}$ and $\$ 1.11 / \mathrm{lb}$ for the pedestal and $\$ 1.22 / \mathrm{lb}$ and $\$ 1.08 / \mathrm{lb}$ for the torque tubes at the low and high rates, respectively. In talks with Butler and Zimmerman, it was not clear if there would be manufacturing process improvements between the low and high production rates, or if the reductions represented simply economies of scale for the higher production rate.

Another estimate for pipe-like components was provided by Ron Lumia ${ }^{4}$ based on steel mill and processing costs, as shown in Table 3-8. The value arrived at was $\$ 0.72 / \mathrm{lb}$ for a retail price of the pedestal. The estimate had a range of uncertainty from about $\$ 0.61 / \mathrm{lb}$ to $\$ 0.83 / \mathrm{lb}$.

Finally, contact was made with Schuff Steel for fabricated steel components. Schuff Steel is the largest fabricator of steel products in the United States, producing products such as the frameworks for large buildings. They have recently become involved in manufacture of solar products, and are teamed with Stirling Energy Systems of Phoenix, Arizona, to build the steel structures of their prototype dish concentrators. If initial tests with a 1-MW field of collectors are successful, they have the potential to build a 20,000-unit solar dish project planned for California. Schuff provided estimates of $\$ 1.00 / \mathrm{lb}$ for fabricated steel products at the high production rate.

4 Manufacturing expert and co-author of this report. 
Table 3-9 summarizes all of the cost estimates for structural steel components. Because of the volume of steel with which Schuff Steel deals, their estimate was given high credence and their values were used for the bottom-up estimate. However, because the pedestal and torque tube are mostly “dumb” steel, the Lumia estimate was used for the prices of those components.

Table 3-8. Estimate of Pedestal Cost Using Steel and Processing Costs

\begin{tabular}{|c|c|c|}
\hline \multicolumn{3}{|l|}{ Cost of Steel } \\
\hline Lowest cost per metric ton & $\$ 500.00$ & \\
\hline Highest cost per metric ton & $\$ 700.00$ & \\
\hline Lowest cost per pound & $\$ 0.2273$ & \\
\hline Highest cost per pound & $\$ 0.3182$ & \\
\hline \multicolumn{3}{|c|}{ Pedestal Estimate (3433 weight of pedestal (in pounds)) } \\
\hline Cost of Steel (low) & $\$ 780.23$ & \\
\hline Cost of Steel (high) & $\$ 1,092.32$ & \\
\hline Machine flat surface (machining at $\$ 1 / \mathrm{min}$ ) & $\$ 10.00$ & \\
\hline $\begin{array}{l}\text { Drill } 12 \text { holes mount drive (assumes quantities so large } \\
\text { that there is no cost for the machines and tooling) }\end{array}$ & $\$ 12.00$ & \\
\hline Welding (20 mins) & $\$ 20.00$ & \\
\hline Miscellaneous machining & $\$ 10.00$ & \\
\hline Total Machining & $\$ 52.00$ & \\
\hline Wholesale cost (low) & $\$ 832.23$ & \\
\hline Wholesale cost (high) & $\$ 1,144.32$ & \\
\hline \multicolumn{3}{|l|}{ Wholesale to Retail (multiply by $2-3$, we will use 2.5 ) } \\
\hline Retail cost (low) & $\$ 2,080.57$ & $\$ 0.61 / l b$ \\
\hline \multirow[t]{2}{*}{ Retail cost (high) } & $\$ 2,860.80$ & $\$ 0.83 / l b$ \\
\hline & & \$ 0.72 Average \\
\hline
\end{tabular}

Table 3-9. Summary of Structural Steel Price Estimates and Quotes

\begin{tabular}{|l|c|c|}
\hline \multicolumn{1}{|c|}{ Source/Component } & $\begin{array}{c}\text { Low Production } \\
\mathbf{( 5 , 0 0 0} \text { heliostats/year) }\end{array}$ & $\begin{array}{c}\text { High Production } \\
\mathbf{( 5 0 , 0 0 0} \text { heliostats/year) }\end{array}$ \\
\hline \hline Butler Corp./trusses & $\$ 1.36 / \mathrm{lb}$ & $\$ 1.31 / \mathrm{bb}$ \\
\hline Zimmerman Metals/Pedestal & $\$ 1.16 / \mathrm{lb}$ & $\$ 1.11 / \mathrm{b}$ \\
\hline Zimmerman Metals/torque Tubes & $\$ 1.22 / \mathrm{lb}$ & $\$ 1.08 / \mathrm{bb}$ \\
\hline Lumia/Pedestal and Torque Tubes & & $\$ 0.72 / \mathrm{bb}$ \\
\hline Schuff Steel/Fabricated Steel Parts & & $\$ 1.00 / \mathrm{b}$ \\
\hline
\end{tabular}

The basis for all the cost components in the bottom-up heliostat estimate (at 50,000 per year production rate) discussed in the preceding paragraphs, as well as other components, is summarized in Table 3-10. 
Table 3-10. Summary of Basis for Bottom-Up Pricing of Glass/Metal Heliostats at 50,000 Heliostats Per Year Production Rate

\begin{tabular}{|l|c|l|}
\hline \multicolumn{1}{|c|}{ Item } & Cost & \multicolumn{1}{c|}{ Source } \\
\hline \hline Azimuth Drive (geardrive) & $\$ 3,000$ & Peerless Winsmith \\
\hline Elevation Drive (ballscrew) & $\$ 1,000$ & Duff Norton \\
\hline Glass Mirrors (4mm) & $\$ 10.22 / \mathrm{m}^{2}$ & Gardner Glass \\
\hline Fabricated Steel Components & $\$ 1 / \mathrm{b}$ & Schuff Steel \\
\hline Pedestal and Torque Tubes & $\$ 0.72 / \mathrm{lb}$ & Lumia analysis \\
\hline Motors and Cabling & $\$ 1.78 / \mathrm{m}^{2}$ & Mavis study [5], extrapolated to 2006\$ \\
\hline Controls & $\$ 1.90 / \mathrm{m}^{2}$ & Mavis study, no extrapolation \\
\hline Foundation & $\$ 350$ & $\begin{array}{l}2.5 \text { yards of concrete @ } \$ 100 / y a r d, ~ \\
\$ 100 \text { rebar cage }\end{array}$ \\
\hline Field Wiring & $\$ 7.40 / \mathrm{m}^{2}$ & Mavis study, extrapolated to 2006 $\$$ \\
\hline Field Assembly and Checkout & $\$ 6.34 / \mathrm{m}^{2}$ & From [14], extrapolated to 2006\$ \\
\hline Overhead/Profit & $\begin{array}{r}20 \% \text { of direct } \\
\text { fabrication cost }\end{array}$ & From Sargent \& Lundy Study [1] \\
\hline
\end{tabular}

Using the information gleaned from the various sources, the costs of the components of the ATS heliostat system were estimated. The following four tables (Tables 3-11 to 3-14) show the estimated costs of the mirror modules, structure, motion control components, and other balanceof-system components. The resulting heliostat price is $\$ 18,720$, or $\$ 126.5 / \mathrm{m}^{2}$.

To estimate the production price of glass/metal heliostats at the lower production rate of 5,000 heliostats per year, the estimates for that production rate were used. Components for which no low-quantity quotes were available had a $10 \%$ premium added to their costs at high production to reflect the lower production rate. Table 3-15 shows the resulting cost breakdown, with a resulting price of $\$ 24,264$ per heliostat or $\$ 163.94 / \mathrm{m}^{2}$. 
Table 3-11. Mirror Module Costs for Glass/Metal Heliostats at 50,000 Heliostats Per Year

\begin{tabular}{|l|c|c|c|c|c|c|}
\hline \multicolumn{1}{|c|}{ Item } & $\begin{array}{c}\text { Quantityl } \\
\text { Unit }\end{array}$ & Cost & Weight & Cost/lb & Cost/m $\mathbf{2}^{2}$ & Cost/Unit \\
\hline \hline Glass Mirror Facets & 100 & $\$ 1,513$ & 3,300 & $\$ 0.46$ & $\$ 10.22$ & \\
\hline Hat Sections & 80 & $\$ 1,430$ & 1,430 & $\$ 1.00$ & $\$ 9.66$ & \\
\hline Cross Members & 60 & $\$ 150$ & 150 & $\$ 1.00$ & $\$ 1.01$ & \\
\hline Adhesive & $160 \mathrm{lb}$ & $\$ 160$ & 160 & $\$ 1.00$ & $\$ 1.08$ & \\
\hline Fasteners & 80 & $\$ 80$ & 80 & $\$ 1.00$ & $\$ 0.54$ & \\
\hline Assembly & $4 \mathrm{MHR}$ & $\$ 80$ & & & $\$ 0.54$ & \\
\hline & $\mathbf{2 0}$ & $\mathbf{\$ 3 , 4 1 3}$ & $\mathbf{5 , 1 2 0}$ & $\mathbf{\$ 0 . 6 7}$ & $\mathbf{\$ 2 3 . 0 6}$ & $\mathbf{\$ 3 , 4 1 2 . 5 6}$ \\
\hline
\end{tabular}

Table 3-12. Structure Component Costs for Glass/Metal Heliostats at 50,000/yr

\begin{tabular}{|l|r|r|r|r|r|c|}
\hline \multicolumn{1}{|c|}{ Item } & Qty/Unit & \multicolumn{1}{c|}{ Cost } & \multicolumn{1}{c|}{ Weight } & Cost/lb & Cost/m & Cost/Unit \\
\hline Torque Tube Assembly & 2 & $\$ 1,595$ & 2,151 & $\$ 0.74$ & $\$ 10.78$ & $\$ 1,595$ \\
\hline Torque Tube Pipe & 2 & $\$ 1,429$ & 1,984 & $\$ 0.72$ & $\$ 9.65$ & \\
\hline Flange & 2 & $\$ 142$ & 142 & $\$ 1.00$ & $\$ 0.96$ & \\
\hline Fasteners & 24 & $\$ 24$ & 24 & $\$ 1.00$ & $\$ 0.16$ & \\
\hline Truss Assembly & 4 & $\$ 1,000$ & 1,000 & $\$ 1.00$ & $\$ 6.75$ & $\$ 1,000$ \\
\hline Truss Subassembly & 4 & $\$ 926$ & 926 & $\$ 1.00$ & & \\
\hline Mounting Adaptor Plate & 4 & $\$ 74$ & 74 & $\$ 1.00$ & & \\
\hline Cross Bracing & 1 set & $\$ 544$ & 544 & $\$ 1.00$ & $\$ 3.68$ & $\$ 544$ \\
\hline Beams & 12 & $\$ 330$ & 330 & $\$ 1.00$ & & \\
\hline Long Diagonals & 16 & $\$ 115$ & 115 & $\$ 1.00$ & & \\
\hline Short Diagonals & 8 & $\$ 36$ & 36 & $\$ 1.00$ & & \\
\hline Stabilizers & 16 & $\$ 14$ & 14 & $\$ 1.00$ & & \\
\hline Wing Ties & 2 & $\$ 11$ & 11 & $\$ 1.00$ & & \\
\hline Brackets & 4 & $\$ 16$ & 16 & $\$ 1.00$ & & \\
\hline Fasteners & 44 & $\$ 22$ & 22 & $\$ 1.00$ & & \\
\hline Pedestal & 1 & $\$ 2,510$ & 3,433 & $\$ 0.73$ & $\$ 16.96$ & $\$ 2,510$ \\
\hline Pedestal Pipe & 1 & $\$ 2,373$ & 3,296 & $\$ 0.72$ & $\$ 16.03$ & \\
\hline Flange & 1 & $\$ 137$ & 137 & $\$ 1.00$ & $\$ 0.93$ & \\
\hline Total Structure Costs & $\mathbf{1}$ & $\$ 5,649$ & $\mathbf{7 , 1 2 7}$ & $\$ 0.79$ & $\$ 38.17$ & $\$ 5,649$ \\
\hline
\end{tabular}


Table 3-13. Motion Control Costs for Glass/Metal Heliostats at 50,000 Heliostats Per Year

\begin{tabular}{|l|c|r|r|r|r|r|}
\hline \multicolumn{1}{|c|}{ Item } & $\begin{array}{c}\text { Quantityl } \\
\text { Unit }\end{array}$ & \multicolumn{1}{c|}{ Cost } & Weight & Cost/lb & Cost/m & Cost/Unit \\
\hline \hline Geardrive & & $\$ 4,012.00$ & $1,512.0$ & $\$ 2.65$ & $\$ 27.11$ & $\$ 4,012.00$ \\
\hline Azimuth Subassembly & 1 & $\$ 3,000$ & $1,000.0$ & $\$ 3.00$ & & \\
\hline Elevation Subassembly & 1 & $\$ 1,000$ & 500.0 & $\$ 2.00$ & & \\
\hline Fasteners & 12 & $\$ 12.00$ & 12.0 & $\$ 1.00$ & & \\
\hline Controls \& Cabling & 1 set & $\$ 281.20$ & & & $\$ 1.90$ & $\$ 281.20$ \\
\hline Drive Motors \& Limit Switches & 1 set & $\$ 263.44$ & & & $\$ 1.78$ & $\$ 263.44$ \\
\hline Total Motion Control Costs & & $\mathbf{\$ 4 , 5 5 6 . 6 4}$ & $\mathbf{1 , 5 1 2 . 0}$ & $\mathbf{\$ 3 . 0 1}$ & $\$ \mathbf{3 0 . 7 9}$ & $\mathbf{\$ 4 , 5 5 6 . 6 4}$ \\
\hline
\end{tabular}

Table 3-14. Total Cost of Glass/Metal Heliostats at 50,000 Heliostats Per Year

\begin{tabular}{|c|c|c|c|c|c|}
\hline Item & Qty/Unit & Cost & Weight & Cost/lb & Cost $/ \mathrm{m}^{2}$ \\
\hline Geardrive & & $\$ 4,012$ & 1,512 & $\$ 2.65$ & $\$ 27.11$ \\
\hline Mirror Module & 20 & $\$ 3,413$ & 5,120 & $\$ 0.67$ & $\$ 23.06$ \\
\hline Torque Tube Assembly & 2 & $\$ 1,595$ & 2,151 & $\$ 0.74$ & $\$ 10.78$ \\
\hline Truss Assembly & 4 & $\$ 1,000$ & 1,000 & $\$ 1.00$ & $\$ 6.75$ \\
\hline Cross Bracing & 1 set & $\$ 544$ & 544 & $\$ 1.00$ & $\$ 3.68$ \\
\hline Controls and Cabling & 1 set & $\$ 281$ & 70 & & $\$ 1.90$ \\
\hline Drive Motors and Limit Switches & 1 set & $\$ 263$ & 50 & & $\$ 1.78$ \\
\hline Pedestal & 1 & $\$ 2,510$ & 3,433 & $\$ 0.73$ & $\$ 16.96$ \\
\hline Fabrication Direct Cost & 1 & $\$ 13,618$ & 13,879 & $\$ 0.98$ & $\$ 92.02$ \\
\hline Overhead/Profit (20\%) & & $\$ 2,724$ & & & $\$ 18.40$ \\
\hline Total Fabrication Cost & 1 & $\$ 16,342$ & & & $\$ 110.42$ \\
\hline Foundation & 1 & $\$ 345$ & & & $\$ 2.33$ \\
\hline Field Wiring & 1 set & $\$ 1,095$ & & & $\$ 7.40$ \\
\hline Field Assembly and Checkout & Per unit & $\$ 938$ & & & $\$ 6.34$ \\
\hline Total Installed Cost & 1 & $\$ 18,720$ & 13,879 & $\$ 1.35$ & $\$ 126.49$ \\
\hline
\end{tabular}


Table 3-15. Cost Breakdown for Glass/Metal Heliostats at 5,000 Heliostats Per Year

\begin{tabular}{|c|c|c|c|c|c|}
\hline Item & Qty/Unit & Cost & Weight & Cost/lb & Cost $/ \mathrm{m}^{2}$ \\
\hline Geardrive & & $\$ 7,200$ & $1,500.0$ & $\$ 4.80$ & $\$ 48.65$ \\
\hline Mirror Module & 20 & $\$ 3,922$ & $5,120.0$ & $\$ 0.77$ & $\$ 26.50$ \\
\hline Torque Tube Assembly & 2 & $\$ 1,755$ & $2,150.8$ & $\$ 0.82$ & $\$ 11.85$ \\
\hline Truss Assembly & 4 & $\$ 1,100$ & 999.6 & $\$ 1.10$ & $\$ 7.43$ \\
\hline Cross Bracing & 1 set & $\$ 598$ & 544.0 & $\$ 1.10$ & $\$ 4.04$ \\
\hline Controls and Cabling & 1 set & $\$ 309$ & 70.0 & $\$ 4.42$ & $\$ 2.09$ \\
\hline Drive Motors and Limit Switches & 1 set & $\$ 395$ & 50.0 & & $\$ 2.67$ \\
\hline Pedestal & 1 & $\$ 2,761$ & $3,433.0$ & $\$ 0.80$ & $\$ 18.66$ \\
\hline Fabrication Direct Cost & 1 & $\$ 18,040$ & $13,867.4$ & $\$ 1.30$ & $\$ 121.89$ \\
\hline Overhead (20\%) & & $\$ 3,608$ & & & $\$ 24.38$ \\
\hline Total Fabrication Cost & 1 & $\$ 21,648$ & & & $\$ 146.27$ \\
\hline Foundation & 1 & $\$ 380$ & & & $\$ 2.56$ \\
\hline Field Wiring & 1 set & $\$ 1,205$ & & & $\$ 8.14$ \\
\hline Field Assembly and Checkout & Per unit & $\$ 1,032$ & & & $\$ 6.97$ \\
\hline Total Installed Cost & & $\$ 24,264$ & & & $\$ 163.94$ \\
\hline
\end{tabular}

\subsection{History of SM Heliostat Development}

The concept of an SM heliostat was first put forward by Dr. Barry Butler and others at the Solar Energy Research Institute (SERI) around 1981. The concept was patented and some preliminary evaluations were performed. A prototype single-membrane reflector was fabricated using a trampoline with increased spring tension and glass mirror tiles glued to the front surface (see Figure 3-3).

Among the chief advantages of the SM concept were that it had very few parts, used highly stressed and therefore minimal weight components, and that a simple vacuum system could provide active focusing of the image. Cost savings relative to glass/metal heliostats were projected based on materials cost reductions, and high performance was projected based on the symmetry of the shape and the adjustable focal length. Therefore, beginning in 1984, the USDOE invested in development of SM heliostats.

In the first round of development, two contractors were selected to create designs and build prototypes, SKI [15] and SAIC [16]. Although both contractors designed dual-membrane mirror modules, they differed in their approaches; SKI used aluminum membranes with a clamping system for tensioning, and SAIC used a stainless steel membrane and a mild steel ring, and an active tensioning system using bladders. Both contractors used blower-based focusing systems to pull a slight vacuum between the membranes to focus the heliostat. Figure 3-4 shows the firstgeneration SAIC heliostat prototype that was installed for testing at Sandia. The prototype was $50 \mathrm{~m}^{2}$ in size. 


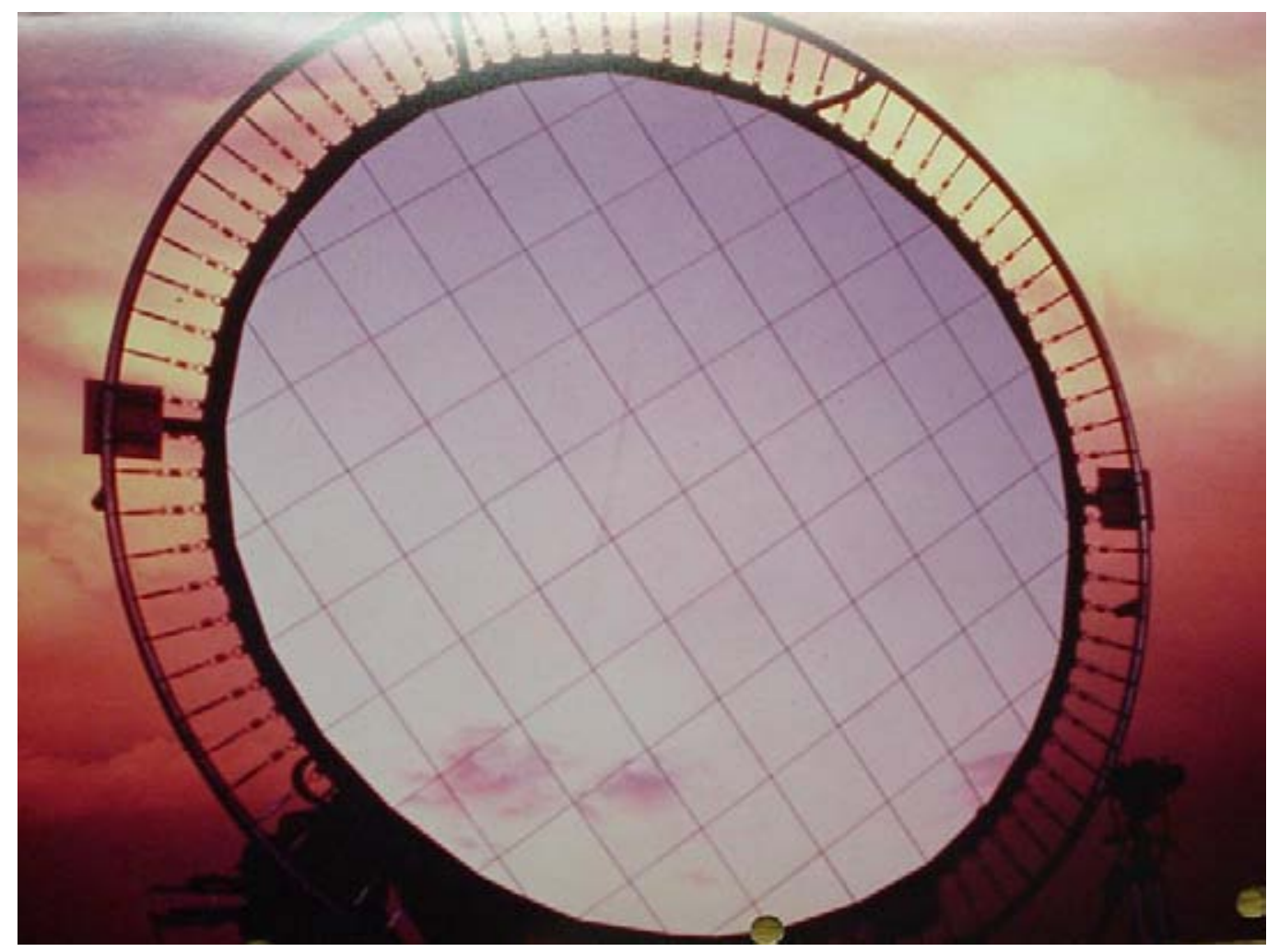

Figure 3-3. First SM heliostat prototype at SERI.
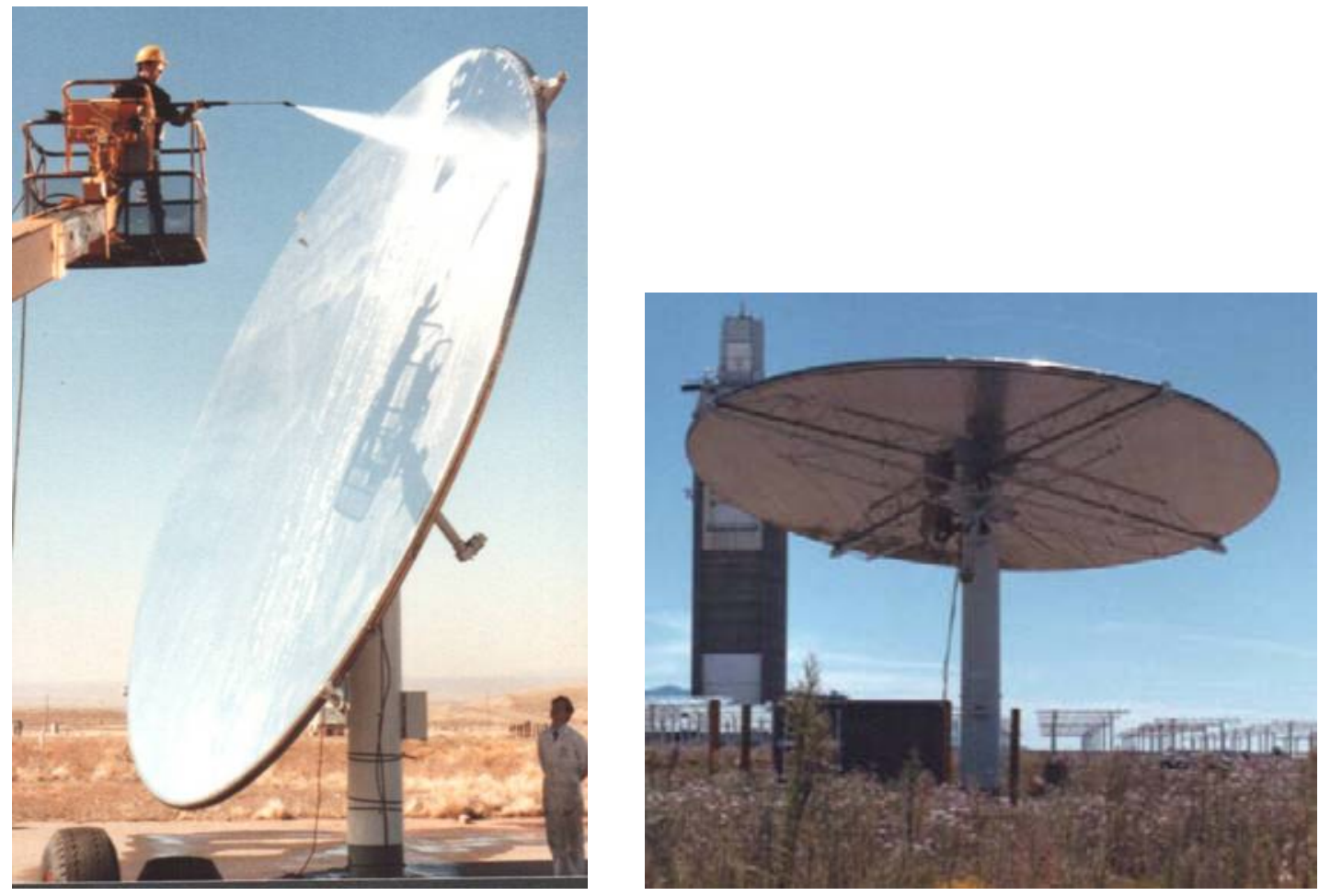

Figure 3-4. SAIC first-generation SM heliostat prototype. 
Much was learned from the first-generation heliostats, and a second round of development contracts were initiated with the same two contractors, resulting in a new pair of $50-\mathrm{m}^{2}$ secondgeneration prototypes and the development of designs for $150-\mathrm{m}^{2}$ commercial SM heliostats. Elegant solutions to the focus control problem were developed by both contractors; the SKI heliostat used a variable-speed fan controlled by the pressure differential across the front membrane, while the SAIC unit employed a linear actuator that pulled directly on the back membrane to induce a vacuum between the membranes. The SAIC heliostat design also incorporated welding of the stainless steel membrane to the steel ring, eliminating the active tensioning system. Figure 3-5 shows the SAIC second-generation prototype, which along with the SKI prototype is still in place at Sandia.

In 1990, a contract was given to SAIC to build a full heliostat using SM mirrors. A design study was conducted that led to selection of a $100-\mathrm{m}^{2}$ dual-module design, with two $50-\mathrm{m}^{2}$ mirror modules. This design, shown in Figure 3-6, allowed for face-down stow of the mirror modules to protect the mirror surfaces from hail and reduce soiling. The support structure for the mirror modules was also reduced to a minimal three-point support.

Finally, in 1995-1998 the SolMaT initiative was sponsored by the USDOE to further develop manufacturing processes and techniques for heliostats and dish concentrators. SAIC was awarded a contract and developed improved manufacturing approaches for SM mirror modules for both dish concentrators and heliostats.
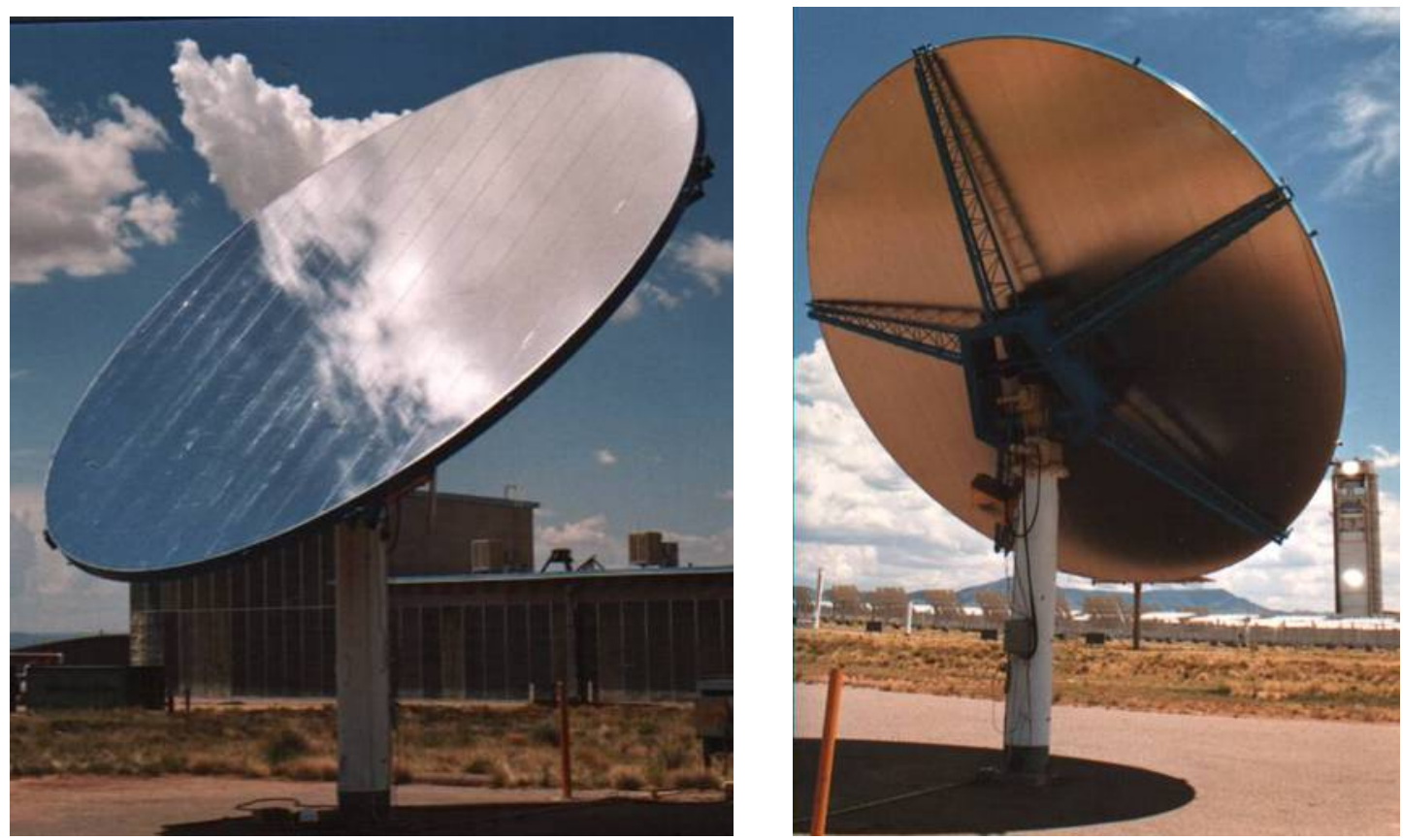

Figure 3-5. Second-generation SM heliostat prototype. 


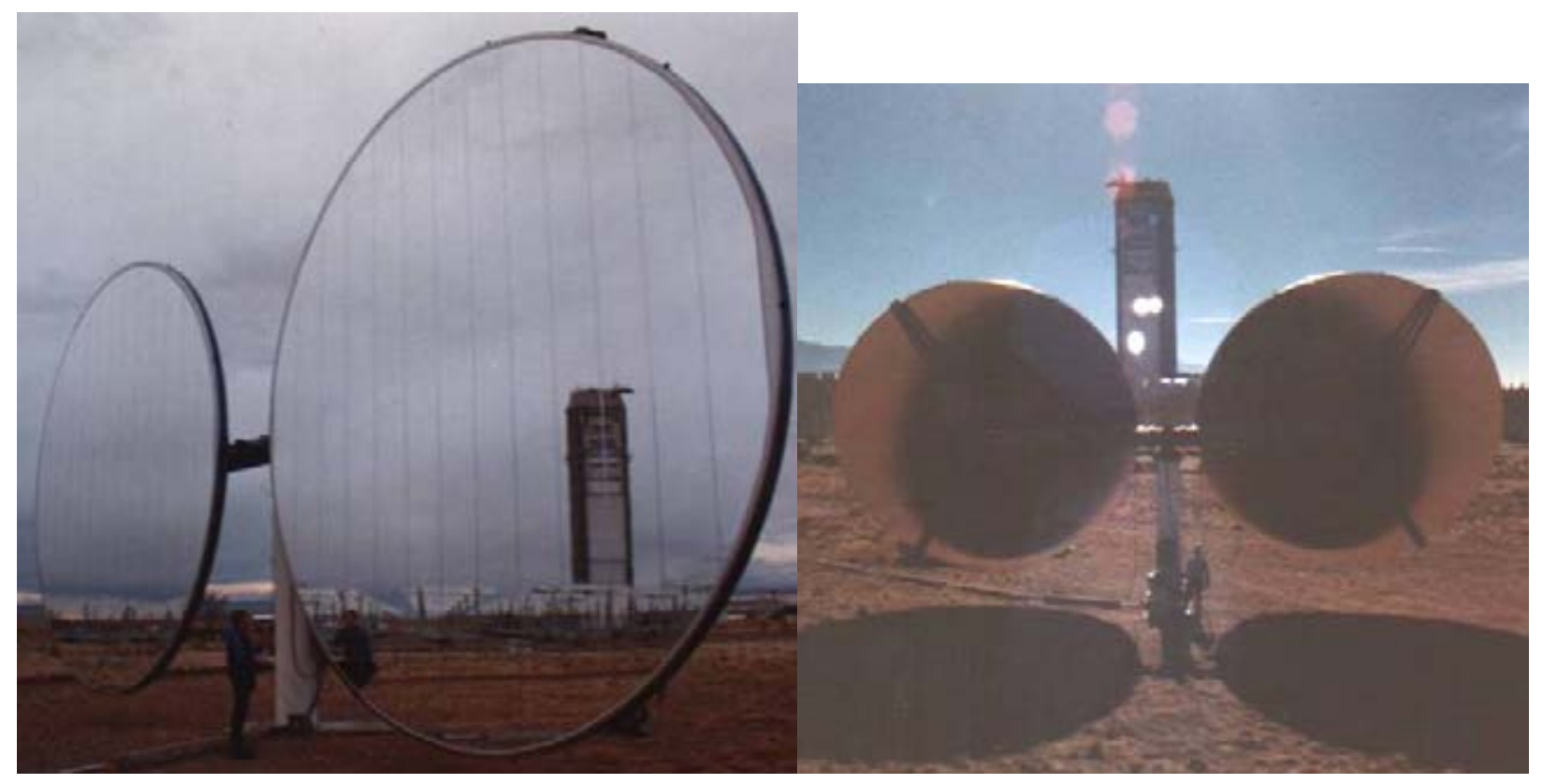

Figure 3-6. Dual-module SM heliostat.

Cost analyses performed by SAIC during the SolMaT program indicated that combining production of dish and heliostat mirror modules into a central manufacturing plant would yield economies of scale, so an interim-production heliostat was designed based on smaller, shippable mirror modules about $3 \mathrm{~m}$ in diameter. This design, optimized for initial market introduction at production rates of about 2,000 systems per year, had 22 3-m-diameter mirror modules mounted on a torque-tube/truss structure similar to that for glass/metal heliostats, as shown in Figure 3-7, for a total area of about $145 \mathrm{~m}^{2}$.

\subsection{Year 2006 Price Estimate for Pedestal-Mounted SM Heliostat}

An updated price was estimated two different ways: extrapolation from historical studies and a bottom-up approach. Each of these analyses is discussed in this section.

Heliostat Price Based on Extrapolations of Prior Studies. The first SM heliostat development program included cost estimates for various production rates. In 1986, Clay Mavis at Sandia [5] combined those estimates into a consistent production cost analysis and compared the SM heliostat to conventional glass/metal designs. The results, shown in Table 3-16, appeared to confirm the potential of the SM design to reduce costs not only for the materials of the mirror modules and support structure, but also for field assembly and checkout. The installed price of the SM heliostat was predicted to be about $15 \%$ less than that of a comparable glass/metal heliostat. 

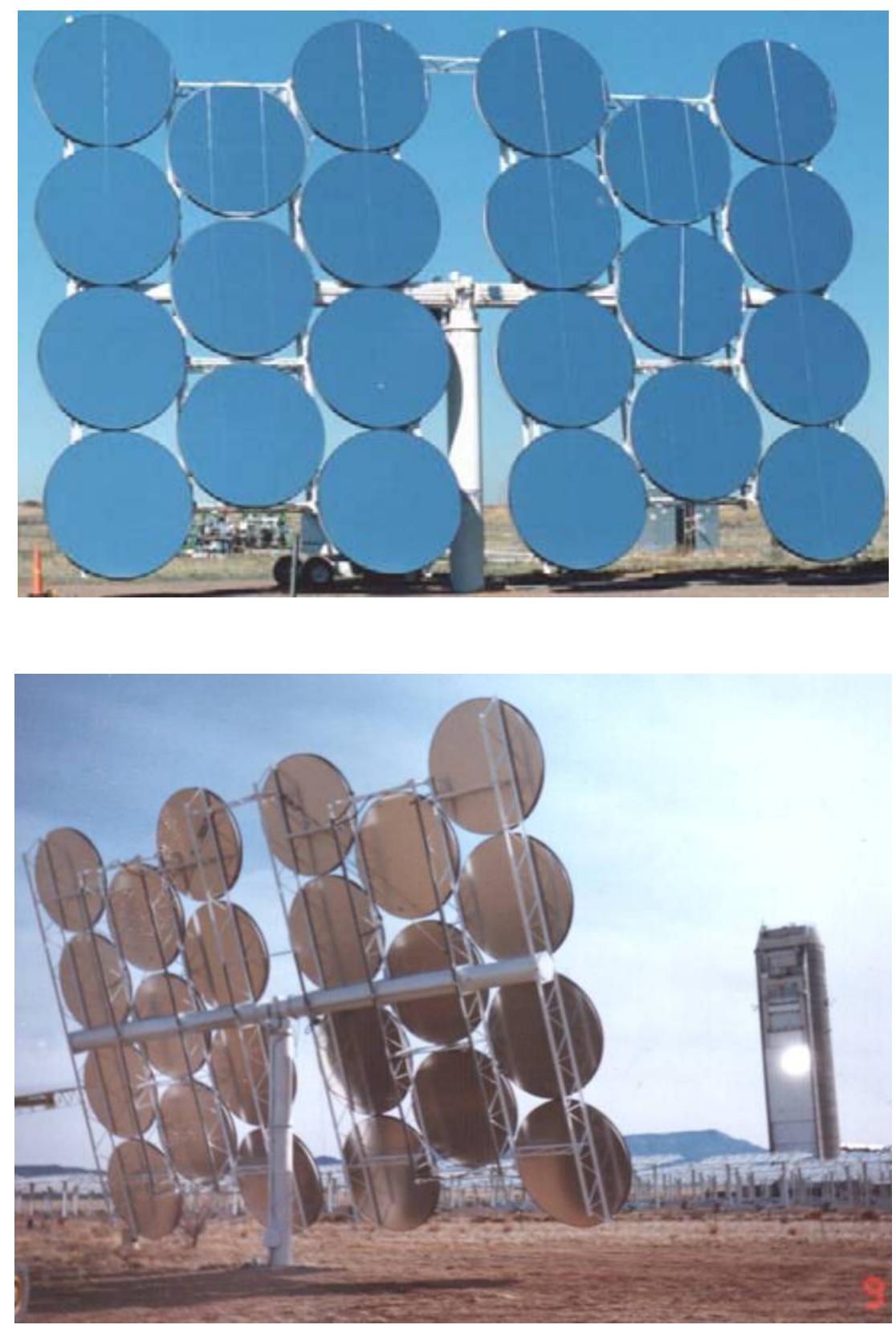

Figure 3-7. $145-m^{2}$ SAIC SolMaT heliostat design with 3-m-diameter SM mirror modules.

The Mavis study predated the second-generation SM heliostat development program. In that program, detailed cost estimates were made for production of heliostat mirror modules and for the manufacturing plant that would be required at a production rate of 50,000 systems per year. Table 3-17 shows the results of that program from 1989 [17]. Note that the second-generation heliostat development program only studied the production costs of the mirror modules and mirror module support structures; costs for balance-of-system components were not included. 
Table 3-16. Comparison of $150 \mathrm{~m}^{2}$ SM and Glass/Metal Heliostat Costs (1986\$)

\begin{tabular}{|c|c|c|}
\hline & Stretched Membrane & Glass/Metal \\
\hline Mirror Module Materials & $\$ 30.30$ & $\$ 32.80$ \\
\hline Support Structure & $\$ 6.30$ & $\$ 10.40$ \\
\hline Drive & $\$ 11.60$ & $\$ 11.60$ \\
\hline Drive Electrical & $\$ 0.95$ & $\$ 0.95$ \\
\hline Foundation & $\$ 6.70$ & $\$ 6.70$ \\
\hline Pedestal & $\$ 1.90$ & $\$ 1.90$ \\
\hline Field Wiring & $\$ 4.00$ & $\$ 4.00$ \\
\hline Controls & $\$ 1.90$ & $\$ 1.90$ \\
\hline Field Assembly/Checkout & $\$ 1.30$ & $\$ 6.30$ \\
\hline $\begin{array}{ll}\text { Total } \\
\end{array}$ & $\$ 64.95$ & $\$ 76.55$ \\
\hline
\end{tabular}

Table 3-17. SAIC Second-Generation Heliostat Mirror

Module Production Cost Estimate, With Mavis Results for Comparison

\begin{tabular}{|c|c|c|}
\hline & $\begin{array}{c}\text { Mavis Costs in } \\
1989 \$ / \mathrm{m}^{2}\end{array}$ & $\begin{array}{c}1989 \text { SAIC } \\
\text { Cost } / \mathrm{m}^{2}\end{array}$ \\
\hline Mirror Module & $\$ \$ 34.24$ & $\$ 38.34$ \\
\hline Ring & & $\$ 2.36$ \\
\hline Membranes & & $\$ 7.35$ \\
\hline Mirror & & $\$ 18.00$ \\
\hline Focus System & & $\$ 5.51$ \\
\hline Mirror Module Tooling & & $\$ 1.15$ \\
\hline Mirror Module Labor & & $\$ 3.97$ \\
\hline Support Structure & $\$ 7.12$ & $\$ 19.17$ \\
\hline Trusses & & $\$ 4.86$ \\
\hline Hub & & $\$ 14.31$ \\
\hline Drive & $\$ 13.11$ & $\$ 13.11$ \\
\hline Drive Electrical & $\$ 1.07$ & $\$ 1.07$ \\
\hline Controls & $\$ 1.90$ & $\$ 1.90$ \\
\hline Pedestal & $\$ 2.15$ & $\$ 2.15$ \\
\hline Total Direct Cost & $\$ 59.59$ & $\$ 75.74$ \\
\hline Overhead/Profit (20\%) & & $\$ 11.50$ \\
\hline Total Fabricated Cost & $\$ 59.59$ & $\$ 87.24$ \\
\hline Field Wiring & $\$ 4.52$ & $\$ 4.52$ \\
\hline Foundation & $\$ 7.57$ & $\$ 7.57$ \\
\hline Field Assembly/Checkout & $\$ 1.47$ & $\$ 1.47$ \\
\hline Total Installed Cost & $\$ 73.15$ & $\$ 100.80$ \\
\hline
\end{tabular}


To obtain a complete installed heliostat cost, the Mavis results were adjusted for inflation between 1986 and 1989 using the CPI increase during that period (13\%) and were used for the balance-of-system costs. The costs for electronic control components were not inflated due to the trend for electronics to decrease in cost rather than inflate due to the home computer and electronics boom. For comparison, the Mavis estimates for the mirror module materials and support structure are also shown in the table.

As shown in the table, the detailed heliostat production cost estimates for the mirror module and support structure are higher than the earlier Mavis estimates, resulting in a total installed price for the heliostat about 38\% higher than the Mavis estimate. A significant part of the increase was the inclusion of a $20 \%$ factor for overhead and profit on the bare production cost of the fabricated mirror module and structure components to account for the business needs of the heliostat manufacturer. Other factors in the price increase were changes in the design and inclusion of more detailed costing resulting from the second-generation study.

Building on the results of the earlier heliostat studies, present-day (2006) prices for installed SM heliostats were estimated. The single-module, $150-\mathrm{m}^{2}$ commercial heliostat design developed in the second-generation development program was taken as the baseline design, since it was developed and optimized for large production rates (50,000 per year). Because of concerns about lifetime and hail survival, a thin glass (1-mm) mirror was assumed instead of the polymer reflector that was used in the second-generation study. As an initial estimate, the predicted installed prices from the Mavis and second-generation costing study were adjusted for inflation and used to produce a baseline. Then, a bottom-up price estimate was generated using presentday prices for the various commodity and specialty components making up the system. These price estimates are described in the following subsections.

As a preliminary to the other cost estimates, the weight of the SM heliostat was updated to reflect the thin glass mirrors and other changes from the second-generation heliostat design. Table 3-18 presents the estimated weight of the SAIC mirror module and support structure (from [17], updated with thin glass mirrors). The total weight of the mirror module system is estimated to be $5,337 \mathrm{lb}$, or about $35.6 \mathrm{lb} / \mathrm{m}^{2}\left(16.1 \mathrm{~kg} / \mathrm{m}^{2}\right)$. The increase in weight due to the mirrors instead of reflective polymer film is $778 \mathrm{lb}$. However, the SM mirror assembly is still 34\% lighter than glass/metal heliostat mirror assembly.

Table 3-18. Weight Estimate for 150- $\mathrm{m}^{2}$ Second-Generation SM Heliostat Mirror Module and Support Structure with Thin Glass Mirrors

\begin{tabular}{|l|r|}
\hline & Weight (lb) \\
\hline \hline Membranes & 415 \\
\hline Ring & 1,084 \\
\hline Mirrors & 825 \\
\hline Mirror Module Mounting Hardware & 260 \\
\hline Trusses & 1,741 \\
\hline Hub & 661 \\
\hline Focus Control Equipment & 350 \\
\hline & Total \\
\hline
\end{tabular}


To update the prior heliostat production cost estimate to 2006 dollars, a combination of factors was used. The general CPI was used for commodity items, and PPIs for steel and concrete were used for components fabricated from those materials. The indices are the same as those used for the glass/metal heliostat price projections, and are summarized in Table 3-19.

Table 3-19. Indices Used for Projection of Prior Cost Estimates for SM Heliostats

\begin{tabular}{|l|l|}
\hline Consumer Price Index & $1986-1989: \quad 113 \%$ \\
& $1986-2006: \quad 185 \%$ \\
\hline Producer Price Index: Steel & $1986-2006: \quad 163 \%$ \\
\hline Producer Price Index: Concrete & $1986-2006: \quad 185 \%$ \\
\hline
\end{tabular}

The results of the projection of the 1989 costs for the SM heliostat are presented in Table 3-20. For each cost component, the source of the extrapolation is given. As before, the electronic component costs were not assumed to inflate over this time period, since electronic parts have been tending to get less, rather than more, expensive over time. The total resulting price for an installed heliostat is estimated at just over $\$ 150$ per square meter.

Table 3-20. Extrapolated SM Heliostat Price

\begin{tabular}{|c|c|l|}
\hline & $\begin{array}{c}\text { SAIC/Mavis Projected } \\
\text { Cost/m } \mathbf{m}^{2} \text { in 2006\$ }\end{array}$ & \multicolumn{1}{|c|}{$\begin{array}{c}\text { Extrapolation } \\
\text { Source }\end{array}$} \\
\hline \hline Mirror Module & $\mathbf{\$ 5 9 . 8 0}$ & \\
\hline Ring & $\$ 3.40$ & PPI Steel \\
\hline Membranes & $\$ 10.60$ & PPI Steel \\
\hline Mirror & $\$ 29.47$ & CPI \\
\hline Focus System & $\$ 7.95$ & PPI Steel \\
\hline Mirror Module Tooling & $\$ 1.88$ & CPI \\
\hline Mirror Module Labor & $\$ 6.50$ & CPI \\
\hline Support Structure & $\$ 27.65$ & \\
\hline Trusses & $\$ 7.01$ & PPI Steel \\
\hline Hub & $\$ 20.64$ & PPI Steel \\
\hline Drive & $\$ 18.91$ & PPI Steel \\
\hline Drive Electrical & $\$ 1.76$ & CPI \\
\hline Controls & $\$ 1.90$ & No increase in electronic parts \\
\hline Pedestal & $\$ 3.10$ & PPI Steel \\
\hline Total Direct Cost & $\$ 113.12$ & \\
\hline Overhead/Profit (20\%) & $\$ 17.49$ & N/A \\
\hline Total Fabricated Cost & $\$ 130.61$ & \\
\hline Field Wiring & $\$ 7.40$ & CPI \\
\hline Foundation & $\$ 11.66$ & $1 / 2$ PPI Steel, $1 / 2$ PPI Concrete \\
\hline Field Assembly/Checkout & $\$ 2.41$ & CPI \\
\hline Total Installed Cost & $\$ 152.07$ & \\
\hline
\end{tabular}


Bottom-Up Production Price Estimate for SM Heliostats. To perform a bottom-up price estimate for the SM heliostat, suppliers were contacted to get present-day quotes for particular components and materials at the 5,000 and 50,000 heliostat per year production rates. Those results relevant to the SM heliostat are summarized in Table 3-21.

In addition to material and component price changes, some changes were encountered in the available materials themselves. Most significantly, the thin stainless steel foil used for the membranes was found to be available now in 40-inch widths, whereas in earlier studies a 24 inch-wide foil was assumed. This change reduces the number of seams in the membranes (from 10 to 6) and therefore the amount of welding and handling required. Also, larger mirror tiles could be used, reducing costs for handling of those components as well. According to the manufacturer, thin mirrors are available up to 62 inches in width, so a 40-inch mirror is well within production capabilities. Finally, the SolMaT program suggested that reductions in cost were possible by using a low-grade (409) stainless steel for the mirror module ring instead of a mild steel ring because welding was simpler and no painting of the ring was required. To reflect these savings, the labor and tooling costs for the production of the heliostats were adjusted downward by $35 \%$, the approximate reduction in the amount of welding required.

Table 3-21. Bottom-Up Cost Components from Vendors

\begin{tabular}{|l|l|c|c|}
\hline \multicolumn{1}{|c|}{ Material/Component } & \multicolumn{1}{|c|}{ Source } & $\begin{array}{c}\text { Cost at } \\
\mathbf{5 , 0 0 0 / y e a r}\end{array}$ & $\begin{array}{c}\text { Cost at } \\
\mathbf{5 0 , 0 0 0 / y e a r}\end{array}$ \\
\hline \hline Fabricated Steel & Schuff Steel & $\$ 1.30 / \mathrm{lb}$ & $\$ 1.00 / \mathrm{lb}$ \\
\hline Thin Glass (1-mm) Mirrors ${ }^{5}$ & Pilkington/Gardner & $\$ 10.95 / \mathrm{m}^{2}$ & $\$ 9.14 / \mathrm{m}^{2}$ \\
\hline Azimuth Drive System & Winsmith & $\$ 5,700$ ea & $\$ 3,000$ ea \\
\hline Elevation Drive Ballscrew & Duff-Norton & $\$ 1,500$ ea & $\$ 1,000$ ea \\
\hline 3 mil 201 SS foil & Allegheny-Ludlum & & $\$ 3.92 / \mathrm{lb}$ \\
\hline
\end{tabular}

Using the updated prices, the price estimate shown in Table 3-22 was obtained for the 50,000per-year production rate. For comparison, the extrapolated SAIC/Mavis price and the price estimate for the glass/metal heliostat are included in the table with the bottom-up calculation. As shown in the table, the extrapolation and the bottom-up estimate agree remarkably well (within $6 \%$ ). In the table, the small differences between the component costs of the SM and glass/metal heliostat are due to normalizing the values to the $150-\mathrm{m}^{2}$ area of the SM compared to the $148-\mathrm{m}^{2}$ area of the glass/metal ATS heliostat.

\footnotetext{
${ }^{5}$ The price of thin mirrors is assumed to be $10 \%$ lower than thick mirrors. See Figure $3-2$.
} 
Table 3-22. Bottom-Up Price Estimate for SM Heliostat at 50,000 Per Year, Compared to Extrapolation and Glass/Metal Heliostat Estimate $\left(2006 \$ / \mathrm{m}^{2}\right)$

\begin{tabular}{|c|c|c|c|}
\hline & $\begin{array}{c}\text { Extrapolated } \\
\text { SAIC/Mavis } \\
1989 \text { Price }\end{array}$ & $\begin{array}{l}\text { Bottom-Up SM } \\
\text { Heliostat Price }\end{array}$ & $\begin{array}{l}\text { Glass/Metal } \\
\text { Heliostat Price }\end{array}$ \\
\hline Mirror Module & $\$ 59.80$ & $\$ 42.99$ & $\$ 23.06$ \\
\hline Ring & $\$ 3.40$ & $\$ 4.79$ & \\
\hline Membranes & $\$ 10.60$ & $\$ 12.36$ & \\
\hline Mirror & $\$ 29.47$ & $\$ 9.14$ & \\
\hline Focus System & $\$ 7.95$ & $\$ 10.70$ & \\
\hline Mirror Module Tooling & $\$ 1.88$ & $\$ 1.23$ & \\
\hline Mirror Module Labor & $\$ 6.50$ & $\$ 4.77$ & \\
\hline Support Structure & $\$ 27.65$ & $\$ 19.08$ & $\$ 21.21$ \\
\hline Trusses & $\$ 7.01$ & $\$ 14.92$ & \\
\hline Hub & $\$ 20.64$ & $\$ 4.17$ & \\
\hline Drive & $\$ 18.91$ & $\$ 26.67$ & $\$ 27.11$ \\
\hline Drive Electrical & $\$ 1.76$ & $\$ 1.76$ & $\$ 1.78$ \\
\hline Controls & $\$ 1.90$ & $\$ 1.87$ & $\$ 1.94$ \\
\hline Pedestal & $\$ 3.10$ & $\$ 16.73$ & $\$ 16.96$ \\
\hline Total Direct Cost & $\$ 113.12$ & $\$ 109.11$ & $\$ 92.06$ \\
\hline \begin{tabular}{|l|l|} 
Overhead/Profit (20\%) \\
\end{tabular} & $\$ 17.49$ & $\$ 21.82$ & $\$ 18.41$ \\
\hline Total Fabricated Price & $\$ 130.61$ & $\$ 130.93$ & $\$ 110.47$ \\
\hline Field Wiring & $\$ 7.40$ & $\$ 7.30$ & $\$ 7.40$ \\
\hline Foundation & $\$ 11.66$ & $\$ 2.30$ & $\$ 2.28$ \\
\hline Field Assembly/Checkout & $\$ 2.41$ & $\$ 2.41$ & $\$ 6.34$ \\
\hline \begin{tabular}{|c|} 
Total Installed Price \\
\end{tabular} & $\$ 152.07$ & $\$ 142.93$ & $\$ 126.49$ \\
\hline
\end{tabular}

To estimate the price of heliostats at the lower production rate (5,000 heliostats per year), component prices obtained from vendors were combined with estimates of volume discounts. As with glass/metal heliostats, a premium of $10 \%$ was assumed for the prices of components for which quotes were not available at the lower production rate. This yielded the bottom-up price shown in Table 3-23 for the 5,000-per-year production rate. As shown in the table, the lowvolume, near-term installed price for SM heliostats is estimated at approximately $\$ 180$ per square meter. 
Table 3-23. Bottom-Up Price Estimate for SM Heliostats at a Production Rate of 5,000 Per Year

\begin{tabular}{|c|c|c|}
\hline & 50,000 per year & 5,000 per year \\
\hline Mirror Module & $\$ 42.99$ & $\$ 48.18$ \\
\hline Ring & $\$ 4.79$ & $\$ 5.27$ \\
\hline Membranes & $\$ 12.36$ & $\$ 13.60$ \\
\hline Mirror & $\$ 9.14$ & $\$ 10.95$ \\
\hline Focus System & $\$ 10.70$ & $\$ 11.77$ \\
\hline Mirror Module Tooling & $\$ 1.23$ & $\$ 1.35$ \\
\hline Mirror Module Labor & $\$ 4.77$ & $\$ 5.25$ \\
\hline Support Structure & $\$ 19.08$ & $\$ 20.99$ \\
\hline Trusses & $\$ 14.92$ & $\$ 16.41$ \\
\hline Hub & $\$ 4.17$ & $\$ 4.58$ \\
\hline Drive & $\$ 26.67$ & $\$ 48.00$ \\
\hline Drive Electrical & $\$ 1.76$ & $\$ 1.93$ \\
\hline Controls & $\$ 1.87$ & $\$ 2.06$ \\
\hline Pedestal & $\$ 16.73$ & $\$ 18.41$ \\
\hline Total Direct Cost & $\$ 109.11$ & $\$ 139.58$ \\
\hline \begin{tabular}{|l|l|} 
Overhead/Profit (20\%) \\
\end{tabular} & $\$ 21.82$ & $\$ 27.92$ \\
\hline Total Fabricated Price & $\$ 130.93$ & $\$ 167.49$ \\
\hline Field Wiring & $\$ 7.30$ & $\$ 8.03$ \\
\hline Foundation & $\$ 2.30$ & $\$ 2.53$ \\
\hline Field Assembly/Checkout & $\$ 2.41$ & $\$ 2.65$ \\
\hline \begin{tabular}{|r|} 
Total Installed Price \\
\end{tabular} & $\$ 142.93$ & $\$ 180.70$ \\
\hline
\end{tabular}

\subsection{Evaluation of Heliostat Price Estimates}

The preceding sections detailed the price estimates for glass/metal and SM heliostats at 5,000 and 50,000 units per year. In this section, the estimates are evaluated and compared to the historical data and to each other. Table 3-24 summarizes the heliostat price estimates used and generated in this study.

Table 3-24. Summary of Heliostat Price Estimates

\begin{tabular}{|l|c|c|}
\hline & $\mathbf{5 , 0 0 0}$ per year & $\mathbf{5 0 , 0 0 0}$ per year \\
\hline \hline $\begin{array}{l}\text { Glass/Metal Heliostat: } \\
\text { Original Mavis Estimate (1986\$) }\end{array}$ & --- & \\
Mavis Estimate (extrapolated to 2006\$) & --- & $\$ 76.55$ \\
\hline ATS Bottom-Up Estimate & $\$ 163.94$ & $\$ 126.49$ \\
\hline SM Heliostat: & & \\
Original Mavis Estimate (1986\$) & --- & $\$ 64.95$ \\
SAIC/Mavis Estimate (1989\$) & --- & $\$ 100.80$ \\
SAIC/Mavis Estimate (extrapolated to 2006\$) & --- & $\$ 152.07$ \\
\hline SAIC Bottom-Up Estimate & $\$ 180.70$ & $\$ 142.93$ \\
\hline
\end{tabular}


Looking at the values in the table, the effects of general inflation between 1986 and 2006 are evident. The CPI increased 85\%, and steel prices 63\%, over that period.

\subsubsection{Comparison of Estimated Glass/Metal Heliostat Prices to Prior Cost Estimates}

Table 3-25 summarizes the detailed cost estimates for glass/metal heliostats at the 50,000-peryear production rate. The total costs agree within $4 \%$, but there is considerable difference in the individual cost components between the Mavis estimate and the present bottom-up estimate. These differences are discussed in the following paragraphs.

The mirror module cost difference is mainly explained by differences in mirror costs and design changes to the mirror modules that make them less expensive. The Gardner mirror quote is significantly less than equivalent mirror prices when the Mavis estimate was made. Also, the original ATS/Arco Solar mirror modules used a laminated glass construction, with mirrored glass laminated to a thicker glass sheet for structural strength. The current ATS design calls for a single, thicker glass mirror with the steel hat sections bonded directly to the rear surface of the mirror.

The present-day estimated price for drives is higher than the Mavis estimate due to design changes in the drive and better estimates of what the drive would cost in production. The lowcost drive study by Peerless Winsmith [12] was performed after the Mavis study, and included detailed production price estimates at 50,000 units per year. The resulting value of $\$ 14.42 / \mathrm{m}^{2}$ (in $1989 \$$ ) inflates to $\sim 25 / \mathrm{m}^{2}$ in $2006 \$$, close to the $\$ 32.53 / \mathrm{m}^{2}$ estimate that was obtained from Winsmith for this study. Subsequent testing of the low-cost drive showed that the chain drive system used in the original design was inadequate and it was replaced by a gear drive system. The improved design also included twice the number of drive pinions for added strength. The increased cost of these gears was reflected in the price for the present-day low-cost drive.

Table 3-25. Comparison of Bottom-Up Price Estimate and Extrapolated Mavis Price for Glass/Metal Heliostats $\left(2006 \$ / \mathrm{m}^{2}\right)$

\begin{tabular}{|c|c|c|}
\hline & $\begin{array}{c}\text { Mavis } \\
\text { (extrapolated } \\
\text { to 2006\$) } \\
\end{array}$ & $\begin{array}{l}\text { ATS Bottom-Up } \\
\text { Estimate (2006) }\end{array}$ \\
\hline Mirror Modules & $\$ 58.27$ & $\$ 27.67$ \\
\hline Support Structure & $\$ 16.95$ & $\$ 25.45$ \\
\hline Drives & $\$ 18.91$ & $\$ 32.53$ \\
\hline Drive Electrical & $\$ 1.78$ & $\$ 2.14$ \\
\hline Foundation & $\$ 11.66$ & $\$ 2.33$ \\
\hline Pedestal & $\$ 3.10$ & $\$ 20.35$ \\
\hline Field Wiring & $\$ 7.40$ & $\$ 7.40$ \\
\hline Controls & $\$ 1.90$ & $\$ 2.28$ \\
\hline Field Assembly and Checkout & $\$ 11.66$ & $\$ 6.34$ \\
\hline Total & $\$ 131.63$ & $\$ 126.49$ \\
\hline
\end{tabular}


The pedestal and foundation costs are different mainly because of a difference in the design of the foundation between the Mavis estimate and the present estimate. The foundation estimated by Mavis included a concrete pedestal that extended a considerable distance above the ground level. Therefore the "pedestal" considered by Mavis was short and relatively lightweight. In contrast, the foundation of the ATS heliostat consists only of an in-ground concrete footing and the steel pedestal extends from below ground to the bottom of the drive unit. Thus, the foundation is relatively less expensive, and the pedestal relatively more expensive, than the Mavis estimate. The total, however, is not hugely different $\left(\sim \$ 15 / \mathrm{m}^{2} \mathrm{vs} . \sim \$ 22 / \mathrm{m}^{2}\right)$. The field assembly and checkout cost is less in the present estimate due to continued development by ATS of assembly and alignment methods that have reduced the manpower needed to perform those tasks.

\subsubsection{Price Sensitivity of the Glass/Metal Heliostat}

ATS performed price sensitivity studies to assess the effects of price variability in major components of the heliostat. Particularly, the prices of mirrors, pedestals and torque tubes, and trusses were varied to study their effects. Mirror prices were allowed to vary plus or minus $20 \%$ from the nominal price. Pedestal and torque tube prices were varied from minus $12.5 \%$ and plus $36 \%$ of the nominal value. Truss prices were allowed to increase about $25 \%$ from the nominal price for the study.

Table 3-26 summarizes the results of the sensitivity studies. If all the prices varied to their low values, a total overall reduction of $\$ 6.47 / \mathrm{m}^{2}$ in heliostat price would result, and if they all floated to the tops of their ranges, an increase of $\$ 16.05 / \mathrm{m}^{2}$ would result. Combined with the base price value of $\$ 126 / \mathrm{m}^{2}$ these sensitivities yield an overall range of glass/metal heliostat prices from about $\$ 120 / \mathrm{m}^{2}$ to $\$ 142 / \mathrm{m}^{2}$.

Table 3-26. Sensitivity Results for Glass/Metal Heliostat Cost Components

\begin{tabular}{|l|c|c|c|c|}
\hline & $\begin{array}{c}\text { Low } \\
\text { Price }\end{array}$ & $\begin{array}{c}\text { Reduction in } \\
\text { Heliostat } \\
\text { Price } \mathbf{( \$ / \mathbf { m } ^ { 2 } )}\end{array}$ & $\begin{array}{c}\text { High } \\
\text { Price }\end{array}$ & $\begin{array}{c}\text { Increase in } \\
\text { Heliostat } \\
\text { Price } \mathbf{( \$ / \mathbf { m } ^ { 2 }}\end{array}$ \\
\hline Glass Mirrors $\left(\$ / \mathrm{m}^{2}\right)$ & $\$ 8.22$ & $\$ 2.40$ & $\$ 12.22$ & $\$ 2.40$ \\
\hline Pedestal and Torque Tubes $(\$ / \mathrm{lb})$ & $\$ 0.63$ & $\$ 4.07$ & $\$ 0.98$ & $\$ 11.77$ \\
\hline Trusses $(\$ / \mathrm{lb})$ & $\$ 1.00$ & - & $\$ 1.25$ & $\$ 1.88$ \\
\hline Overall Effect $\left(\$ / \mathrm{m}^{2}\right)$ & & $\$ 6.47$ & & $\$ 16.05$ \\
\hline
\end{tabular}

\subsubsection{Comparison of SM Heliostat Price Estimates}

Table 3-27, repeated from Table 3-22, shows the breakdown of costs for the SM heliostat at 50,000 units per year. As was the case for glass/metal heliostats, the bottom-up price compares well to the extrapolated SAIC/Mavis estimate (within 6\%).

Major differences in component prices include a significant reduction in mirror costs from the Mavis estimate, and increases in the drive and pedestal costs (as discussed above). The hub cost 
is significantly reduced in the updated estimate because it is based on raw steel costs rather than individual costs for specific tubing segments.

Compared to the glass/metal heliostat, the SM heliostat has an overall higher estimated cost. Costs for the mirror module are higher than the glass/metal design, mainly due to the costs of the membranes and focus control components. It appears that the present-day higher membrane material costs negate the SM heliostat's advantage in reduced weight compared to the glass/metal heliostat.

Table 3-27. Summary of SM Heliostat Price Estimates, and Comparison to Glass/Metal Heliostat Estimate

\begin{tabular}{|l|c|c|c|}
\hline & $\begin{array}{c}\text { Extrapolated } \\
\text { SAIC/Mavis } \\
\text { 1989 Price }\end{array}$ & $\begin{array}{c}\text { Bottom-Up } \\
\text { Stretched } \\
\text { Membrane } \\
\text { Heliostat Price }\end{array}$ & $\begin{array}{c}\text { Glass/Metal } \\
\text { Heliostat Price }\end{array}$ \\
\hline Mirror Module & $\$ 59.80$ & $\$ 42.99$ & $\$ 23.06$ \\
\hline Ring & $\$ 3.40$ & $\$ 4.79$ & \\
\hline Membranes & $\$ 10.60$ & $\$ 12.36$ & \\
\hline Mirror & $\$ 29.47$ & $\$ 9.14$ & \\
\hline Focus System & $\$ 7.95$ & $\$ 10.70$ & \\
\hline Mirror Module Tooling & $\$ 1.88$ & $\$ 1.23$ & \\
\hline Mirror Module Labor & $\$ 6.50$ & $\$ 4.77$ & \\
\hline Support Structure & $\$ 27.65$ & $\$ 19.08$ & $\$ 21.21$ \\
\hline Trusses & $\$ 7.01$ & $\$ 14.92$ & \\
\hline Hub & $\$ 20.64$ & $\$ 4.17$ & \\
\hline Drive & $\$ 18.91$ & $\$ 26.67$ & $\$ 27.11$ \\
\hline Drive Electrical & $\$ 1.76$ & $\$ 1.76$ & $\$ 1.78$ \\
\hline Controls & $\$ 1.90$ & $\$ 1.87$ & $\$ 1.94$ \\
\hline Pedestal & $\$ 3.10$ & $\$ 16.73$ & $\$ 16.96$ \\
\hline \multicolumn{1}{|c|}{ Total Direct Cost } & $\$ 113.12$ & $\$ 109.11$ & $\$ 92.06$ \\
\hline Overhead/Profit (20\%) & $\$ 17.49$ & $\$ 21.82$ & $\$ 18.41$ \\
\hline Total Fabricated Price & $\$ 130.61$ & $\$ 130.93$ & $\$ 110.47$ \\
\hline Field Wiring & $\$ 7.40$ & $\$ 7.30$ & $\$ 7.40$ \\
\hline Foundation & $\$ 11.66$ & $\$ 2.30$ & $\$ 2.28$ \\
\hline Field Assembly/Checkout & $\$ 2.41$ & $\$ 2.41$ & $\$ 6.34$ \\
\hline \multicolumn{1}{|c|}{ Total Installed Price } & $\$ 152.07$ & $\$ 142.93$ & $\$ 126.49$ \\
\hline
\end{tabular}

The drive and pedestal account for about $30 \%$ of the total materials cost for the SM system. A low-cost, non-pedestal drive that took advantage of the SM structure might have the potential to reduce the total cost significantly.

Several features of an SM heliostat relative to a glass/metal heliostat are estimated to be worth about $\$ 10 / \mathrm{m}^{2}$ on a system basis. The circular shape of the heliostat allows tighter packing of 
heliostats in the field and requires fewer overall heliostats for the same power output. Also, each membrane reflector can be focused at the exact slant range to the receiver, which is not practical with fixed-focus glass/metal heliostats, and this leads to a smaller and less expensive receiver. The analyses leading to these conclusions are presented in Chapter 4 . When this factor is deducted from the SM heliostat price, the overall estimated price is $\$ 132 / \mathrm{m}^{2}$, and the price of an SM heliostat appears nearly the same as that of a glass/metal heliostat (within 5\%).

\subsubsection{General Comments Regarding Supplier Estimates}

Multiple factors make it difficult to generate precise cost estimates for a study like this one. In some cases (e.g., mirrors), the production quantities involved are beyond many suppliers' capacities, requiring them to make extrapolations of their present costs to new facilities that would be required. Also, it is difficult to get suppliers to apply large efforts to making accurate cost estimates for a nascent and unfamiliar market. In some cases, suppliers feel that they are under no competitive pressure, and they therefore tend to be more conservative in their estimates. A production pricing study that includes representative manufacturing companies could possibly provide a higher degree of certainty. However, in the end, accurate pricing can only be obtained by issuing competitive RFPs to multiple vendors. Even this, if it is to be effective, requires a credible promise that the proposals will result in actual sales, preferably over many years. 


\section{ECONOMIC VALUE OF HELIOSTAT OPTICAL VARIABLES}

Heliostat optical design variables affect the cost of the heliostat and can impact the overall performance of a power tower system. The variables are listed below.

- $\quad$ Size (e.g., 150 vs. $100 \mathrm{~m}^{2}$ )

- Mirror surface slope error

- Tracking error

- Wind-induced tracking error

- Mirror canting

- Mirror focusing

- $\quad$ Type (e.g., ATS base case vs. SM)

In this chapter we investigate how the major optical variables affect the LEC of the molten-salt power tower described in Chapter 1.

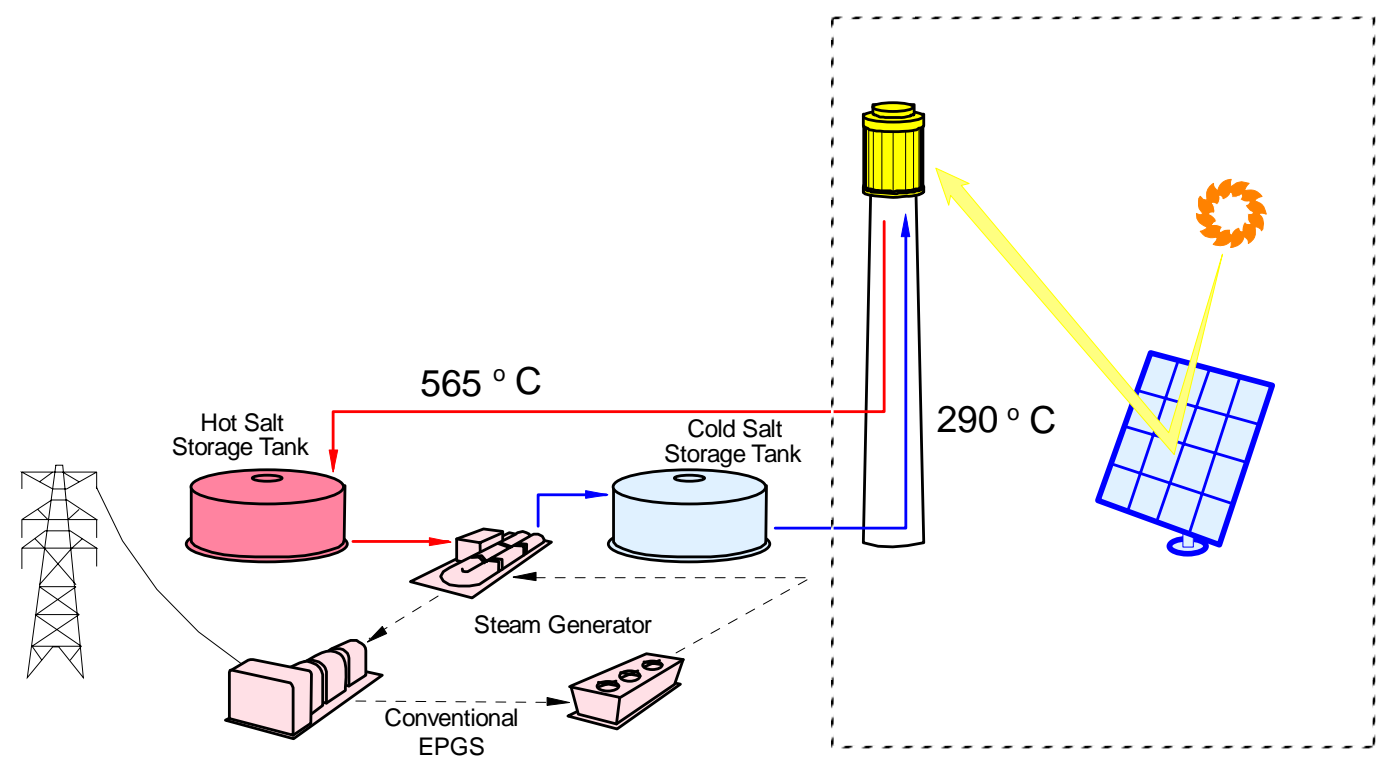

Figure 4-1. The base-case 100-MWe molten salt power tower consists of a 700-MWt receiver with a surface area of $1380 \mathrm{~m}^{2}$, a 240-m-tall-tower, and 9500 ATS-type heliostats $\left(147 \mathrm{~m}^{2}\right.$ each, 2 mrad slope error ${ }^{6}$ [11]) that surround the tower.

For a given receiver power rating, heliostat optical variables affect three system design features shown within the box in Figure 4-1: (1) the number of heliostats, (2) the size of the receiver, and (3) the height of the tower. For example, if the heliostats have better optical quality than the base-case ATS (say 1 instead of 2 mrad), the number of heliostats could be reduced to achieve

6 2 mrad error was measured for times >2 hours from solar noon. Near solar noon, a 1.2 mrad error was measured. 
the same 700-MWt receiver power because the beam sizes are smaller and more of the heliostats' energy is intercepted by the receiver. Alternatively, the number of heliostats could remain the same but the receiver size could be reduced because of the smaller beam size.

The DELSOL computer code [18] was used to determine the optimum combination of the three system design features given an optical-design change in the base-case ATS heliostat. During the re-optimization the cost of the new heliostat was changed to achieve the same LEC as the base-case power tower system. The economic value of the optical variables was determined in this way. The results of nine case studies are shown in Table 4-1.

Table 4-1. Economic Value of Heliostat Optical Variables. ${ }^{7}$

Optical changes are underlined. SR is slant range, SM is SM, and THT is tower height.

\begin{tabular}{|c|c|c|c|c|c|c|}
\hline $\begin{array}{c}\text { Case } \\
\text { Study }\end{array}$ & $\begin{array}{c}\text { Heliostat } \\
\text { Size }\end{array}$ & $\begin{array}{c}\text { Slope } \\
\text { Error }\end{array}$ & $\begin{array}{c}\text { Cant } \\
\text { Distance }\end{array}$ & $\begin{array}{c}\text { Mirror } \\
\text { Focus } \\
\text { Distance }\end{array}$ & $\begin{array}{c}\text { Heliostat } \\
\text { Cost }\end{array}$ & $\begin{array}{c}\Delta \text { Capital } \\
\text { Cost }\end{array}$ \\
\hline \hline & $147 \mathrm{~m}^{2}$ & $2 \mathrm{mrad}$ & $\mathrm{SR}$ & $6 \times \mathrm{THT}$ & $\$ 126 / \mathrm{m}^{2}$ & Base Case \\
\hline 1 & $147 \mathrm{~m}^{2}$ & $2 \mathrm{mrad}$ & $\mathrm{SR}$ & $\underline{\mathrm{SR}}$ & $\$ 126 / \mathrm{m}^{2}$ & $\$ 0 / \mathrm{m}^{2}$ \\
\hline 2 & $147 \mathrm{~m}^{2}$ & $2 \mathrm{mrad}$ & $\underline{6 \mathrm{XTHT}}$ & 6 X THT & $\$ 123.7 / \mathrm{m}^{2}$ & $-\$ 2.3 / \mathrm{m}^{2}$ \\
\hline 3 & $147 \mathrm{~m}^{2}$ & $2 \mathrm{mrad}$ & $\mathrm{SR}$ & $\underline{\text { No Focus }}$ & $\$ 125 / \mathrm{m}^{2}$ & $-\$ 1.0 / \mathrm{m}^{2}$ \\
\hline 4 & $147 \mathrm{~m}^{2}$ & $2 \mathrm{mrad}$ & $\underline{\text { No Cant }}$ & $\underline{\text { No Focus }}$ & $\$ 118.1 / \mathrm{m}^{2}$ & $-\$ 7.9 / \mathrm{m}^{2}$ \\
\hline 5 & $147 \mathrm{~m}^{2}$ & $\underline{1 \mathrm{mrad}}$ & $\mathrm{SR}$ & $6 \times \mathrm{THT}$ & $\$ 133.5 / \mathrm{m}^{2}$ & $+\$ 7.5 / \mathrm{m}^{2}$ \\
\hline 6 & $\underline{9 \mathrm{~m}^{2}}$ & $2 \mathrm{mrad}$ & $\mathrm{SR}$ & $6 \times \mathrm{THT}$ & $\$ 128.0 / \mathrm{m}^{2}$ & $+\$ 2.0 / \mathrm{m}^{2}$ \\
\hline 7 & $\underline{95 \mathrm{~m}^{2}}$ & $\underline{1 \mathrm{mrad}}$ & $\mathrm{SR}$ & $6 \mathrm{XTHT}$ & $\$ 135.5 / \mathrm{m}^{2}$ & $+\$ 9.5 / \mathrm{m}^{2}$ \\
\hline 8 & $\underline{320 \mathrm{~m}^{2}}$ & $\underline{2 \mathrm{mrad}}$ & $\mathrm{SR}$ & $6 \times \mathrm{THT}$ & $\$ 123.4 / \mathrm{m}^{2}$ & $-\$ 2.6 / \mathrm{m}^{2}$ \\
\hline 9 & $\underline{147 \mathrm{~m}^{2} \mathrm{SM}}$ & $\underline{1 \mathrm{mrad}}$ & $\begin{array}{c}\text { Not } \\
\text { Applicable }\end{array}$ & $\mathrm{SR}$ & $\$ 136.2 / \mathrm{m}^{2}$ & $+\$ 10.2 / \mathrm{m}^{2}$ \\
\hline
\end{tabular}

For example, in Case Study 7 the size of the ATS was reduced from $147 \mathrm{~m}^{2}$ to $95 \mathrm{~m}^{2}$ and the mirror slope error was reduced from $2 \mathrm{mrad}$ to $1 \mathrm{mrad}$. DELSOL predicts the cost of this smaller, more accurate heliostat could be significantly higher $\left(\$ 9.5 / \mathrm{m}^{2}\right)$ than the base-case ATS and still achieve the same system LEC. Canting of the heliostat facets is shown to have a significant impact (Case 4), but facet focusing is not (Case 3).

Notes:

1) ATS believes that 2-mrad slope can be reduced to $1.4 \mathrm{mrad}$ through changes to canting procedure.

2) All calculations assume a 0.75-mrad tracking error.

3) Slope error for $121 \mathrm{~m}^{2}$ at PS-10 is $1.3 \mathrm{mrad}$, tracking $0.65 \mathrm{mrad}$. 
In Case 9, the ATS mirror modules and support structure were replaced with a single SM facet with a 1-mrad slope error. ${ }^{8}$ DELSOL predicted that such a heliostat could cost $\$ 10.2$ more. The reason the higher cost can be tolerated and still achieve the same LEC is because

- the re-optimized system has 5\% fewer heliostats,

- tower height is reduced by $15 \%$, and

- receiver surface area is reduced by $10 \%$,

relative to the base-case power tower system. Besides the improved slope error, an additional advantage of the stretched membrane is the improved field packing density afforded by its circular shape.

It is important to note that the economic values presented in Table 4-1 were calculated relative to the base-case ATS heliostat price of $\$ 126 / \mathrm{m}^{2}$. As described in Chapter 3, this is the price given a production rate of 50,000 units/year. If the production rate is lower than this, the base-case price will increase and so will the economic values. DELSOL analysis suggests that the economic values given a higher base-case price can be approximated by multiplying the values in Table $4-1$ by the ratio of the higher price divided by 126 . For example, if the price is $\$ 170 / \mathrm{m}^{2}$ given a lower production rate then the economic values should be multiplied by a factor of $\sim 170 / 126=1.35$.

As should be obvious by now, the information presented in Table 4-1 can be used to help decide whether it is cost-effective to make a particular change to the base-case design, i.e., if the cost of the change is significantly less than the economic value, the change should be made.

8 Less than 1 mrad was measured for a 150-m² SM heliostat tested in Europe (Figure 2-10) [9]. 


\section{A MANUFACTURING PERSPECTIVE OF THE BASELINE ATS HELIOSTAT}

This chapter explores the ATS heliostat from a manufacturing cost perspective. The heliostat design was reviewed by manufacturing experts. ${ }^{9}$ It was their assessment that the azimuth drive is the only component in the heliostat that offers the possibility of major savings through better manufacturing methods. Consequently, manufacturing of the azimuth drive is the primary focus of this chapter. It is shown that mass production of the azimuth drive, i.e., when demand justifies a dedicated line, provides savings that become a substantial percentage of the total heliostat cost. As discussed in Chapter 3, when demand increases from $5 \mathrm{~K}$ to $50 \mathrm{~K}$ drives per year, Winsmith estimates the cost of the drives to drop from $\$ 5700$ to $\$ 3000$. Though insufficient data are available to quantitatively substantiate the Winsmith estimate, it appears reasonable.

The three critical issues explored in this chapter are:

- Can the drive do job?

- What is the risk associated with using the drive?

- Can the cost of the azimuth drive be reduced?

It is shown through analysis that the Winsmith design offers the best alternative for all three critical issues.

\subsection{Generic Manufacturing Considerations}

Assembly Line Control

There are two fundamentally different approaches to control an assembly line: "push” and "pull." In a push system, an order forces a scheduler to compute when each component in the Bill of Materials (BOM) should start production so as to be ready for subsequent processing. Once this computation is done, there is a clear and obvious plan when all activities should occur (barring machine breakdown, etc.). Consequently, the plan "pushes" the parts through the factory.

Pull manufacturing is the total opposite. In a pull system, an order goes to the last workstation in the factory. To satisfy this order, requests are sent to the previous workstation to supply materials needed by the last workstation. This request concept is recursively applied to all previous workstations, and the product is "pulled” from the factory. The requests are controlled by kanbans, which are pieces of paper that request a specific part from a previous workstation. Pull manufacturing controls the total amount of work in progress (WIP) by controlling the request quantities on the kanban. Since WIP is inventory, minimizing WIP saves money.

It does not matter if a factory uses "push" or "pull” manufacturing; the issue is always how much WIP is created, how the WIP is controlled, and how is it scheduled to achieve desired production.

9 Ron Lumia (Manufacturing Professor at University of New Mexico and President of INControl, Inc.) and Matt Donnelly (Sandia National Laboratories Advanced Manufacturing Center). 


\section{Little's Law}

Little's Law is the Newton's Law of manufacturing. The equation is:

$W I P=R_{p}^{*} C T$

$R_{p}$ is the production rate

$C T$ is the Cycle Time

As a factory experiences increasing product orders, the production rate eventually saturates, limited by the slowest machine in the facility. From that point forward there is a linear relationship between the WIP, the partially completed components of a product, and the Cycle Time (CT), the time it takes from starting a new product until it rolls off the line. It should be noted that if WIP is introduced arbitrarily into the factory, usually justified by the idea of "keeping workers busy," the CT must increase. As the CT increases, the factory is less responsive to customers, delivering product later.

Little's Law works at all levels of the factory, from the work cell to the line to the factory level. Minimizing WIP saves money both in space (less factory floor space is needed to store the WIP) and time (less time required to make a product).

\section{Factory Layout Alternatives}

Ignoring airplanes and buildings, and other very large products, there are two basic ways to manufacture objects. The first is called a process line. In a process line, all equipment is grouped by process, e.g., all vertical mills are grouped together, all drill presses, etc. This organization is used when demand for objects is low. Factories using a process line, e.g., a job shop, typically have many products but relatively low volumes. Each product has a different path through the machines, depending on the product itself. Therefore, it is impossible to put machines in the proper order to manufacture a product because the order is different for every product.

In contrast to the process line is the product line. In a product line, the equipment is organized such that the product flows from one machine directly to a neighboring machine. This is the best organization for high-volume manufacturing, but it requires considerably more capital equipment than a process line. The efficiency of this approach, even with the penalty of the capital equipment, is realized only when demand for the product is considerable.

\section{Lean Manufacturing Approaches}

Lean Manufacturing is a specific type of "pull” manufacturing generally associated with Toyota. When implemented properly, Lean Manufacturing approaches in a factory are hard to beat in terms of both quality and efficiency. The concept of Lean Manufacturing started with Toyota in 1945 and 60 years later the approach continues to evolve. Basically, Lean Manufacturing identifies waste and removes it. The process of continual improvement never ends.

Lean Manufacturing should not be perceived as a panacea. It is a viable approach when there are relatively few different products on a line and each product has a relatively constant demand. If demand fluctuates wildly, lean approaches can break down because "flow" is adversely affected. However, with a steady stream of demand, lean production is about as good as it gets. 
Several different techniques are commonly used in Lean Manufacturing. The first is called 5S: sort, stabilize, shine, sustain, stabilize. The basic idea is that a clean and efficient work area promotes pride and encourages high quality. Another common technique is error-proofing, or Poka-Yoke. Errors are minimized though part design and assigning tasks intelligently during assembly. For example, using the same size bolt for an entire assembly rather than many similar-sized bolts eliminates the possibility of an error. Lean Manufacturing also attempts to minimize the time required to set up to manufacture a different part. Clever mechanical jigs, etc., are used to quickly change from one part to another. This encourages small batches or even single-object manufacturing. This reduces WIP and therefore the cost of manufacturing. Total Productive Maintenance, another common Lean Manufacturing technique, considers how to keep machines running efficiently and effectively. Standard Work defines each worker's job, so that cross-trained workers perform operations on a work cell in exactly the same way, thereby promoting high-quality parts. While these techniques are often associated with Lean Manufacturing, they are "common sense” techniques applicable to any manufacturing line.

\subsection{Azimuth Drive Manufacture}

\section{Introduction to the Winsmith Drive}

The current Winsmith Drive is shown in Figure 5-1 [19]. It consists of one drive gear and three idler gears that distribute and balance the load. This represents a marked improvement over the earlier chain/sprocket design [12]. The planocentric design provides extraordinary gear reduction in an extremely compact package. The design is extremely clever and is precisely what is needed for a heliostat's azimuth control. It is unfortunate that heliostats appear to be the only application for this azimuth drive. ${ }^{10}$ Consequently, there is no additional demand from other applications adding to the heliostat demand.

\section{Manufacturing Cost Issues}

The major components of the heliostat include the mirror modules, support structure, drives, drive electronics, foundation, pedestal, field wiring controls and the field assembly and checkout. For many of the components, the cost of the heliostat is directly related to the cost of the raw materials. Examples include the foundation (cement and rebar), pedestal (“dumb” steel), truss structure ("dumb” steel), and mirrors (glass). For those components that correlate most closely with the cost of the raw material, there is a simple strategy to follow: engage companies that already use a lot of that raw material to manufacture specific heliostat components. An example of this is the use of Schuff Steel. ${ }^{11}$ Schuff already uses significant quantities of "dumb” steel to construct buildings. Therefore, their marginal cost associated with using additional steel for the pedestal and support structure, for example, is relatively small, making them an obvious low-cost manufacturing company.

10 However, as described in Chapter 7, this drive might also be used for a solar dish. Thus, demand could be increased by combining an order for solar dishes and solar heliostats.

11 As discussed in Chapter 3, Schuff is a large U.S. steel-product supplier who (with Stirling Energy Systems, Inc.) is also planning to deploy a large solar-dish project in California. 

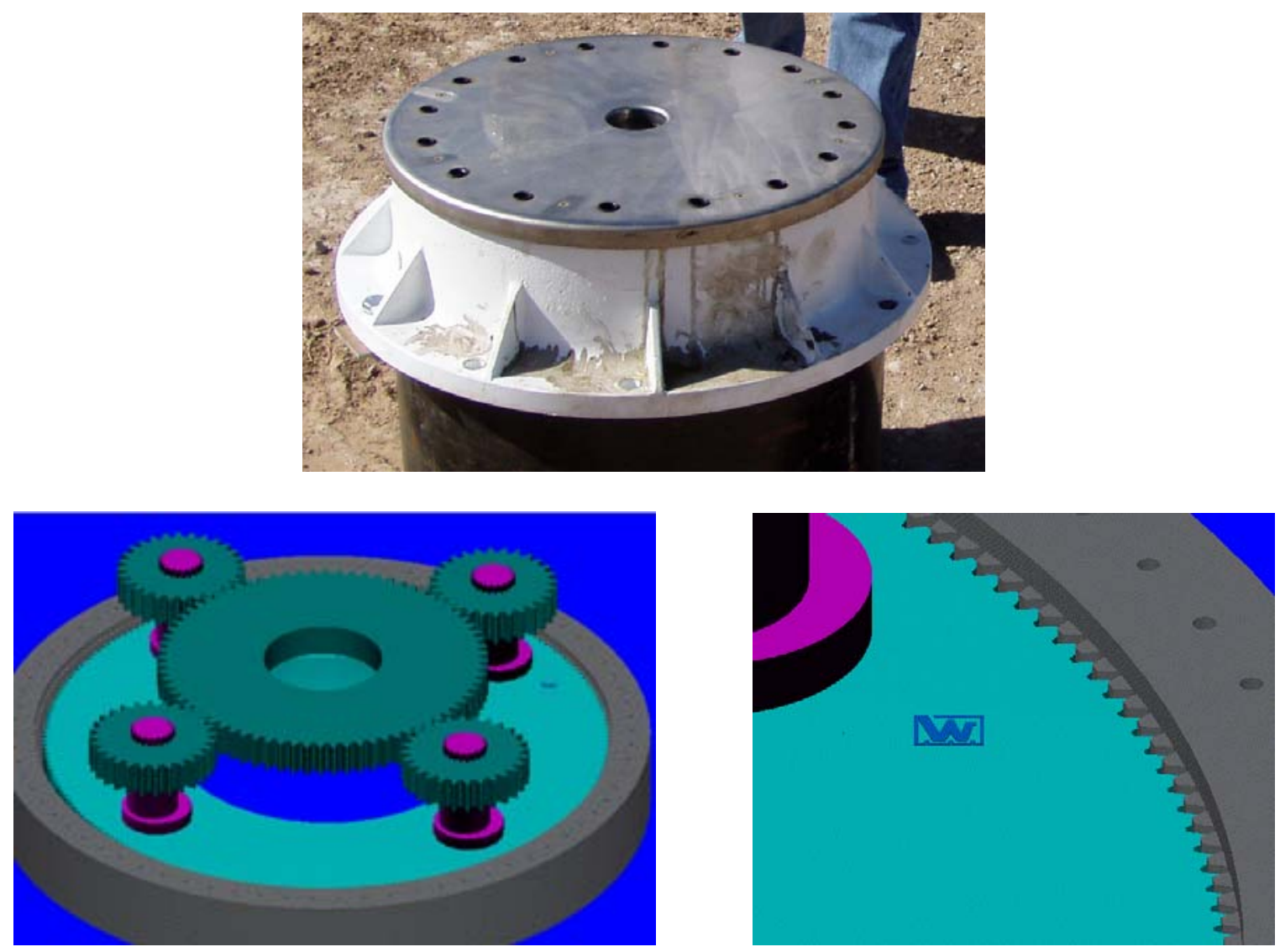

Figure 5-1. Winsmith planocentric azimuth drive. One of the four small gears within the unit is driven by an external electric motor.

The remaining three idler gears are connected to this drive gear by the center larger gear with the hole. The motion of each of the four small gears is connected to a plate via an eccentric race. This causes the plate to wobble back and forth and rotate the outer ring connected to the heliostat structure. The speed reduction between motor and outer ring is -33000:1.

The azimuth drive is the only component in the heliostat that offers substantial savings from mass production. While the cost of raw materials relates to the cost of any object, the more sophisticated the machinery and processing required to fabricate the components, the less sensitive that product becomes to raw material costs. The simple reason is that the raw materials become a very small percentage of the total cost of the object because labor and capital equipment costs dominate. In the heliostat azimuth drive, the cost of raw materials becomes relatively unimportant. Manufacturing costs dominate. Obviously, the 1,200 lb of drive cannot be worth less than the equivalent amount of steel, so it is clear that at $\$ 0.30$ per pound, the raw material costs place a floor of $\$ 360$ on the drive, but the drive costs significantly more than that. Winsmith estimates that the drive will cost $\$ 5700$ with a demand of 5,000 drives per year that falls to $\$ 3000$ when the demand reaches 50,000 drives per year. It is important to understand where this savings comes from, and whether it is real. 


\section{Manufacturing Quantity Issues}

Currently, the azimuth drive is manufactured in a process line, previously described in Section 5.1. It is important to understand precisely why an azimuth drive costs so much in a process line. There are roughly 50-75 parts in the azimuth drive. Each part must go through multiple machines before reaching final assembly. In a process line, work queues in front of a machine until it can be processed. In most process lines, it is common to see a part waiting in a queue $95 \%$ of the time, with the remaining 5\% split between setup and actual production. Consequently the cycle time, the time from starting the drive to final assembly, is very long. Furthermore, there is significant space required on the floor to store all the WIP. Not only is large WIP expensive (floor space, holding costs, etc.), it encourages batch manufacturing, further exacerbating the WIP problem. If there is ever a problem, e.g., an error in fabricating a component, large numbers of parts will need to be thrown away. However, when production volumes are small, capital equipment must be shared among all products. When this is the case, a product line is the only economically sane way to manufacture.

The azimuth drive will see significant price reductions only when the sales volume reaches the point where it is economically viable to transition from a process line to a product line. Therefore, the question is what constitutes sufficient volume to justify a product line dedicated to manufacturing the azimuth drive.

Investment Requirements for Dedicated Azimuth Drive Line

Since many of the numbers used by Winsmith are simply estimates based on experience, it is not possible to perform a detailed investment analysis. However, a ballpark estimate is possible and desirable. Winsmith claims that a \$3-4 M investment is needed to buy the capital equipment for a dedicated line to manufacture the azimuth drives.

Most rational companies do not invest in projects that pay back in greater than 24 months, so we will adopt 24 months as the payback period. Also, since this payback period is relatively short and we are only after a ballpark answer, we will also ignore the time value of money. If we assume a value somewhere in the middle of the \$3-4 M, e.g., \$3.6 M, and a payback of 24 months, we have $\$ 150 \mathrm{~K}$ per month amortization of capital equipment. It is hard to imagine a company selling anything if their capital equipment amortization costs are more than $5 \%$ of gross sales. Therefore, for the 24-month payoff, they must produce

$$
\begin{aligned}
& \frac{\$ 150 K}{5 \%}=\$ 3 M \text { gross sales per month } \\
& \text { At } \$ 5700 \text { per unit (the initial cost for } 5000 \text { units per year) } \\
& \frac{\$ 3 M \text { sales } / \text { month }}{\$ 5700 \text { per unit }}=526 \text { drives per month } \\
& 526 \text { drives per month }=6315 \text { drives per year }
\end{aligned}
$$

The first issue is that 6,315 is close to Winsmith's estimate of $\$ 5,700$ per drive with a yearly demand of 5,000 units. This is encouraging. The second issue is that this demand of 6,315 drives per year constitutes the lower bound of acceptability. Since the solar industry has had problems in the past predicting demand, it is hard to imagine Winsmith, or any other company, 
eager to make such an investment with only one 6,000 unit order. It is roughly a break-even scenario. Why bother? However, two or three orders of 6,000 would definitely justify the investment in the dedicated line. This would be especially true if these orders were from different companies, each of whom had a contract to build a power station. Properly designed, the line could manufacture several different sizes of the drive for different sizes of arrays, if that is desired.

\section{Where to Manufacture Drives}

This is a very tricky problem. Winsmith has a very clever planocentric design that has been field-tested for some time. Cutting them out of the manufacturing process, and therefore out of the manufacturing profit, is simply unfair. It is unethical to bring along Winsmith simply to cut them out at the final moment by sending the design to China for fabrication.

Since many of the parts are high quality and labor intensive, it would not be surprising to find China the preferred location. What is not currently known, and cannot be known without additional analysis, is where problems exist that add to manufacturing costs. If assembly is an issue, as determined by a Boothroyd and Dewhurst design for manufacturing (DFM) analysis [20], then China will definitely be the place to build and assemble the drives. If assembly is not an issue, the drives could be assembled in the United States from parts manufactured in China.

Another alternative manufacturing scenario is to use subcontractors in the automobile industry. The azimuth drive is in many respects similar to an auto transmission and could benefit from the same economy of scale used in that industry. This is but one example how Winsmith could explore subcontracting the manufacture of certain subcomponents.

Finally, if the processes to make the constituent components are highly automated and assembly is relatively easy, there could be considerable economic benefit to keep the entire line in the United States. It is not possible to tell with the information that is available; additional analysis is needed.

\subsection{Recommendations}

Recommendations concerning the drive relate to four categories: design, manufacturing, system, and research. Each will be described below. Some of the recommendations relate to short-term goals while others relate to longer-term research directions.

\section{Design of Drive}

Review of the specifications. Some of the drive specifications need to be revisited. For example, one of the many specs found in Reference 12 indicates the drive shall have a maximum $12^{\circ}$ slew rate. One would think the slew rate spec should be a minimum rather than a maximum. Incorrect specifications can lead to early failure or lead to a drive that is grossly overdesigned and too costly. A knowledgeable group should review the specifications. This need was also recognized by Winsmith and other heliostat experts and would be a fundamental input to the future low-cost drive project proposed in Chapter 6. 


\section{Drive Manufacturing}

Boothroyd and Dewhurst analysis of azimuth drive. Currently, there is not a definitive bill of materials for the azimuth drive. Winsmith has said that there are 50-75 parts in the drive. There is neither timing analysis for manufacturing the constituent components nor for the final assembly of the components into the drive. A timing (cost) analysis using Boothroyd and Dewhurst [20], or some similar DFM approach, is really needed to understand where the design can be improved in order to reduce costs. The Boothroyd and Dewhurst method estimates the time it will take to assemble a part. It takes into account part size, orientation, weight, and a variety of other factors to make this assembly time estimation. When one component requires significantly more time to assemble than other components, it is often a candidate for redesign. The Boothroyd and Dewhurst analysis also tries to minimize the number of parts in a design because fewer parts nearly always yield a lower-cost device.

Extend simulation(s) of plant layout. Factory simulation software, e.g., Extend [21], can be used to model the performance of a factory. The simulation can model workstation downtime, e.g., scheduled and unscheduled downtime, production rates, etc. This can be used to help lay out a factory, justify specific equipment, and help in the economic analysis of the factory. This analysis uses the processing times that have to be known by the manufacturer to estimate profit. Any information that is needed by Extend but unavailable is clearly a problem for a manufacturer and must be determined before it is prudent to make a substantial investment in capital equipment. Specifically, two Extend models should be developed. The first is the model of the current way to make an azimuth drive. Once that model is developed and verified, i.e., the model reflects the reality of the current production methods, multiple models of future factories can be explored to determine the specific blend of equipment that balances production costs, expansion for additional orders, cycle time for manufacturing a drive, etc. For example, it is common in Lean Manufacturing to organize production in a cellular layout, as shown in Figure 5-2, where three workers divide the tasks associated with the machines in the cell. If demand were lower, two workers might share the load, while if demand were higher, four workers might be assigned to the cell. This type of manufacturing flexibility can be analyzed in Extend to avoid costly mistakes in purchasing the wrong capital equipment.

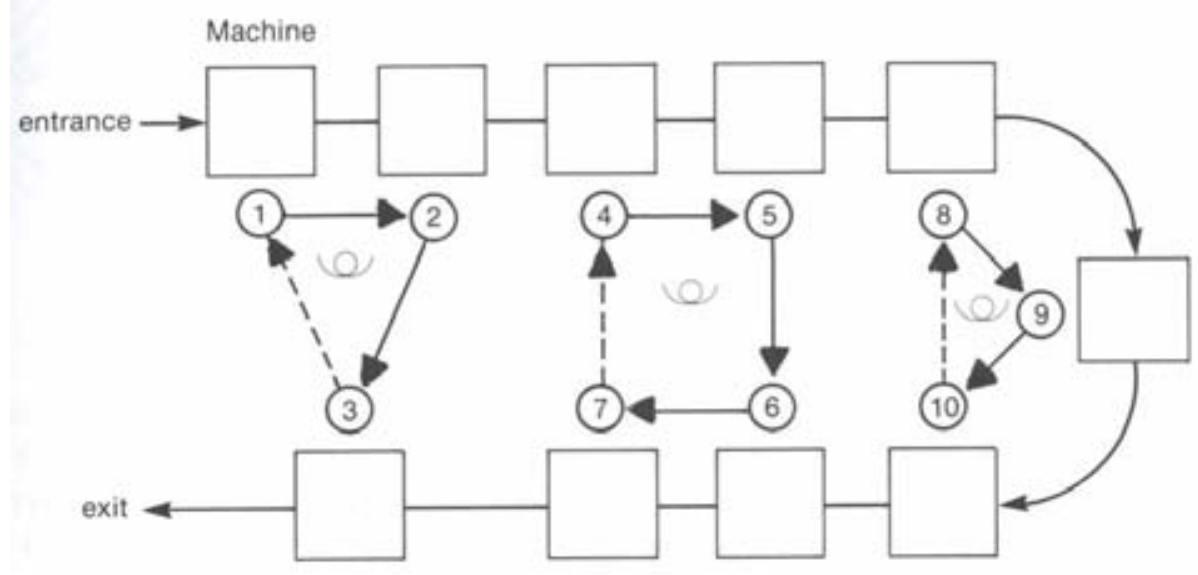

Figure 5-2. Cellular manufacturing concept. 


\section{System Issues}

Standard electronic interface. It would be valuable to launch a project to define a standard interface for heliostats. This could be used for initial installation calibration, debugging, and other data-gathering activities. It would significantly reduce the life-cycle costs of a heliostat if it could be fixed quickly, and this interface could help immensely. Imagine a computer-based analysis analogous to an auto shop analyzer. When not in use, an inexpensive plug is placed in the interface. When in use, the plug is removed and the analyzer is inserted. There is virtually no additional cost (save that of the plug) for a lot of potential value. If all heliostats were required to support a standard interface, lots of time (and therefore money) could be saved.

Standard mechanical interface. As fields of heliostats are developed, maintenance will be required. A study should propose a standard mechanical interface for each of the main components. This will ease replacement/maintenance of drives, mirror components, etc. The results could be distributed as "suggestions" to contractors building the subcomponents of the heliostat. This is a life-cycle cost issue, and costs very little if the study is done a priori. Maintenance becomes increasingly expensive after the fact when each contractor building a system component makes local optimization decisions that impact the entire system maintenance costs. For example, what is the mechanical interface between the pedestal and the azimuth drive that allows the azimuth drive to be removed and replaced in the shortest amount of time?

Communications study. The cost of sending wires from a control tower to each heliostat is an important life-cycle cost. Imagine fixing a broken wire! It could take days to just find it. Twenty years ago, GM claimed that every connector they use in a factory generates $\$ 25$ in repair costs for exactly the same reason: maintenance cost. It seems preferable to update the technology. One alternative is wireless internet communication. The obvious advantage of no wires is balanced by the possibility of interference. Another alternative is to connect each heliostat to a single buried internet cable. Though there is a wire, it can be run in a trough with maintenance access. It will be very difficult to "jam" the signal, as is possible with the wireless approach. The answer, even between these two alternatives, is not obvious. This study will reduce risk as well as cost in the field of heliostat implementation.

\section{Research at Sandia National Laboratories}

Instrumentation project. It would be valuable for Sandia to instrument a couple of heliostats to really understand the relationship with wind since the forces and torques generated by wind are critically important to the design. Measuring the forces and torques generated on the support structures as well as other data coming from the study could provide a more fundamental understanding of heliostat operation. It will become really clear after a year or two how wind really affects the heliostat field. Tests like this are currently planned for the Stirling dish concentrators at Sandia so it should not be difficult to extend this testing to a couple of heliostats. Also, as discussed in Chapter 2, the German national laboratory DLR has recently began to instrument heliostats located at a tower project in Spain.

Large array study. The current 20.5-inch Winsmith drive is probably conservative for the $150-\mathrm{m}^{2}$ heliostat. To reduce risk in early projects, it is a good idea to follow the conservative approach for the mainstream heliostats. However, it might be useful to work with Winsmith and others to determine the largest heliostat size they would consider possible. Heliostat size is 
relatively insensitive to the pedestal and foundation costs, for example. The consequence of this argument is that for heliostats "bigger is better" when it comes to the mirror array. If Sandia were to put a couple of larger heliostats in the field and study them using the instrumentation project just described, there could be a significant benefit with relatively little cost.

\subsection{Conclusions}

Can the azimuth drive do the job? There is no question. The azimuth drive appears to do the job better than any other alternative in the United States.

Is there a lower-risk alternative for the azimuth drive? The answer is simple: no. The Winsmith design has been tested in the field more than any other alternative, and there is no other design that even comes close in terms of use. All other alternatives have higher risk. The Winsmith drive is recommended for the first several power stations even if other alternatives are studied in a research mode during that time.

Can the cost of the azimuth drive be reduced? There is absolutely no question that the cost of the drive decreases significantly with demand. The fundamental reason is that larger demand justifies a dedicated production line, which is a great deal more efficient. However, there is another way to ask this question. Is the price drop for the azimuth drive from $\$ 5700$ to $\$ 3000$ as quantity increases from 5,000 to 50,000 drives per year believable? Here the answer is a qualified yes. To estimate the true savings, an in-depth study of the drive needs to be done. This includes the use of DFM techniques, e.g., Boothroyd and Dewhurst analysis, along with economic analysis of the specific capital equipment required for a dedicated line. However, given the information that is available, the price drop estimated by Winsmith is certainly plausible. 


\section{EVALUATION OF TECHNOLOGY IMPROVEMENT OPPORTUNITIES}

\subsection{Introduction}

Given a production of 50,000 heliostats per year $\left(7,500,000 \mathrm{~m}^{2} / \mathrm{yr}\right)$, the price of the ATS heliostat is estimated in Chapter 3 to be $\$ 126 / \mathrm{m}^{2}$. Given this price, the levelized cost of electricity and hydrogen can be estimated from Table $6-1$. This price is higher than the $\$ 100 / \mathrm{m}^{2}$ goal (discussed in Chapter 1 ) to achieve competitively priced electricity ( $<6$ cents/kWh) and hydrogen $(<\$ 3 / \mathrm{kg})$ from solar power towers.

Table 6-1. Effect of Heliostat Cost on Power Tower Economics. See Chapter 1 for more details.

\begin{tabular}{|c|c|c|}
\hline $\begin{array}{c}\text { Heliostat } \\
\text { Cost }\end{array}$ & $\begin{array}{c}\text { Molten Salt } \\
\text { Power Tower } \\
\text { (S\&L economics) }\end{array}$ & $\begin{array}{c}\text { Hybrid Sulfur } \\
\text { Hydrogen Plant } \\
\text { (H2A economics) }\end{array}$ \\
\hline \hline$\$ 80 / \mathrm{m}^{2}$ & 5.4 cents $/ \mathrm{kWh}$ & $\$ 2.6 / \mathrm{kg}$ \\
\hline$\$ 100 / \mathrm{m}^{2}$ & 5.9 cents $/ \mathrm{kWh}$ & $\$ 2.9 / \mathrm{kg}$ \\
\hline$\$ 150 / \mathrm{m}^{2}$ & 7.3 cents $/ \mathrm{kWh}$ & $\$ 3.5 / \mathrm{kg}$ \\
\hline$\$ 200 / \mathrm{m}^{2}$ & 8.7 cents $/ \mathrm{kWh}$ & $\$ 4.1 / \mathrm{kg}$ \\
\hline$\$ 300 / \mathrm{m}^{2}$ & 12 cents $/ \mathrm{kWh}$ & $\$ 5.4 / \mathrm{kg}$ \\
\hline
\end{tabular}

The $\$ 126 / \mathrm{m}^{2}$ does not include the effect of learning that naturally occurs over a several-year period of deployment. Cost reductions due to learning were estimated by Sargent \& Lundy [1]. As shown in Figure 6-1, the average progress ratio was 92\% during the initial 9-GW deployment of solar power towers over $\sim 16$-year period.

Historical deployments of wind turbines over a similar time period suggest this progress ratio is reasonable. For example, the Danish deployed $10 \mathrm{GW}$ of wind turbines with a progress ratio of 92\% [22] (see Figure 6-2). To a first order, wind turbines and heliostats can be viewed as similar; both are large steel outdoor structures with gear drives.

Given $9 \mathrm{GW}$ of heliostat deployments, there are four doublings of production. Thus, a heliostat that costs $\$ 126 / \mathrm{m}^{2}$ during the initial deployment will cost $(0.92)^{4} * 126=\$ 91 / \mathrm{m}^{2}$ after $9 \mathrm{GW}$. The source of this cost reduction is twofold: technology advancements and manufacturing/installation productivity improvements.

In this chapter we focus on possible technology advancements, otherwise known as TIOs at the DOE. We will show that the TIOs identified during this study could yield $\sim 50 \%$ (or $\sim \$ 17 / \mathrm{m}^{2}$ ) of the expected cost reduction from $\$ 126$ to $\$ 91 / \mathrm{m}^{2}$ during the 9-GW deployment scenario. 


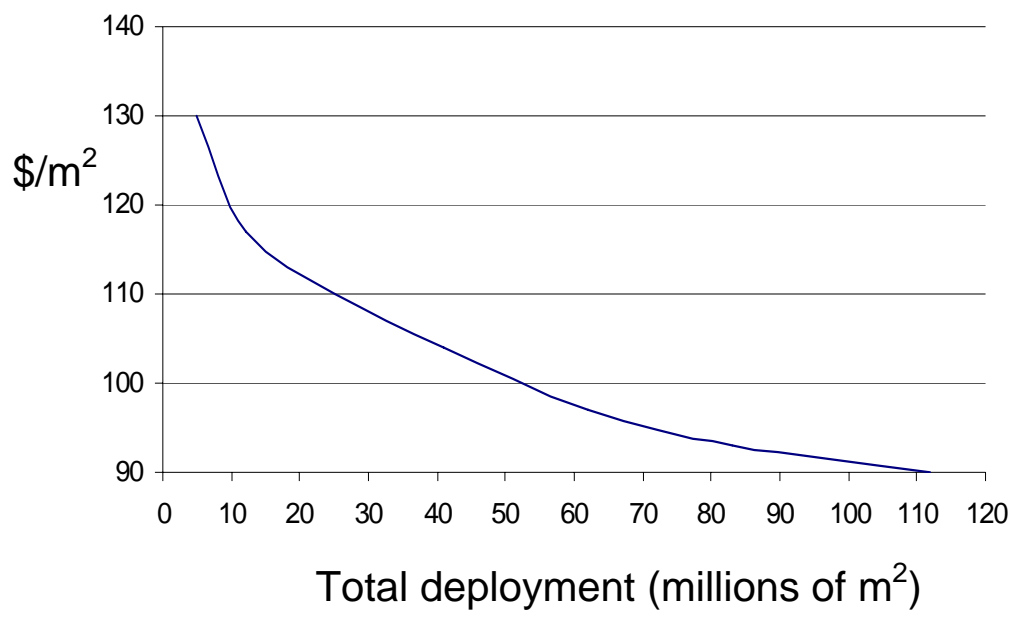

\begin{tabular}{|c|c|c|c|}
\hline $\begin{array}{c}\text { Total } \\
\mathbf{m}^{2}\end{array}$ & $\begin{array}{c}\text { Total } \\
\mathbf{G W}\end{array}$ & $\begin{array}{c}\text { Price } \\
\mathbf{\$} / \mathbf{m}^{2}\end{array}$ & $\begin{array}{c}\text { Progress } \\
\text { Ratio }\end{array}$ \\
\hline \hline $7.5 \mathrm{E} 6$ & 0.55 & 125 & \\
\hline $15 \mathrm{E} 6$ & 1.1 & 115 & $92 \%$ \\
\hline $30 \mathrm{E} 6$ & 2.2 & 108 & $94 \%$ \\
\hline $60 \mathrm{E} 6$ & 4.4 & 98 & $91 \%$ \\
\hline $120 \mathrm{E} 6$ & 8.8 & 90 & $92 \%$ \\
\hline
\end{tabular}

Figure 6-1. Given 50,000 heliostats/yr, S\&L estimated a 92\% progress ratio. Heliostat prices in S\&L are 2002 dollars.

Experience curve for wind turbines installed in Denmark 1981-2000

Progress ratio $92 \%$

$r^{2}=0.81$

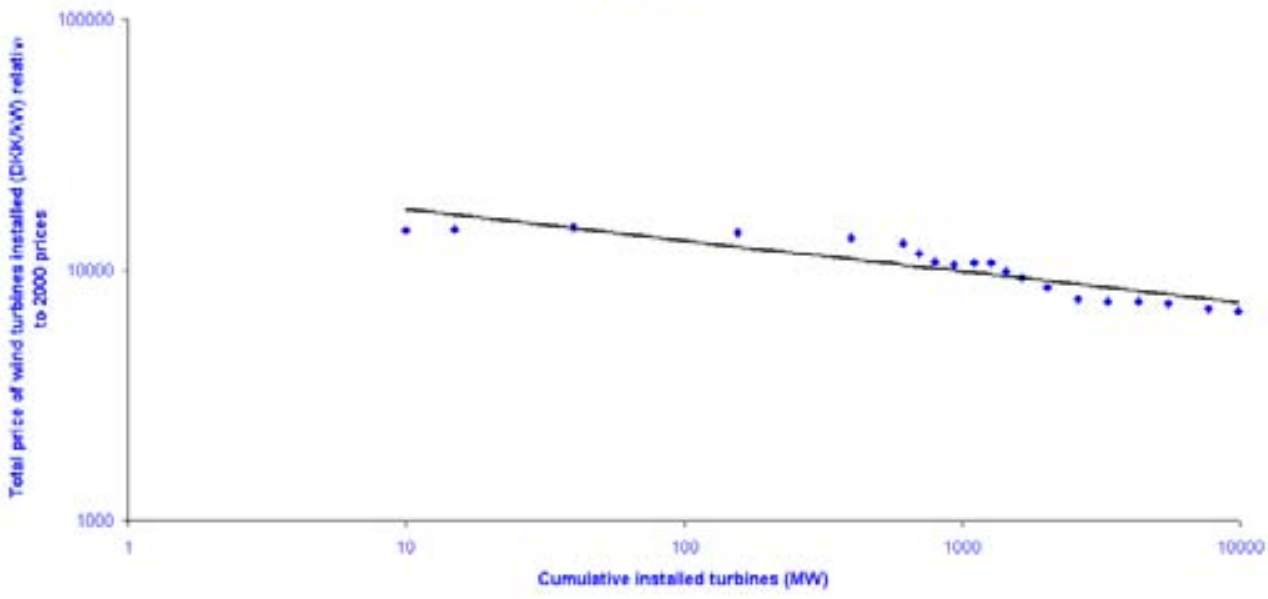

Figure 6-2. Wind turbine learning curve. 
The $50 \%$ cost reduction due to productivity improvements is expected but not analyzed in detail here. However, an example of the many possible improvements can be seen in our analysis. In Chapter 3 we estimate the price of the ATS to be $\$ 164 / \mathrm{m}^{2}$ given a deployment scenario of $5000 / y r$. This is significantly higher than the $\$ 126$ value given $50,000 / y r$. The higher price is primarily due to the drives; at the lower production rate, less automation is used in the drive factory. ${ }^{12}$ It should also be noted that the price of $\$ 164 / \mathrm{m}^{2}$ is reasonably consistent with the $\$ 126$ value, given a $92 \%$ progress ratio. ${ }^{13}$

\subsection{Identification of TIOs}

TIOs were identified within brainstorming sessions involving 30 participants attending the first workshop. Three separate sessions focused on glass/metal heliostats, SM heliostats, and innovative concepts. The one-to-two-hour sessions were facilitated by two manufacturing experts (Ron Lumia and Matt Donnelly).

The facilitators presented the goal of the brainstorming, "to reduce the capital and O\&M cost of the heliostat," and provided opening questions for the group to consider. The opening questions are listed below.

\section{Glass/Metal Brainstorm}

- What are the biggest technological problems that need to be solved to make glass/metal heliostats economically viable?

- Which components of the heliostat offer the greatest potential for cost reduction?

- What is the most economically viable way to manufacture the glass/metal array?

- Which manufacturing technologies offer the greatest potential for cost reduction (given a suitable volume)?

- Would offshore outsourcing help reduce costs? All components or only some?

\section{SM Brainstorm}

- What are the biggest technological problems that need to be solved to make SM heliostats economically viable?

- What are the best materials for stretched membrane?

- What are the alternative technologies available to fabricate the stretched membrane? Which is the most economically viable?

- What are the pros and cons of SM vs. GM heliostats?

- Is the SM heliostat fundamentally less costly than the glass metal/heliostat? If so, by how much?

12 Personal communication from George Tedesco, Winsmith, 2006.

13 Assuming the initial deployment is 5000 heliostats $\left(750,000 \mathrm{~m}^{2}\right)$, after three doublings the total deployment will be $6,000,000 \mathrm{~m}^{2}$ and the expected price would be $(0.92)^{3} * 164=\$ 128 / \mathrm{m}^{2}$. This is similar to the value of $\$ 126 / \mathrm{m}^{2}$ we calculate assuming an initial deployment of 50,000 heliostats $\left(7,500,000 \mathrm{~m}^{2}\right)$. 


\section{Innovative Concepts Brainstorm}

- Is the pedestal mount the best approach? Are there better alternatives?

- Are ball-jack screw elevation and planocentric azimuth the best drives? Are there better alternatives?

- Does closed-loop control offer advantages over the current open-loop approach?

- Which materials are the "best" reflectors? Is there the possibility of cost reduction with a new material?

- What new technologies are on the horizon for heliostats?

At the end of each brainstorming session, each participant was asked to vote up to 10 times on the ideas he liked best. The participant was given freedom to vote any way he wanted. For example, all 10 votes could be placed on one idea or the votes could be distributed among more than one idea. The TIOs identified in the brainstorming and the results of the voting are shown in Tables 6-2 through 6-4.

Table 6-2. Glass Metal TIOs

\begin{tabular}{|l|c|c|}
\hline & Score & \% \\
\hline 1. Develop volume mfg for drives & 10 & $6 \%$ \\
\hline 2. Explore outsource of drives to China & 6 & $\mathbf{4} \%$ \\
\hline 3. Explore whether drive specs are too conservative & $\mathbf{2 1}$ & $\mathbf{1 2 \%}$ \\
\hline 4. Reduce load specs for inner heliostats vs. heliostats on edge of field & 21 & $12 \%$ \\
\hline $\begin{array}{l}\text { 5. Heliostat designer and drive designer work together to minimize } \\
\text { drive cost }\end{array}$ & $\mathbf{3 2}$ & $\mathbf{1 9 \%}$ \\
\hline 6. Use brake to loosen drive backlash spec & $\mathbf{2 4}$ & $\mathbf{1 4 \%}$ \\
\hline 7. Explore how to build business volume for drives & $\mathbf{1 6}$ & $\mathbf{9 \%}$ \\
\hline 8. Explore separating overturning moment from drive requirements & 0 & $0 \%$ \\
\hline 9. Study "pipe-in-pipe" drive concept & $\mathbf{3 0}$ & $\mathbf{1 8 \%}$ \\
\hline $\begin{array}{l}\text { 10. Compare base case torque tube mirror support structure to a radial- } \\
\text { support structure }\end{array}$ & $\mathbf{9}$ & $\mathbf{5 \%}$ \\
\hline $\begin{array}{l}\text { 11. Explore low-cost tooling options for mirror modules and study volume } \\
\text { mfg of mirror modules }\end{array}$ & 2 & $\mathbf{1 \%}$ \\
\hline
\end{tabular}


Table 6-3. Stretched-Membrane TIOs

\begin{tabular}{|l|c|c|}
\hline & Score & $\%$ \\
\hline 1. Study cost of single large module vs. many small modules & $\mathbf{2 9}$ & $\mathbf{2 2 \%}$ \\
\hline 2. Compare pedestal-drive system to alternative drive concepts & $\mathbf{2 3}$ & $\mathbf{1 8 \%}$ \\
\hline 3. For carousel-type drive, explore pre-cast, truckable concrete bases & $\mathbf{2 3}$ & $\mathbf{1 8 \%}$ \\
\hline $\begin{array}{l}\text { 4. For carousel-type drive, study process for compensating for uneven } \\
\text { concrete base }\end{array}$ & $\mathbf{5}$ & $\mathbf{4 \%}$ \\
\hline 5. Evaluate three-point ground-mounted drive concept & 12 & $9 \%$ \\
\hline 6. Study ballasted SM heliostat & 8 & $6 \%$ \\
\hline $\begin{array}{l}\text { 7. Find source or develop capability to use wider stainless steel strips } \\
\text { to make SM }\end{array}$ & 7 & $5 \%$ \\
\hline $\begin{array}{l}\text { 8. Study use of an impregnated fabric as the membrane instead of } \\
\text { stainless steel }\end{array}$ & $\mathbf{1 8}$ & $\mathbf{1 4 \%}$ \\
\hline $\begin{array}{l}\text { 9. Study use of a polymer sheet (covered with glass) as the membrane } \\
\text { instead of stainless steel }\end{array}$ & 6 & $5 \%$ \\
\hline
\end{tabular}

Table 6-4. Innovative Concepts TIOs

\begin{tabular}{|l|c|c|}
\hline & Score & $\%$ \\
\hline 1. NM Tech water-ballasted heliostat & $\mathbf{2 0}$ & $\mathbf{1 3 \%}$ \\
\hline $\begin{array}{l}\text { 2. Review material choices that may become viable with changing } \\
\text { prices }\end{array}$ & $\mathbf{3 1}$ & $\mathbf{2 1 \%}$ \\
\hline 3. Mega-heliostat systems study (>300 $\mathbf{~ m 2 )}$ & $\mathbf{2 2}$ & $\mathbf{1 5 \%}$ \\
\hline 4. Improve systems-level modeling software & 2 & $\mathbf{1 \%}$ \\
\hline 5. Hydraulic-drive study & $\mathbf{2 0}$ & $\mathbf{1 3 \%}$ \\
\hline $\begin{array}{l}\text { 6. Study latest closed-loop control options including signal mirror } \\
\text { technology }\end{array}$ & $\mathbf{2 5}$ & $\mathbf{1 7 \%}$ \\
\hline 7. Review Francia drive principles for advantages & 9 & $6 \%$ \\
\hline 8. Use of bubbles or green-house concepts to protect heliostats from wind & 0 & $0 \%$ \\
\hline 9. Coat mirrors with SuNyx to eliminate mirror washing & 20 & $13 \%$ \\
\hline
\end{tabular}

\subsection{Evaluation of TIOs}

In the months following the initial workshop, the heliostat cost-reduction team evaluated the TIOs. The goals of this evaluation were to:

1. Propose future R\&D projects that address the lion's share of the TIOs.

2. Estimate expected reduction in heliostat cost resulting from each R\&D project.

3. Estimate the cost of performing the R\&D for each project.

4. Rank the proposed R\&D projects given different possible DOE funding scenarios to identify the projects that give the "most bang for the buck."

As shown in Table 6-5, the team identified seven possible projects that address $76 \%$ (227/300, Bolded TIOs) of the possible voting points from the brainstorming group. 
Table 6-5. Possible R\&D Projects Suggested by Brainstorming

\begin{tabular}{|c|c|c|l|}
\hline $\begin{array}{c}\text { R\&D } \\
\text { Project \# }\end{array}$ & $\begin{array}{c}\text { TIOs } \\
\text { Addressed }\end{array}$ & $\begin{array}{c}\text { TIO Score } \\
\text { \% }\end{array}$ & \multicolumn{1}{|c|}{ Prototype Hardware Developed } \\
\hline \hline 1 & SM1 & 22 & $\begin{array}{l}\text { Large }\left(150-\mathrm{m}^{2}\right) \text { single metal-based stretched- } \\
\text { membrane facet }\end{array}$ \\
\hline 2 & $\mathrm{GM} 3 / 5 / 6 / 7$ & 54 & $\begin{array}{l}\text { Less-conservative, high-volume, pedestal- } \\
\text { mounted azimuth drive }\end{array}$ \\
\hline 3 & $\mathrm{GM} 9$ & 18 & Pipe-in-pipe azimuth drive \\
\hline 4 & $\mathrm{SM} 2 / 3 / 4$ & 40 & Large $\left(150-\mathrm{m}^{2}\right)$ carousel-type SM heliostat \\
\hline 5 & $\mathrm{SM} 8 / \mathrm{IC} 2$ & 35 & Large $\left(150-\mathrm{m}^{2}\right)$ single-fabric-based SM facet \\
\hline 6 & $\mathrm{IC} 3 / 5$ & 28 & $\begin{array}{l}\text { Transform large }\left(>300-\mathrm{m}^{2}\right) \text { APS PV tracker to a } \\
\text { heliostat }\end{array}$ \\
\hline $7^{*}$ & $\mathrm{IC} 1 / 6$ & 30 & $\begin{array}{l}\text { NM Tech water-ballasted heliostat with closed- } \\
\text { loop control }\end{array}$ \\
\hline Total & & $\mathbf{2 2 7}$ & \\
\hline
\end{tabular}

The proposed R\&D projects are discussed in the paragraphs that follow. The potential cost reductions for the projects are summarized in Table 6-6. The cost reductions resulting from the R\&D projects are judged relative to the cost of the current $148-\mathrm{m}^{2}$ ATS heliostat. This is the base-case heliostat modeled in the Sargent \& Lundy study [1] and a prototype has successfully operated at Sandia since the late 1980s.

Project 1 - Large SM facet

In this project a large $\left(150-\mathrm{m}^{2}\right)$ stretched-membrane facet is developed that can be integrated into a pedestal-type heliostat. In the United States, only $50-\mathrm{m}^{2}$ facets have been built (see Section 3.6). Scale-up to $150 \mathrm{~m}^{2}$ was proposed to reduce cost on a $\$ / \mathrm{m}^{2}$ basis. In effect, the ATS glass/metal structure and mirror modules above the drive would be replaced with a single SM mirror module. Early evaluations in the 1980s suggested this type of heliostat would result in a heliostat that cost $20 \%$ less than the GM heliostat. However, analysis presented in Section 3.6 indicates that this type of SM heliostat actually results in a higher cost. This project is therefore eliminated from further consideration.

Project 2 - Less-conservative azimuth drive

As described in Section 5.2, the azimuth drive is the most significant heliostat cost contributor, especially at low production volumes (5000/yr). During the brainstorming, Winsmith stated that the design of their "gear-type" azimuth drive may be too conservative and that a lessconservative, less-costly drive might be developed if Winsmith could get a better understanding of the wind loads and torques on the heliostat drive. Significant cost reduction can also be achieved through highly automated production-line manufacturing techniques. A production line does not currently exist. This R\&D project would provide a detailed price estimate for a lessconservative gear-type azimuth drive given differing amounts of manufacturing automation. A $33 \%$ price reduction is targeted. If detailed analysis indicates this target can be achieved, a new prototype drive would be built and tested. 
Table 6-6. Price Reduction Potential Resulting from Proposed Heliostat R\&D Projects

\begin{tabular}{|c|c|c|c|c|}
\hline \multirow{2}{*}{$\#$} & \multirow{2}{*}{ Name } & \multicolumn{3}{|c|}{ Price Reduction Potential } \\
\hline & & Point Estimate & Optimistic Bound & Pessimistic Bound \\
\hline 1 & Large SM facet & $\begin{array}{l}\$-6 / \mathrm{m}^{2} \\
\text { Increase hardware cost } \\
\text { by } \$ 16 / \mathrm{m}^{2} \text {. Performance } \\
\text { improvement is } \$ 10 / \mathrm{m}^{2} \text {, } \\
\text { for a net of } \$-6 / \mathrm{m}^{2} \text {. }\end{array}$ & NON-STARTER & NON-STARTER \\
\hline 2 & $\begin{array}{l}\text { Less-conservative, } \\
\text { high-volume azimuth } \\
\text { drive }\end{array}$ & $\begin{array}{l}\$ 8 / \mathrm{m}^{2} \# \\
\text { Reduce az drive price } \\
\text { from } \$ 3000 \text { to } \$ 2000 \text {. }\end{array}$ & $\begin{array}{l}\frac{\$ 12 m^{2} \#}{\text { Assume price cut in }} \\
\text { half to } \$ 1,500 \text {. }\end{array}$ & $\begin{array}{l}\frac{\$ 2 / \mathrm{m}^{2}}{\text { At least a small amount }} \\
\text { of price reduction is } \\
\text { likely. }\end{array}$ \\
\hline 3 & $\begin{array}{l}\text { Pipe-in-pipe azimuth } \\
\text { drive }\end{array}$ & $\begin{array}{l}\$ 8 / \mathrm{m}^{2 \#} \\
\text { Thin-wall pipe }+ \\
\text { bushings }+ \text { gears might } \\
\text { cost } \$ 2000 .\end{array}$ & $\begin{array}{l}\$ 12 \mathrm{~m}^{2 \#} \\
\text { Optimized design } \\
\text { might cost } \$ 1,500 .\end{array}$ & $\begin{array}{l}-\$ 5 / \mathrm{m}^{2} \\
\text { Price may be higher } \\
\text { than existing az drive. } \\
\text { Solar Systems PTY has } \\
\text { experience with } p \text {-in-p } \\
\text { but is pursuing } \\
\text { alternative approaches. }\end{array}$ \\
\hline 4 & Carousel SM heliostat & $\begin{array}{l}\$ 23 / \mathrm{m}^{2} \\
\text { PSA estimated } 20 \% \text { cost } \\
\text { reduction relative to } \\
\text { Spanish glass/metal } \\
\text { heliostat. We take } 10 \% \\
\text { reduction plus } \$ 10 \\
\text { performance } \\
\text { improvement. Weight is } \\
\sim 50 \% \text { less than ATS. }\end{array}$ & $\begin{array}{l}\frac{\$ 28 / \mathrm{m}^{2}}{\text { Assume 20\% better }} \\
\text { than point estimate. }\end{array}$ & $\begin{array}{l}\frac{-\$ 13 / m^{2}}{D L R} \text { and Solucar stated } \\
\text { that first-gen carousel } \\
\text { approaches are more } \\
\text { expensive. Complex } \\
\text { foundation appears } \\
\text { partly to blame. } \\
\text { Assume } 10 \% \text { higher } \\
\text { price than ATS. }\end{array}$ \\
\hline 5 & Large fabric SM facet & $\begin{array}{l}\$ 8.5 / \mathrm{m}^{2 \#} \\
\text { Fabric plus hoop-in-hoop } \\
\text { assembly reduces cost } \\
\text { of mirror module by } \\
\$ 7 / \mathrm{m} 2 \text {. Combine with } \\
\text { Project } 4 \text {. }\end{array}$ & $\begin{array}{l}\$ 10 / \mathrm{m}^{2 \#} \\
\text { Assume } 10 \% \text { better } \\
\text { than point estimate. }\end{array}$ & $\begin{array}{l}\frac{0 / \mathrm{m}^{2}}{\text { Fabric combined with }} \\
\text { hoop-in-hoop facet may } \\
\text { not be cheaper than } \\
\text { conventional metal } \\
\text { membrane approach. }\end{array}$ \\
\hline 6 & Mega heliostat & $\begin{array}{l}\$ 16 / \mathrm{m}^{2} \\
\frac{\text { Increase total heliostat }}{\text { price by }(320 / 148) 0.8 \text {. }} \\
\text { Total price }=1.85 * \text { ATS } \\
=\$ 34,600 \text {. This is } \\
\$ 108 / \mathrm{m}^{2} \text { or } \$ 18 / \mathrm{m}^{2} \text { less } \\
\text { than ATS. Subtract } \\
\$ 2.5 / \mathrm{m}^{2} \text { optics penalty. }\end{array}$ & $\begin{array}{l}\frac{\$ 19 / \mathrm{m}^{2}}{\text { Assume } 20 \% \text { better }} \\
\text { than point estimate. }\end{array}$ & $\begin{array}{l}\frac{-\$ 10 / m^{2}}{\text { Mega-helio with }} \\
\text { hydraulic drives may } \\
\text { cost more than ATS. }\end{array}$ \\
\hline
\end{tabular}

\# Price reduction includes overhead/profit of 20\%. For example, Project 2 reduces drive price by $\$ 1,000$ or $1,000 / 147=\$ 6.8 / \mathrm{m}^{2}$. Heliostat manufacturer adds $20 \%$ to this for a price of $\$ 8.2 / \mathrm{m}^{2}$. 
Project 3 - Pipe-in-pipe azimuth drive

As described in Section 5.2, the azimuth drive is the most significant cost contributor, especially at low production volumes (5000/yr). The brainstorming group explored different approaches to the conventional gear-type drive historically built by Winsmith and Flender. At the White Cliffs plant in Australia (Figure 6-3), a pipe-in-pipe approach was successfully used to position relatively small $\left(\sim 7-\mathrm{m}^{2}\right)$ solar dishes. In this concept, azimuth motion is achieved by rotating a pipe within the fixed pedestal. The driving motor is located at the bottom of the pedestal and the wind loads on the drive are distributed along the length of the pipes, as opposed to a single point within the Winsmith. Cost reductions relative to a gear-type drive appear feasible because manufacturing of the pipe-in-pipe could be simpler. This R\&D project would provide a detailed price estimate for pipe-in-pipe drive that is suitable for a $150-\mathrm{m}^{2}$ heliostat. A $33 \%$ price reduction relative to the current Winsmith azimuth drive is targeted. If detailed analysis indicates this target can be achieved, a new prototype drive would be built and tested.
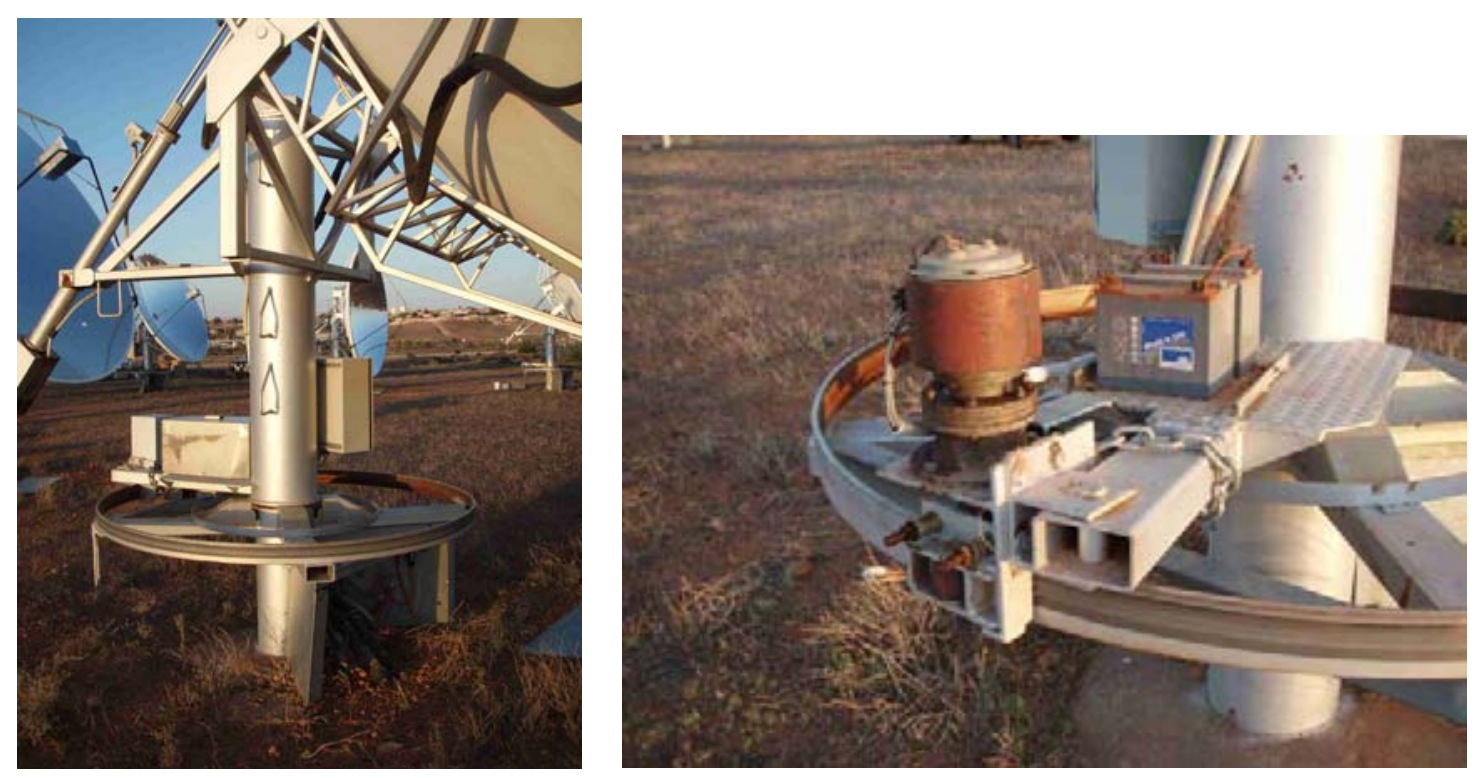

Figure 6-3. The "pipe-in-pipe" azimuth drives at White Cliffs required little maintenance during the 17-year operating history of the plant.

Project 4 - Large carousel-type SM heliostat

A large $\left(150-\mathrm{m}^{2}\right)$ heliostat like this has been operating at Plataforma Solar de Almeria, Spain, for 10 years (called ASM-150, see Figure 2-10). The optical performance of this heliostat is significantly better than the ATS glass/metal type. According to the DELSOL analysis presented in Chapter 4, this optical advantage is worth $\sim \$ 10 / \mathrm{m}^{2}$. In addition, analysis conducted in the 1990s [9] indicates the cost of this heliostat should be significantly lower than a glass/metal heliostat built by a Spanish company. However, a few in the brainstorming group suggested the concrete foundation for the ASM-150 is too complex and costly. The group then explored ideas on how to drastically reduce the cost of the foundation. Precast concrete foundations that "roll off a truck" were thought to be a possible low-cost solution. This R\&D project would provide a detailed price estimate for a large carousel-type SM heliostat with a low-cost foundation. A 
$>10 \%$ capital cost reduction relative to the ATS is targeted. This appears feasible because it weighs $\sim 50 \%$ less than the ATS. Combining this with the performance improvement of $\sim \$ 10 / \mathrm{m}^{2}$ should result in an overall cost reduction of $\sim 20 \%$. If detailed analysis indicates this target can be achieved, a new prototype drive would be built and tested.

Project 5 - Large single-fabric-based SM facet

As described in Section 3.6, today's SM facets are created by welding multiple strips of stainless steel across a ring. The welding process is complex and cumbersome. The brainstorming group thought that significant cost reduction for the facet could be achieved if the stainless steel strips were replaced with a single large piece of fabric. Besides eliminating expensive stainless steel, connection to the outer ring could be greatly simplified by using an "embroidery-hoop" method, i.e., two concentric hoops are press-fit together to form the connection between the material and the ring. The fabric must not leak air to maintain the vacuum within the facet plenum. Thus, the fabric would need to be impregnated with a sealer. This R\&D project would provide a detailed price estimate for a large fabric facet. Rough calculations suggest this facet could lead to an additional cost reduction of $\sim \$ 7 / \mathrm{m}^{2}$ relative to the carousel heliostat described in Project 4 . If detailed analysis indicates this target can be achieved, a new fabric-based facet would be built and tested.

\section{Project 6 - Mega heliostat}

Arizona Public Service currently operates several large-area two-axis PV concentrators. The largest is $\sim 320 \mathrm{~m}^{2}$ (see Figure 6-4). This device could be converted to a heliostat by replacing the Fresnel-PV modules with mirrors. At this size the use of hydraulic type azimuth and elevation drives appears to be justified. The brainstorming group generally concluded that hydraulic drive systems are more complex and require more maintenance than mechanical drive systems. However, they are very strong and could be the preferred low-cost approach for mega heliostats. This R\&D project would provide a detailed price estimate for a mega heliostat greater than $300 \mathrm{~m}^{2}$ in size. Engineering scaling laws indicate the cost of this heliostat could be $\$ 21 / \mathrm{m}^{2}$ less than the $148-\mathrm{m}^{2}$ ATS heliostat. However, the optical quality of the mega heliostat will be worse than the ATS because the reflected beam will be larger. DELSOL calculations presented in Chapter 4 predict the optical penalty is $\sim \$ 3 / \mathrm{m}^{2}$. Thus, the net cost reduction is $\sim \$ 18 / \mathrm{m}^{2}$.
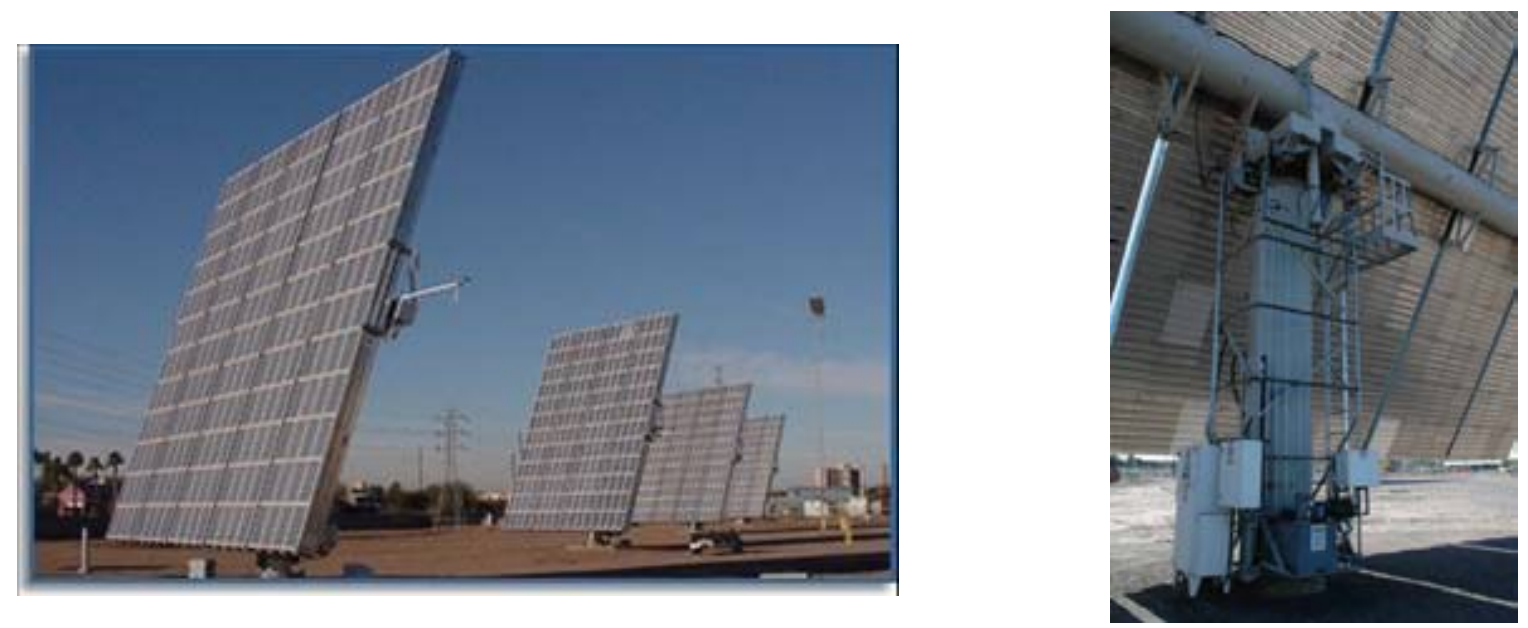

Figure 6-4. The 320- $m^{2}$ PV trackers at APS use hydraulic drives. 


\section{Project 7 - Water-ballasted heliostat}

Students at New Mexico Tech are exploring innovative "water-ballasted" heliostats. Heliostat tracking is achieved by pumping water between chambers located on the back of the mirror. This eliminates the use of costly gear drives. Two different approaches are been investigated (see Figure 6-5). In the rolling ball concept, flexure of the ball structure and ground-surface irregularities will result in pointing errors that will require correction by use of a closed-loop control system. A few in the brainstorming group suggested that signal-mirror technology can be used to close the loop (see Figure 6-6). After the initial heliostat workshop, NM Tech began to investigate a non-ball approach. Water is still pumped between chambers, but the mirror does not move until electric brakes are released at the pivots. NM Tech has their own funding from EPA to explore these concepts. SAIC has given NM Tech several 8- $\mathrm{m}^{2} \mathrm{SM}$ facets and Sandia is part of the review committee. We will keep abreast of their progress. No DOE funding is requested at this time.
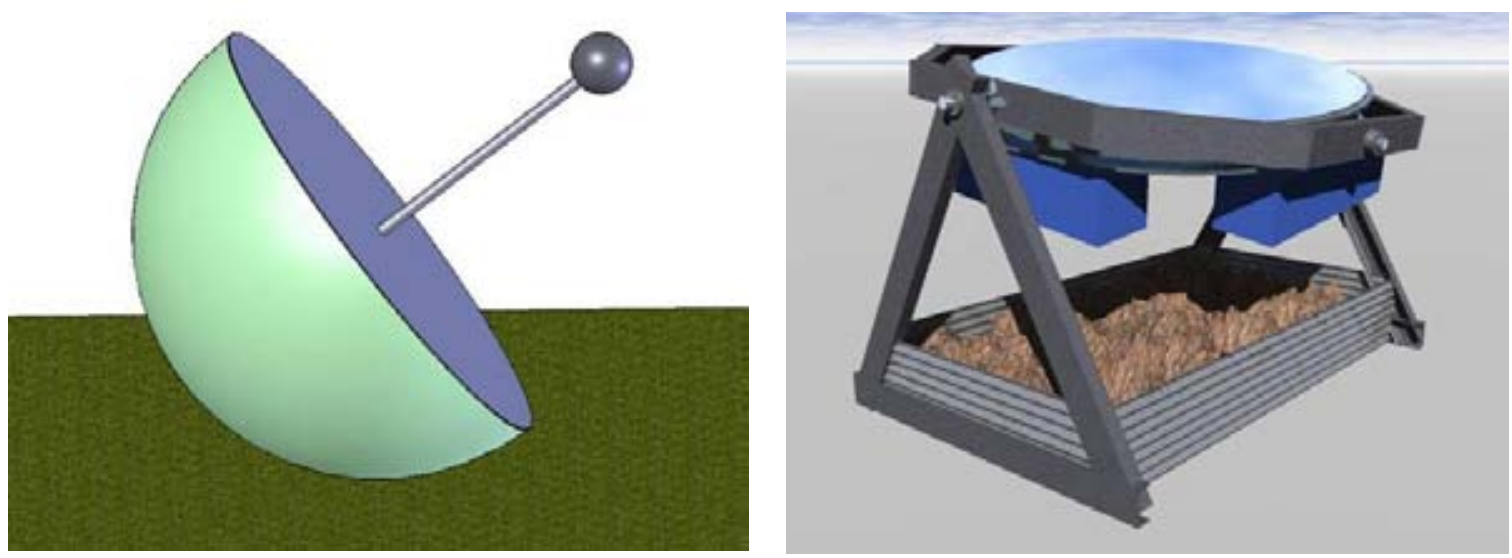

Figure 6-5. NM Tech water-ballasted heliostats. The heliostats are moved by pumping water between internal chambers. The ball at the end the post is a counterweight.
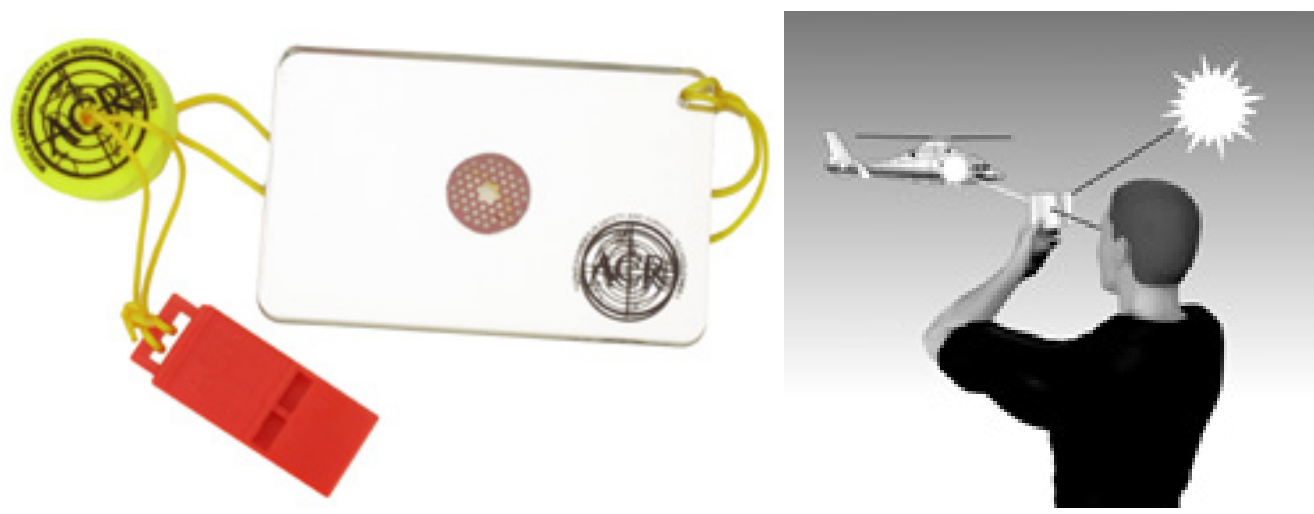

Figure 6-6. A signal mirror combined with an optical camera (instead of man) could be used to accurately reflect the suns rays from a heliostat to the receiver target (instead of helicopter). ${ }^{14}$

14 http://www.acrelectronics.com/hotshot/hotshot.html 


\subsection{Project Selection Given Uncertainty and a Constrained R\&D Budget}

As seen in Table 6-6, the price reductions from the proposed heliostat R\&D projects are highly uncertain. For each project a point estimate, an optimistic bound, and a pessimistic bound are described. It can be noted that in some cases the pessimistic bound is negative. This means that heliostat price could actually increase, relative to the base-case ATS heliostat.

Triangular distributions were used to model the uncertainty associated with price-reduction potential. For example, the distribution for the pipe-in-pipe drive project is shown in Figure 6-7.

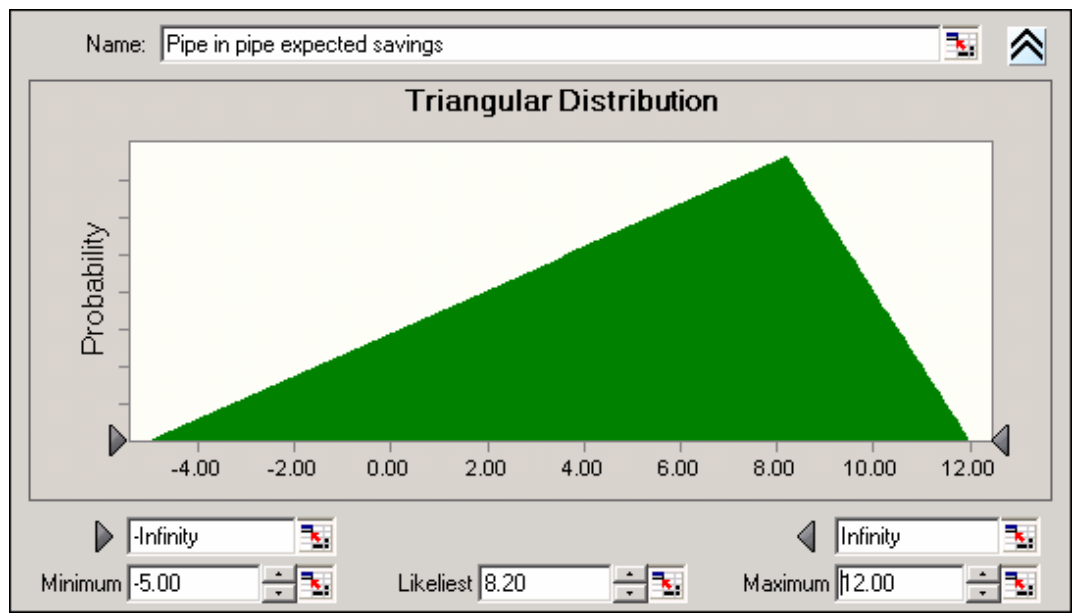

Figure 6-7. The pipe-in-pipe azimuth drive is expected to reduce heliostat price by $\$ 8 / \mathrm{m}^{2}$. Optimistically, the price could be reduced by $\$ 12 / \mathrm{m}^{2}$ Pessimistically, heliostat price could increase by $\$ 5 / \mathrm{m}^{2}$.

Since the purpose of $R \& D$ is to reduce uncertainty, the bounds will shrink as the work progresses. However, given our current state of knowledge, we need to decide which R\&D projects should be given highest priority. If money was no object, all the projects could be pursued. However, we live in a world of limited R\&D budgets and need to identify those that will give the "most bang for the buck." This is common problem faced by many R\&D organizations. Fortunately, there are tools available to help the decision maker.

Crystal Ball software [23] is being used by USDOE and many other organizations to assess the risk/uncertainty of achieving the goals of proposed R\&D projects. ${ }^{15}$ Crystal Ball is a software add-on to EXCEL-based models. Uncertain parameters are propagated via Monte Carlo simulation. The software identifies the model parameters that have the largest impact on overall uncertainty. In addition, many pre-programmed models exist that can be adapted to solve a particular problem. One such model, "Budget-Constrained Project Selection," was adapted to solve the problem at hand. Besides the uncertainty estimates expressed in Table 6-6, the model

15 DOE's wind turbine program has also ranked wind TIOs using Crystal Ball and triangular distributions. 
requires the user to define (1) a forecast function, (2) R\&D prototype success probability, and (3) cost of each $\mathrm{R} \& \mathrm{D}$ project.

\section{Forecast function}

A mathematical expression is written to describe the problem to solve. In words, this function states that "we want to develop the future heliostat that leads to the maximum cost reduction." Projects 2 through 6 can lead to five different types of future, lower-cost heliostats. ${ }^{16}$ Projects 2 or 3 would lead to an incremental improvement to the ATS. Project 4, or Projects 4 and 5, or Project 6 would lead to a totally new heliostat. In EXCEL, this price reduction is expressed as $\operatorname{MAX}(2,3,4,(4+5), 6)$.

\section{$R \& D$ prototype success probability}

This is the probability the project will develop hardware that meets design specifications and will not fail within several years. Our subjective assessment for each of the hardware items is presented in Table 6-7. The project with the highest risk of failure is the fabric facet, since nothing similar to this has ever been done before. Crystal Ball expresses this uncertainty as a Bernoulli (Yes/No) distribution (Figure 6-8).

Table 6-7. R\&D Prototype Success Probability

\begin{tabular}{|c|c|l|}
\hline $\begin{array}{c}\text { Hardware Success } \\
\text { Probability }\end{array}$ & $\begin{array}{c}\text { Project } \\
\#\end{array}$ & \multicolumn{1}{c|}{$\begin{array}{c}\text { Prototype } \\
\text { Hardware Developed }\end{array}$} \\
\hline \hline $90 \%$ & 2 & Less-conservative, high-volume, pedestal-mounted azimuth drive \\
\hline $90 \%$ & 3 & Pipe-in-pipe azimuth drive \\
\hline $80 \%$ & 4 & Large $\left(150-\mathrm{m}^{2}\right)$ carousel-type SM heliostat \\
\hline $50 \%$ & 5 & Large $\left(150-\mathrm{m}^{2}\right)$ single-fabric-based SM facet \\
\hline $90 \%$ & 6 & Transform large $\left(>300-\mathrm{m}^{2}\right)$ APS PV tracker to a heliostat \\
\hline
\end{tabular}

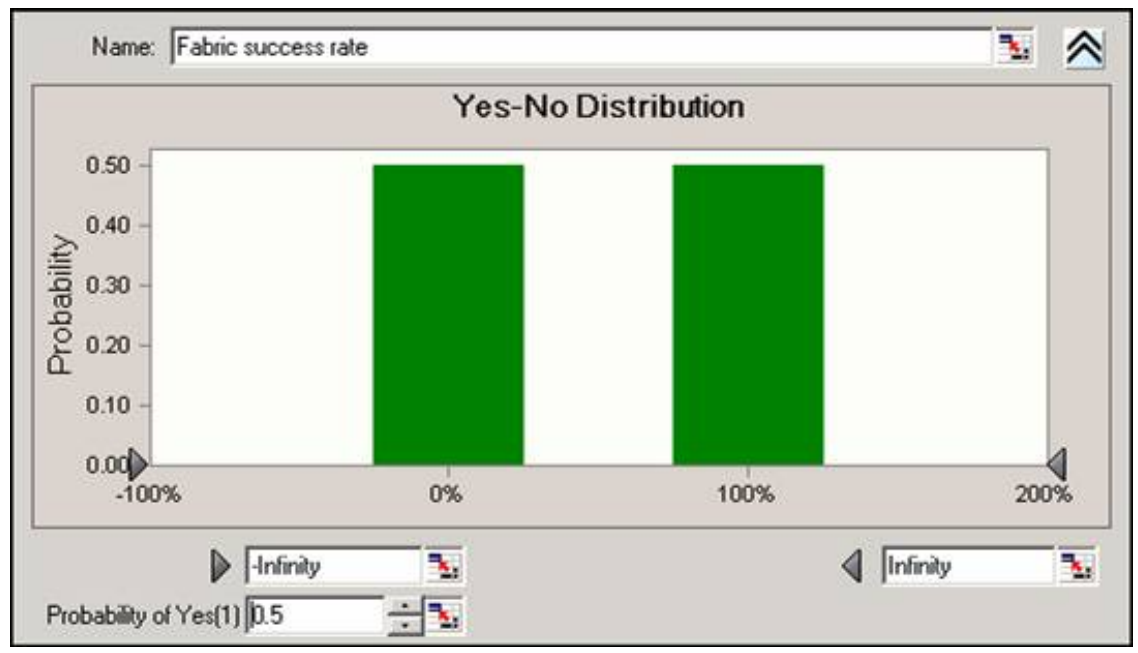

Figure 6-8. Bernoulli or Yes/No Distribution

16 Project 1 was eliminated because our point estimate suggested that heliostat price would increase, relative to the ATS. 
It is instructive to perform a hand calculation to get a feel for how the Crystal Ball model works. In the Table 6-8, we calculate price reduction based on only the point estimates (i.e., we ignore the uncertainties). The "expected return" is calculated by multiplying columns 2 and 3 . The MAX function operates upon the expected return column. Thus, MAX(2,3,4,(4+5),6) yields a value of $\$ 22.6 / \mathrm{m}^{2}$. By inspection we see this value is the combination of Projects $4+5$. Crystal Ball performs a similar calculation but also includes the uncertainties.

Table 6-8. Expected Return of R\&D Based on Point Estimates

\begin{tabular}{|c|c|c|c|l|}
\hline & $\begin{array}{c}\text { Cost Reduction } \\
\text { Point Estimate }\end{array}$ & $\begin{array}{c}\text { Hardware } \\
\text { Success Probability }\end{array}$ & $\begin{array}{c}\text { Expected } \\
\text { Return }\end{array}$ & $\begin{array}{c}\text { Prototype Hardware } \\
\text { Developed }\end{array}$ \\
\hline \hline 2 & $\$ 8.2 / \mathrm{m}^{2}$ & $90 \%$ & $\$ 7.4 / \mathrm{m}^{2}$ & Less-conservative drive \\
\hline 3 & $\$ 8.2 / \mathrm{m}^{2}$ & $90 \%$ & $\$ 7.4 / \mathrm{m}^{2}$ & Pipe-in-pipe azimuth drive \\
\hline 4 & $\$ 23 / \mathrm{m}^{2}$ & $80 \%$ & $\$ 18.4 / \mathrm{m}^{2}$ & Carousel-type SM heliostat \\
\hline 5 & $\$ 8.4 / \mathrm{m}^{2}$ & $50 \%$ & $\$ 4.2 / \mathrm{m}^{2}$ & Fabric SM facet \\
\hline 6 & $\$ 16 / \mathrm{m}^{2}$ & $90 \%$ & $\$ 14.4 / \mathrm{m}^{2}$ & Mega-Helio \\
\hline
\end{tabular}

Cost of $R \& D$ projects

Sandia experience suggests a typical heliostat R\&D project requires $\$ 500 \mathrm{~K}$ to $\$ 700 \mathrm{~K}$ to $\underline{D}$ esign, plus one to two times this amount to Build a prototype. The following rules were used to develop the cost estimates displayed in Table 6-9.

- $\$ 1 \mathrm{M}=0.5 \mathrm{D}+0.5 \mathrm{~B}$, Relatively simple device and something similar done in the United States before

- $\$ 1.5 \mathrm{M}=0.5 \mathrm{D}+1.0 \mathrm{~B}$, Relatively simple device and something similar not done in the United States before

- $\quad \$ 1.4 \mathrm{M}=0.7 \mathrm{D}+0.7 \mathrm{~B}$, Relatively complex device and something similar done in the United States before

- $\quad \$ 2.1 \mathrm{M}=0.7 \mathrm{D}+1.4 \mathrm{~B}$, Relatively complex device and something similar not done in the United States before

Table 6-9. Cost of Proposed R\&D Projects

\begin{tabular}{|c|c|l|}
\hline R\&D Cost & Project \# & \multicolumn{1}{c|}{ Prototype Hardware Developed } \\
\hline \hline$\$ 1 \mathrm{M}$ & 2 & Less-conservative, high-volume, pedestal-mounted azimuth drive \\
\hline$\$ 1.5 \mathrm{M}$ & 3 & Pipe-in-pipe azimuth drive \\
\hline$\$ 2.1 \mathrm{M}$ & 4 & Large $\left(150-\mathrm{m}^{2}\right)$ carousel-type SM heliostat \\
\hline$\$ 1.5 \mathrm{M}$ & 5 & Large $\left(150-\mathrm{m}^{2}\right)$ single-fabric-based SM facet \\
\hline$\$ 1 \mathrm{M}$ & 6 & Transform large $\left(>300-\mathrm{m}^{2}\right)$ APS PV tracker to a heliostat \\
\hline
\end{tabular}

The "Budget-Constrained Project Selection" model was operated several times to determine the funding priorities. The Crystal Ball tool known as "OptQuest” was used to find the optimal solutions shown in Table 6-10. 
Table 6-10. Budget-Constrained Funding Priorities

\begin{tabular}{|c|c|c|c|c|c|c|}
\hline $\begin{array}{c}\text { R\&D } \\
\text { Budget }\end{array}$ & $\begin{array}{c}\text { Mean Price } \\
\text { Reduction }\end{array}$ & $\begin{array}{c}\mathbf{2} \\
\text { Less- } \\
\text { Conservative } \\
\text { Az Drive }\end{array}$ & $\begin{array}{c}\mathbf{3} \\
\text { Pipe-in- } \\
\text { Pipe Az } \\
\text { Drive }\end{array}$ & $\begin{array}{c}\mathbf{4} \\
\text { Carousel } \\
\text { SM Helio }\end{array}$ & $\begin{array}{c}\mathbf{5} \\
\text { Large } \\
\text { Fabric } \\
\text { SM Facet }\end{array}$ & $\begin{array}{c}\mathbf{6} \\
\text { Mega- } \\
\text { Helio }\end{array}$ \\
\hline \hline$\$ 1 \mathrm{M}$ & $\$ 7.8 / \mathrm{m}^{2}$ & & & & & $\mathrm{X}$ \\
\hline$\$ 2 \mathrm{M}$ & $\$ 10.2 / \mathrm{m}^{2}$ & $\mathrm{X}$ & & & & $\mathrm{X}$ \\
\hline$\$ 3 \mathrm{M}$ & $\$ 10.6 / \mathrm{m}^{2}$ & & & $\mathrm{X}$ & & \\
\hline$\$ 4 \mathrm{M}$ & $\$ 13.8 / \mathrm{m}^{2}$ & & & $\mathrm{X}$ & & $\mathrm{X}$ \\
\hline$\$ 5 \mathrm{M}$ & $\$ 15.8 / \mathrm{m}^{2}$ & & & $\mathrm{X}$ & $\mathrm{X}$ & $\mathrm{X}$ \\
\hline$\$ 6 \mathrm{M}$ & $\$ 16.4 / \mathrm{m}^{2}$ & $\mathrm{X}$ & & $\mathrm{X}$ & $\mathrm{X}$ & $\mathrm{X}$ \\
\hline$\$ 7 \mathrm{M}$ & $\$ 16.4 / \mathrm{m}^{2}$ & $\mathrm{X}$ & & $\mathrm{X}$ & $\mathrm{X}$ & $\mathrm{X}$ \\
\hline$\$ 8 \mathrm{M}$ & $\$ 16.6 / \mathrm{m}^{2}$ & $\mathrm{X}$ & $\mathrm{X}$ & $\mathrm{X}$ & $\mathrm{X}$ & $\mathrm{X}$ \\
\hline
\end{tabular}

A \$5 M R\&D budget produces the majority of the cost reduction. Carousel and mega-heliostat prototypes would first be designed. Each project would only proceed to the build stage if the analysis of the design indicates the cost-reduction goal can be achieved. If the carousel is the winning approach and hardware using a conventional metal-membrane facet is successful (Project 4), the fabric facet would be designed to see if it meets the cost-reduction goal. If it does, the fabric facet would be built (Project 5) and replace the metal-membrane facet on the existing carousel heliostat.

Given a \$5 M R\&D budget, the mean expected heliostat price reduction is $\$ 15.8 / \mathrm{m}^{2}$. This is the mean. The total distribution of possible values is shown in Figure 6-9. Given our current state of knowledge and a \$5 M R\&D budget, Crystal Ball predicts there is an $80 \%$ chance of achieving at least a $\$ 10 / \mathrm{m}^{2}$ price reduction, a $50 \%$ chance of achieving $\$ 16$, and a $20 \%$ chance of achieving \$24. Also shown is Crystal Ball's assessment of the parameters that are most important to the variance. Most of the variance is due to the price reduction predicted for the carousel heliostat. 


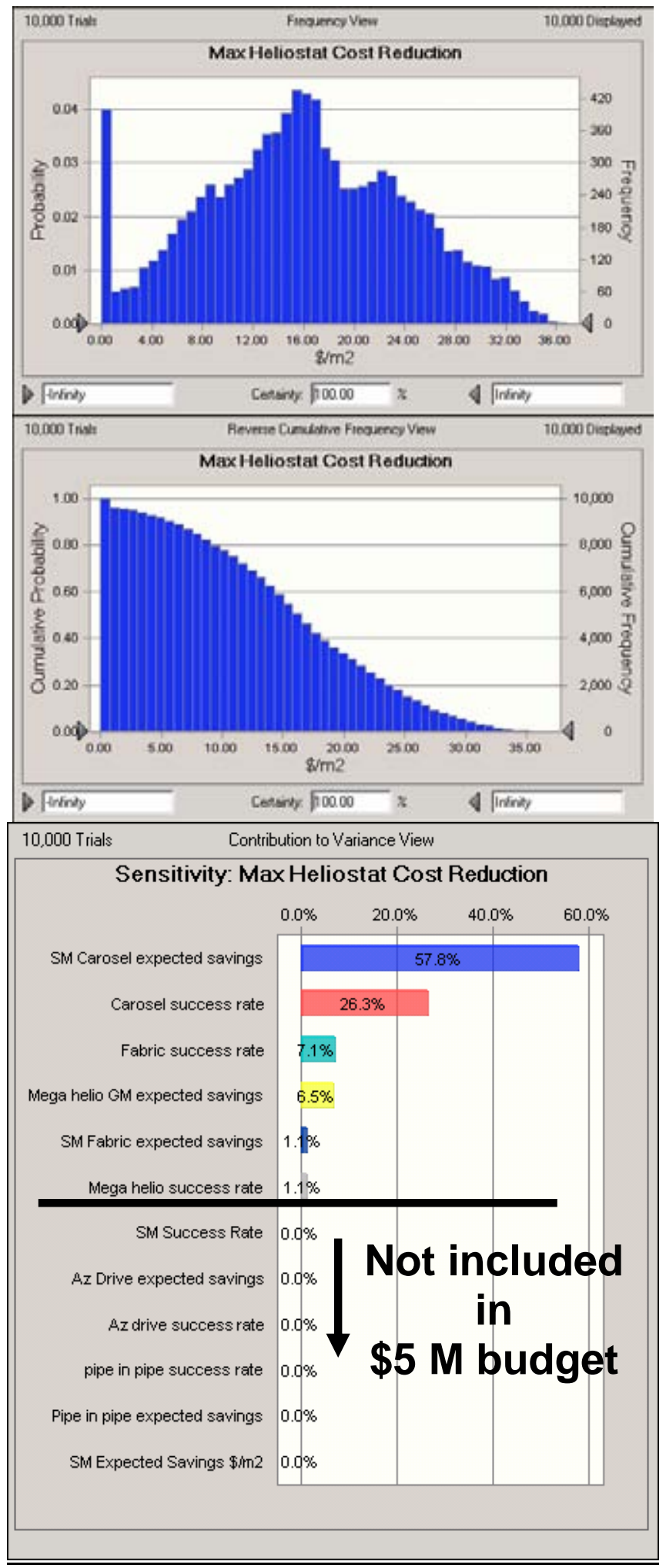

Figure 6-9. Crystal Ball results for expected heliostat price reduction achieved with a \$5 M R\&D budget. 


\section{CONCLUSIONS}

Heliostats are the most important cost element of a solar power tower plant. Since they constitute $\sim 50 \%$ to the capital cost of the plant, it is important to reduce the cost of heliostats to as low as possible to improve the economic viability of power towers. A 2006 price-year goal of less than $\$ 100 / \mathrm{m}^{2}$ is proposed since at that price the levelized cost of electricity ( $<6$ cents $/ \mathrm{kWh}$ ) or hydrogen $(<\$ 3 / \mathrm{kg}$ ) from power towers may be low enough to be competitive on the open market, especially if carbon-offset trading becomes the norm. Our analysis suggests that a price of $\sim \$ 90 / \mathrm{m}^{2}$ can be achieved through additional $\mathrm{R} \& D$, as well as through the effect of learning that naturally occurs over a several-year period of deployment. Other important conclusions and insights are detailed below.

Heliostat price is strongly dependent on production rate.

Heliostat prices were estimated at production rates of 5,000/yr and 50,000/yr. This corresponds to $60 \mathrm{MW}_{\mathrm{e}}$ and $600 \mathrm{MW}_{\mathrm{e}}$ of power plants. Given current technology, the price of heliostats in 2006 is estimated to be $\$ 164 / \mathrm{m}^{2}$ given $5,000 / \mathrm{yr}$ and $\$ 126 / \mathrm{m}^{2}$ given 50,000 yr. The lower price at the higher production rate is primarily due to a lower-cost azimuth drive; at the higher rate more automation would be incorporated into the factory that produces the drive. The key to achieving reasonable production rates is for a solar company to obtain multiple power-purchase agreements from electric-utility companies over a several-year period. For example, a solar-dish developer (SES) has recently signed agreements with Southern California Edison for $500 \mathrm{MW}$, expandable to $850 \mathrm{MW}$. With San Diego Gas and Electric they have signed agreements for $300 \mathrm{MW}$, expandable to $900 \mathrm{MW}$. With these agreements in hand, SES can now justify a highly automated production facility. Like SES, a power tower developer needs to sign multiple power-purchase agreements. However, if the SES projects proceed as planned, the power tower developer could benefit because the dish azimuth drive is nearly identical to the heliostat azimuth drive.

The ATS heliostat is the current low-cost baseline in the United States.

The 148- $\mathrm{m}^{2}$ heliostat developed by ATS is cost-efficient from a manufacturing point of view. Except for the azimuth drive, it uses common parts that are already mass-produced. A prototype has operated reliably at the NSTTF for the last 19 years. To reduce technology risk, initial U.S. power tower projects will likely use an ATS-like heliostat. In Europe, heliostats similar to the ATS are being used in the recently constructed PS-10 and PS-20 projects.

Large heliostats are more cost-efficient than small ones.

Like most engineered systems heliostats benefit from "economies of scale." Thus, large heliostats cost less on a $\$ / \mathrm{m}^{2}$ basis than very small ones. A detailed analysis of capital, O\&M, and installation costs of heliostats that measure a few $\mathrm{m}^{2}$ up to a few-hundred $\mathrm{m}^{2}$ indicates an optimum size of $150 \mathrm{~m}^{2}$ or more. However, less-detailed data suggest that similar costs might be achieved with heliostats as small as $50 \mathrm{~m}^{2}$.

Moderate investments in $R \& D$ should be able to reduce the heliostat price by at least $\$ 17 / \mathrm{m}^{2}$. A price reduction from $\$ 126 / \mathrm{m}^{2}$ to $\$ 109 / \mathrm{m}^{2}$ was estimated by evaluating TIOs proposed by 30 heliostat and manufacturing experts during a two-day workshop. Approximately \$8 M in R\&D is needed to achieve the full potential. However, a $\$ 5 \mathrm{M}$ budget achieves $\$ 16 / \mathrm{m}^{2}$ and gets the "most bang for the buck." Given a \$5 M budget, priority should be given to developing the 
mega-heliostat, the carousel SM heliostat, and the fabric-membrane mirror facet. Given a $\$ 1$ or \$2 M budget, priority should be given developing a less-conservative azimuth drive and the mega-heliostat. Continued price reduction from $\$ 109 / \mathrm{m}^{2}$ to $\$ 90 / \mathrm{m}^{2}$ is expected through learning during the deployment of the initial $9 \mathrm{GW}$ of power plants over a decade or more. A progress ratio of $92 \%$ is required to achieve $\$ 90 / \mathrm{m}^{2}$. This ratio has been predicted by other DOE-sponsored heliostat studies and matches the actual experience of the wind-turbine industry. 


\section{REFERENCES}

1. Sargent \& Lundy, Assessment of Parabolic Trough and Power Tower Solar Technology Cost and Performance Forecasts, SL-5641, May 2003, http://www.energylan.sandia.gov/sunlab/PDFs/Assessment.pdf.

Electric Power Research Institute, Renewable Energy Technology Characterizations, EPRI TR-109496, December 1997.

2. Kolb, G. J., R. Diver, and N. Siegel, Central Station Solar Hydrogen Power Plant, Journal of Solar Energy Engineering, American Society of Mechanical Engineers, May 2007.

3. “DOE H2A Analysis,” http://www.hydrogen.energy.gov/h2a_analysis.html.

4. Jones, D. and J. A. Eibling, Rotating Field Collector Subsystem Phase 1 Study and Evaluation, Alden E. Stilson \& Associates, SAND82-8184. Sandia National Laboratories, Albuquerque, NM, October 1982.

5. Mavis, C. L., A Description and Assessment of Heliostat Technology, SAND87-8025. Sandia National Laboratories, Albuquerque, NM, January 1989.

6. McDonnel Douglas Astronautics Company, Final Report - Second Generation Heliostat with High Volume Manufacturing Facility Defined by General Motors, SAND81-8177. Sandia National Laboratories, Albuquerque, NM, April 1981.

7. Dietrich, et al., Optimization of the Second Generation Heliostat Specification, McDonnell Douglas Astronautics Company, SAND82-8181. Sandia National Laboratories, Albuquerque, NM, May 1982.

8. Rafael Osuna (Solucar), personal communication during Solar Power 2006 conference, San Jose, CA, October 2006.

9. Monterreal, R. and P. Heller, Large Area Heliostat Comparison at PSA, Internal Report, Plataforma Solar de Almeria, Spain, November 1997.

10. Northrup Incorporated (a subsidiary of ARCO), Second Generation Heliostat Development for Solar Central Receiver Systems, SAND81-8178. Sandia National Laboratories, Albuquerque, NM, March 1981.

11. Strachan, J. W., and R. M. Houser, Testing and Evaluation of Large-Area Heliostats for Solar Thermal Applications, SAND92-1381. Sandia National Laboratories, Albuquerque, NM, February 1993.

12. Peerless-Winsmith Inc., Development of a Low-Cost Drive Tracking Mechanism for Solar-Heliostats or PV Arrays, contract report for Sandia National Laboratories, Document No. 90-5753, February 1989.

13. Arthur D. Little, Inc., “Heliostat Cost Review,” June 2001.

14. Gorman, D. and B. Thomas, “Cost Analysis for Glass/Metal Heliostats,” Advanced Thermal Systems, under contract to Bechtel National Incorporated, Contract 18717-TSC-008, April 1987. 
15. Solar Kinetics, Inc., Design and Demonstration of an Improved Stretched-Membrane Heliostat, SAND89-7028. Sandia National Laboratories, Albuquerque, NM, December 1989.

16. Science Applications, Inc., Development of the Stressed-Membrane Heliostat Mirror Module Final Report, SAND87-8179. Sandia National Laboratories, Albuquerque, NM, April 1987.

17. Beniga, K., et al., An Improved Design for Stretched-Membrane Heliostats, Science Applications International Corporation, SAND89-7027. Sandia National Laboratories, Albuquerque, NM, June 1989.

18. Kistler, B. L., A User's Manual for DELSOL3: A Computer Code for Calculating the Optical Performance and Optimal System Design for Solar Thermal Central Receiver Plants, SAND86-8018. Sandia National Laboratories, Albuquerque, NM, November 1986.

19. Peerless-Winsmith Inc., Enhanced Azimuth Solar Drive Project Summary Report, contract report for Sandia National Laboratories, Contract No. BF-0031, October 1999.

20. Boothroyd, Geoffrey, Peter Dewhurst and Winston Knight, Product Design for Manufacture and Assembly, Second Edition, New York, Marcel Dekker, 2002.

21. Extend Software described at http://www.imaginethatinc.com/prods_prodline.html.

22. Experience curve: a tool for energy policy programmes assessment (EXTOOL). Sponsored by the European Commission. Partners are: the Environmental and Energy System Studies (EESS) at Lund University in Sweden (coordinator), the Systems Analysis Department at Risoe and the Institut für Solare Energieversorgungstechnik e. V. (ISET) in Germany. http://www.iset.uni-kassel.de/extool/Extoolframe.htm.

23. Decision Engineering, Crystal Ball Version 7.2.2, http://www.decisioneering.com/. 


\title{
APPENDIX A. Heliostat Cost as a Function of Size For Molten-Salt Power Towers
}

\author{
Scott Jones \\ Sandia National Laboratories \\ April 2000
}

\section{A.1 Overview}

Previously, the Department of Energy program has favored increasing the size of heliostats to reduce their specific cost, measured in dollars per square meter $\left(\$ / \mathrm{m}^{2}\right)$. Others have suggested that, in addition to having better optical performance that may be desirable for high-flux applications, smaller heliostats may actually be less expensive per square meter than large heliostats. Our industrial partners were considering very small heliostats for use at Solar Tres, a molten-salt Power Tower proposed for the Spanish market. In addition, Dan Sagie of Rotem Industries in Israel recently spent a one-year sabbatical at the National Renewable Energy Laboratory (NREL) and performed an analysis concluding that small heliostats were less expensive than large ones. To address this important issue, an internal study was performed to evaluate how heliostat cost changes with heliostat size. The approach used was to start with a baseline heliostat design and cost projections and then to scale component costs and labor costs using an appropriate mathematical relationship as the heliostat size changes. Since the goal of this study was to establish trends between heliostat size and cost, estimates and assumptions based upon engineering judgment were frequently used. To improve the accuracy of the cost scaling estimates would have required detailed, optimized designs at each size - a significant increase in time and effort that was simply impractical.

Recognizing that there may be design differences between small and large heliostats, such as the use of angle bracket supports in small heliostats and roof trusses in large heliostats, two designs were used in the study, the $148-\mathrm{m}^{2}$ Advanced Thermal Systems (ATS) heliostat and the 30- $\mathrm{m}^{2}$ Heliostats Inc. (HI) heliostat. Both heliostat designs are nominally square, where the length of one side is called the chord length. The heliostat area is therefore the chord squared. Many of the cost scaling relationships used were a function of the chord length, or, similarly, the heliostat area. Others costs were scaled by a function of the number of mirror modules. Common assumptions were applied to both designs when possible and the scope of the analysis was broadened to include effects that may impact the comparison such as life-cycle operations and maintenance costs, as well as optical performance. The superior optics of smaller heliostats were rewarded because less total field reflective area was required for a given size receiver to achieve the same annual power delivery. In contrast, small heliostats have higher maintenance costs because there are more control systems for the same field area.

The cost estimates for the baseline ATS design are based upon numerous studies, the most used being the recent SOLMAT project funded by SunLab, and extensive experience building trackers for actual projects. ATS has fielded about 1,000 trackers of this basic design, including 864 of the $95-\mathrm{m}^{2}$ size and 44 of the $148-\mathrm{m}^{2}$ size. One hundred eight of the $95-\mathrm{m}^{2}$ photovoltaic trackers 
were recycled for use as heliostats at Solar Two. For the SOLMAT project completed in 1996 by Solar Kinetics Incorporated and ATS, updated price quotes from vendors were obtained for most components such as roof trusses, torque tubes, mirrors, etc., for a build quantity of 1,000 heliostats. David Gorman and Robert Thomas of ATS provided valuable assistance with costing their heliostat design for this study. Beyond the reference size of $148 \mathrm{~m}^{2}$, three other sizes were studied: $53 \mathrm{~m}^{2}, 95 \mathrm{~m}^{2}$, and $214 \mathrm{~m}^{2}$. These size increments represent simple changes in the length and quantity of mirror modules that are built with four-foot-square facets. The 53- and $95-\mathrm{m}^{2}$ sizes have been studied and built before, while the $214-\mathrm{m}^{2}$ heliostat has never been proposed and was added to the study as an afterthought to help determine where the minimum specific cost may lie for the ATS design.

Dan Sagie worked with Kirk Drumheller to cost the baseline HI design, apparently in a build quantity of 1,000 units, based on written and phone quotes, plus estimates. To the best of my knowledge, only one prototype HI heliostat has been built. The HI design was altered for this study to use conventional wired controls and communications, and the same mirror supplier (and cost) was used for both the HI and ATS heliostats. Costing of the baseline HI heliostat used raw material costs and with all labor performed in-house. For example, raw steel costs of $\$ 0.30 / 1 b$ were usually used. The HI labor costs for the baseline $30.1-\mathrm{m}^{2}$ heliostat in a production scenario appeared to be based upon estimates rather than experience or detailed studies. For these reasons, the cost estimates of the baseline HI design are considered to be preliminary and to have greater uncertainty than the ATS estimates. In addition to the baseline size, the design was scaled to sizes of $13.4,53,95$, and $148 \mathrm{~m}^{2}$.

The HI material cost scaling was, with the exception of the control system, unaltered for this study. HI scaled individual part costs of each component versus heliostat chord length with linear, square, or cubic relationships. However, HI labor cost scaling relations (not baseline costs) were omitted in favor of the ones described here. Except for mirror support structure, where more detailed analysis was performed, the ATS material costs were scaled on the component level using relationships described later. It may be helpful to consult the attached spreadsheets containing the costs for each size and design of heliostat while reading the description of how the numbers were calculated. It should be pointed out that in addition to the differences in maturity of cost estimates, there may well be differences in performance between the two heliostat styles. The ATS heliostat has been through extensive independent testing and field application, whereas the HI has undergone neither of these.

\section{A.2 Learning Curves}

Learning curves are sometimes used to predict the drop in cost of items as production volume increases. The progress ratio of the learning curve expresses the drop in cost for each doubling of production. For example, consider a custom electronics board that costs $\$ 100$ for a quantity of 1,000 . For a typical progress ratio of 0.85 , the learning curve methodology estimates the cost of that part to be $\$ 85$ for a build quantity of 2,000 units and $\$ 72.30$ for a build quantity of 4,000 units. This seems a good approximation for "custom" items, but may not be valid for the "offthe-shelf" materials where other applications dictate the overall quantity of the item produced and the production method. The heliostat costs were typically analyzed by subsystem in this study, and many parts were chosen in part because they were readily available and "off the 
shelf.” For example, consider a pipe used as a heliostat torque tube and produced in much larger quantities for other applications. The difference in cost to a heliostat builder of this part between an order quantity of 1,000 and 4,000 units would be much smaller, if not negligible, than the $27 \%$ reduction from the previous example. This is because the initial order quantity is large enough to already qualify for quantity discounts, and the larger-size order is still very small compared to the total part output. No changes in the method of production would occur between the two order quantities that would change the cost to build each part.

Labor costs to assemble parts and install heliostats would likely follow a learning curve as improved automation and tooling were implemented. For the scenario studied here- the building of a single heliostat field without promise of future builds-simple automation was assumed and no reductions in labor costs were estimated due to the building of more, smaller heliostats. With a few exceptions, the material costs used in this study were not modified to account for changes in build quantities from the reference estimates, and were only modified to account for changes in size. The exceptions to this include the logic controllers, where a learning curve was used, and the Pilkington mirrors, where there were vendor quotes as a function of total area ordered.

\section{A.3 Wind Loads and Material Cost Scaling Theory}

While there is uncertainty in and disagreement among the various sources of wind load predictions, the key here is to correctly estimate how loads scale relative to heliostat size and how that affects the cost of components. For structural components, the cost is assumed to vary with the weight, as it would in high-volume production. The weight of a structural member is its length times its cross-sectional area times its density.

$$
\text { cost }=\text { length } * \text { cross-sectional area } * \text { density }
$$

Excluding the density because the same material is used for all sizes yields the proportionality relationship

$$
\text { cost } \sim \text { length * cross-sectional area. }
$$

The length of structural components is proportional to the chord length of the heliostat, so

$$
\text { cost } \sim \text { chord * cross-sectional area. }
$$

Next, the total force applied due to the wind is the wind pressure times the area, therefore a function of the chord squared.

$$
\text { wind force } \sim \text { chord }^{2}
$$

The common case of a non-uniform wind pressure distribution over the heliostat area results in a moment acting to turn the heliostat. The resulting moment can be modeled more simply by a single force acting at a fixed distance - the "moment arm." In general, the moment arm scales with the heliostat chord so that the moment scales with the chord cubed.

$$
\text { wind moment } \sim \text { chord }^{3}
$$


The different sources of wind load predictions reviewed for this study agree with this scaling relationship, and differ only on the actual values for a given size heliostat and wind direction. Peterka et al. (1992) predictions (SAND92-7009) are used by ATS and are shown here as an example. Figure A-1 shows the worst-case wind moments on a single heliostat with a pedestaltop drive in an open field as a function of its size for wind gusts of $50 \mathrm{mph}$ in operation and 90 $\mathrm{mph}$ in stow. Wind gusts are assumed to be 1.6 times the mean wind speed. The azimuth moment acts to turn the heliostat around the axis of the pedestal and the worst case occurs during operation with the heliostat pointed at the horizon and the wind incident at an azimuth angle of 65 degrees. The hinge moment acts to turn the heliostat in the elevation axis, or at 90 degrees to the elevation axis (cross-elevation), and the worst case occurs during stow with the heliostat face-up. It is worth noting that the azimuth and overturning moments are of very similar magnitude. ${ }^{1}$ Both moments shown in the graph are for a zero offset between the mirror surface and the axis of rotation. If there is an offset, as is frequently the case in heliostat designs, this will act to increase the overturning moment to a larger extent than the azimuth moment.

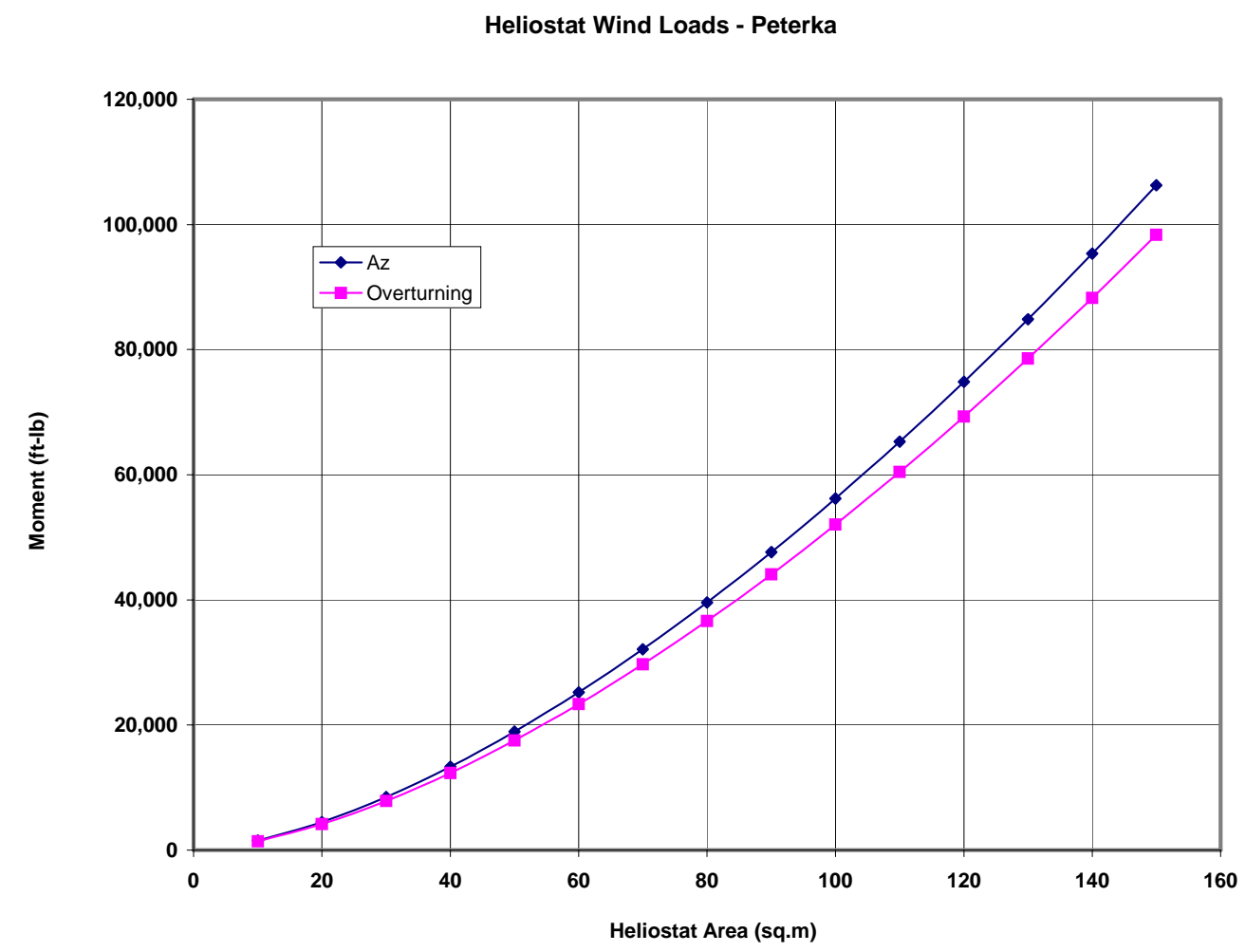

Figure A-1. Wind load predictions from Peterka for a single heliostat in an open field.

1 Peterka et al. predictions for circular, $\mathrm{f} / \mathrm{D}=0.625$ dishes result in higher hinge and lower azimuth moments than rectangular heliostats of the same total area. 
The scaling done in this study maintained a constant maximum stress in the components as heliostat size changed, leading to a consistent factor of safety for a given material. This is stresslimited, rather than deflection-limited design. To establish the impact of size scaling on component cost, a relationship between the cross-sectional area of a component and its capacity to withstand bending moments from wind loading was required. However, this is a strong function of the component geometry. Bending moment capacity is dictated by the elastic section modulus, I/c, that is the moment of inertia of the cross section divided by the distance from the neutral axis to the most remote fiber. So beams of differing geometry can have equal crosssectional area but very different bending moment capacity. For a given material with its maximum permissible stress,

$$
\text { Max. Moment }=\text { Max. Stress * I/c. }
$$

To establish a general rule of thumb relationship between cross-sectional area and maximum bending moment capacity, two typical engineering components were examined: thin tubing and the I-beam. The bending moment capacity of thin tubing is

$$
\mathrm{I} / \mathrm{c}=\pi * \mathrm{R}^{2} * \mathrm{t}
$$

Where $\mathrm{R}$ is the average radius and $\mathrm{t}$ is the tube thickness, while the cross-sectional area is

$$
\text { cross-sectional area }=2 * \pi * \mathrm{R} * \mathrm{t} \text {. }
$$

As a heliostat is scaled in size, it is reasonable to assume the relative size of tubular parts, that is the ratio of the wall thickness to the radius, will remain constant.

$$
\mathrm{t}=\text { constant } * \mathrm{R}
$$

It follows then from the above three equations that the bending moment capacity of the tube is proportional to $\mathrm{R}^{3}$, while the cross-sectional area is proportional to $\mathrm{R}^{2}$, leading to the relation

$$
\text { bending moment capacity } \sim \text { cross-sectional area }{ }^{3 / 2} \text {. }
$$

A review of typical sizes of I-beams (Popov, 1976) also showed nominally a 3/2-power relationship between bending moment capacity and cross-sectional area. Figure A-2 shows the $\mathrm{I} / \mathrm{C}$ values as a function of cross-sectional area for typical size I-beams. Again, the cost scaling of a structural member is

$$
\text { cost } \sim \text { chord * cross-sectional area. }
$$




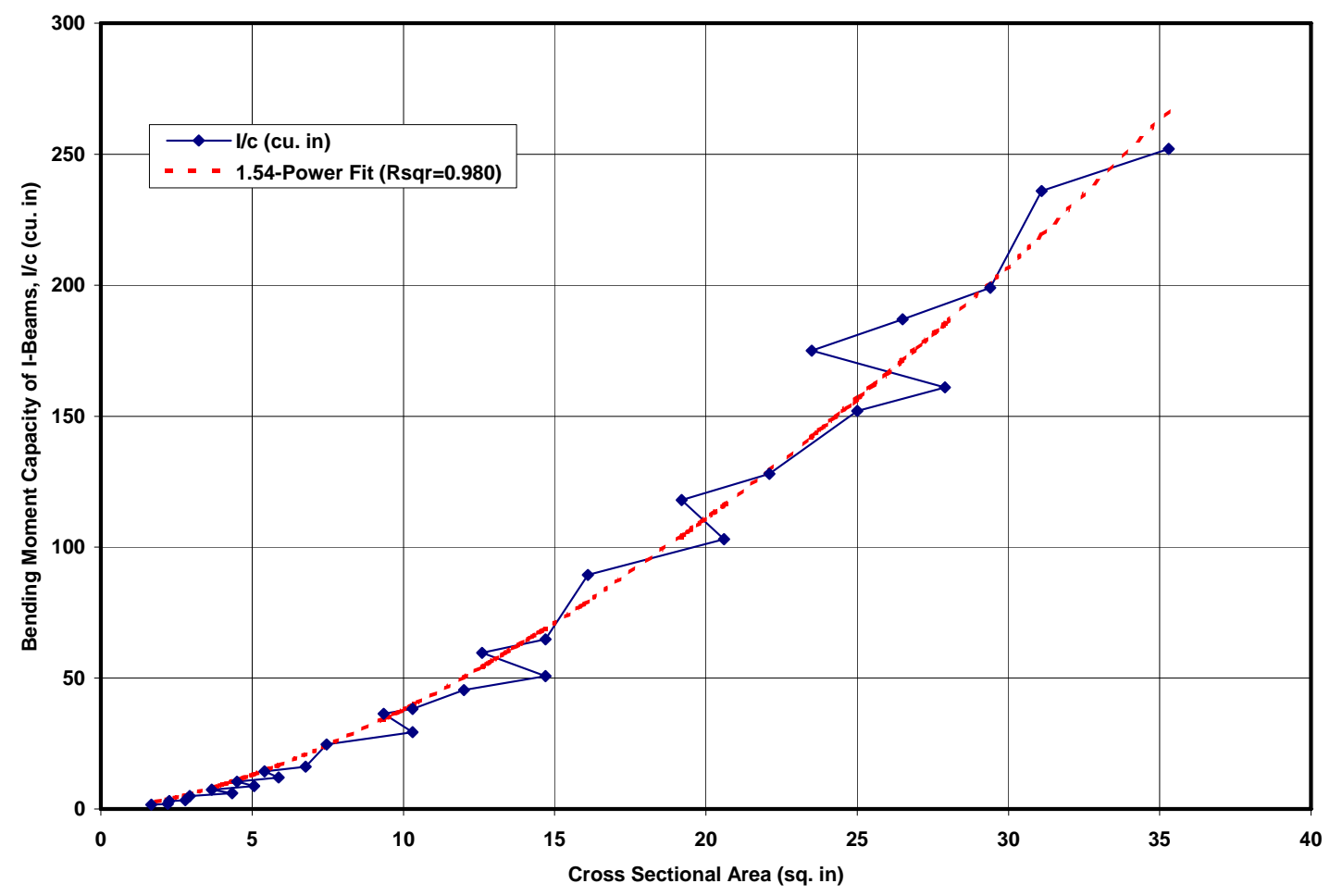

Figure A-2. Bending moment capacity of typical size I-beams.

Inverting and substituting the results from above relating bending moment capacity to crosssectional area gives

$$
\text { cost } \sim \text { chord } * \text { moment }{ }^{2 / 3} \text {. }
$$

Substituting the chord cubed rule for moments due to the wind, and simplifying yields

$$
\begin{gathered}
\text { cost } \sim \text { chord } *\left(\operatorname{chord}^{3}\right)^{2 / 3} \\
\text { cost } \sim \operatorname{chord}^{3}
\end{gathered}
$$

It will be shown later that this rule of thumb is frequently, but not always, validated by other approaches.

\section{A.4 Material Costs}

\section{Foundation Cost}

The ATS heliostat foundation is made by drilling a hole in the ground, inserting the tubular steel pedestal, and filling the hole with concrete. The cost here includes both materials and labor provided by a subcontractor. The required strength of the foundation is a function of the wind loads that go as the chord cubed. In practice, the diameter of the pedestal changes little with heliostat size, and the diameter of surrounding concrete probably also changes little. The length 
of the pedestal and its depth in the ground is likely the most significant change with size. To account for this, half of the cost of the foundation is scaled linearly with heliostat chord. The other half of the cost is assumed constant because the labor required does not change much with heliostat size. The baseline cost for the $148-\mathrm{m}^{2}$ heliostat foundation is $\$ 200$ based upon ATS experiences in prior field installations in the 1980s, and could be updated to reflect more recent pricing.

In the HI design, the pedestal and foundation are both concrete, and Dan Sagie used the rule-ofthumb 3/2-power law with area for scaling the materials costs.

\section{Drives}

The Winsmith planocentric azimuth drive (the so-called "Sandia" or "low-cost" drive), used on a prototype ATS 148- $\mathrm{m}^{2}$ heliostat at Sandia, was specified here for all sizes of ATS-style heliostats since we had the best pricing data for this drive. All of the ATS heliostats fielded for projects used worm drives rather than the planocentric drive. However, the planocentric drive survived a severe wind event (breaking the wind meter at $113 \mathrm{mph}$ ) a few years ago that destroyed other concentrators, and is believed to be the lowest-cost option for baseline ATS heliostat size. Winsmith recently completed a project for Sandia to update price estimates of the $148-\mathrm{m}^{2}$ size of this drive in one-time production quantities up to 500 units. Cost-cutting measures identified by Winsmith and others through Design for Manufacture and Assembly (DFMA) workshops are included in the price quote of $\$ 4,000$ for 1,500 planocentric azimuth drives. ${ }^{2}$ Based upon actual experience building a single prototype unit for Sandia, Werner Heller of Winsmith thought a ball screw elevation drive for the $148-\mathrm{m}^{2}$ heliostat would cost from $\$ 1,500-\$ 2,000$ in the quantities desired, and the upper-bound guess was used. Werner also suggested that optimizing the mirror support structure for use with a ball screw elevation drive could reduce the total cost of the drive and interface below his lower-bound estimate.

The scaling of drive costs were explored further by looking at costs of off-the-shelf Winsmith worm drives built in large quantities. Figure A-3 shows the cost of these drives as a function of their torque capacity, whereas Figure A-4 shows their cost as a function of their overhung moment capacity. The overhung moment capacity is similar to the hinge moment capacity important for solar drives. The data were fit with a power relationship, yielding the results that follow.

$$
\begin{gathered}
\text { drive cost } \sim \text { reference cost * (torque capacity/reference torque capacity) }{ }^{0.372} \\
\text { drive cost } \sim \text { reference cost * (overhung moment capacity/reference overhung capacity) }
\end{gathered}
$$

2 The price quoted by Winsmith dropped insignificantly for a volume increase from 500 to 1,500 units. 


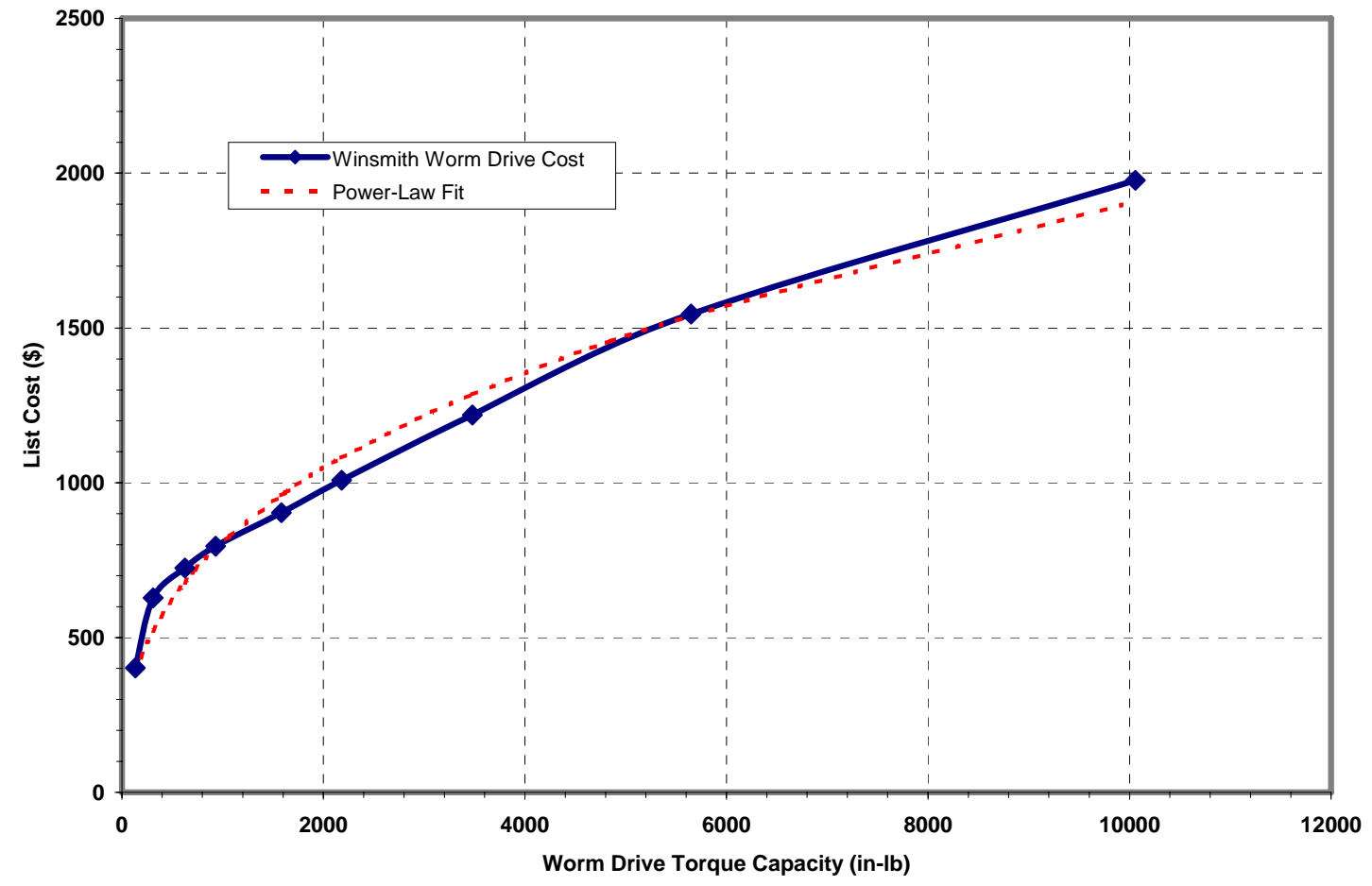

Figure A-3. Cost of off-the-shelf Winsmith worm drives as a function of torque capacity.

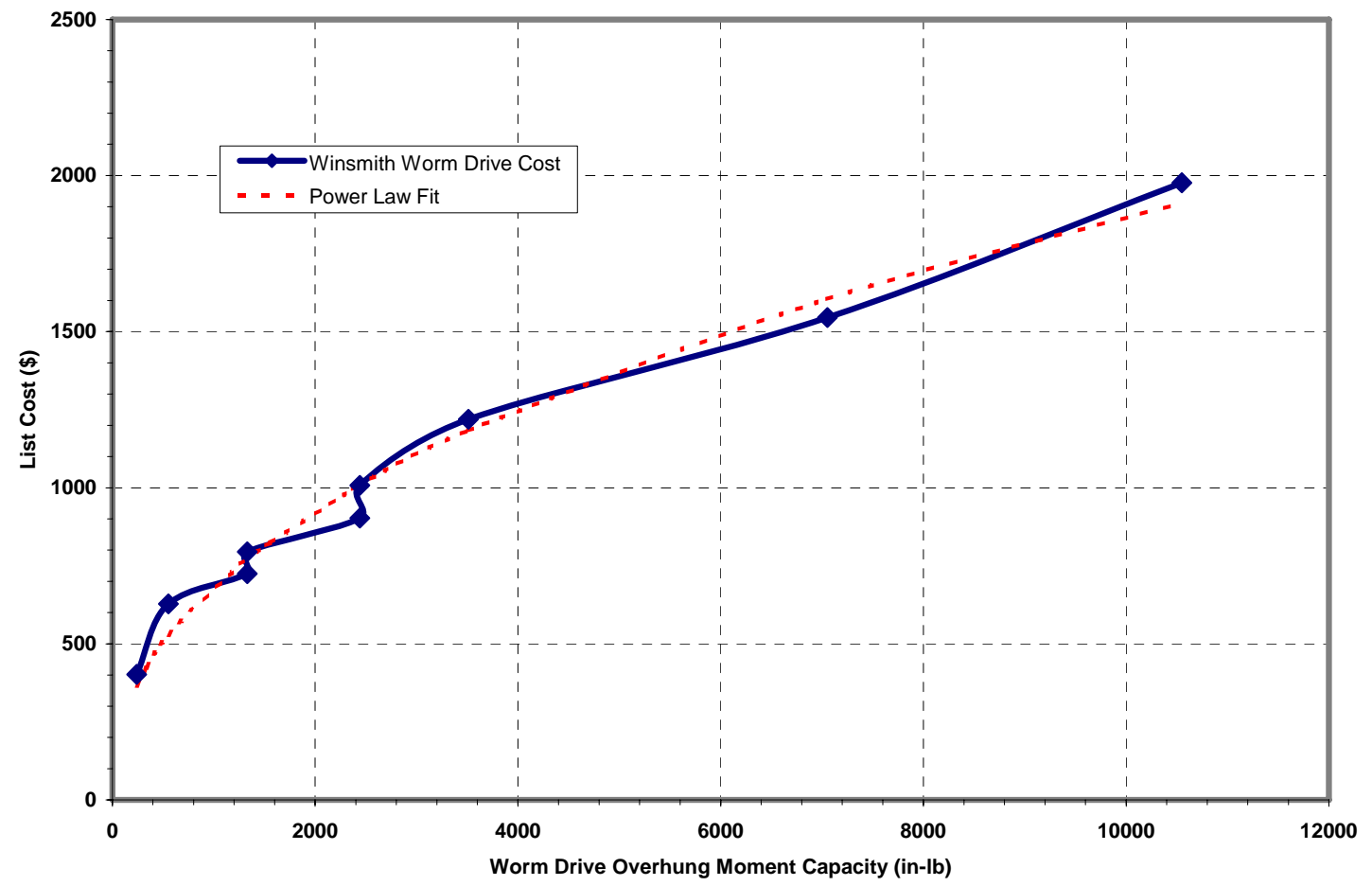

Figure A-4. Cost of off-the-shelf Winsmith worm drives as a function of overhung moment capacity. 
Fit accuracy was good, as reflected in $\mathrm{R}^{2}$ values of 0.984 and 0.982 , respectively, for the two cases. The exponents would increase to 0.539 and 0.579 , and $\mathrm{R}^{2}$ values would increase to 0.992 and 0.988 , if a non-zero intercept was permitted in the fit. However, a fit with a zero intercept was preferred because it allows the reference costs to be directly scaled without added uncertainty from normalizing to match actual cost quotes. As shown earlier, the moment requirements on the drive should scale roughly with the heliostat area to the $3 / 2$ power, leading to the overall relationship that drive cost is proportional to heliostat area to a power between 0.56 and 0.65 .

$$
\text { drive cost } \sim \text { reference cost } * \text { area }{ }^{0.56-0.65}
$$

An average value of 0.6 was chosen for cost scaling of the ATS heliostat drive design. Please note this cost scaling result is substantially different than was found for thin tubing and I-beams, where the exponent was 1.5. The mathematical relationship governing torque capability of a worm drive is certainly more complicated than that governing the bending moment capacity of a beam, and may be partly responsible for the unexpected results. However, the overhung moment capability of a worm drive would intuitively seem to have similar governing relations as a beam. It is also possible that the cost of manufacturing worm drives, even in large-scale production, is influenced more by manufacturing costs than are beams, whose cost tend to be dominated by raw materials. This surprising result merits further investigation.

The 0.6 power-law predictions for solar drive costs were compared with other data to check their validity. Winsmith has also built a smaller-size planocentric azimuth drive for a prototype 46- $\mathrm{m}^{2}$ dish. If we assume this drive is also appropriately sized for a $46-\mathrm{m}^{2}$ heliostat, ${ }^{3}$ the 0.6 power-law exponent suggests a cost of $\$ 2,980$ for both the azimuth unit and a linear actuator elevation drive. Winsmith said price estimates for this smaller-size drive in the quantities required for Solar Tres have more uncertainty than for the larger drive because it has been studied less, and they provided high and low bounding estimates of \$3,000 and \$2,300 for the azimuth unit. Using Winsmith's low estimate leaves $\$ 680$ for the elevation drive, a reasonable but low-end value. Winsmith's upper-bound price estimate for the azimuth drive leaves no money for the elevation drive when compared with the power-law estimate. Given the uncertainties in these estimates, this data suggests the power-law price estimate is valid, but falls towards the lower-bound price.

Winsmith also provided a cost estimate for the old “Arco" azimuth worm drive design sufficient for a $95-\mathrm{m}^{2}$ heliostat. In a quantity of 2,400 units, the verbal price quote was $\$ 3,530$. However, it was suggested that a cost-reduction program similar to that performed on the large planocentric drive could reduce this cost. Although this is a worm, rather than a planocentric azimuth drive, the comparison with the power-law price estimate of \$5,000 for this size heliostat still provides an interesting data point. This leaves about $\$ 1,500$ for the elevation drive, a very reasonable value that supports the power-law approach.

3 The rated load-handling capabilities of the smaller planocentric have an unusual relationship to the larger unit. The torque capability is less than $1 / 10$ of the larger size, while the overturning moment capability is one half that of the larger unit. The manufacturer's azimuth moment capability may very conservative. Also see footnote 1 for comments on the differences between dish and heliostat wind loads. 
Comparing these two data points, it seems possible that the planocentric drive design is more expensive for smaller-size heliostats than the worm drive. Winsmith has pointed out that in the highly competitive worldwide conveyor market, with smaller loads than for large heliostats, worm drives dominate and are less costly than a planocentric drive. Conversely, a study by Winsmith and Cummins predicted the large planocentric solar drive (suitable for a $150-\mathrm{m}^{2}$ heliostat) would be less expensive than a comparably sized worm drive.

Dan Sagie scaled the HI drive cost on an individual parts basis versus heliostat chord length with linear, square, or cubic relationships. Beyond a parts list, details of the drive design were not available. The overall HI drive cost scaling was put on a power-law basis in Table A-1 for comparison with Winsmith results for commercial worm drives. The exponent, $\mathrm{n}$, does not fall within expected bounds, and increases substantially with heliostat area in a manner highly unfavorable to larger heliostats. This leads to an HI drive cost for a 148- $\mathrm{m}^{2}$ heliostat 2.7 times greater than the quoted cost of the well-tested Winsmith planocentric drive.

Table A-1. Effective Exponent (n) for Heliostat Drives if Cost $\sim$ Heliostat Area $^{n}$

\begin{tabular}{|c|c|c|c|c|}
\hline $\begin{array}{c}\text { Heliostat Area } \\
\left(\mathbf{m}^{\mathbf{2}} \mathbf{)}\right.\end{array}$ & $\begin{array}{c}\text { ATS } \\
\text { Drive Cost }\end{array}$ & $\mathbf{n}$ & $\begin{array}{c}\text { HI Drive } \\
\text { Cost }\end{array}$ & $\mathbf{n}$ \\
\hline 13.4 & - & - & $\$ 1,037$ & 0.5 \\
\hline 30.1 & - & - & $\$ 1,552$ & Reference Size \\
\hline 53 & $\$ 3,240$ & 0.6 & $\$ 2,471$ & 0.82 \\
\hline 95 & $\$ 4,600$ & 0.6 & $\$ 6,626$ & 1.26 \\
\hline 148 & $\$ 6,000$ & Reference Size & $\$ 15,948$ & 1.46 \\
\hline 214 & $\$ 7,486$ & 0.6 & - & - \\
\hline
\end{tabular}

\section{Mirror Modules}

Table A-2 shows the module size and number of mirror modules for the different size heliostats. The ATS mirror modules are built from multiple $4 \mathrm{ft} \times 4 \mathrm{ft}$ mirror facets with "hat" sections glued to the back. In all fielded designs, 1-mm-thick mirrors were bonded to 3-mm-thick glass to form a very corrosion-resistant package that was minimally affected by cracking and glass breakage. Here, both the ATS and HI heliostats designs use a single 4-mm-thick Pilkington mirror. ${ }^{4}$ This change to the ATS design was proposed in the SOLMAT project to reduce costs. It was thought the three-layer paint coating added to the back of mirrors was, while probably less resistant to corrosion than the laminate design, still sufficiently durable, as proven through more than 10 years of operation at the Solar Energy Generating Systems (SEGS) plants. In the HI design, these mirrors are used without any stiffening structure like on the ATS heliostat. The HI mirrors are directly mounted to the structure with ceramic pads, as was done at the SEGS plants, and hence have less resistance to breakage than the ATS design. However, no additional operation and maintenance (O\&M) expenses were assumed for the HI design.

4 Dan Sagie selected Spanish mirrors over the more expensive and proven Pilkington mirrors for the HI heliostat, but Pilkington mirrors were used instead for consistency. This choice does not affect the heliostat cost/size comparison. 
Table A-2. Size and Quantity of Mirror Modules

\begin{tabular}{|c|c|c|}
\hline $\begin{array}{c}\text { Heliostat } \\
\text { Area } \mathbf{( m}^{\mathbf{2}} \mathbf{)}\end{array}$ & $\begin{array}{c}\text { Number of } \\
\text { Modules }\end{array}$ & $\begin{array}{c}\text { Module Area } \\
\left(\mathbf{m}^{\mathbf{2}} \mathbf{)}\right.\end{array}$ \\
\hline 13.4 & 3 & 4.47 \\
\hline 30.1 & 6 & 5.02 \\
\hline 53 & 12 & 4.46 \\
\hline 95 & 16 & 5.95 \\
\hline 148 & 20 & 7.43 \\
\hline 214 & 24 & 8.92 \\
\hline
\end{tabular}

The materials cost for mirror modules nominally scales with area so has little affect the optimum heliostat size. Based upon a SOLMAT quote from Pilkington, a cost of $\$ 2.51 / \mathrm{ft}^{2}\left(\$ 27 / \mathrm{m}^{2}\right)$ is used for the quantity required at Solar Tres.

\section{Mirror Support Structure}

To scale the cost of ATS support structure (pedestal, torque tubes, trusses and mounting hardware), three steps were taken. The loads were calculated for the new heliostat sizes using the rule that moments and axial loads scale with the cube of the chord. Moment loads were calculated for the trusses, torque tubes, and the truss upper and lower members and the tubular supports between trusses. Next, the thickness and length of the members was adjusted to meet the revised load requirements and size while the diameter (or depth of the truss) was kept constant-a simplification. The accuracy of this approach decreases as size changes increase, but should be sufficient here. Table A-3 shows the geometrical scaling results for two parts.

Table A-3. Scaling of Pedestal and Torque Tube Thickness From ATS Baseline 148- $m^{2}$ Heliostat

\begin{tabular}{|c|c|c|}
\hline $\begin{array}{c}\text { Area } \\
\left(\mathbf{m}^{2}\right)\end{array}$ & $\begin{array}{c}\text { Pedestal } \\
\text { Thickness (in.) }\end{array}$ & $\begin{array}{c}\text { Torque Tube } \\
\text { Thickness (in.) }\end{array}$ \\
\hline 148 & $3 / 8$ & $1 / 2$ \\
\hline 95 & $2 / 10$ & $1 / 4$ \\
\hline 53 & $1 / 10$ & $1 / 10$ \\
\hline
\end{tabular}

In some cases, the stresses dictated a lower wall thickness than was commercially available or considered safe due to buckling concerns. A full design optimization may have arrived at different diameters and wall thickness, but that was beyond the scope of this study. For the 214- $\mathrm{m}^{2}$ ATS heliostat added later to the study, the 3/2-power rule was used to scale the costs from the reference size. Clearly, an optimum design for this larger size would require increasing tube diameter, not just wall thickness.

Finally, the weight of the scaled structural members were computed and the costs estimated assuming a constant cost per pound. Please note that price quotes for manufactured components for the 148- $\mathrm{m}^{2}$ SOLMAT heliostat as listed in Table A-4 were used as a basis, rather than mill prices of $\$ 0.30 / \mathrm{lb}$. 
Table A-4. Specific Cost of ATS Heliostat Components from SOLMAT

\begin{tabular}{|c|c|}
\hline $\begin{array}{c}\text { ATS } \\
\text { Component }\end{array}$ & $\begin{array}{c}\text { Cost } \\
\mathbf{( \$ / l b )}\end{array}$ \\
\hline Pedestal & $\$ 0.50$ \\
\hline Torque Tube & $\$ 0.31$ \\
\hline Trusses & $\$ 0.74$ \\
\hline Braces & $\$ 0.28-\$ 0.52$ \\
\hline
\end{tabular}

Individual HI mirror support structure parts were scaled individually using linear, squared, or cubic relations to chord length. For comparison purposes, Table A-5 lists the ATS and HI mirror support structure costs for different size heliostats and the effective power-law cost scaling exponent. It should be noted that the pedestal is included in this category for the ATS design, but is considered part of the foundation for the HI design (where it is scaled with a 3/2-power exponent). The HI scaling exponent is fairly constant near a value of 1 , quite a bit lower than the 1.5 rule of thumb. Considering that a limited engineering analysis was performed on the ATS mirror support structure-pipe diameter was held constant and the thickness/Radius ratio was changed, rather than an "optimum" geometry selected for each heliostat size-the effective exponents show pretty close agreement with the rule of thumb value. Again, the rule of thumb exponent of 1.5, rather than engineering analysis, was used to scale costs for the $214-\mathrm{m}^{2}$ heliostat. Excluding the pedestal for comparison purposes, the ATS mirror support structure estimated costs are $\$ 1,816$ for a $148-\mathrm{m}^{2}$ heliostat, much higher than the HI estimate of only $\$ 402$ for the same size heliostat.

Table A-5. Effective Exponent (n) for Heliostat Mirror Support Structure if Cost $\sim$ Heliostat Area ${ }^{n}$

\begin{tabular}{|c|c|c|c|c|}
\hline $\begin{array}{c}\text { Heliostat Area } \\
\left(\mathbf{m}^{\mathbf{2}}\right)\end{array}$ & $\begin{array}{c}\text { ATS Structure } \\
\text { Cost (Incl. } \\
\text { Pedestal) }\end{array}$ & $\mathbf{n}$ & $\begin{array}{c}\text { HI Drive Cost } \\
\text { (Without } \\
\text { Pedestal) }\end{array}$ & $\mathbf{n}$ \\
\hline 13.4 & - & - & $\$ 36$ & 1.00 \\
\hline 30.1 & - & - & $\$ 81$ & Reference Size \\
\hline 53 & $\$ 900$ & 1.30 & $\$ 145$ & 1.03 \\
\hline 95 & $\$ 1,846$ & 1.42 & $\$ 257$ & 1.00 \\
\hline 148 & $\$ 3,521$ & Reference Size & $\$ 402$ & 1.01 \\
\hline 214 & $\$ 6,122$ & 1.50 (fixed) & - & - \\
\hline
\end{tabular}

\section{Controls}

Standard, wired controls and communications proven effective in the $~ 1,000$ trackers fielded by ATS were used for both designs, and the cost estimates listed in Table A-6 were based mostly upon SOLMAT data. Some of the control component costs are not a function of heliostat size. The electronic controller for heliostat logic and motor functions, limit switches, position encoders, and box enclosure are examples of this. All but possibly the controller are 
commercially available parts whose price would change little for the differences in quantities required between a field of small heliostats and a field of large heliostats. For custom-built controllers, which are predicted to be less expensive than adapting off-the-shelf controllers to the application, the additional quantities needed for a field of small heliostats may reduce the per unit cost. A learning curve with a progress ratio of 0.85 was used to model this effect. The reference cost of \$300 from SOLMAT (1996) for a quantity of 1,000 units was input used in the learning curve calculation. The recent advances in computer and electronics technology should be explored to see if this cost could be reduced.

Table A-6. Heliostat Control System Costs

\begin{tabular}{|rrrrrrrr|}
\hline Heliostat Area (sq. m) & $\mathbf{1 3 . 4}$ & $\mathbf{2 0}$ & $\mathbf{3 0 . 1}$ & $\mathbf{5 3}$ & $\mathbf{9 5}$ & $\mathbf{1 4 8}$ & $\mathbf{2 1 4}$ \\
Number of Heliostats & 17,192 & 11,668 & $\mathbf{7 , 6 9 6}$ & 4,403 & 2,490 & 1,625 & 1,147 \\
\hline Electronic logic \& motor controller & $\$ 245$ & $\$ 252$ & $\$ 260$ & $\$ 270$ & $\$ 281$ & $\$ 290$ & $\$ 297$ \\
wiring harness & $\$ 65$ & $\$ 68$ & $\$ 73$ & $\$ 80$ & $\$ 90$ & $\$ 100$ & $\$ 110$ \\
4 limit/kill switches & $\$ 65$ & $\$ 65$ & $\$ 65$ & $\$ 65$ & $\$ 65$ & $\$ 65$ & $\$ 65$ \\
2 encoders & $\$ 30$ & $\$ 30$ & $\$ 30$ & $\$ 30$ & $\$ 30$ & $\$ 30$ & $\$ 30$ \\
weatherproof box & $\$ 120$ & $\$ 120$ & $\$ 120$ & $\$ 120$ & $\$ 120$ & $\$ 120$ & $\$ 120$ \\
2 DC motors & $\$ 53$ & $\$ 70$ & $\$ 92$ & $\$ 135$ & $\$ 200$ & $\$ 270$ & $\$ 347$ \\
\hline Total Cost & $\$ 579$ & $\$ 605$ & $\$ 639$ & $\$ 700$ & $\$ 786$ & $\$ 875$ & $\$ 969$ \\
\hline
\end{tabular}

Motor costs do vary with torque requirements and heliostat size. To establish how costs scale with torque, data from commercially available DC motors were taken from Grainger Catalog \#386 (1995) and a power-law fit relating torque to cost was performed.

$$
\text { motor cost } \sim \text { reference cost } * \text { (torque capacity/reference torque capacity) }{ }^{0.451}
$$

Figure A-5 shows the motor cost data and fit. Fit accuracy was good, as reflected in $\mathrm{R}^{2}$ values of 0.960. As shown earlier, the load requirements on the motors should scale roughly with the heliostat area to the $3 / 2$ power, leading to the overall relationship that motor cost is proportional to heliostat area to the power 0.677. Like drives, this is lower than the $3 / 2$ power rule of thumb.

$$
\text { motor cost } \sim \text { reference cost } * \text { area }^{0.677}
$$

The wiring between the control box and the motors and encoders is frequently called the wiring harness. The length of this harness must change with heliostat pedestal height. It was assumed that one half of the cost of the harness is in the cost of the wire, while the remainder is in connectors and labor, leading to the relation:

$$
\text { Wiring harness cost }=\text { reference cost } / 2 *(1+\text { chord/reference chord }) \text {. }
$$




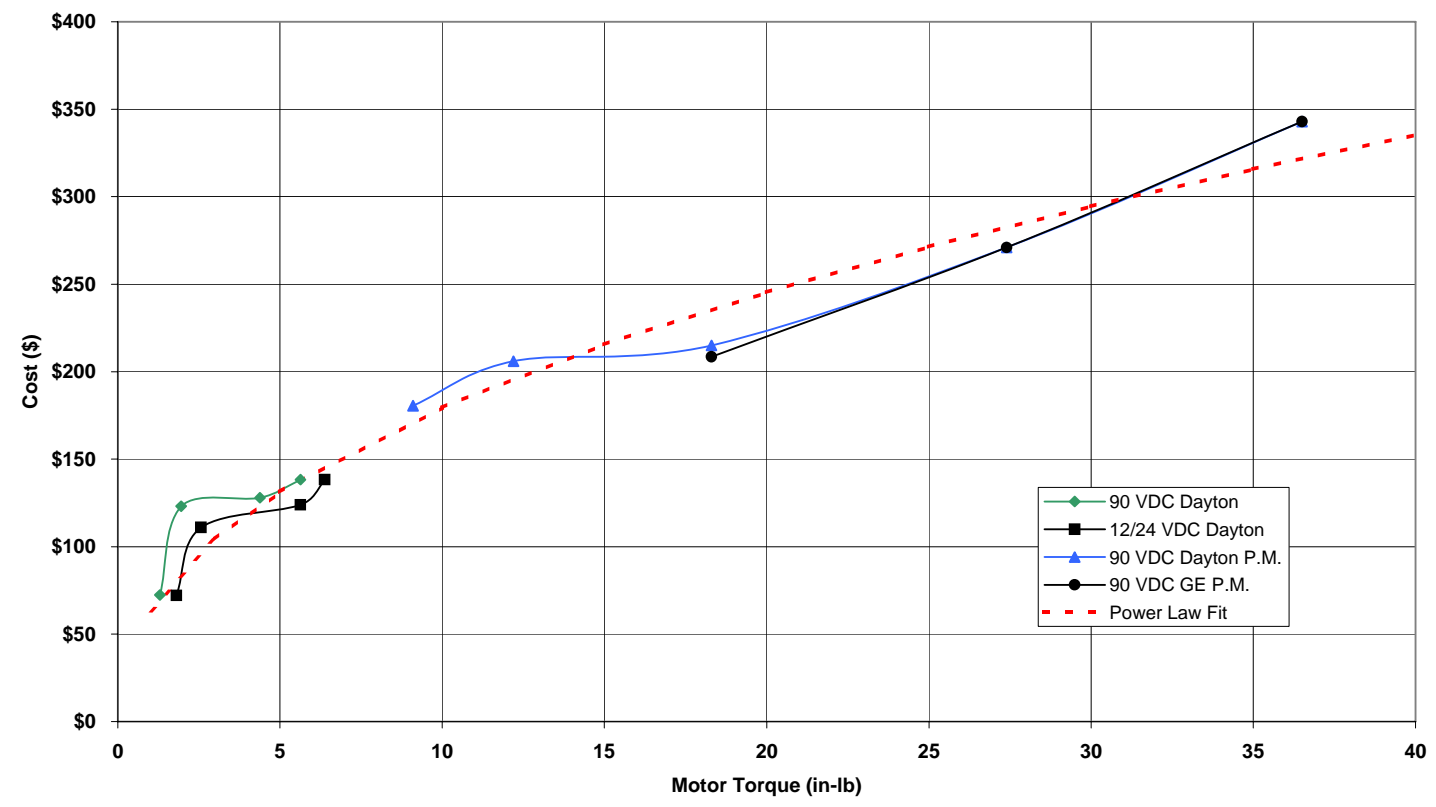

Figure A-5. Low-volume cost of DC motors as a function of peak torque.

\section{Wiring Costs}

Direct burial of standard copper communication and power wiring was thought to be the best low-cost, low-risk approach and was used in this study. The wiring cost estimates were generated by DELSOL using 20-year-old input parameters, and certainly this cost would benefit from further analysis. Wiring costs are not constant throughout the field as heliostats located further from the tower require a longer radial communication line than those close to the tower. In addition, heliostats are spaced further apart both axially and radially as distance from the tower increases. Figure A-6 shows the DELSOL estimated wiring costs for the entire field and the average cost per heliostat for different heliostat sizes. A power law fit $\left(\mathrm{R}^{2}=0.983\right)$ was performed to the data with a resulting average wiring costs per heliostat of

$$
\text { Wiring cost/heliostat }=\$ 93.45 *\left(\text { area in } \mathrm{m}^{2}\right)^{0.448} \text {. }
$$

Since this is not a structural component, there is no expectation it would match the $3 / 2$ power rule of thumb. The DELSOL estimates were almost $\$ 900$ for a $150-\mathrm{m}^{2}$ heliostat. ATS previously estimated wiring costs for the 148- $\mathrm{m}^{2}$ heliostat at \$125 (1987) and \$200 (1990), again suggesting that further work is needed to improve wiring cost estimates. These high wiring costs are unfavorable to small heliostats. 


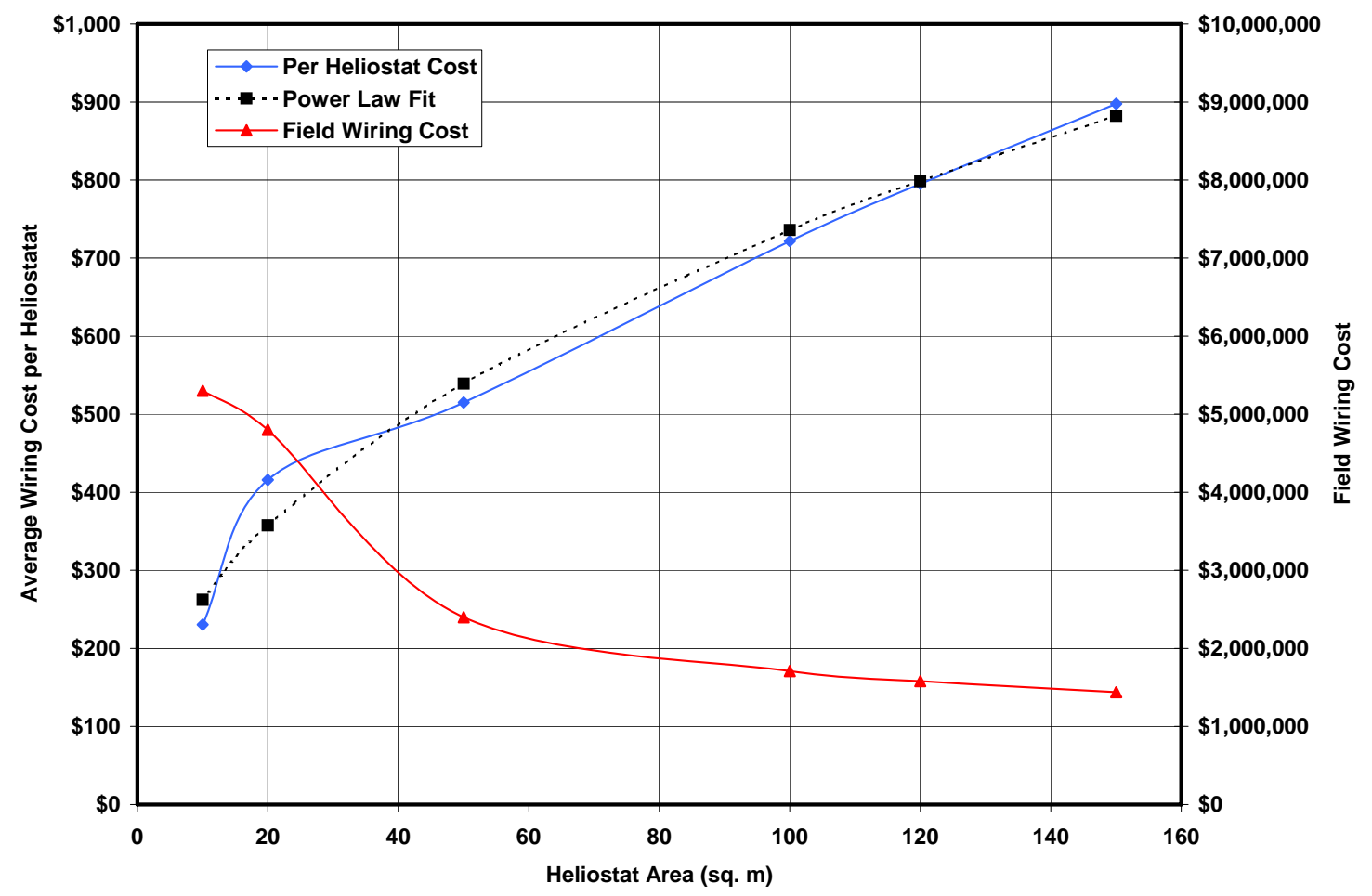

Figure A-6. DELSOL estimated wiring costs for Solar Tres by heliostat area.

\section{A.5 Labor Costs}

\section{Heliostat Assembly Labor}

The SOLMAT labor estimates for the baseline 148- $\mathrm{m}^{2}$ ATS heliostat in builds of 1,000 were very aggressive and based upon time and motion studies and new concepts for assembly tooling. ATS and the author felt these estimates may be too low for the first plant. The values used here are from 1990 ATS estimates that are based upon actual experiences building trackers in quantities of hundreds. For example, the labor estimated for mirror module construction was 24 hours, while 8 hours was estimated for mirror support structure, and the installation and checkout was estimated at 24 hours. The much lower SOLMAT estimates for those three tasks were 8, 6.8 , and 3.3 hours respectively.

The labor required to build the baseline HI heliostat was estimated by Kirk Drumheller and Dan Sagie and is believed to have more uncertainty than the ATS estimates because only one unit has been built. There was no evidence that a detailed study had been performed to estimate labor costs for large build quantities. 


\section{Labor Scaling}

The estimated scaling of labor hours with heliostat size varies by task, as listed in Table A-7. These relationships were based upon engineering judgment, not rigorous study, but should be adequate for use in this study intended to establish trends, not exact costs. For some tasks, labor is constant with heliostat size, while for other tasks labor varies in whole, or in part, with the number of mirror modules or with heliostat size. While material costs may trend towards zero as size decreases, this is not true of labor costs. Assembling small parts can, in some cases, even take longer than large parts.

On the ATS heliostat, labor associated with the mirror support structure includes such activities as the alignment and welding of trusses to torque tubes and the installation of cross bracing. The trusses are delivered pre-drilled for mounting mirror modules and cross braces. The number of cross braces and their installation time likely scales with less than the chord of the heliostat. The same is true of the time spent aligning and welding components. Since more labor is done inhouse on the HI heliostat, the number of mirror modules and the heliostat size may have slightly larger impact on labor required. However, the time required for setup and alignment again varies little with size. The same relationship was used for both heliostat designs, with $50 \%$ of the labor scaling with the chord length, and 50\% fixed.

Table A-7. Scaling of Labor Hours by Task

\begin{tabular}{|c|c|c|c|c|}
\hline Task & $\begin{array}{l}\text { ATS Reference } \\
\text { (hours) }\end{array}$ & ATS Scaling & $\begin{array}{l}\text { HI Reference } \\
\text { (hours) }\end{array}$ & HI Scaling \\
\hline \multicolumn{5}{|c|}{ Shop Fabrication } \\
\hline $\begin{array}{l}\text { Mirror Support } \\
\text { Structure }\end{array}$ & 8 & $\begin{array}{l}50 \% \text { linear w/ } \\
\text { chord }\end{array}$ & 8 & $\begin{array}{l}50 \% \text { linear w/ } \\
\text { chord }\end{array}$ \\
\hline Mirror Modules & 24 & $\begin{array}{l}\text { Linear w/ number } \\
\text { of mirror } \\
\text { modules }\end{array}$ & 4 & $\begin{array}{l}\text { Linear w/ number } \\
\text { of mirror } \\
\text { modules }\end{array}$ \\
\hline Controls & 0 & Subcontracted & 0 & Subcontracted \\
\hline Drives & 0 & Subcontracted & 12 & $\begin{array}{l}50 \% \text { linear w/ } \\
\text { chord }\end{array}$ \\
\hline \multicolumn{5}{|c|}{ Installation and Checkout } \\
\hline $\begin{array}{l}\text { Pedestal } \\
\text { Installation }\end{array}$ & 3 & Linear w/ chord & $\begin{array}{l}.4 \text { (scaled from } \\
\text { ATS baseline) } \\
\end{array}$ & Linear w/ chord \\
\hline Painting & 2 & Linear w/ area & 1 & Linear w/ area \\
\hline Final Assembly & 24 & $\begin{array}{l}50 \% \text { linear w/ } \\
\text { number of mirror } \\
\text { modules }\end{array}$ & 8.3 & $\begin{array}{l}50 \% \text { linear } \mathrm{w} / \\
\text { number of mirror } \\
\text { modules }\end{array}$ \\
\hline $\begin{array}{l}\text { Check } \\
\text { Out/Startup }\end{array}$ & 1 & Constant & 1 & Constant \\
\hline $\begin{array}{l}\text { Alignment and } \\
\text { Canting }\end{array}$ & 0 & $\begin{array}{l}\text { Part of final } \\
\text { assembly }\end{array}$ & 4 & $\begin{array}{l}\text { Linear w/ number } \\
\text { of mirror } \\
\text { modules }\end{array}$ \\
\hline
\end{tabular}


To the first order, the labor associated with mirror module construction is treated as proportional to the number of mirror modules, not module size, for the modest changes in module sizes studied. This is largely due to the use of tooling optimized for the job. For example, consider the application of hat section braces to the back of ATS mirror modules. The hat section braces and mirrors are delivered already cut to the proper size and shape. The laborer must prepare and align the parts first, with the help of a fixture and possibly tooling to help handle the various pieces. The assembler must then apply adhesive and attach the hat sections, ensuring a good joint is formed. A jig could be developed to help apply the adhesive, quickly in straight lines, at the proper locations. The additional time increment to perform these steps for a somewhat larger mirror module is typically small compared to the total time for the process. This becomes a better assumption as automation increases, and it was thought that the automation for mirror module production would be well developed because mirror modules are likely the largest quantity item built on site, and the automation is relatively simple to implement.

Only the HI heliostat has labor associated with the drive. The ATS design uses drives provided by a subcontractor so the labor costs associated with building the drive are already included in the materials costs. Since details of the HI drive were unavailable, there was greater uncertainty in establishing the labor scaling relationship. It was felt that the labor should scale with a lower factor than the amount of material in the drive. For example, installing a large bolt typically takes a similar amount of time as installing a small one, even though it weighs more. It was assumed that $50 \%$ of the labor cost was proportional to the heliostat chord, and $50 \%$ was fixed.

$$
\text { HI drive labor cost }=\text { reference cost } / 2 *(1+\text { chord/reference chord })
$$

The pedestal installation labor was assumed linear with chord length to account for changes in the time to drill a hole and pour concrete. No details on the installation of HI pedestals were available, so the same baseline and scaling as the ATS design were used. This is probably a low estimate considering the requirement for rebar installation in the concrete pedestal and foundation.

For both heliostat designs, the painting estimates were scaled with the chord length of the heliostat to match the change in length of the metal support structure such as the pedestal, torque tubes, and trusses. The Pilkington mirror modules used in both designs are already painted.

Final assembly and mirror module alignment (canting) were treated separately in the HI design, and lumped together under the category of final assembly in the ATS design. Mirror alignment labor clearly scales with the number of mirror modules, while the scaling of final assembly tasks such as installing mirror modules on support structure, installing the support structure and drive on the pedestal, and installing control hardware is harder to categorize. It was assumed that 50\% of the labor scales with the number of mirror modules, and $50 \%$ is constant.

The final checkout is a test of the heliostat and control system to ensure everything works properly. The duration of this task is influenced by how quickly the heliostat moves (and whether any problems exist), but is independent of heliostat size. 


\section{A.6 Indirect Costs}

Indirect costs were broken down into categories. The first category includes overhead expenses, profit, and contingencies and was estimated at a constant $25 \%$ of direct costs for both designs and for all heliostat sizes. The overhead includes both management and engineering oversight for the procurement of parts and the heliostat build. In addition, engineering design is required for building a field of heliostats. For this study, we assume a proven heliostat design is used, and only engineering related to the specific project is required. Examples of this include the development of site-specific assembly processes and facilities, designing field wiring and communication systems, addressing siting and permitting issues, etc. An estimate of $\$ 250,000$ is used in this study for these tasks. If a new or unproven heliostat is used, the cost of engineering to develop and validate a design is additional large cost. The cost of assembly tooling and leasing a facility for the heliostat build is estimated at $\$ 800,000$. The cost of leasing heavy equipment such as cranes and fork lifts is estimated at $\$ 200,000$. These estimates have a large uncertainty, but they were included to clearly show that these are cost elements that must be included in a heliostat field budget. The heliostat price is the sum of the direct and indirect costs.

\section{A.7 Optical Performance}

The optical performance of different size heliostats was quantified using the DELSOL code. First, an optimization run was performed to determine the optimum receiver size and tower height for $150-\mathrm{m}^{2}$ heliostats. Other input values used include a heliostat cost of $\$ 150 / \mathrm{m}^{2}$; a max permissible flux of $1.1 \mathrm{MW} / \mathrm{m}^{2}$; horizontal and vertical optical slope errors of $1.4 \mathrm{mrad}$ rootmean-square (RMS); and azimuth and elevation tracking errors of 1 mrad RMS. Default DELSOL input values were used for many parameters. The optimum values determined for the receiver of $8 \mathrm{~m}$ diameter and $9.6 \mathrm{~m}$ height $\left(76.8 \mathrm{~m}^{2}\right)$, and for tower height of $95 \mathrm{~m}$ were then held constant for subsequent performance runs with changing heliostat size. As heliostat size was changed, the total field reflective area was adjusted to achieve the same annual absorbed power as the $150-\mathrm{m}^{2}$ heliostat field. Figure A-7 shows the resulting relationship between heliostat size and total field area. A linear fit to the data was performed, and is also shown in the figure.

$$
\text { field area }=75.7 * \text { heliostat area }\left(\mathrm{m}^{2}\right)+229,359 \mathrm{~m}^{2}
$$

The optical performance of heliostats was valued financially by computing an "adjusted" heliostat cost per square meter equal to the life-cycle cost scaled by the total field area as a fraction of the total field area required for a $150-\mathrm{m}^{2}$ heliostat.

$$
\text { adjusted heliostat cost }=\text { heliostat cost } * \text { field area/field area for } 148-\mathrm{m}^{2} \text { heliostats }
$$

It should be noted that the optical analysis assumes perfectly stiff heliostats that do not sag due to gravity loads. While this assumption may be reasonable for a typical small-to-moderate-sized heliostat (i.e., up to $50 \mathrm{~m}^{2}$ ), it is not true for the typical large heliostat with a stress-limited, rather than a deflection-limited, design. Testing on large heliostats located in the north field has shown that optical performance in the morning and afternoon is worse than predicted by optical codes that assume a perfectly stiff heliostat. The net effect of this modeling deficiency is to make large heliostats appear less costly on an optics-corrected basis than they will be in reality. Until improved modeling of gravity sag is available, this fact must be handled qualitatively in the selection of heliostat size. 


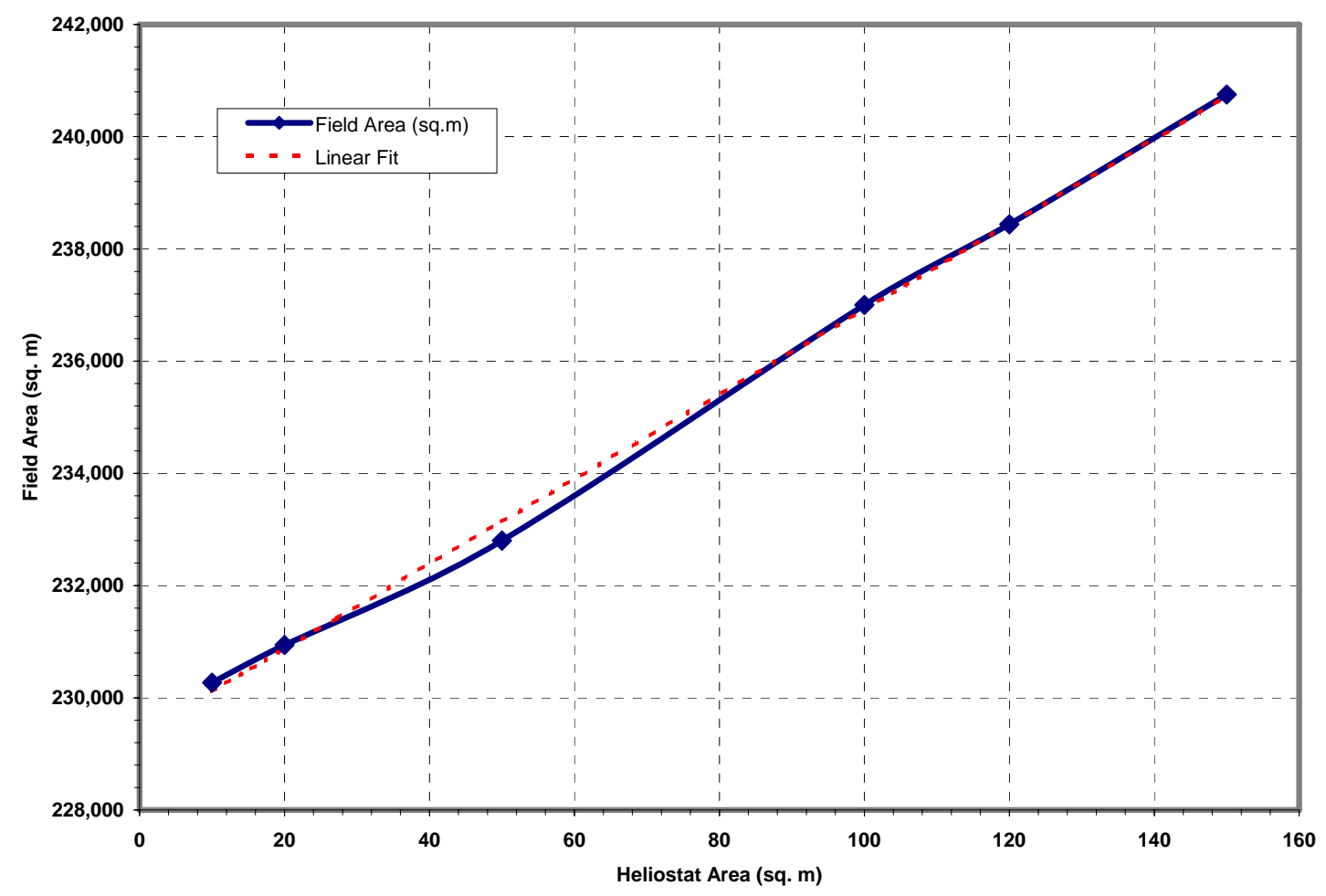

Figure A-7. DELSOL results relating field area and heliostat area.

\section{A.8 Life-Cycle Costs}

Life-cycle costs were included in the analysis because they can differ substantially with heliostat size. This constant-dollar analysis assumes O\&M costs are incurred at the end of each period. The present value, $\mathrm{P}$, may then be found from

$$
P=A \frac{(1+i)^{N}-1}{i(1+i)^{N}}
$$

where $\mathrm{A}$ is the cost per period, $\mathrm{i}$ is the interest per period, and $\mathrm{N}$ is the number of periods.

Simplifying yields

$$
P=A \frac{1-(1+i)^{-N}}{i}
$$

Using financial assumptions of a one-year period, a plant lifetime (n) of 30 years, and a discount rate (i) of $10 \%$ leads to a present value of 9.4 times the annual cost.

$$
\mathrm{P}=9.4 * \mathrm{~A}
$$




\section{Heliostat Operation and Maintenance Costs}

A review was performed in 1999 of collector field O\&M costs at prior and existing solar plants that indicated a wide range of expenses (Table A-8). Labor use at Kramer Junction Company (KJC) was on the low side, while Solar Two had very high labor usage. The KJC data was felt to be the best data available and most representative of a mature, commercial solar plant. In addition, the O\&M tasks related to the troughs at KJC differ some from those relating to heliostats at a power tower plant. The majority of collector field O\&M expenses at a power tower plant are related to correcting heliostat control system failures, whereas HCE problems tend to be included as collector expenses at a trough plant. Only maintenance costs relevant to heliostats were considered.

In 1998, a typical year at KJC, it was estimated 30\% of technician labor was spent correcting communication problems related to poor installation of buried cables. Of the remaining collector system failures, $97.5 \%$ were related to controls electronics and motors. Only $0.3 \%$ of the drives failed, with the vast majority of failures occurring at the earlier plants - suggesting that the root cause was addressed at the later plants. Approximately two technicians are required annually at KJC to maintain the 4,368 collectors, or about one hour per collector per year. A 1987 ATS estimate for field maintenance of 5,000 heliostats, based upon experiences at the Taft enhanced oil recovery project, and tracking photovoltaic (PV) facilities in Hesperia and Carrissa Plains, showed very similar results. Annual parts and materials expenses were estimated at $0.5 \%$ of the control system cost and $0.1 \%$ of the drive cost, a relationship that approximates KJC experiences.

The O\&M expenses predicted in this study may be a bit optimistic for a first plant, and do not include the costs of unexpected problems that may occur. While a field of small heliostats may have a comparable number of mirror modules to a large heliostat field, the quantity of control system components is far greater. In the event of a design error (even the best engineers make mistakes sometimes), manufacturing error, component failure, or uncontrollable event, the cost to fix the problem will likely scale with the number of units, and may be dominated by labor costs. Examples include the systematic failure of a resistor on the control logic board, the failure of motor seals, the degradation of wiring harness from ultraviolet (UV) exposure, or fuse replacement required by a lightning strike. If the fix costs $\$ 100 \mathrm{~K}$ for a field of $100-\mathrm{m}^{2}$ heliostats, it may cost $\$ 1 \mathrm{M}$ to fix a field of $10-\mathrm{m}^{2}$ heliostats. Another potential expense in a scenario like this is a reduction in revenue stream (plant output) because of the difficulty in mobilizing sufficient manpower to quickly fix the problem.

The "bathtub" reliability model suggests that systems undergo a break-in period when failure rates from manufacturing or design flaws are higher, then a period of steady, lower failure rates, and finally a wear-out period when failure rates again rise. While the present value of the wearout phase is low, this is not the case with the break-in period. The failure rates used in this study were from the "bottom" of the bathtub curve at KJC, and did not include the break-in and wearout effects. 
Table A-8. Annual Solar Collector Maintenance Costs Per Unit

\begin{tabular}{|c|c|c|c|c|c|c|c|c|c|c|}
\hline \multirow{2}{*}{$\begin{array}{c}\text { Work Hours/Year } \\
\text { Site }\end{array}$} & \multirow{2}{*}{$\begin{array}{c}2000 \\
\# \\
\text { Collectors }\end{array}$} & \multicolumn{2}{|c|}{ Annual Labor } & \multirow[b]{2}{*}{$\begin{array}{l}\text { Labor } \\
\text { Rate } \\
\text { (\$/hour) }\end{array}$} & \multirow{2}{*}{$\begin{array}{l}\text { Labor } \\
\text { Rate } \\
\text { Other } \\
\text { (\$/hour) }\end{array}$} & \multirow[b]{2}{*}{$\begin{array}{l}\text { Parts \& } \\
\text { Tools } \\
\text { (\$/col) }\end{array}$} & \multirow[b]{2}{*}{ Availability } & \multirow[b]{2}{*}{$\begin{array}{l}\text { Yearly Cost } \\
\text { (\$/Collector) }\end{array}$} & \multirow[b]{2}{*}{$\begin{array}{c}\text { Present } \\
\text { Value }= \\
9.4 \mathrm{x}\end{array}$} & \multirow[b]{2}{*}{ Notes } \\
\hline & & \begin{tabular}{c|} 
Technician \\
(hours/ \\
collector)
\end{tabular} & $\begin{array}{l}\text { Other } \\
\text { (est.) }\end{array}$ & & & & & & & \\
\hline $\mathrm{KJC}$ & 4,368 & $\begin{array}{r}0.92 \\
\end{array}$ & 0.11 & 25 & 40 & $\$ 8.60$ & $99 \%$ & 36.1 & 339.1 & 2 \\
\hline Solar One & 1,818 & 1.65 & & 25 & 40 & & $96 \%-99 \%$ & 41.3 & 387.8 & 4 \\
\hline Solar Two & 1,926 & 2.08 & 0.52 & 25 & 40 & $\$ 156$ & $88 \%$ & 228.5 & $2,147.5$ & 1 \\
\hline SSPS (PSA) & 92 & 8.15 & & 25 & 40 & & & 203.8 & $1,915.8$ & \\
\hline CESA-1 (PSA) & & & & 25 & 40 & & & 0.0 & 0.0 & \\
\hline CRTF & 222 & 5.94 & & 25 & 40 & & & 148.5 & $1,395.9$ & 5 \\
\hline $\begin{array}{l}\text { Gorman } 1987 \\
\text { Estimate }\end{array}$ & 5,000 & 0.93 & 0.00 & 25 & 40 & & & 35.3 & 331.9 & \\
\hline $\begin{array}{l}\text { CP \& Lugo (PV) + } \\
\text { Taft (EOR) }\end{array}$ & 937 & 6.40 & 0.00 & 25 & 40 & & & & & \\
\hline \multicolumn{11}{|c|}{$\begin{array}{l}\text { Notes: } \\
\text { 1. Field Efficiency } \sim 85 \% \text { of predictions, due to geometrical tracking errors and intermittent controls failures that do not show up in } \\
\text { availability numbers. Two technicians at end of project, more early on and during "pushes." } \\
\text { 2. Harvey Stephens estimates that operators spend } 8-10 \text { hours/week assisting with field controls maintenance. } \\
\text { 3. Based upon experience gained at Carrissa \& Hesperia PV plants, EOR ( } 1,000 \text { heliostats). } \\
\text { 4. For final year of 5-day/week operation. } \\
\text { 5. Average repair rate of } 0.66 \text { units/year @ } 9 \text { hours each ( } 0.3 \% \text { of capital cost). } \\
\text { 6. Includes repair of PV hardware (panels, inverters, etc.)? }\end{array}$} \\
\hline
\end{tabular}

\section{Heliostat Washing}

Heliostat washing costs are based upon other recent studies (Jones, 1999a, 1999b, 1999c) and reflect the use of high-pressure spray methods used at KJC and currently thought to be the optimal approach for troughs. Median input values were used here. Specifically, it is assumed these non-inverting heliostats will experience an average soiling rate of $0.35 \%$ per day with the equivalent of 10 natural washes per year, a labor rate of \$20/hour, and a cleanliness target of $97 \%$. This leads to an annual washing cost of $\$ 0.35 / \mathrm{m}^{2}$, assumed constant across heliostat size variations. Washing costs for small heliostats would probably be slightly higher in developed countries due to an increase in labor required per square meter of mirror.

\section{A.8 Results and Conclusions}

Attached are spreadsheets showing costs, broken down by category, for the various sizes of each heliostat design. Figure A-8 shows the optics-adjusted, life-cycle cost for varying sizes of the ATS and HI design. The optimum size of the HI heliostat was $53 \mathrm{~m}^{2}$, while the optimum size ATS heliostat was $214 \mathrm{~m}^{2}$, in both cases larger than the baseline size. As discussed in the optical modeling section, better modeling of gravity sag would increase the effective cost of very large heliostats. The author and ATS both believe the optimum size of their design would be no larger than $150 \mathrm{~m}^{2}$ if optical performance were modeled more accurately. Since the HI cost estimates are considered less mature and to have higher uncertainty, it is not recommended to compare them directly with the ATS estimates. Given this uncertainty, a fair conclusion to draw from the study is that the optimum heliostat size for a molten-salt power tower is between 50 and $150 \mathrm{~m}^{2}$. 
Additionally, a number of graphs are shown displaying the breakdown of costs by category and the percentage of parts costs by component. Overall, it is clear that the part costs dominate both labor costs and the present value of O\&M costs for all heliostat sizes studied here, so further work to refine the scaling of labor costs with heliostat size is not of great value. The low O\&M costs used in this study are achievable assuming a proven design and well-tested components are used. Anything less could increase O\&M costs substantially, particularly for smaller heliostats.

Conversely, the scaling of materials costs, particularly drives and mirror support structure, is critical in optimizing the size of heliostats. The ATS results show that the drive cost, as a percentage of the materials costs, decreases for larger-size heliostats. The mirror support structure shows the inverse trend. The HI drive and mirror support costs and scaling relationships differed from those found for the ATS design, but should be given less consideration as they were found to disagree with established benchmarks and reasonable expectations. To improve estimates, the costs and cost scaling of planocentric and worm drives should be further explored for the build quantities of Solar Tres and for potential future plants as well. The cost of linear actuator elevation drives is not well known and should be established with more certainty. Mirror cost does not affect the size scaling issue, but does impact the final cost. Using silvered Saint-Gobain mirrors from Cristaleria Espanola at approximately $\$ 12 / \mathrm{m}^{2}$, rather than Pilkington mirrors at $\$ 27 / \mathrm{m}^{2}$, would reduce heliostat cost. Durability is the concern and should be tested. Finally, the logic controller and especially the wiring costs would benefit from an update.

The cost fraction of controls becomes significant only for very small heliostats, so efforts to significantly reduce these costs only become important if new information reverses the trends seen here and supports very small heliostats as less costly.

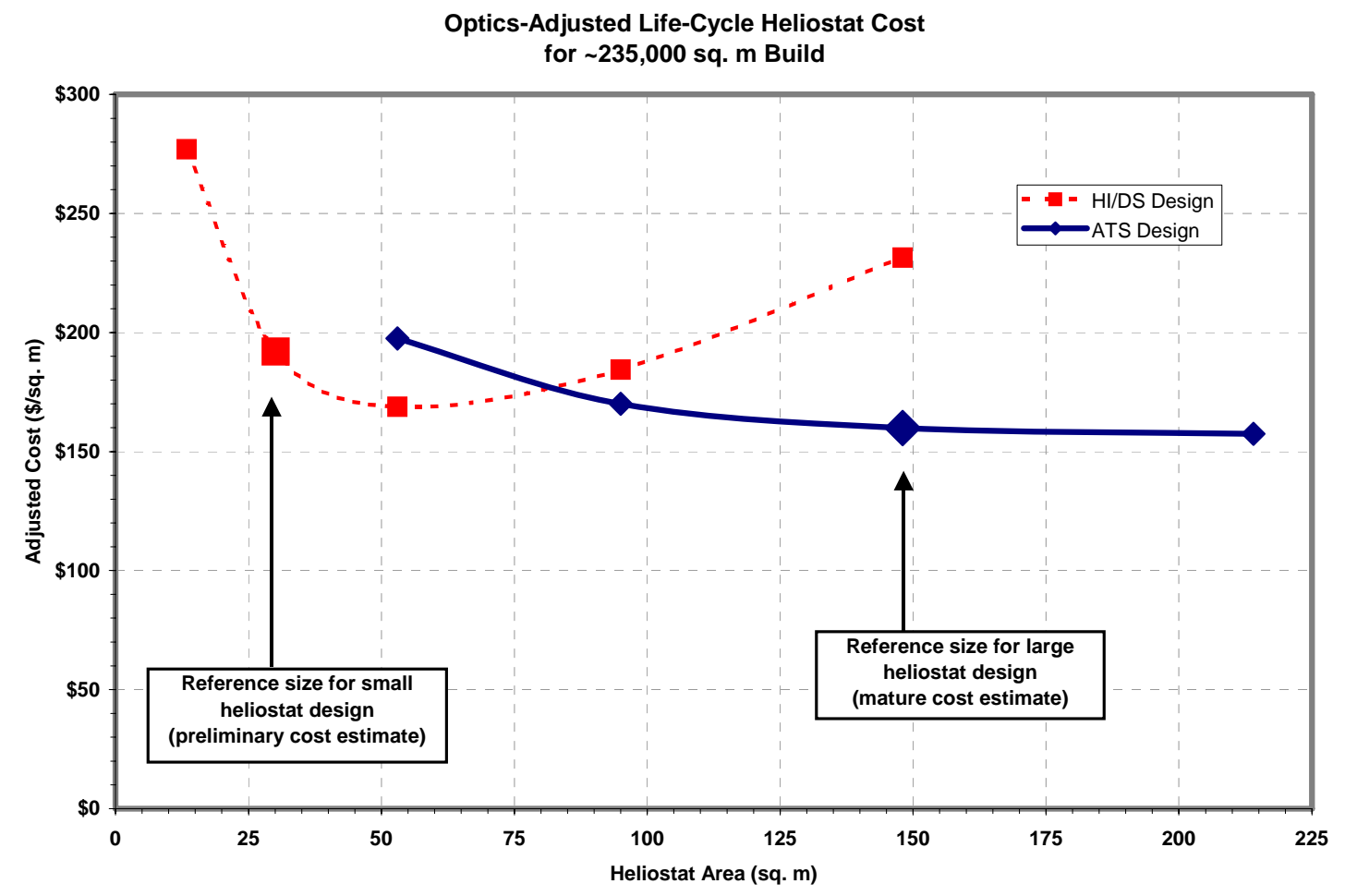

Figure A-8. Optics-adjusted, life-cycle cost of ATS and HI heliostats. 


\section{A.9 References}

Peterka, J.A., and R.G. Derickson, 1992, Wind Load Design Methods for Ground Based Heliostats and Parabolic Dish Collectors, Sandia National Laboratories, SAND92-7009, September 1992.

Popov, E.P., 1976, Mechanics of Materials, Second Edition, Prentice-Hall, p. 572.

SOLMAT Final Review Meeting Vu-Graphs, Sandia National Laboratories, May 1996. Contact: Tom Mancini or Greg Kolb, gjkolb@sandia.gov.

These references appear at the end of this appendix:

Jones, S.A., 1999a, "Calculating the Present Value of Heliostat Inverted-Stow Capability," Memo to Distribution, July 8, 1999, Sandia National Laboratories, Albuquerque, NM.

Jones, S.A., 1999b, "Estimating Annual Cost and Present Value of KJC's Two-Method MirrorWashing Program,” Memo to Distribution, July 7, 1999, Sandia National Laboratories, Albuquerque, NM.

Jones, S.A., 1999c, "Estimating the Present Value of Collector Washing Costs at a Solar Plant," Memo to Distribution, Sandia National Laboratories, July 6, 1999, Albuquerque, NM. 


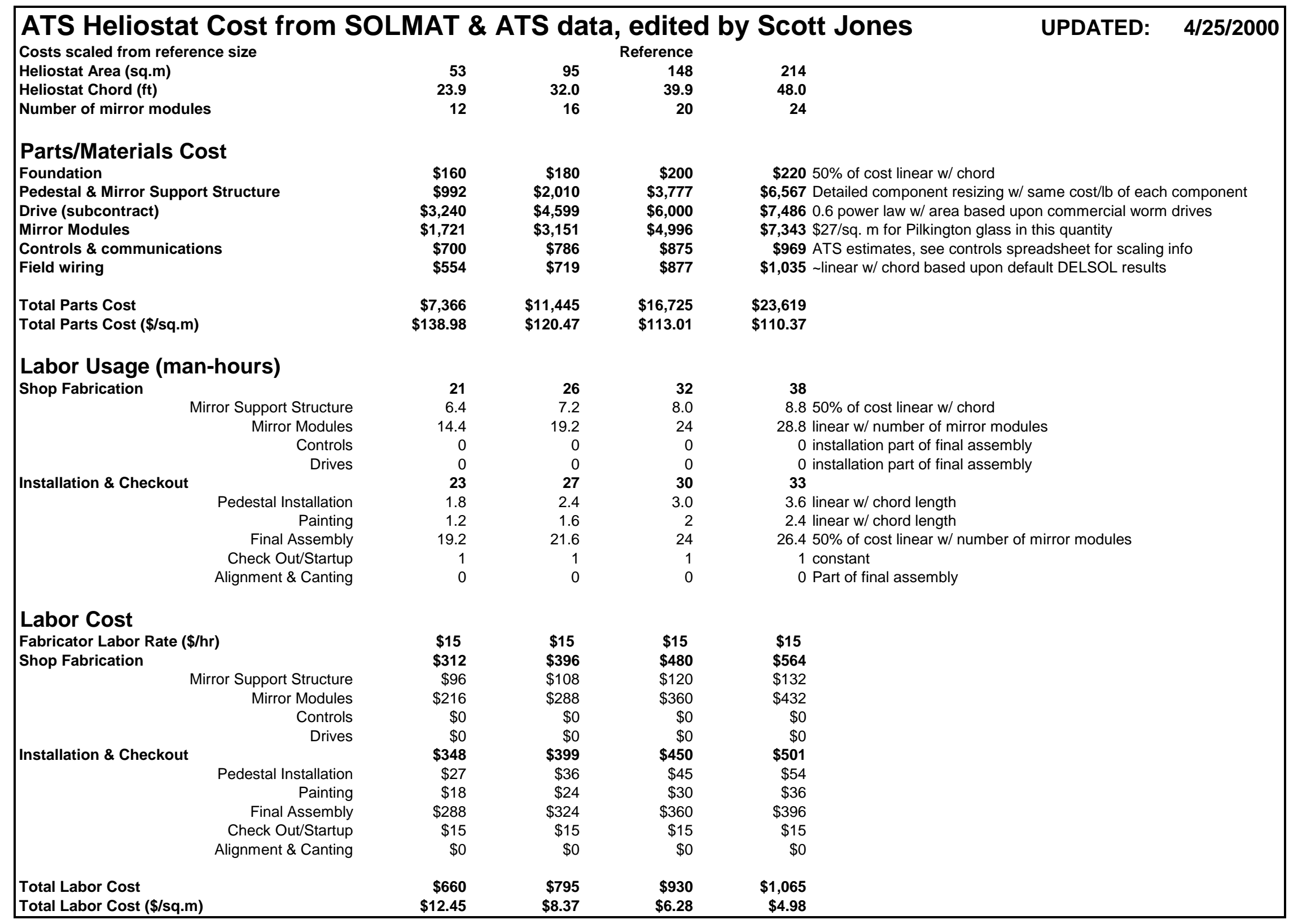




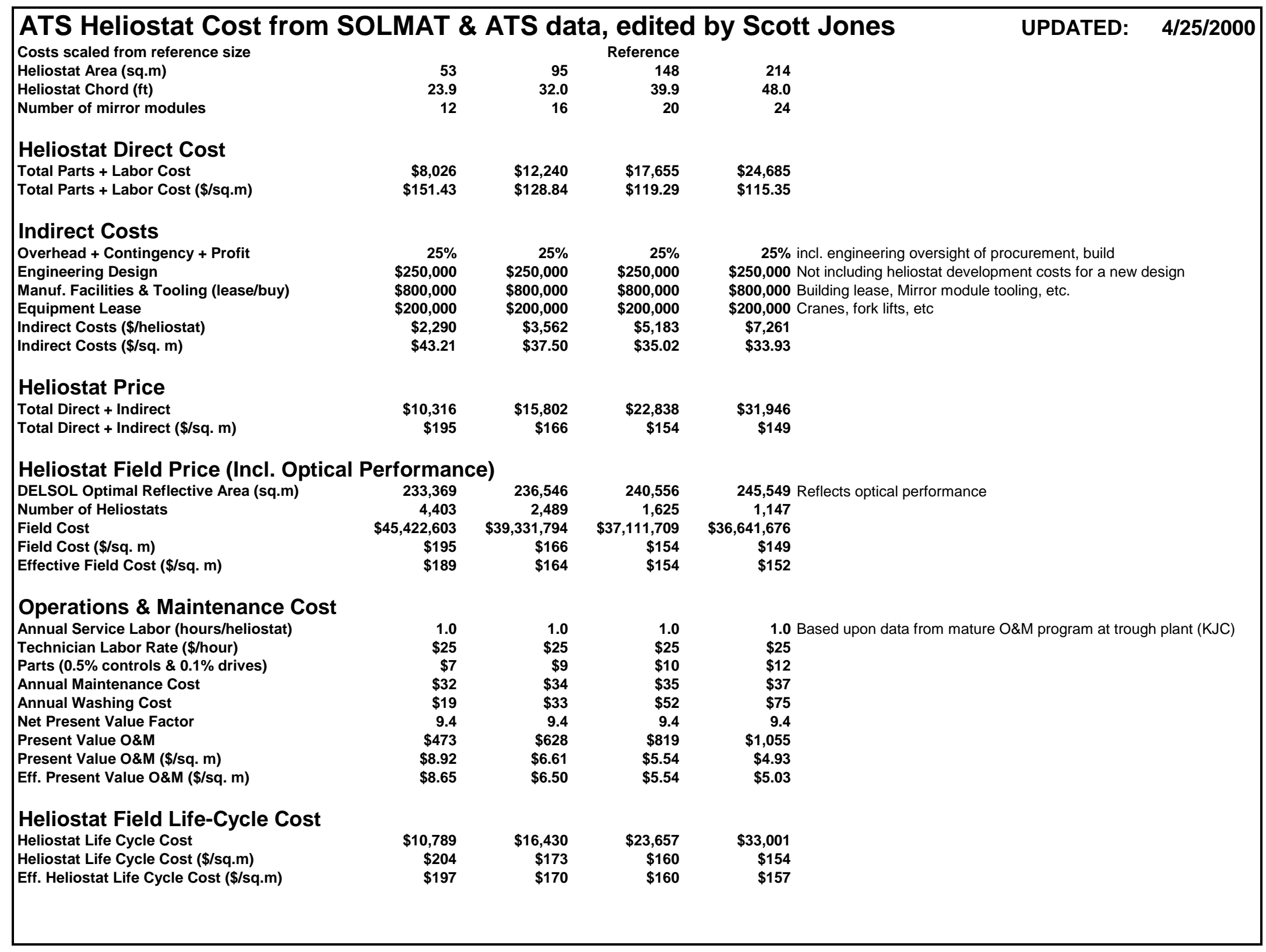




\begin{tabular}{|c|c|c|c|c|c|}
\hline \multicolumn{6}{|c|}{ Heliostat Inc. Heliostat Cost from Kirk Drumheller \& Dan Sagie, modified by Scott Jones } \\
\hline Heliostat Area (sq.m) & 13.4 & 30.1 & 53 & 95 & 148 \\
\hline Heliostat Chord (ft) & 12.0 & 18.0 & 23.9 & 32.0 & 39.9 \\
\hline Number of mirror modules & 3 & 6 & 12 & 16 & 20 \\
\hline \multicolumn{6}{|l|}{ Parts/Materials Cost } \\
\hline Foundation \& Pedestal & $\$ 60$ & $\$ 204$ & $\$ 471$ & $\$ 1,101$ & $\$ 2,234$ Cubic w/ chord \\
\hline Mirror Support Structure & $\$ 36$ & $\$ 81$ & $\$ 145$ & $\$ 257$ & $\$ 402$ Square w/ chord \\
\hline Drive Materials & $\$ 964$ & $\$ 1,506$ & $\$ 2,471$ & $\$ 6,626$ & $\$ 15,948$ Motors part of control system \\
\hline Mirror Modules & $\$ 385$ & $\$ 867$ & $\$ 1,519$ & $\$ 2,670$ & $\$ 4,282$ Modified to use Pilkington quote for glass \\
\hline Controls \& wired communications & $\$ 579$ & $\$ 639$ & $\$ 700$ & $\$ 786$ & \$875 standard logic controller \& wired communications \\
\hline Field wiring & $\$ 299$ & $\$ 430$ & $\$ 554$ & $\$ 719$ & $\$ 877 \sim$ linear w/ chord based upon default DELSOL results \\
\hline Total Parts Cost & $\$ 2,322$ & $\$ 3,727$ & $\$ 5,859$ & $\$ 12,159$ & $\$ 24,618$ \\
\hline Total Parts Cost (\$/sq.m) & $\$ 173.29$ & $\$ 123.82$ & $\$ 110.56$ & $\$ 127.99$ & $\$ 166.34$ \\
\hline \multicolumn{6}{|l|}{ Labor Usage (man-hours) } \\
\hline Shop Fabrication & 19 & 24 & 31 & 38 & 46 \\
\hline Mirror Support Structure & 6.7 & 8.0 & 9.3 & 11.1 & $12.950 \%$ of cost linear w/ chord \\
\hline Mirror Modules & 2.0 & 4.0 & 8.0 & 10.7 & 13.3 linear $w /$ number of mirror modules \\
\hline Controls & 0.0 & 0.0 & 0.0 & 0.0 & 0.0 subcontracted \\
\hline Drives & 10.0 & 12.0 & 14.0 & 16.7 & $19.350 \%$ of cost linear w/ chord \\
\hline Installation \& Checkout & 12 & 17 & 28 & 36 & 44 \\
\hline Pedestal construction \& Installation & 0.9 & 1.4 & 1.8 & 2.4 & 3.0 linear $w /$ chord length \\
\hline Painting & 0.4 & 1 & 1.8 & 3.2 & 4.9 linear w/ chord length \\
\hline Final Assembly & 7.5 & 10 & 15.0 & 18.3 & $21.750 \%$ of cost linear w/ number of mirror modules \\
\hline Check Out/Startup & 1 & 1 & 1 & 1 & 1 constant \\
\hline Alignment \& Canting & 2.0 & 4 & 8.0 & 10.7 & 13.3 linear w/ number of mirror modules \\
\hline \multicolumn{6}{|l|}{ Labor Cost } \\
\hline Fabricator Labor Rate (\$/hr) & $\$ 15$ & $\$ 15$ & $\$ 15$ & $\$ 15$ & $\$ 15$ \\
\hline Shop Fabrication & $\$ 280$ & $\$ 360$ & $\$ 469$ & $\$ 576$ & $\$ 683$ \\
\hline Mirror Support Structure & $\$ 100$ & $\$ 120$ & $\$ 140$ & $\$ 167$ & $\$ 193$ \\
\hline Mirror Modules & $\$ 30$ & $\$ 60$ & $\$ 120$ & $\$ 160$ & $\$ 200$ \\
\hline Controls & $\$ 0$ & $\$ 0$ & $\$ 0$ & $\$ 0$ & $\$ 0$ \\
\hline Drives & $\$ 150$ & $\$ 180$ & $\$ 209$ & $\$ 250$ & $\$ 290$ \\
\hline Installation \& Checkout & $\$ 178$ & $\$ 260$ & $\$ 413$ & $\$ 533$ & $\$ 659$ \\
\hline Pedestal Installation & $\$ 14$ & $\$ 20$ & $\$ 27$ & $\$ 36$ & $\$ 45$ \\
\hline Painting & $\$ 7$ & $\$ 15$ & $\$ 26$ & $\$ 47$ & $\$ 74$ \\
\hline Final Assembly & $\$ 113$ & $\$ 150$ & $\$ 225$ & $\$ 275$ & $\$ 325$ \\
\hline Check Out/Startup & $\$ 15$ & $\$ 15$ & $\$ 15$ & $\$ 15$ & $\$ 15$ \\
\hline Alignment \& Canting & $\$ 30$ & $\$ 60$ & $\$ 120$ & $\$ 160$ & $\$ 200$ \\
\hline Total Labor Cost & $\$ 458$ & $\$ 620$ & $\$ 882$ & $\$ 1,110$ & $\$ 1,341$ \\
\hline Total Labor Cost (\$/sq.m) & $\$ 34$ & $\$ 21$ & $\$ 17$ & $\$ 12$ & $\$ 9$ \\
\hline
\end{tabular}




\begin{tabular}{|c|c|c|c|c|c|}
\hline \multicolumn{6}{|c|}{ Heliostat Inc. Heliostat Cost from Kirk Drumheller \& Dan Sagie, modified by Scott Jones } \\
\hline $\begin{array}{l}\text { Costs scaled from reference size } \\
\text { Heliostat Area (sq.m) }\end{array}$ & 13.4 & $\begin{array}{r}\text { Reterence } \\
30.1\end{array}$ & 53 & 95 & 148 \\
\hline Heliostat Chord (ft) & 12.0 & 18.0 & 23.9 & 32.0 & 39.9 \\
\hline Number of mirror modules & 3 & 6 & 12 & 16 & 20 \\
\hline \multicolumn{6}{|l|}{ Heliostat Direct Cost } \\
\hline Total Parts + Labor Cost & $\$ 2,780$ & $\$ 4,347$ & $\$ 6,742$ & $\$ 13,269$ & $\$ 25,959$ \\
\hline Total Parts + Labor Cost (\$/sq.m) & $\$ 207$ & $\$ 144$ & $\$ 127$ & $\$ 140$ & $\$ 175$ \\
\hline \multicolumn{6}{|l|}{ Indirect Costs } \\
\hline Overhead + Contingency + Profit & $25 \%$ & $25 \%$ & $25 \%$ & $25 \%$ & $\mathbf{2 5 \%}$ incl. engineering oversight of procurement, build \\
\hline Engineering Design & $\$ 250,000$ & $\$ 250,000$ & $\$ 250,000$ & $\$ 250,000$ & $\$ 250,000$ Not including heliostat development costs for a new design \\
\hline Manuf. Facilities \& Tooling (lease/buy) & $\$ 1,000,000$ & $\$ 1,000,000$ & $\$ 1,000,000$ & $\$ 1,000,000$ & $\$ 1,000,000$ Building lease, Mirror module tooling, etc. \\
\hline Equipment Lease & $\$ 200,000$ & $\$ 200,000$ & $\$ 200,000$ & $\$ 200,000$ & $\$ 200,000$ Cranes, fork lifts, etc \\
\hline Indirect Costs (\$/heliostat) & $\$ 779$ & $\$ 1,275$ & $\$ 2,015$ & $\$ 3,900$ & $\$ 7,382$ \\
\hline Indirect Costs (\$/sq. m) & $\$ 58.16$ & $\$ 42.37$ & $\$ 38.01$ & $\$ 41.05$ & $\$ 49.88$ \\
\hline \multicolumn{6}{|l|}{ Heliostat Price } \\
\hline Total Direct + Indirect & $\$ 3,559$ & $\$ 5,622$ & $\$ 8,757$ & $\$ 17,169$ & $\$ 33,342$ \\
\hline Total Direct + Indirect (\$/sq. m) & $\$ 266$ & $\$ 187$ & $\$ 165$ & $\$ 181$ & $\$ 225$ \\
\hline \multicolumn{6}{|c|}{ Heliostat Field Price (Incl. Optical Performance) } \\
\hline DELSOL Optimal Reflective Area (sq.m) & 230,373 & 231,637 & 233,369 & 236,546 & 240,556 Reflects optical performance \\
\hline Number of Heliostats & 17,192 & 7,695 & 4,403 & 2,489 & 1,625 \\
\hline Field Cost & $\$ 61,190,643$ & $\$ 43,265,109$ & $\$ 38,555,378$ & $\$ 42,734,112$ & $\$ 54,179,954$ \\
\hline Field Cost (\$/sq. m) & $\$ 266$ & $\$ 187$ & $\$ 165$ & $\$ 181$ & $\$ 225$ \\
\hline Effective Field Cost (\$/sq. m) & $\$ 254$ & $\$ 180$ & $\$ 160$ & $\$ 178$ & $\$ 225$ \\
\hline \multicolumn{6}{|c|}{ Operations \& Maintenance Cost } \\
\hline Annual Service Labor (hours/heliostat) & 1.0 & 1.0 & 1.0 & 1.0 & 1.0 Based upon data from mature O\&M program at trough plant (KJC) \\
\hline Technician Labor Rate (\$/hour) & $\$ 25$ & $\$ 25$ & $\$ 25$ & $\$ 25$ & $\$ 25$ \\
\hline Parts $(0.5 \%$ controls $\& 0.1 \%$ drives $)$ & $\$ 4$ & $\$ 5$ & $\$ 6$ & $\$ 11$ & $\$ 20$ \\
\hline Annual Maintenance Cost & $\$ 29$ & $\$ 30$ & $\$ 31$ & $\$ 36$ & $\$ 45$ \\
\hline Annual Washing Cost & $\$ 5$ & $\$ 11$ & $\$ 19$ & $\$ 33$ & $\$ 52$ \\
\hline Net Present Value Factor & 9.4 & 9.4 & 9.4 & 9.4 & 9.4 \\
\hline Present Value O\&M & $\$ 315$ & $\$ 378$ & $\$ 465$ & $\$ 647$ & $\$ 913$ \\
\hline Present Value O\&M (\$/sq. m) & $\$ 23.53$ & $\$ 12.57$ & $\$ 8.78$ & $\$ 6.81$ & $\$ 6.17$ \\
\hline Eff. Present Value O\&M (\$/sq. m) & $\$ 22.54$ & $\$ 12.10$ & $\$ 8.52$ & $\$ 6.69$ & $\$ 6.17$ \\
\hline \multicolumn{6}{|l|}{ Heliostat Field Life-Cycle Cost } \\
\hline Heliostat Life Cycle Cost & $\$ 3,875$ & $\$ 6,001$ & $\$ 9,222$ & $\$ 17,816$ & $\$ 34,254$ \\
\hline Heliostat Life Cycle Cost (\$/sq.m) & $\$ 289$ & $\$ 199$ & $\$ 174$ & $\$ 188$ & $\$ 231$ \\
\hline Eff. Heliostat Life Cycle Cost (\$/sq.m) & $\$ 277$ & $\$ 192$ & $\$ 169$ & $\$ 184$ & $\$ 231$ \\
\hline
\end{tabular}




\section{国 Sandia National laboratories \\ Operated for the U.S. Department of Energy by}

Sandia Corporation

\section{date: July 8, 1999 \\ Distribution}

subject: Calculating the Present Value of Heliostat Inverted-Stow Capability

The value of heliostat inverted-stow capability has been analyzed previously. In August 1979, a study by J.B. Blackmon et al. of McDonnell Douglas was published showing net cost savings of $12-13 \%$ by removing the inverting capability from their $50 \mathrm{~m}^{2}$ heliostat design [1]. The savings were the result of a $4 \%$ increase in present value costs due to more frequent mirror washing that was more than offset by $8 \%$ cost reductions from each: A) removing a second jack screw from the elevation drive, and B) reducing the number of heliostats by $10 \%$ after filling the vertical slot required for inverted stow with reflective area. In June 1981, A. Kerstein of Sandia published a study in response concluding that the cost savings are very design dependent, and with worst-case assumptions may not favor the non-inverting heliostat like the previous study [2]. This memo provides an updated estimate of the value of inverting capability based on a more detailed model using the latest input data available.

In Reference 1, they examined three costs associated with stow position: dust buildup, hail damage, and beam safety. They concluded that the hail damage and beam safety issues were not important factors, and our experiences since with glass reflectors (all current and nearterm designs use glass) have only confirmed this observation. Thin, polymer-film, membrane reflectors may be more subject to hail damage, so further analysis would be required for this case. The key issue then becomes dust buildup—also known as mirror soiling —and the associated cost of mirror washing. The costs of mirror washing were estimated with a new model developed for this purpose. The model and input data are described in Reference 3 in detail, so will not be discussed here. Three scenarios were examined to estimate the likely value of inverted-stow capability as well as find the upper and lower bounds of that value. Table 1 shows the input data used for the 3 scenarios.

The likely cost scenario uses mostly data from KJC for the Mr. Twister method, an inverted soiling rate of $0.30 \%$ per day, 10 equivalent natural washes per year, and a discount rate of $10 \%$. The low cost scenario uses a lower inverted soiling rate of $0.20 \%$ per day, 15 natural washings per year, reduced labor use (equal to KJC), and a labor cost of $\$ 5 / \mathrm{hr}$ to approximate costs in a developing nation. Assuming a discount rate of $15 \%$ and equipment lifetime of 15 years also reduces costs in this scenario. The annual cleanliness target is $97 \%$ for the both the low cost and likely cost scenarios, but is only $95 \%$ for the high cost scenario to reflect that economics will dictate less washing if it is expensive. In addition, the high cost scenario assumes a more expensive wash vehicle capable of $99 \%$ cleanliness, rather than $98 \%$, because the high wash costs encourage technology improvements. The high cost scenario assumes more expensive labor (e.g. union), water, and fuel. It is also assumes that the 
average inverted soiling rate is higher at $0.40 \%$ per day, while the discount rate is only $5 \%$. Finally, the high cost scenario assumes that labor costs to wash non-inverted heliostats are actually $25 \%$ higher than to wash inverted heliostats - certainly a worst-case assumption.

Table 1. Input Data for Scenarios Analyzed

\begin{tabular}{|c|c|c|c|c|c|c|}
\hline \multirow[b]{2}{*}{ Parameter } & \multicolumn{2}{|c|}{ Low Cost } & \multicolumn{2}{|c|}{ Likely Cost } & \multicolumn{2}{|c|}{ High Cost } \\
\hline & Inverting & Non-Inverting & Inverting & Non-Inverting & Inverting & Non-Inverting \\
\hline Labor Use (man-hours/sq.m) & 0.0003 & 0.0003 & 0.0004 & 0.0004 & 0.0004 & 0.0005 \\
\hline Labor Rate $(\$ / h r)$ & 5 & 5 & 20 & 20 & 40 & 40 \\
\hline DI Water Use (gal/sq.m) & 0.25 & 0.25 & 0.25 & 0.25 & 0.25 & 0.25 \\
\hline DI Water Cost (\$/gal) & 0.003 & 0.003 & 0.003 & 0.003 & 0.01 & 0.01 \\
\hline Fuel Use (gal/sq.m) & 0.00038 & 0.00038 & 0.0004 & 0.0004 & 0.0008 & 0.0008 \\
\hline Fuel Cost (\$/gal) & 1 & 1 & 1.2 & 1.2 & 1.8 & 1.8 \\
\hline Equipment Cost (\$/sq.m) & 0.2 & 0.2 & 0.44 & 0.44 & 0.6 & 0.6 \\
\hline Equipment Lifetime (years) & 15 & 15 & 10 & 10 & 10 & 10 \\
\hline Discount Rate (\%/year) & $15 \%$ & $15 \%$ & $10 \%$ & $10 \%$ & $5 \%$ & $5 \%$ \\
\hline Soiling Rate (\%/day) & $0.2 \%$ & $0.2-0.5 \%$ & $0.3 \%$ & $0.3-0.6 \%$ & $0.4 \%$ & $0.4-0.7 \%$ \\
\hline Cleanliness Target (\%) & $97 \%$ & $97 \%$ & $97 \%$ & $97 \%$ & $95 \%$ & $95 \%$ \\
\hline Cleanliness After Wash(\%) & $98 \%$ & $98 \%$ & $98 \%$ & $98 \%$ & $99 \%$ & $99 \%$ \\
\hline Effective Natural Wash Frequency & 15 & 15 & 10 & 10 & 5 & 5 \\
\hline Annual Addt'I Wash Frequency & 21.5 & $21.5-76.2$ & 26.5 & $26.5-63.0$ & 13.3 & 13.3-26.9 \\
\hline
\end{tabular}

Figure 1 shows the number of supplemental washes for each case required of the noninverting heliostat as a function of the difference in soiling rate between inverted and noninverted heliostats during severe weather. Reference 1 provides an estimate of $0.05-0.2 \%$ per day difference between the two stow methods under severe weather, a range indicated on the graph.

The net present value of inverting capability for each scenario is presented in Figure 2. The likely scenario indicates a value of $\$ 0.53-2.12 / \mathrm{m}^{2}$ for inverting capability. The bounding values are $\$ 0.16 / \mathrm{m}^{2}$ on the low end and $\$ 4.17 / \mathrm{m}^{2}$ on the upper end. It is hard to imagine a heliostat design with inversion capability for an incremental cost less than even the high-end estimated value. In Reference 1 , the cost of inversion capability was estimated to be $\$ 11 / \mathrm{m}^{2}$ of a $\$ 65 / \mathrm{m}^{2}$ heliostat (1978\$). The main reason for this result-even more favorable to noninverting heliostats than the McDonnell Douglas study —is that the cost of washing is very low. KJC's costs are less than $1 / 2$ of the McDonnell Douglas estimates before correction to current dollars. 


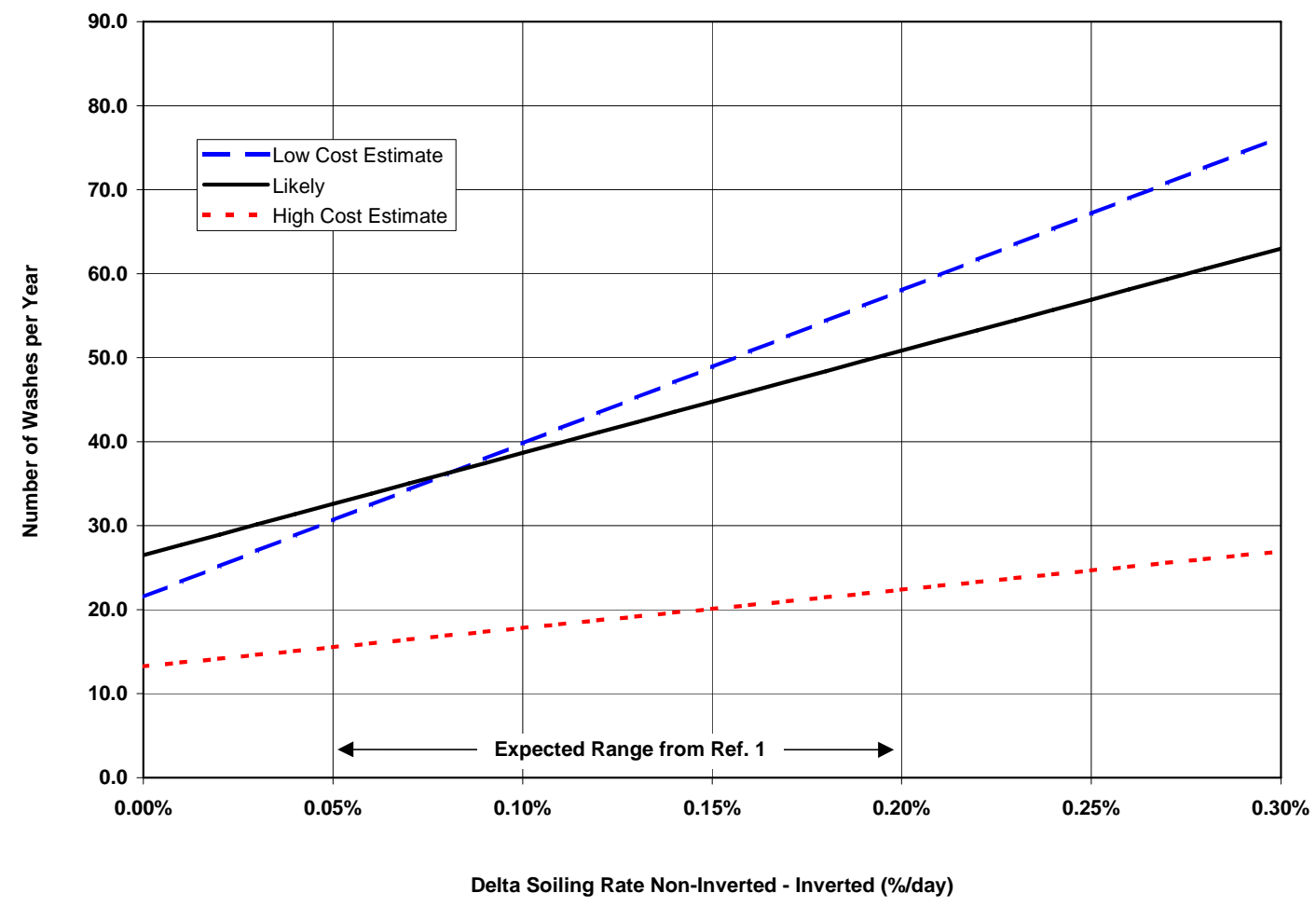

Figure 1. Number of Annual Washes for Non-Inverting Heliostats as a Function of the Difference in Soiling Rate between Inverting and Non-Inverting Heliostats.

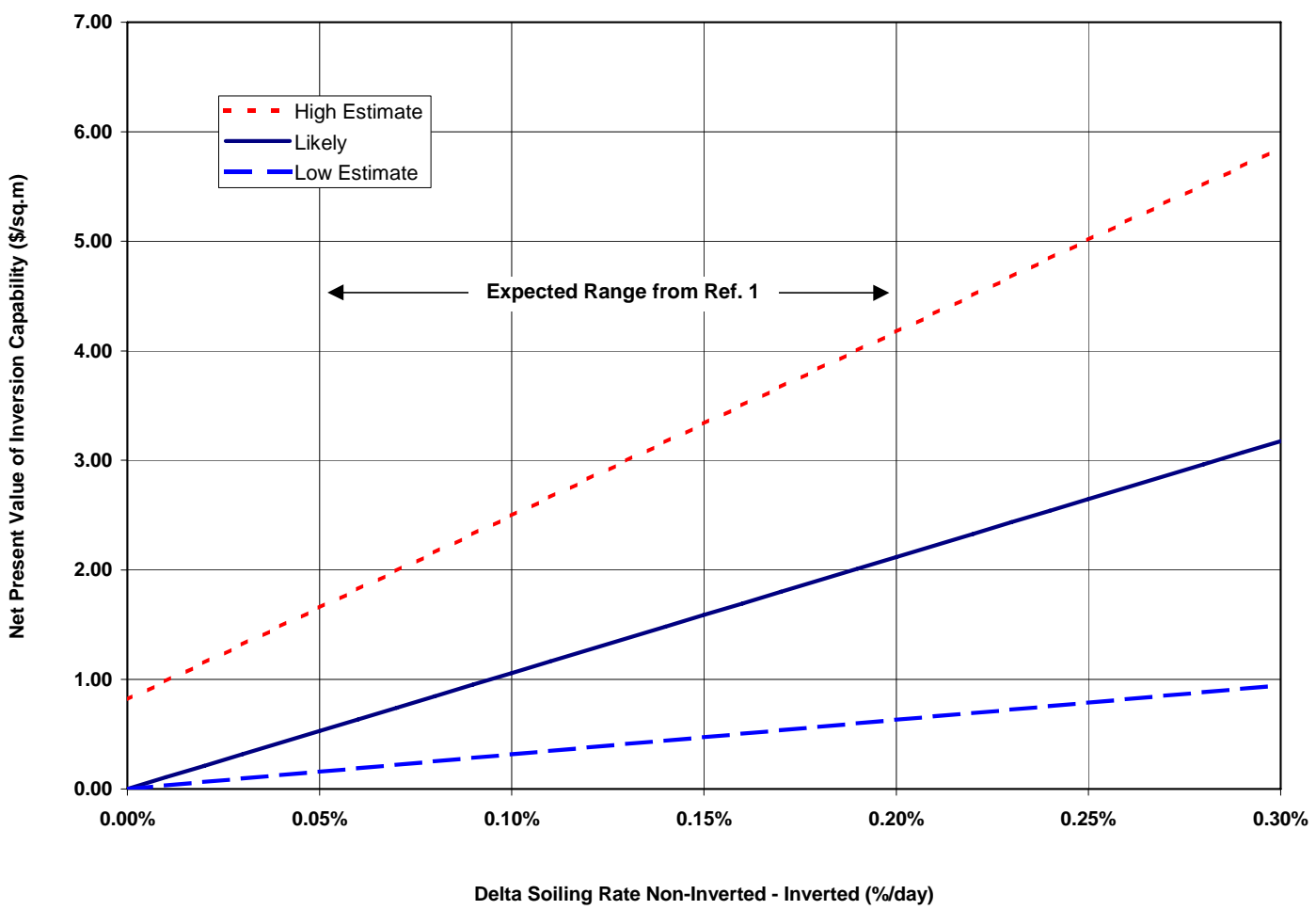

Figure 2. Present Value of Heliostat Inverted-Stow Capability as a Function of Difference between Soiling Rates for Inverted and Non-Inverted Heliostats 


\section{References}

[1] J.B. Blackmon, D.W. Harvey, R.H. McFee, “Non-Inverting Heliostat Study,” SAND788190, Sandia National Laboratories, Livermore, CA, August 1979.

[2] A. Kerstein, "Evaluation of Inverted Stow Capability for Heliostats,” SAND81-8277, Sandia National Laboratories, Livermore, CA, June 1981.

[3] S.A. Jones, "Estimating the Present Value of Collector Washing Costs at a Solar Plant,” Memo to Distribution, Sandia National Laboratories, Albuquerque, NM, July 6, 1999.

\section{Distribution:}

Rich Diver, MS-0703 (6216)

Greg Kolb, MS-0703 (6216)

Jim Pacheco, MS-0703 (6216)

Hugh Reilly, MS-0703 (6216)

Craig Tyner, MS-0703 (6216)

Robert Edgar, MS-1127 (6215)

Richard Houser, MS-1127 (6215)

Jim Grossman, MS-1127 (6215)

Rod Mahoney, MS-1127 (6215)

Joe Tillerson, MS-1127 (6215)

Scott Faas, MS-9014 (2271)

Mary Jane Hale, NREL

Hank Price, NREL

Dan Sagie, NREL

Tim Wendelin, NREL 
Operated for the U.S. Department of Energy by Sandia Corporation
date: July 7, 1999
to: Distribution

Albuquerque, New Mexico 87185-0703

from: Scott A. Jones, MS-0703 (6216)

subject: $\quad$ Estimating Annual Cost and Present Value of KJC’s Two-Method Mirror Washing Program

A related memo describes the development of a general model for estimating the present value of mirror washing costs for a solar plant [1]. That model assumes one mirror cleaning approach is used, whereas KJC uses a combination of two cleaning methods: Mr. Twister and the Deluge truck [2]. The general strategy used by KJC is to wash with the deluge truck twice between each Mr. Twister wash. The deluge truck is much faster and was used about 32 times in 1998, but only washed to $961 / 2 \%$ cleanliness on average. Mr. Twister washed to $98 \%$ cleanliness on average and was used about 16 times in 1998. A more complicated model than previously developed is needed to simulate this approach at KJC. Figure 1 shows the parameters used in this simulation. In addition to instantaneous washing, a constant soiling rate, $\mathrm{R}_{\text {soil }}$, and a consistent threshold cleanliness at which washing occurs are assumed.

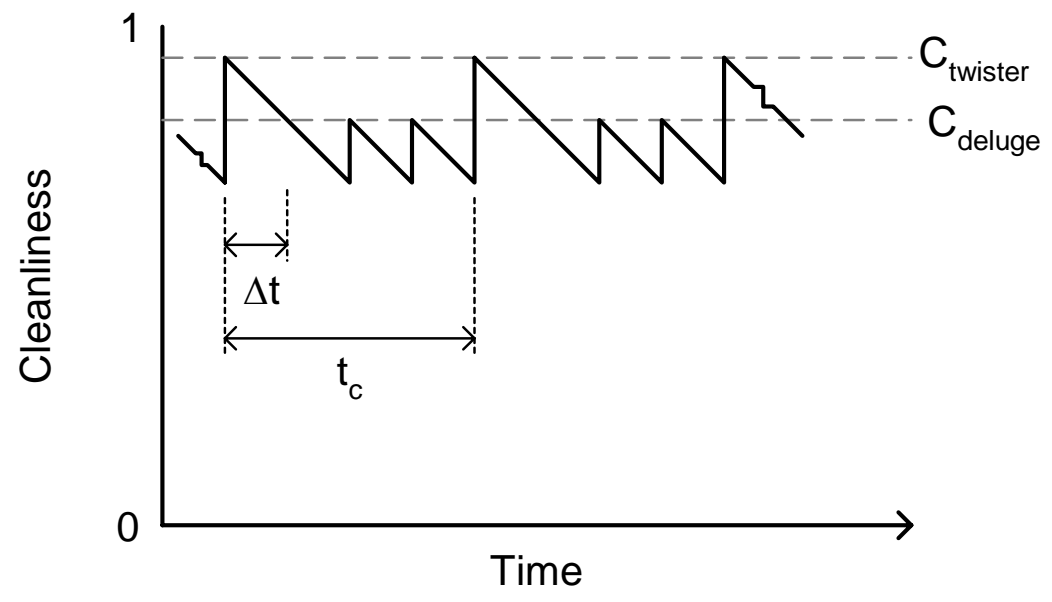

Figure 1. Model of 2-Method Mirror Washing

The Twister achieves a cleanliness of $\mathrm{C}_{\text {twister, }}$, while the deluge truck provides a lower $\mathrm{C}_{\text {deluge }}$ cleanliness. A complete cycle requires time $t_{c}$ to complete, and the period $\Delta t$ is the time it takes for the cleanliness to drop from $\mathrm{C}_{\mathrm{twister}}$ to $\mathrm{C}_{\text {deluge. }}$. Please note that $\Delta \mathrm{t}$ must be less than $\mathrm{t}_{\mathrm{c}}$ and is defined by

$$
\Delta t=\frac{C_{\text {twister }}-C_{\text {deluge }}}{R_{\text {soil }}} .
$$


The average cleanliness, C, over the wash cycle is defined by

$$
\mathrm{C}=\frac{\mathrm{C}_{1} \Delta \mathrm{t}+\mathrm{C}_{2}\left(\mathrm{t}_{\mathrm{c}}-\Delta \mathrm{t}\right)}{\mathrm{t}_{\mathrm{c}}}
$$

where

$$
\mathrm{C}_{1}=\frac{\mathrm{C}_{\text {twister }}+\mathrm{C}_{\text {deluge }}}{2}
$$

and

$$
\mathrm{C}_{2}=\mathrm{C}_{\text {deluge }}-\frac{\mathrm{R}_{\text {soil }}}{6}\left(\mathrm{t}_{\mathrm{c}}-\Delta \mathrm{t}\right)
$$

The supplemental washing frequency, $\omega$, and the natural washing frequency, $\omega_{\mathrm{nw}}$, determine the wash cycle time in days over the washing period, $\mathrm{P}_{\mathrm{w}}$, expressed in terms of the number of months per year spent washing.

$$
t_{c}=\frac{365 P_{w}}{12\left(\omega+\omega_{n w}\right)}
$$

Substituting equations 3 and 4 into equation 2 results in a second-order relation in terms of the wash cycle time that may be solved with the quadratic formula.

$$
0=\left(\frac{\mathrm{C}_{\text {twister }}-\mathrm{C}_{\text {deluge }}}{2}\right) \Delta \mathrm{t}-\frac{\mathrm{R}_{\text {soil }}}{6} \Delta \mathrm{t}^{2}+\left(\mathrm{C}_{\text {deluge }}+\frac{\mathrm{R}_{\text {soil }}}{3} \Delta \mathrm{t}-\mathrm{C}\right) \mathrm{t}_{\mathrm{c}}-\frac{\mathrm{R}_{\text {soil }}}{6} \mathrm{t}_{\mathrm{c}}{ }^{2}
$$

KJC performs no supplemental mirror washing during 3-4 months of the winter, when the field cleanliness is actually higher than the annual average due to natural washing from weather. Only the 8.5-month summer period, when the cleanliness averaged $95.9 \%$ in both 1997 and 1998, will be modeled here. Using the KJC measured summer soiling rate of $0.49 \%$ drop in cleanliness per day (0.45 reflectivity points/day [2]) leaves only one parameter, $\omega_{\mathrm{nw}}$, to adjust in order to achieve the actual wash cycle frequency of 16 from 1998. A value of $1 \frac{1 / 2}{2}$ natural washes in the summer results in 16 wash cycles of 15 -day duration per year. This seems reasonable for the summer months in the Mojave Desert. Figure 2 shows the number of summertime washes and corresponding annual washing costs as a function of cleanliness goal using equipment lifetimes, labor, and water costs from [1]. For KJC's summertime cleanliness of $95.5 \%$, the annual trough washing costs are estimated at $\$ 0.21 / \mathrm{m}^{2}$. Applying financial assumptions of a $10 \%$ discount rate and a 30 year plant lifetime results in a present value 9.4 times the annual cost, or about $\$ 2 / \mathrm{m}^{2}$. While it is not possible to comment about the payback on the mirror washing without knowing the value in terms of additional power produced, it does appear that KJC has chosen a cleanliness goal that is located at the "knee" of the curve in Figure 2, where high return on investment occurs. Increasing the cleanliness goal would cost dramatically more, whereas lowering the goal by the same amount would not lower costs significantly. It should be pointed out that if the cleanliness goal is increased beyond the level attainable by the deluge method (96.4\%), the strategy (number of deluge washes per twister wash) and hence the model would optimally change as well. 


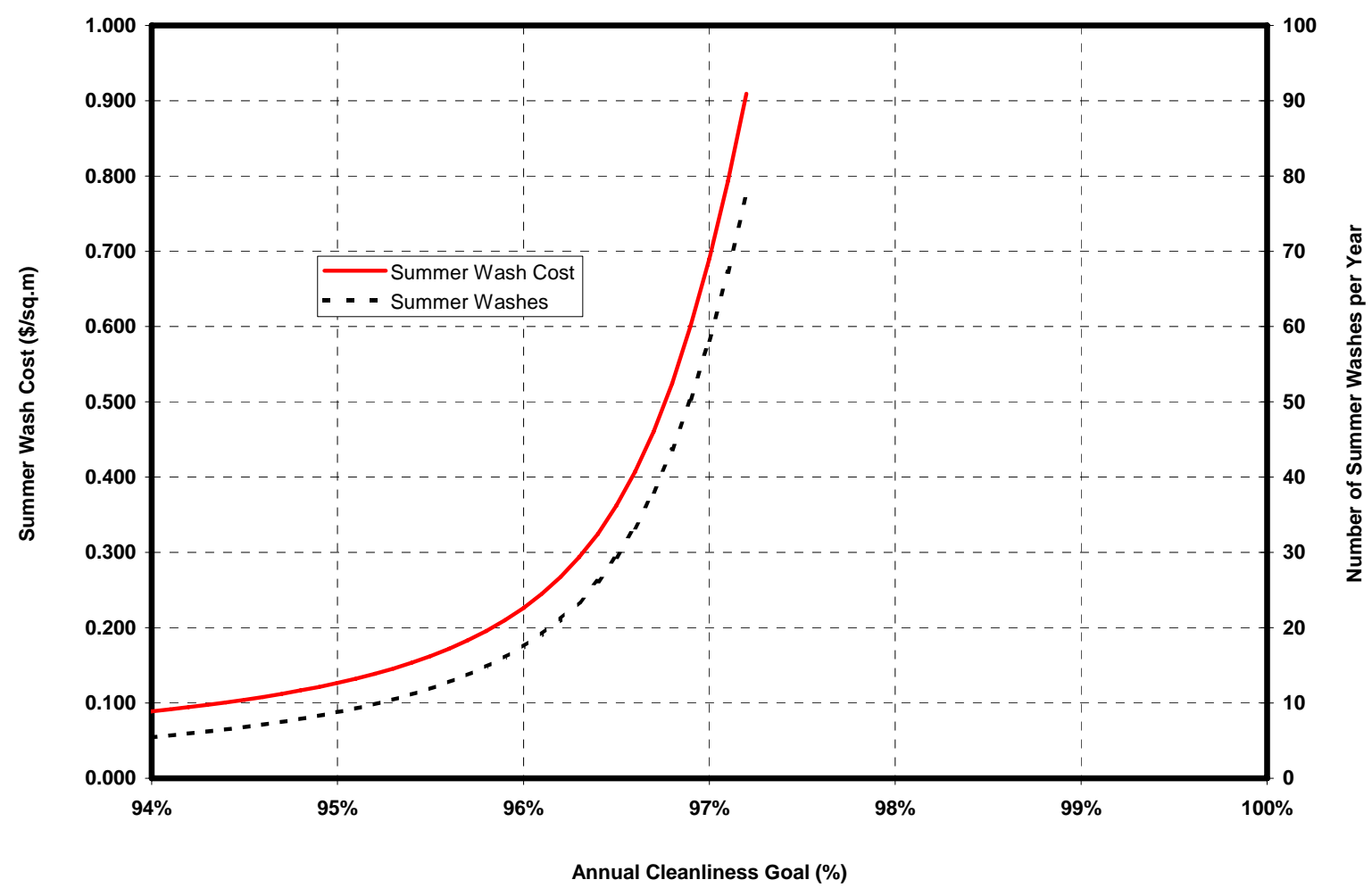

Figure 2. Cleanliness versus Washing Costs for 2-Method KJC Approach

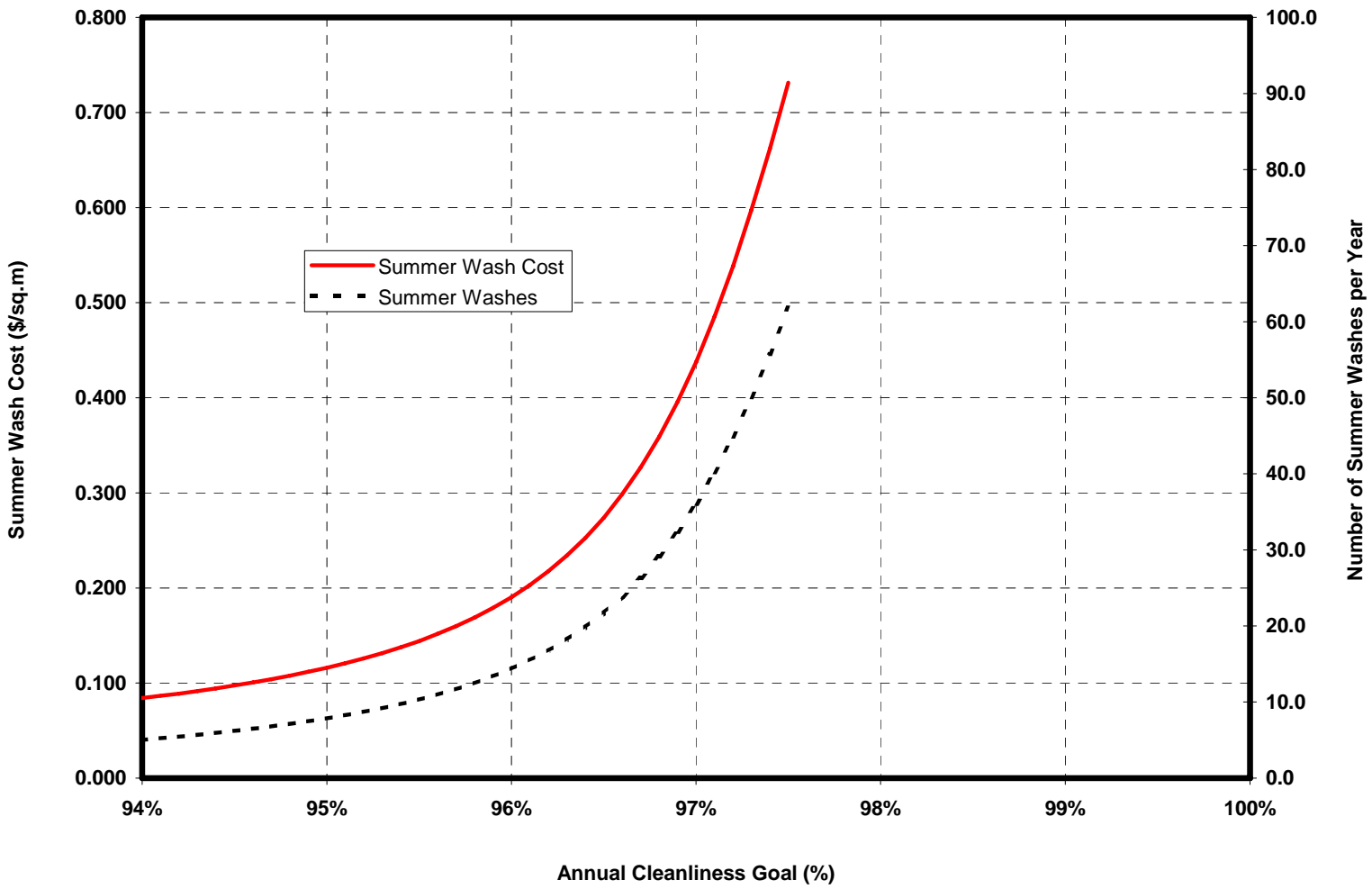

Figure 3. Cleanliness versus Washing Costs for 98.5\% Effective Mr. Twister 
Next, the model is used to evaluate a new scenario. Figure 3 shows the results of increasing the cleaning effectiveness of Mr. Twister by 0.5 points, to $98 \frac{1}{2} \%$, through technical advances. If the washing cycle is maintained, the summertime cleanliness will rise to $96.2 \%$. Another option would be to retain the $95.9 \%$ cleanliness goal, in which case the wash cycle frequency drops to 13 cycles/year of 17 -day duration, for a cost savings of $\$ 0.03 / \mathrm{m}^{2}$ per year with an estimated present value of $\$ 0.29 / \mathrm{m}^{2}$. Other scenarios are easily evaluated with the model as well.

\section{References:}

[1] S.A. Jones, "Estimating the Present Value of Collector Washing Costs at a Solar Plant," Memo to Distribution, Sandia National Laboratories, Albuquerque, NM, July 6, 1999.

[2] G. Cohen, D. Kearney, G. Kolb, "Final Report on the Operation and Maintenance Improvement Program for Concentrating Solar Power Plants,” SAND99-1290, Sandia National Laboratories, Albuquerque, NM, June 1999.

\section{Distribution:}

Rich Diver, MS-0703 (6216)

Greg Kolb, MS-0703 (6216)

Jim Pacheco, MS-0703 (6216)

Hugh Reilly, MS-0703 (6216)

Craig Tyner, MS-0703 (6216)

Robert Edgar, MS-1127 (6215)

Richard Houser, MS-1127 (6215)

Jim Grossman, MS-1127 (6215)

Rod Mahoney, MS-1127 (6215)

Joe Tillerson, MS-1127 (6215)

Scott Faas, MS-9014 (2271)

Mary Jane Hale, NREL

Hank Price, NREL

Dan Sagie, NREL

Tim Wendelin, NREL

Bob Cable, KJC

Harvey Stephens, KJC 
Distribution

from: Scott A. Jones, MS-0703 (6216)

subject: Estimating the Present Value of Collector Washing Costs at a Solar Plant

A tool was developed to calculate the present value of washing costs for solar collectors. It can be used to compare different washing approaches as well as evaluate the impact of collector design tradeoffs that impact washing costs. Other operations and maintenance (O\&M) costs, like routine electrical and hardware maintenance, and their impact on design tradeoffs of the collectors could be evaluated with a similar approach. This need has come up most recently in an optimization study of large versus small heliostats being performed with DELSOL, which has no capability to account for future O\&M costs. In order for factors like washing costs to enter in to the full system optimization, they must be converted to present value costs.

\section{Financial Model}

This constant-dollar analysis assumes O\&M costs are incurred at the end of each period. The present value, $\mathrm{P}$, may then be found from

$$
P=A \frac{(1+i)^{N}-1}{i(1+i)^{N}}
$$

where $\mathrm{A}$ is the cost per period, $\mathrm{i}$ is the interest per period, and $\mathrm{N}$ is the number of periods [11]. Simplifying yields

$$
P=A \frac{1-(1+i)^{-N}}{i}
$$

The model for the cost of mirror washing per period, A, includes both variable and fixed costs

$$
\mathrm{A}=\left(\mathrm{LL}_{\mathrm{c}}+\mathrm{WW}_{\mathrm{c}}\right) \omega+\mathrm{F} / \delta \text {. }
$$

where $\mathrm{L}$ is the labor required per wash (including equipment maintenance), $\mathrm{L}_{\mathrm{c}}$ is the cost of labor, $\mathrm{W}$ is the water (and any cleaning agents) used per wash, $\mathrm{W}_{\mathrm{c}}$ is the cost of the water and cleaning agents, $\omega$ is the wash frequency - the number of full-field washes per period, $F$ is the fixed cost of equipment and $\delta$ is the replacement lifetime of that equipment in periods. For this application, a yearly period will be used. 


\section{$\underline{\text { Washing Costs }}$}

Low- and high-pressure de-ionized water spray, acid cleaning, and contact (brush) cleaning are all options for cleaning solar concentrators. Spray cleaning has been found to be the most economical method for cleaning troughs - where the collector tube makes automated contact cleaning more difficult — and has become the standard for concentrating solar power applications. While heliostats should provide an easier platform for contact cleaning, the one attempt made to do this at Solar One was not very successful. Acid based cleaning was found very effective by McDonnell Douglas, but is simply too hazardous for today's stricter environmental and safety regulations. Many of the costs associated with washing should be rather constant per square meter with concentrator size, such as water and equipment costs, but labor costs may increase for smaller concentrators. This is because the cleaning process typically dictates the velocity of the wash rig. For smaller concentrators, a shorter wash rig is required, but it still travels at the same velocity, decreasing the wash speed per $\mathrm{m}^{2}$ and increasing the labor cost. Dishes may also be more expensive to clean as they combine difficulties of both heliostats and troughs by being spaced apart, having complex geometry with deep curvature, and having receiver and support hardware blocking access.

In general, it would be reasonable to assume that cleaning effectiveness improves-or equally, that costs decline-with experience gained since concentrating solar power is still a fairly new technology. In the U.S., the cost of labor dominates the cleaning costs, so advancements in technology have been key to reducing costs. The conversion at KJC from using hi-pressure wands to Mr. Twister, and reducing labor use by $2 / 3$, is an example of this evolution [8]. In other countries with low labor costs, technology may be a less significant factor, but a learning curve will still reduce costs as experience is gained.

Table 1 shows washing cost estimates presented in terms of $\$ / \mathrm{m}^{2}$ from studies, small scale tests, and from Kramer Junction Corporation (KJC) O\&M records. The first two columns are estimates from a 1978 McDonnell Douglas study for an acid wash procedure [1]. The next 3 columns are from recent KJC data, where a combination of the deluge truck and high pressure spray cleaning are used. The current annual wash cost at KJC is estimated the sum of the deluge and Twister costs or $\$ 0.21 / \mathrm{m}^{2}$, and represents a pretty mature, optimized value for trough washing. The Twister was also brought to Solar Two for testing on heliostats and comparison with the Solar Two spray wash truck [13]. The last two columns represent the results of those tests. Mr. Twister was less effective at Solar Two than at KJC because of a film on the mirrors it could not remove. The labor use was also much higher because Mr. Twister (and the Solar Two wash truck) could only clean $1 / 2$ of the heliostat surface per pass. This could be corrected if the equipment were optimized for that particular application. Another factor that cannot be corrected is that heliostats are spaced less densely than troughs, so more time is spent traveling without washing. During this test, the Twister had no shut-off valve so water was wasted when traveling between heliostats, raising the water use rates and labor use because more frequent fills were required.

Labor costs can vary significantly depending upon the country and whether unionized workers are used. It is worth pointing out that the costs of cleaning at KJC today are less than $1 / 2$ (even without converting to current dollars) the costs estimated in the 1978 McDonnell Douglas study. No data on cleaning costs at Solar One were found, apparently because the equipment was frequently broken or left unused due to other priorities. 
Table 1. Washing Costs and Parameters from Estimates, Small Tests, and KJC Data

\begin{tabular}{|c|c|c|c|c|c|c|c|}
\hline Parameter or Cost & $\begin{array}{l}\text { M-D Acid } \\
\text { Wash A [1] }\end{array}$ & $\begin{array}{c}\text { M-D Acid } \\
\text { Wash B [1] }\end{array}$ & $\begin{array}{c}\text { KJC Deluge } \\
{[8]}\end{array}$ & $\begin{array}{c}\text { KJC Spray } \\
\text { Rig [8] }\end{array}$ & $\begin{array}{l}\text { KJC Mr. } \\
\text { Twister [8] }\end{array}$ & $\begin{array}{c}\text { Spray Rig } \\
\text { [13] }\end{array}$ & $\begin{array}{c}\text { Solar Two Mr. } \\
\text { Twister [13] }\end{array}$ \\
\hline Cleanliness after wash & $100 \%$ & $100 \%$ & $96.5 \%$ & $98.0 \%$ & $98.0 \%$ & $96 \%$ & $96 \%$ \\
\hline Annual Washes & 12 & 12 & 32 & 11 & 16 & 25 & 25 \\
\hline $\begin{array}{l}\text { Wash vehicles } \\
(\# / \text { sq.m) }\end{array}$ & 8.90E-06 & 4.45E-06 & $2.20 \mathrm{E}-06$ & 1.10E-06 & 1.70E-06 & $1.20 \mathrm{E}-05$ & $1.20 \mathrm{E}-05$ \\
\hline $\begin{array}{l}\text { Wash vehicle Cost } \\
(\$ / \text { sq.m) }\end{array}$ & 0.44 & 0.22 & 0.19 & 0.09 & 0.14 & 1.22 & 1.22 \\
\hline Lifetime (years) & 10 & 10 & 15 & 10 & 10 & 15 & 10 \\
\hline $\begin{array}{l}\text { Labor (man- } \\
\text { hours/sq.m) }\end{array}$ & 0.00071 & 0.00038 & 0.000065 & 0.00078 & 0.00026 & 0.00032 & 0.0006 \\
\hline $\begin{array}{l}\text { Labor cost (\$/man- } \\
\text { hour) }\end{array}$ & 15 & 15 & 20 & 20 & 20 & 40 & 40 \\
\hline $\begin{array}{l}\text { Vehicle maintenance } \\
\text { (man-hours/sq.m) }\end{array}$ & 3.60E-05 & 3.60E-05 & $6.50 \mathrm{E}-06$ & 7.80E-05 & 2.60E-05 & 3.20E-05 & $6.00 \mathrm{E}-05$ \\
\hline $\begin{array}{l}\text { Vehicle maintenance } \\
(\$ s / \text { sq.m) }\end{array}$ & 30 & 30 & 20 & 20 & 20 & 60 & 60 \\
\hline Labor cost (\$/sq.m) & 0.0117 & 0.0068 & 0.0014 & 0.0172 & 0.0057 & 0.0147 & 0.0276 \\
\hline $\begin{array}{l}\text { Fuel required } \\
\text { (gal/sq.m) }\end{array}$ & 0.0043 & 0.0043 & 0.00017 & 0.00038 & 0.00038 & 0.0008 & 0.0009 \\
\hline Fuel cost (\$/gal) & 0.56 & 0.56 & 1.2 & 1.2 & 1.2 & 1.2 & 1.2 \\
\hline Fuel cost (\$/sq.m) & 0.0024 & 0.0024 & 0.0002 & 0.0005 & 0.0005 & 0.0010 & 0.0011 \\
\hline DI water (gal/sq.m) & 0.15 & 0.15 & 0.23 & 0.19 & 0.19 & 0.26 & 0.55 \\
\hline DI water cost (\$/gal) & 0.025 & 0.025 & 0.003 & 0.003 & 0.003 & 0.006 & 0.006 \\
\hline DI water cost (\$/sq.m) & 0.0038 & 0.0038 & 0.0007 & 0.0006 & 0.0006 & 0.0016 & 0.0033 \\
\hline $\begin{array}{l}\text { Wash solution } \\
\text { (gal/sq.m) }\end{array}$ & 0.0015 & 0.0015 & & & & & \\
\hline Wash sol cost (\$/gal) & 3.25 & 3.25 & & & & & \\
\hline Wash sol cost (\$/sq.m) & 0.0049 & 0.0049 & & & & & \\
\hline $\begin{array}{l}\text { Per Wash Cost } \\
(\$ / \text { sq.m) }\end{array}$ & 0.0228 & 0.0178 & 0.0023 & 0.0182 & 0.0067 & 0.0173 & 0.0320 \\
\hline incl. Equipment & 0.0264 & 0.0196 & 0.0027 & 0.0190 & 0.0076 & 0.0205 & 0.0368 \\
\hline Per Year Cost (\$/sq.m) & 0.3172 & 0.2358 & 0.0868 & 0.2094 & 0.1224 & 0.5134 & 0.9208 \\
\hline
\end{tabular}




\section{Washing Frequency}

Washing frequency is ideally chosen to optimize net profit by balancing increased revenues from additional power production with increased costs of washing. This is a very complicated optimization that is a function of many variables and can have a solution that varies frequently. The difficulty in continuously calculating the optimum cleaning frequency causes this decision to remain somewhat an art, rather than be pure science. At KJC, with the most advanced solar plant O\&M program in the world, experience has taught them to change cleaning frequency seasonally with the goal of maintaining a field average reflectivity of $90 \%$ (96\% cleanliness), a more tangible and measurable goal than optimizing profit. Their power purchase contracts are such that power produced in the summer is worth more than that produced in the winter, so KJC cleans the mirrors only during the 8-9 "summer" months. Despite this, the average cleanliness during the winters of 1997 and 1998 was higher than during the summers, as shown in Table 2. The combined natural washing and reduced soiling rate in the 3-4 month "winter" period more than compensated for the lack of supplemental washing. Interestingly, the annual average cleanliness achieved was slightly above the stated goal and equal both years, while summer cleanliness values were below the annual average and also equal both years - quite a display of consistency.

Table 2. KJC Field Cleanliness by Season for All Plants

\begin{tabular}{lcc}
\hline Period & 1997 & 1998 \\
\hline Summer & $95.9 \%$ & $95.9 \%$ \\
Winter & $97.8 \%$ & $97.3 \%$ \\
Annual Avg & $96.4 \%$ & $96.4 \%$ \\
\hline
\end{tabular}

A cleaning program will also have to periodically contact clean the mirrors (if the routine program does not involve contact or acid cleaning) because of accumulated soiling that cannot be removed by hi-pressure spray methods. It is likely that more frequent hi-pressure spray washing with an effective device like Mr. Twister increases the interval between required contact cleanings. The cooling towers at KJC also cause additional soiling of 2-3\% of the field area that requires additional effort in removal. Neither these special cases nor management costs are reflected in the cost estimates listed in Table 1.

A very important point to make is that mirror cleanliness can have more value than intuition would suggest. KJC has found that "a change in reflectivity of $1 \%$ resulted in a performance change of about $1.2 \%$ in solar field thermal delivery" [8]. This is mostly because the receiver thermal losses are a function of temperature and thus stay constant as the reflectivity changes. Startup energy also stays constant when mirror cleanliness changes. This effect was also observed in power tower modeling [12] where a drop in reflectivity from 0.91 to 0.82 (a 9.9\% drop) caused a $14.2 \%$ drop in net annual electricity produced.

Adopting KJC's experience-based approach here requires a model with a cleanliness goal that permits a period each year without washing. Like previous models [1,2,9], a constant annual soiling rate, $R_{\text {soil, }}$ is assumed, here expressed in terms of the drop in cleanliness per day. This model is more complex than those previously used in that additional parameters are added to 
more accurately model cleaning behavior. For instance, $\omega_{\text {nw }}$ accounts for the effect of natural washing by representing the equivalent number of washes provided by weather. $\mathrm{C}_{\mathrm{w}}$ is the cleanliness obtained by washing, a parameter to permit imperfect washing that returns mirrors to lower than fully clean reflectivity. Experiences at KJC and Solar One and Two have indicated this is usually the case, with washing typically achieving less than $100 \%$ cleanliness. $\mathrm{P}_{\mathrm{w}}$ is the wash period, expressed in months/year that washing occurs. Assuming instantaneous washes, the yearly average cleanliness goal, C, is described by

$$
C=C_{w}-\frac{P_{w}}{12} \frac{365 R_{\text {soil }}}{2\left(\omega+\omega_{n w}\right)}
$$

Solving for the washing frequency gives

$$
\omega=\frac{15.21 R_{\text {soil }} P_{w}}{C_{w}-C}-\omega_{n w} .
$$

As with any model, the output is only as good as the input. The input parameters have been carefully chosen here to be values that can be well measured or estimated and easily adapted to different sites and scenarios. For instance, specific values (per $\mathrm{m}^{2}$ ) are suggested for use since these are more likely constant for different technologies and sizes. Nonetheless, the user should be cautioned that the uncertainties in the input variables cause uncertainties in the output. In particular, estimates of the soiling rate are subject to uncertainty and will be the topic of the next section.

\section{$\underline{\text { Soiling Rate }}$}

Soiling rates can be significantly influenced by a number of factors, including geographical location, season, instantaneous weather patterns, mirror construction, and collector orientation. Soiling rate is typically expressed in one of two ways: 1) the drop in reflectivity per day ( $\mathrm{d} \rho / \mathrm{dt})$, or 2 ) the drop in mirror cleanliness per day (dC/dt). Mirror cleanliness is defined as the ratio of the reflectivity to the clean reflectivity

$$
C=\frac{\rho}{\rho_{0}}
$$

The two metrics are related by the equation

$$
\mathrm{R}_{\text {soil }}=\frac{\mathrm{dC}}{\mathrm{dt}}=\frac{1}{\rho_{0}} \frac{\mathrm{d} \rho}{\mathrm{dt}}
$$

where $\mathrm{dC} / \mathrm{dt}$ is given the name $\mathrm{R}_{\text {soil }}$ to indicate it is assumed constant here. If two mirrors of similar construction, but different initial reflectivity, were exposed to the same environment, they would experience an equal degradation in cleanliness, not reflectivity [10]. For this reason, an attempt has been made to present all soiling rates in terms of cleanliness, but in some cases, it was difficult to tell from the source on what basis the data were reported and also to determine the value of the clean reflectivity of the mirrors. 
There have been many studies of soiling rate and with few exceptions, all found that soiling rates vary considerably. However, some trends do emerge. For instance, heliostats in facedown and vertical positions were found to soil much less than those face-up [3,4]. Prior studies on the value of heliostat inversion [1,2] assume a linear correlation between soiling rate and projected face-up area and assume a constant 45 degree angle during operation, but they use different input data in their calculation. Although Reference 4 does not display a totally linear relation, it still seems a reasonable assumption considering the dust buildup for both inverting and non-inverting designs is equal during operation. Stow in vertical and facedown orientations is considered equal in Reference 1 under benign weather, but slightly different values are used for each stow position in Reference 2. In severe weather with high winds, the non-inverting heliostats must be stowed face-up rather than vertical and will suffer from more rapid soiling than the inverting heliostats. Both studies use the same data for this case, taken from [3]. The soiling rates used in these studies are listed in Table 3 along with more recent data from solar plants.

Table 3. Soiling Rates Used in Previous Studies and Recent Data from Solar Plants

\begin{tabular}{|c|c|c|c|c|c|}
\hline \multirow[b]{2}{*}{$\begin{array}{l}\text { Source } \\
\text { [Reference] }\end{array}$} & \multirow{2}{*}{$\begin{array}{c}\text { Heliostat or } \\
\text { Concentrator } \\
\text { Type } \\
\end{array}$} & \multicolumn{3}{|c|}{ Soiling Rate (\%/day) } & \multirow[b]{2}{*}{ Notes } \\
\hline & & $\begin{array}{c}\text { Benign } \\
\text { Weather }\end{array}$ & $\begin{array}{c}\text { Severe } \\
\text { Weather }\end{array}$ & Total & \\
\hline A. Kertstein & Inverting & 0.27 & - & $0.32-0.47$ & 45 deg daytime, face-down stow \\
\hline$[2,3,5]$ & Non-Inverting & 0.38 & $0.05-0.2$ & $0.42-0.58$ & 45 deg daytime, vertical stow, face-up in severe weather \\
\hline McDonnell & Inverting & 0.15 & - & 0.15 & 45 deg daytime, face-down stow \\
\hline Douglas $[1,3,6]$ & Non-Inverting & 0.15 & $0.05-0.19$ & $0.2-0.34$ & 45 deg daytime, vertical stow, face-up in severe weather \\
\hline Solar One [7] & MMC inverting & & & 0.28 & annual average for 1984 . Varied from 0.1 to 0.4 from $1981-1985$ \\
\hline $\mathrm{KJC}[8]$ & LS-2 trough & & & 0.49 & 3-month test w/o washing during summer (worst case) \\
\hline
\end{tabular}

\section{Natural Washing}

Natural washings provided by Mother Nature can be very effective at increasing cleanliness of correctly positioned mirrors. The best example is probably snow, that when allowed to melt and slowly slide off the mirror can scrub the surface to nearly $100 \%$ clean. Rains of greater than $1 / 4$ inch also clean well and very heavy frost can act like show. On the other hand, the combination of blowing dust and a light rain can actually decrease mirror cleanliness. Light frost or dew in the morning can be detrimental as well by contributing to the "cementation" of soil to the surface [13]. It is the job of the operators to maximize the benefits and minimize the harm from weather. Table 3 shows the probabilities of different meteorological events from four typical solar sites in the U.S. 
Table 3. Mean Percentage of Days per Month for Occurrence of Various Meteorological Phenomena from Daily Observations (from [1])

\begin{tabular}{|c|c|c|c|c|c|c|c|c|}
\hline Station & Location & $\begin{array}{c}\text { Elevation } \\
(\mathrm{m})\end{array}$ & $\begin{array}{l}\text { Thunder- } \\
\text { storms }\end{array}$ & Rain/Drizzle & $\begin{array}{l}\text { Snow/sleet/ } \\
\text { freezing rain }\end{array}$ & Fog & $\begin{array}{l}\text { Blowing } \\
\text { Dust/Sand }\end{array}$ & $\begin{array}{c}\text { Years of } \\
\text { Observations }\end{array}$ \\
\hline \multicolumn{9}{|l|}{ Naval Weapons } \\
\hline Center & Indian Wells Valley, CA & 760 & 0.9 & 9.6 & 0.5 & 0.7 & 1.2 & 20 \\
\hline $\begin{array}{l}\text { Edwards Air Force } \\
\text { Base }\end{array}$ & $\begin{array}{l}\text { Western Mojave Desert } \\
\text { near Mojave,CA }\end{array}$ & 770 & 1.2 & 9.6 & 0.9 & 1.9 & 1.6 & 19 \\
\hline $\begin{array}{l}\text { George Air Force } \\
\text { Base }\end{array}$ & $\begin{array}{l}\text { Western Mojave Desert } \\
\text { near Victorville, CA }\end{array}$ & 960 & 1.7 & 10.1 & 1.4 & 2.3 & 1 & 18 \\
\hline \multicolumn{9}{|l|}{ Kirtland Air Force } \\
\hline Base & Albuquerque, NM & 1780 & 10.2 & 22.9 & 6.9 & 2.7 & 1.2 & 26 \\
\hline
\end{tabular}

\section{Example}

Assume a device like Mr. Twister was used to clean the heliostat field of a 30 MWe power tower plant in Spain. The effectiveness of cleaning is assumed to be $98 \%$, closer to the KJC results than the results found at Solar Two because these heliostats don't have edge seals that collect water and contribute to the "cementation" of dirt found at Solar Two [13]. The annual average soiling rate for the non-inverting heliostats is estimated at a $0.35 \%$ drop in cleanliness per day, and washing occurs year-round. The site has natural washings equivalent to 15 cleanings with Mr. Twister. It is reasonable to assume 1 Twister machine $\left(4 \times 10^{-6}\right.$ machines $/ \mathrm{m}^{2}$ ) can service the entire field if the wash cycle is at least 1 week in duration. The use of small (e.g. $10 \mathrm{~m}^{2}$ ) heliostats would likely increase the number of Twister machines and operators required, increasing the cost per square meter, and only slightly reduce the cost of each Twister machine (because they are smaller). This example assumes large heliostats of $\sim 100 \mathrm{~m}^{2}$. Further assumptions for the DI water and labor costs are from KJC. An equipment cost of $\$ 100,000$ and a replacement lifetime of 10 years are also assumed. Varying the annual cleanliness goal provides the results shown in Figure 1.

Clearly, it gets very expensive to approach a cleanliness goal as high as the post-wash cleanliness. The large number of annual washes reduces the wash cycles and increases cost even more than modeled because of all the equipment needed. For the same amount spent annually on washing at $\mathrm{KJC}\left(\$ 0.21 / \mathrm{m}^{2}\right)$, the annual cleanliness attainable in this case would be about $961 \frac{1}{2} \%$. Using financial assumptions of a 30 -year plant lifetime and a discount rate of $10 \%$, the present value of washing costs becomes 9.4 times the annual cost, or about $\$ 2 / \mathrm{m}^{2}$. However, a higher cleanliness goal may be justified economically-the value of cleanliness is not addressed here. At KJC, the cleanliness goal occurs at the "knee" of the curve where the slope starts to increase rapidly-in this case, at about $971 / 4 \%$. 


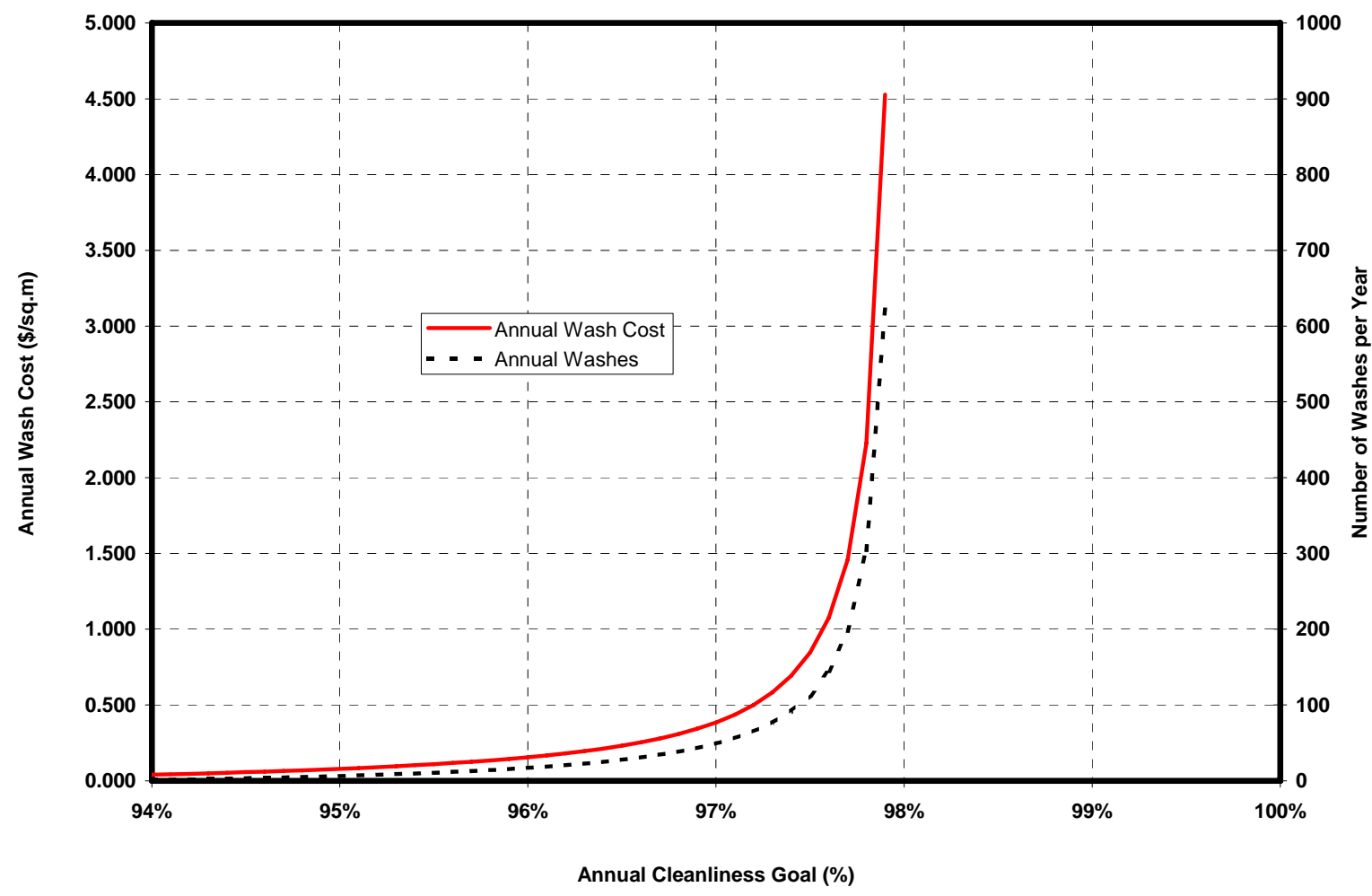

Figure 1. Annual Washes and Annual Wash Cost for an Example Heliostat Field

\section{References:}

[1] J.B. Blackmon, D.W. Harvey, R.H. McFee, "Non-Inverting Heliostat Study,” SAND788190, Sandia National Laboratories, Livermore, CA, August 1979.

[2] A. Kerstein, "Evaluation of Inverted Stow Capability for Heliostats,” SAND81-8277, Sandia National Laboratories, Livermore, CA, June 1981.

[3] J.B. Blackmon, “Dust Buildup Tests of Heliostats and Mirror Specimens,” McDonnell Douglas Internal Report, MDC G7543, September 1978.

[4] E.P. Roth, R.B. Pettit, "The Effects of Soiling on Solar Mirrors and Techniques Used to Maintain High Reflectivity,” SAND 79-2422, June 1980.

[5] E.P Roth, A.J. Anaya, “ The Effect of Natural Soiling and Cleaning on the Size Distribution of Particles Deposited on Glass Mirrors,” ASME Journal of Solar Energy Engineering, vol. 102, 248, 1980.

[6] D.L. King, J.E. Myers, "Environmental Reflectance Degradation of CRTF Heliostats," Proceedings of the SPIE Symposium, Optics in Adverse Environments, Los Angeles, CA, February 1980. 
[7] C.L. Mavis, "10 MWe Solar Thermal Central Receiver Pilot Plant Heliostat and Beam Characterization System Evaluation, November 1981-December 1986,” SAND 87-8003, Sandia National Laboratories, Livermore, CA, May 1988.

[8] G. Cohen, D. Kearney, G. Kolb, "Final Report on the Operation and Maintenance Improvement Program for Concentrating Solar Power Plants,” SAND99-1290, Sandia National Laboratories, Albuquerque, NM, June 1999.

[9] E.D. Eason, “The Cost and Value of Washing Heliostats,” SAND78-8813, Sandia National Laboratories, Livermore, CA, June 1979.

[10] R. Mahoney, Sandia National Laboratories, Personal communications, June 28, 1999.

[11] J.L. Riggs, Engineering Economics, McGraw-Hill, New York, 1977.

[12] P.K. Falcone, “A Handbook for Solar Central Receiver Design,” SAND86-8009, Sandia National Laboratories, Livermore, CA, December 1986, Table 4.3-6.

[13] S.A. Jones, "Heliostat Cleanliness Measurements and Washing Tests at Solar Two," Memo to Distribution, Sandia National Laboratories, Albuquerque, NM, December 15, 1998.

Distribution:

Rich Diver, MS-0703 (6216)

Greg Kolb, MS-0703 (6216)

Jim Pacheco, MS-0703 (6216)

Hugh Reilly, MS-0703 (6216)

Craig Tyner, MS-0703 (6216)

Robert Edgar, MS-1127 (6215)

Richard Houser, MS-1127 (6215)

Jim Grossman, MS-1127 (6215)

Rod Mahoney, MS-1127 (6215)

Joe Tillerson, MS-1127 (6215)

Scott Faas, MS-9014 (2271)

Mary Jane Hale, NREL

Hank Price, NREL

Dan Sagie, NREL

Tim Wendelin, NREL

Bob Cable, KJC

Harvey Stephens, KJC 


\section{APPENDIX B. \\ DLR Germany Project to Develop \\ a Low-Cost Heliostat Drive}

For more information, contact Reiner Buck

Reiner.Buck@dlr.de

Förderprogramm des BMU zur Erforschung und Entwicklung solarthermischer Kraftwerke

\section{Analyse der Auslegungskriterien für Heliostat-Antriebe und Optimierung der Antriebssysteme (HELIANT)}

Bei Solarturmkraftwerken wird die Solarstrahlung mittels zwelachsig nachgefôhrter Splegel, den sog. Heliostaten, tokussiert. Das Hellostatenteld kann bis zu $50 \%$ der Investitionskosten des gesamten Kraftwerks verschlingen. Entscheidender Kostentaktor für Heliostaten ist der aus Elektromotor und Getriebe bestehende Antrieb, der hohen Windlasten standhaiten muss. Bei den derzeit erhăltichen Heliostaten werden noch immer Standardgetriebe verwendet, die nicht aut ihren Einsatz in Heliostaten optimiert sind

Im Rahmen von HELIANT sollen daher anhand von Windkanalversuchen und strömungstechnischen Analysen die genauen Belastungen der Antriobe im Stillstands- und Botriebstall untersucht worden. Dabei werden insbesondere die Wechselwirkungen zwischen der Heliostatstruktur und dem Getriebe ermittelt. Auf dieser Basis wird ein optimiertes Getriebe mit dem Ziel einer deutlichen Kostenreduzierung gegenuber dem Stand der Technik entwickelt, konstruiert und als Prototyp getestet.

Derzeit befinden sich mehrere Solarturmkraftwerke in Bau bzw, werden projektiert. GröBere Kraftwer. ke erfordern Heliostatenfelder, die aus mehreren Tausend Einzelheliostaten bestehen und damit einen großen Markt tor das neue Produkt bieten. Daruber hinaus tohren Kostenreduzierungen im Bereich der Antriebe zu einer Erhöhung der Gesamtwirtschaftlichkeit und damit zu verbesserten Marktaussichten von Turmkraftwerken insgesamt
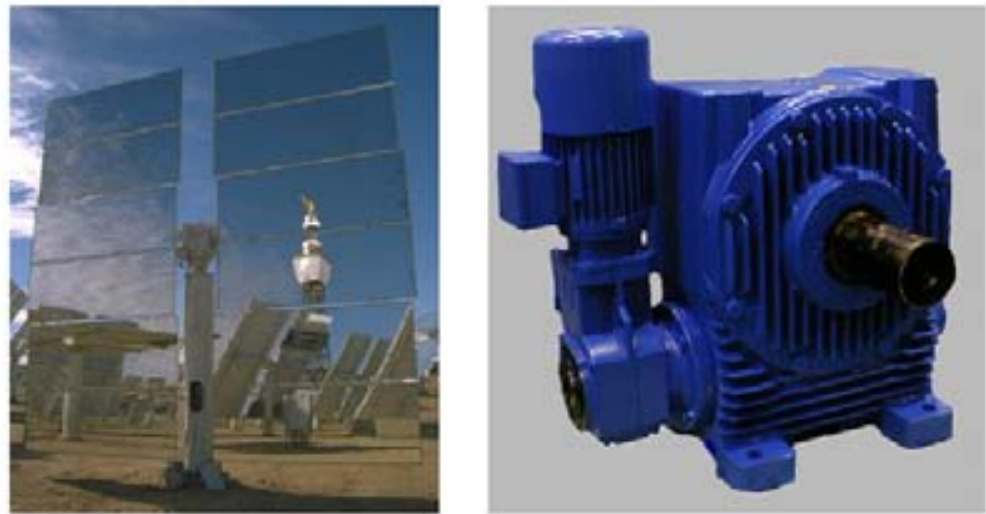

Heliostat eines der ersten Solarturmkraftwerke (Solar Two in Barstow, Kalifornien; linkes Bild), daneben ein noch nicht fûr Heliostate optimierter Antrieb aus dem FLENDER - Standardprogramm (rechtes Bild).

Projektpartner: Projektkosten Laukeit:
- FLENDER Tübingen GmbH, TObingen ca. $622 \mathrm{~T} \in$ (ca, $46 \%$ Förderung durch das BMU) April 2006 bis Marz 2008 


\section{Analysis of the Construction Criteria for Heliostat Drives and the Optimization of Drive Systems (HELIANT)}

In central receiver solar power plants, solar radiation is focused using two-axis mirrors, called heliostats. The field of heliostats can make up nearly $50 \%$ of the investment costs for the whole power plant. An important factor in the cost of heliostats is the drive mechanism, made up of an electric motor and gears, which must be able to withstand high wind loads. In heliostats currently available, standard drive mechanisms are still used that have not been optimized for use with heliostats.

Within the context of HELIANT, the exact loads on the drives will be investigated at rest and in operation using wind tunnel experiments and technical flow analyses. In this way, the reciprocal effectsparticularly between the heliostat structure and the drive mechanism-will be determined. Using this information, an optimized drive mechanism will be developed, constructed, and a prototype tested with the goal of realizing a clear reduction in cost with regard to the state of the technology.

At present, many central receiver power plants are being constructed or are planned. Larger power plants require heliostat fields composed of several thousand single heliostats, thus offering a large market for the new product. Reduction in costs for the drive mechanism will improve the economic value of such plants in general and thus to a better market value for solar power tower plants generally.

Figure caption: The heliostat at one of the first central receiver power plants, Solar Two, Barstow, CA (left); and (right) a drive mechanism that has not been optimized for heliostats from the FLENDER, Standard program.

Project Partner: FLENDER, Tubingen

Project Costs: about 622,000 Euros (including ca. 46\% stipend from the Federal Ministry for the Environment, BMU)

Duration: April 2006-March 2008. 


\section{APPENDIX C. \\ Small Heliostat R\&D in Europe and Australia}

For more information, contact Reiner Buck

Reiner.Buck@dlr.de

\section{GHER S.A. HELLAS 01}

- $\quad$ reflective area: $19.2 \mathrm{~m}^{2}$
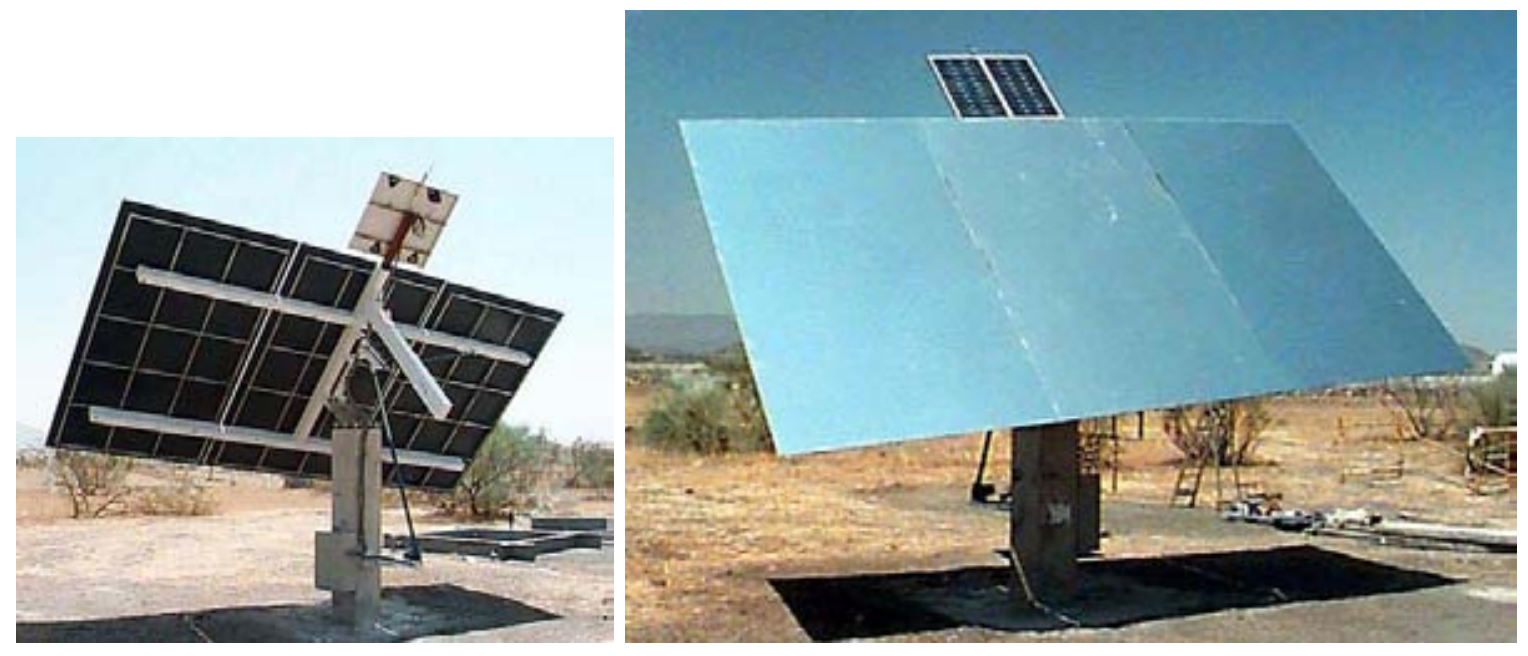

\section{Carpe Diem Solar: HelioCa 16}

- reflective area: $16 \mathrm{~m}^{2}$
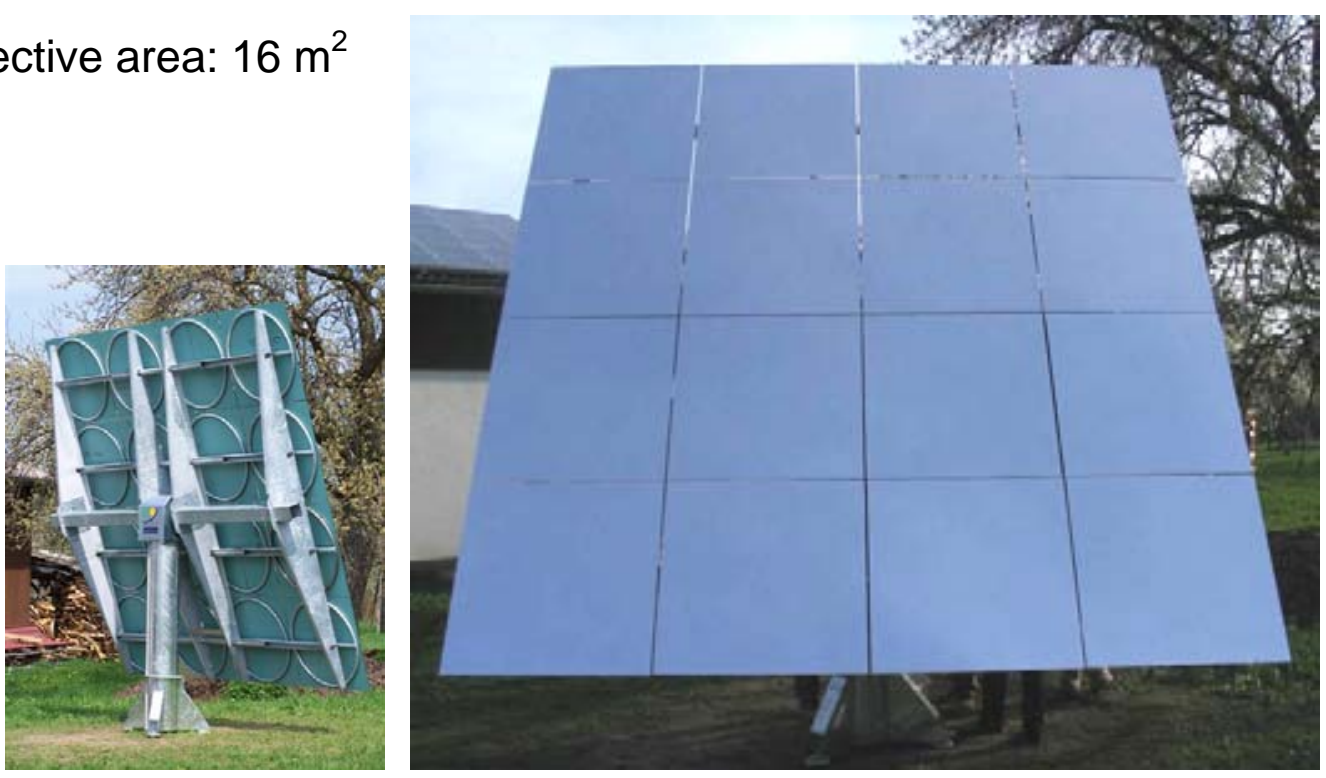
Förderprogramm des BMU zur Erforschung und Entwicklung solarthermischer Kraftwerke

\section{Entwicklung eines kostengünstigen Heliostaten kleiner Bauweise (HELIKO)}

Bei solaren Turmkraftwerken stellt das aus sog. Heliostaten (s. Abb.) bestehende Spiegelfeld einen erheblichen Kostenfaktor dar. Dabei können die einzelnen Heliostaten Spiegelflächen zwischen einigen wenigen und weit über $100 \mathrm{~m}^{2}$ aufweisen. Bei Kleinheliostaten sind zwar Kostennachteile aufgrund höherer spezifischer Kosten einzelner Komponenten zu verzeichnen, jedoch ermöglichen geringere Windlasten überproportionale Reduzierungen von Material und Antriebsleistung. Zudem lassen sich Kleinheliostaten zu einem größeren Anteil kostengünstig in der Fabrik montieren und erzielen bei kleinen Turmkraftwerken eine höhere Effizienz.

Im Rahmen von HELIKO wird ein Kleinheliostat mit einer Spiegelfläche von $16 \mathrm{~m}^{2}$ auf Basis eines bereits vorliegenden Designs weiterentwickelt. Dabei wird die Konstruktion im Hinblick auf eine zukünftige Serienfertigung sowie für den Einsatz von Antrieben aus der Massenproduktion optimiert. Darüber hinaus werden kostengünstige Fundamente für unterschiedliche Bodenverhältnisse sowie ein einfacher, aber präziser Sonnenstandssensor einschließlich Regelung entwickelt. Von dem neuen Heliostaten soll ein Prototyp gebaut und qualifiziert werden.

Die Produkte könnten z. B. in dem ab 2007 errichteten Demonstrationskraftwerk in Jülich mit über 1.000 Einheiten zum Einsatz kommen. Für weitere Projekte in Italien bzw. Libyen liegen Anfragen vor. Darüber hinaus ermöglicht der sich derzeit entwickelnde Markt Absatzmöglichkeiten z. B. in Spanien und im gesamten Mittelmeerraum.
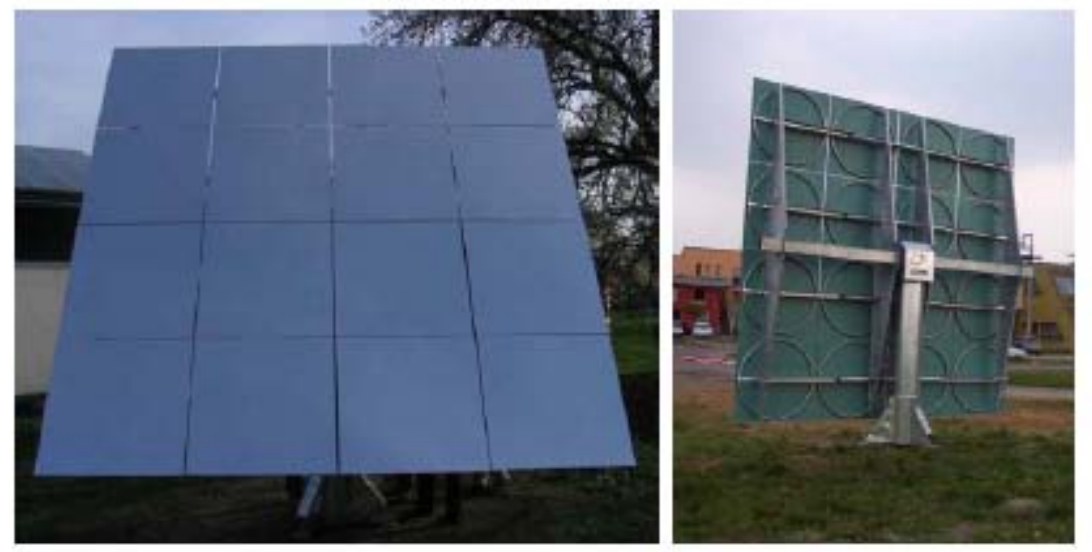

Ausgangsprodukt für die Entwicklung eines kostengünstigen Kleinheliostaten mit einer Spiegelfläche von $16 \mathrm{~m}^{2}$ zum Einsatz in Solarturmkraftwerken.

Projektpartner: $\quad$ - TOP Montage, Rosenfeld

Projektkosten: Laufzeit: - Deutsches Zentrum für Luft- und Raumfahrt e. V. (DLR), Stuttgart ca. $356 \mathrm{~T} €(74 \%$ Förderung durch das BMU) September 2006 bis März 2008 


\section{Development of a Small, Affordable Heliostat (HELIKO)}

The field of mirrors, made up of heliostats, constitutes a considerable cost for a central receiver solar power plant. The individual mirror faces of the heliostats can measure between a few and many more than $100 \mathrm{~m}^{2}$. With smaller heliostats, there are cost disadvantages because of the higher specific costs of a few components, yet the lower wind loads allow a reduction in materials and load on drive mechanism. For this reason, small heliostats are for the most part suitable to be produced and assembled in the factory and thus offer a higher efficiency in building smaller solar power tower plants.

Within the HELIKO, a small heliostat with a mirror surface of $16 \mathrm{~m}^{2}$ is being further developed using an existing design. In doing so, consideration is being paid to future assembly line production, as well as optimizing them for using mass-produced drive mechanisms. In addition, we are developing economical foundations for different kinds of field conditions as well as a simple but precise solar tracker including controller. A prototype of the new heliostat is planned to be built and qualified.

The products could, for example, be installed in the demonstration power plant at Jülich in 2007, calling for more than 1,000 units. We have inquires about further projects in Italy and also Libya. Beyond that, there are currently market possibilities in already developed markets, such as Spain and the entire Mediterranean area.

Caption: Prototype product for the development of an economical small heliostat with a mirror surface of $16 \mathrm{~m}^{2}$ for installation in solar power tower plants.

Project partners: TPO Montage

DLR Stuttgart

Project costs: ca 356, 000 Euros, (74\% federal money)

Duration: September 2006 to March 2008 


\section{SHAP}

- $\quad$ reflective area: $25 \mathrm{~m}^{2}$

- target-aligned configuration
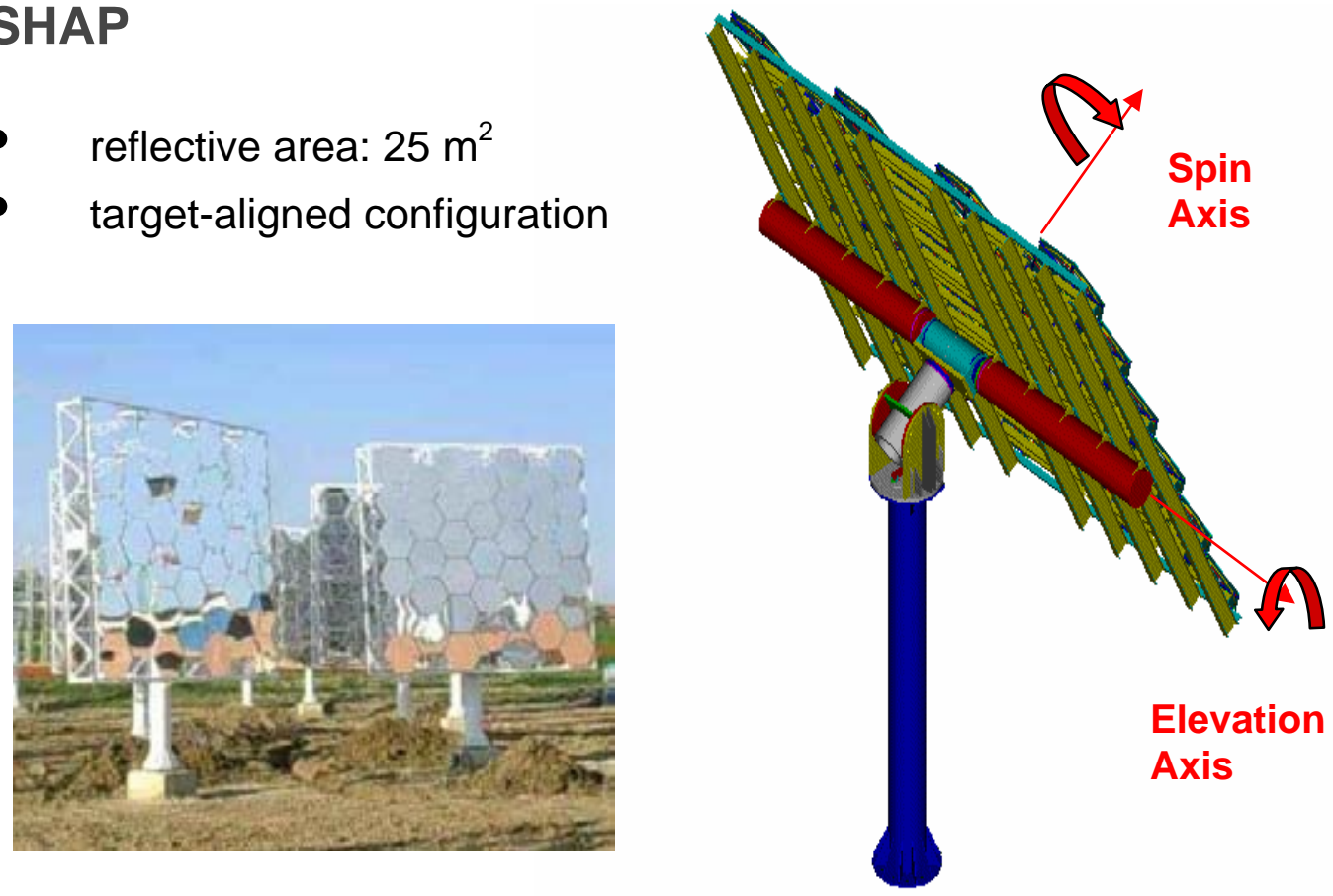

\section{SHP (Australia)}

- $\quad 4.3 \mathrm{~m}^{2}$ heliostat

- $\quad$ single facet

- 200 units at NSEC/CSIRO (Australia)
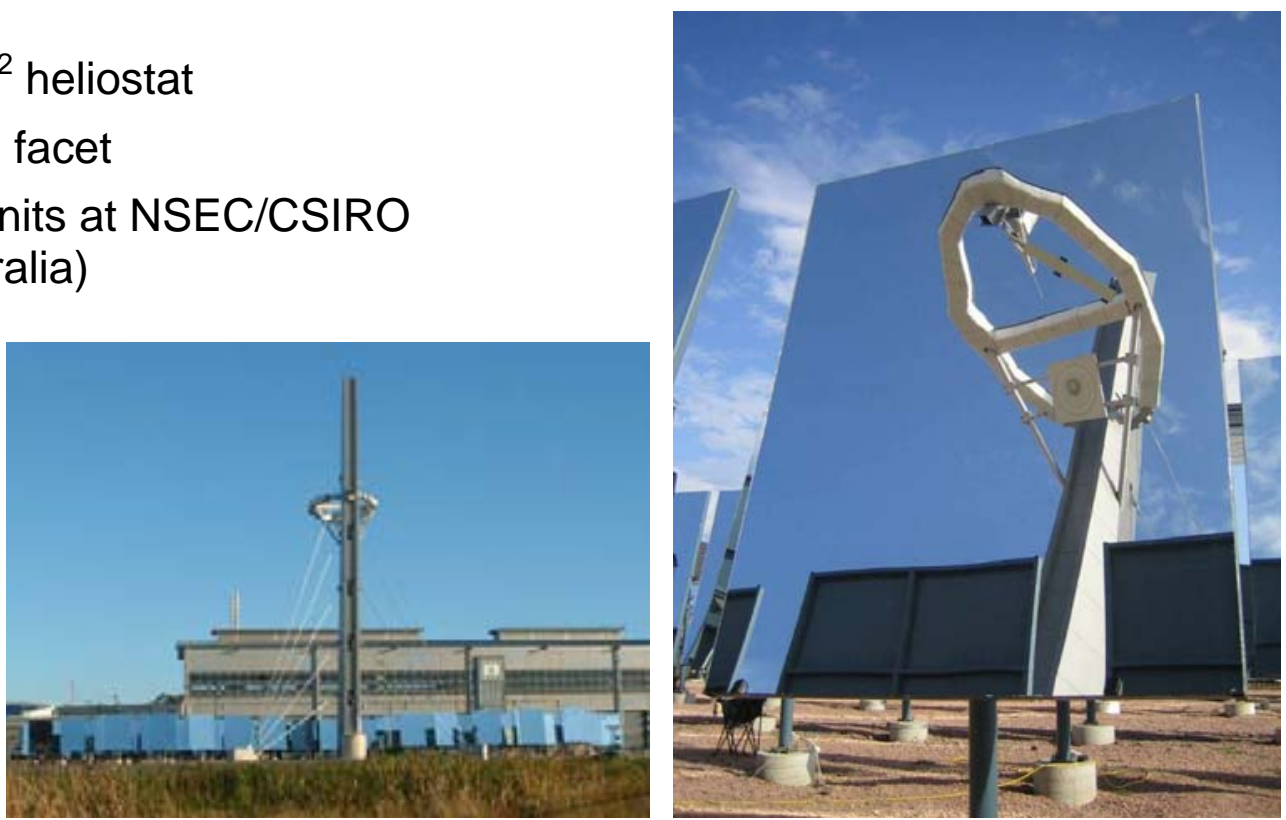


\section{SHP (Australia)}

- $8 \mathrm{~m}^{2}$ heliostat

- $\quad$ single facet

- $\quad$ prototypes for

Jülich, Germany
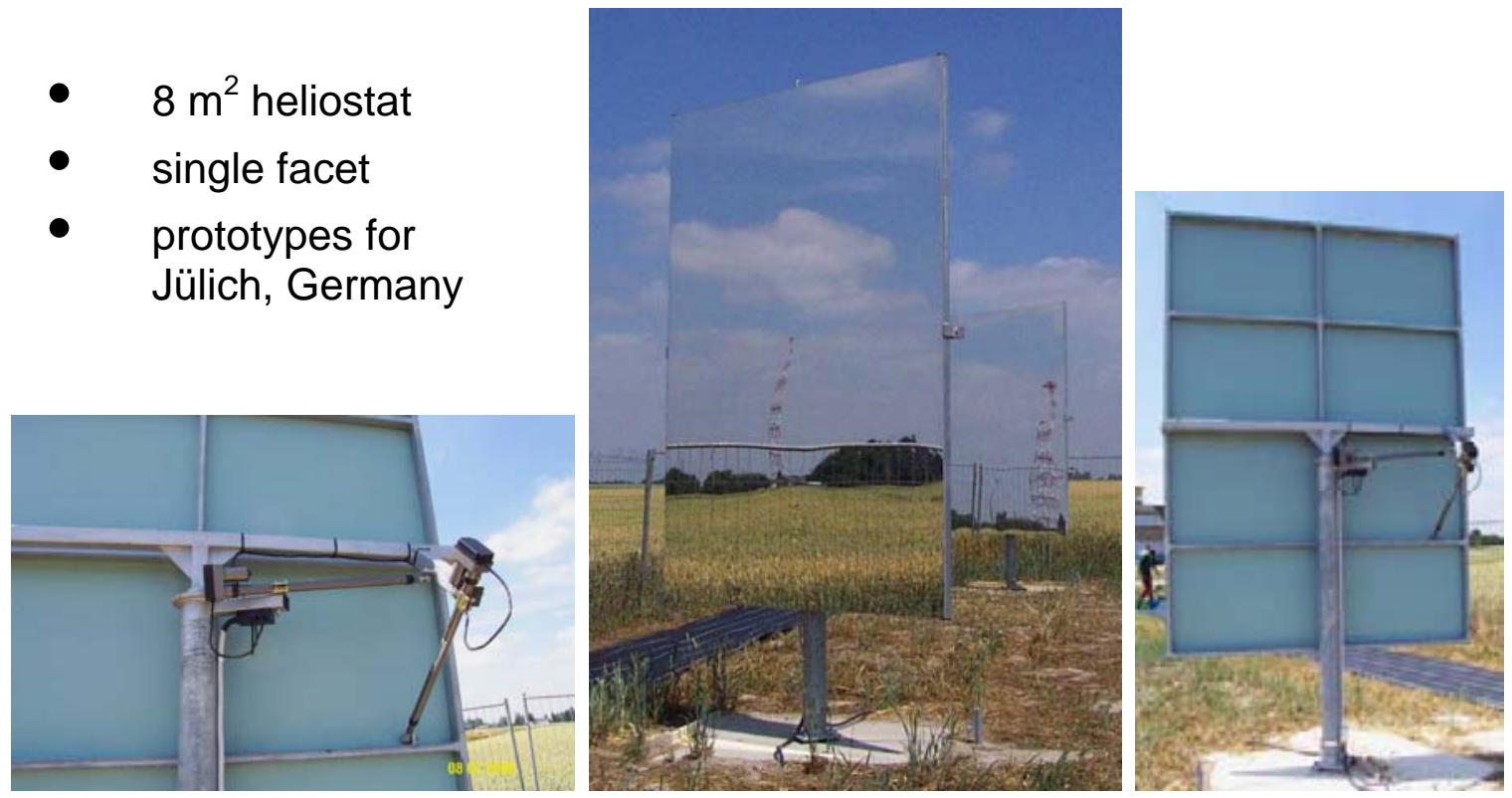


\section{Förderprogramm des BMU zur Erforschung und Entwicklung solarthermischer Kraftwerke}

\section{Entwicklung von Mikrospiegelsystemen für Solarthermische Kraftwerke (Mikrohelix)}

Die Kosten für das Heliostatenfeld eines Turmkraftwerkes können bis zu $50 \%$ der gesamten Kraftwerksinvestitionen ausmachen. Obwohl noch beträchtliche Kostensenkungspotenziale ausgeschöpft werden können, existiert bei konventionellen Heliostatstrukturen eine - aufgrund des für die geforderte Stabilität notwendigen Stahleinsatzes- relativ hohe Kostenuntergrenze. Daher sollen neue Wege zur Fokussierung des Sonnenlichtes beschritten werden.

Es wird ein unbewegliches Heliostatsegment entwickelt, das mit innen liegenden Mikrospiegeln arbeiten soll. Diese Mikrospiegel sollen durch geeignete Aktuatoren angetrieben und mit einer neu zu entwickelnden Software zweiachsig der Sonne nachgeführt werden. Ein mit dieser Technik erstellter Prototyp wird vermessen und seine Einsatzmöglichkeiten in solarthermischen Kraftwerken quantitativ bewertet. Dazu gehören auch die Analyse von Kostensenkungspotenzialen sowie das Erstellen von Ökobilanzen.

Diese Technologie könnte deutschen Herstellern, die im Bereich der Heliostate noch schwach vertreten sind, einen Markteinstieg ermöglichen. Insbesondere wäre es möglich, diese High-Tech Komponenten wettbewerbfähig am Standort Deutschland zu produzieren. Darüber hinaus könnte das System für weitere Anwendungen, wie z. B. für die konzentrierende Photovoltaik, zum Einsatz kommen.

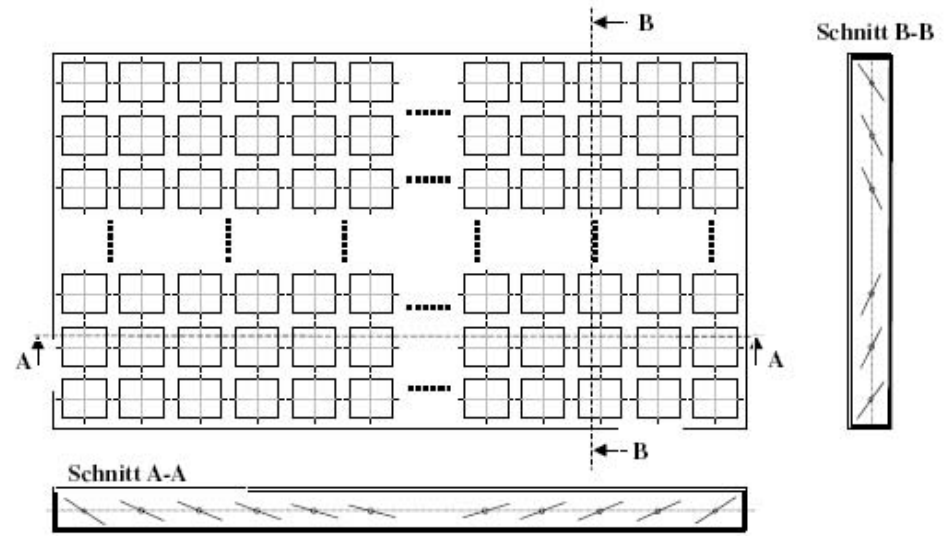

Prinzipieller Aufbau eines aus Mikrospiegeln aufgebauten Heliostaten, für den im Rahmen dieses Projektes ein Prototyp entwickelt wird.

Projektpartner: $\quad$ - FH Aachen, Solar-Institut Jülich (SIJ), Jülich - FhG Institut für Zuverlässigkeit und Mikrointegration (IZM), Oberpfaffenhofen

Projektkosten: ca. $410 \mathrm{~T} €(96 \%$ Förderung durch das BMU) Laufzeit: Juli 2006 bis Dezember 2008 


\section{Development of Micro Mirror Systems for Solar Thermal Power Plants (Mikrohelix)}

The heliostat field of a solar power tower plant can amount to $50 \%$ of the total cost of the plant. Although some potential cost reductions can be achieved, a relatively high fixed cost exists for conventional heliostats because of the requisite steel supports needed for stability. For this reason, we are pursuing new approaches to focusing solar radiation.

A stationery segment for a heliostat is being developed that is designed to work with interior micromirrors. These micro-mirrors are designed to be activated by designated actuators and driven by a newly developed software to track the sun in two axes. A prototype using this technology is being evaluated and its possibility for use in solar thermal power plants is being determined. These studies include analysis of investment potential and well as assumptions of obligations.

This technology could facilitate a market increase for German companies, which have not been strong in the heliostat market. In particular, it would be possible to produce these high-tech components competitively at Standort Germany. The system could be used for other purposes as well, for example, for photovoltaic concentrators.

(Schematic) Theoretical construction of a heliostat with micro-mirrors, for which a prototype is being developed within the scope of this project.

Partners: FH Aachen, Solar Institue Jülich IZM

Project Costs: about 410,000 Euros (96\% Federal)

Duration: July 2006-December 2008 


\section{DISTRIBUTION}

1 Jeffrey English

Technical Sales Manager

Naugatuck Glass

Thermo Fisher Scientific

408 Crescent Park

Warren, PA 16365

1 James B. Blackmon, Ph.D.

Research Professor

Propulsion Research Center

Technology Hall S233

Department of Mechanical and Aerospace Engineering

University of Alabama in Huntsville

Huntsville, AL 35899

1 Rafael Osuna

Solucar R\&D

Av. Buhaira 2

41018 Sevilla

Spain

1 Lorin L. Vant-Hull

Emeritus Professor of Physics, Univ. of Houston

128 N. Red Bud Trail

Elgin, TX 78621

1 Bob Litwin

Pratt \& Whitney Rocketdyne

6633 Canoga Ave MC RLA-11

P.O. Box 7922

Canoga Park, CA 91309

1 Alan W. Weimer, Ph.D., PE

Executive Director, Colorado Center for Biorefining and Biofuels

H.T. Sears Professor

Department of Chemical and Biological Engineering

1111 Engineering Drive

University of Colorado

Boulder, CO 80309-0424 
1 TIAX LLC

Kurt W. Roth, Ph.D.

15 Acorn Park

Cambridge, MA 02140

1 Mark Mehos

NREL

1617 Cole Blvd

Golden, CO 80401

1 Alain FERRIERE

PROMES-CNRS

Rue du four solaire, 7

66120 FONT-ROMEU, FRANCE

1 DLR Stuttgart

Att. Reiner Buck, ITT

Pfaffenwaldring 38-40

D-70569 Stuttgart

Germany

1 Josef Langenkamp

Seidenstr. 5

51063 Koeln

Germany

$1 \quad$ Herb Hayden, MS 8372

APS Solar Technology Coordinator

P.O. Box 53999

Phoenix, AZ 85072

3 NMT: c/o Mechanical Engineering Dept (Helio)

800 Leroy

Attn: Professor Warren Ostergren

Socorro, NM 87801

1 Dave Gorman

Advanced Thermal Systems

5031 Red Rock Drive

Larkspur, CO 80118

1 Michael Epstein

Director, Solar Research Unit

The Weizmann Inst. of Science

POB 26, REHOVOT, ISRAEL 76100 
1 Mike Doman

Regenesis Power

206 Camino El Rincon

Camarillo, CA 93012

1 Tommy Rueckert

US Department of Energy

Office of Solar Energy Technologies

1000 Independence Avenue, SW

Washington, DC 20585

1 Dave Edwards

5 Rosslyn Street,

Blackburn South, 3130

Victoria, Australia

1 Fred Morse

Morse Associates, Inc.

236 Massachusetts Ave., NE

Suite 605

Washington, DC 20002

1 George Tedesco

Peerless-Winsmith, Inc

172 Eaton St

Springville, NY 14141

1 Mark D. Paster

US Department of Energy

Hydrogen and Fuel Cells Program

1000 Independence Avenue, SW

Washington, DC 20585

$1 \quad$ Frank Wilkens

US Department of Energy

Office of Solar Energy Technologies

1000 Independence Avenue, SW

Washington, DC 20585

1 Hank Price

Solucar Power

11500 W. 13th Ave.

Lakewood, CO 80215 
1 Timothy M. Leonard, President Precision Solar Technologies Corporation (formerly) Enhancement Electronics, Inc. \#10 Camino del Senador

Tijeras, NM 87059-7631

2 MS9018 Central Technical Files, 8944

1 MS0563 Matt W. Donnelly, 2431

1 MS0973 Scott A. Jones, 5741

1 MS1033 Charles J. Hanley, 6335

1 MS1110 Jeff S. Nelson, 6337

1 MS1124 Paul S. Veers, 6333

1 MS1127 Richard B. Diver, 6337

1 MS1127 Tom R. Mancini, 6337

1 MS1127 Nathan P. Siegel, 6337

1 MS1127 Robert M. Edgar, 6337

1 MS1127 Tim A. Moss, 6337

10 MS1127 Greg J. Kolb, 6335

2 MS0899 Technical Library, 4536 